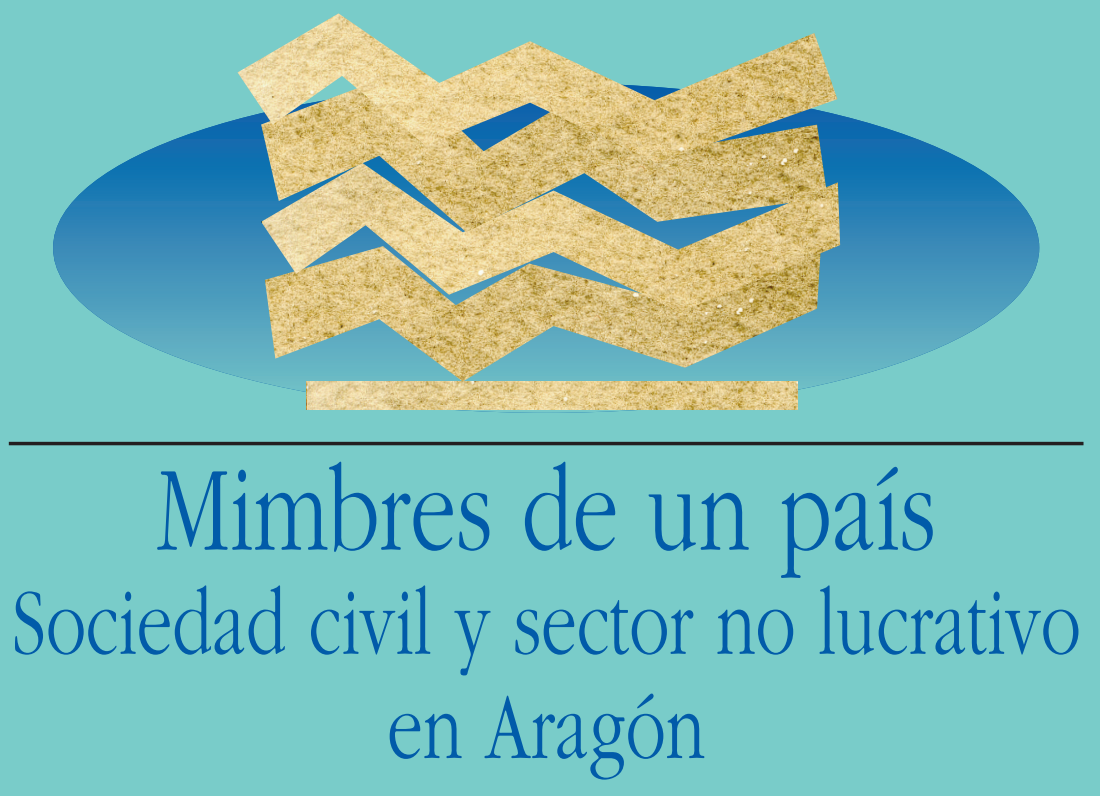

Ana Bellostas Pérez-Grueso Carmina Marcuello Servós Chaime Marcuello Servós José Mariano Moneva Abadía

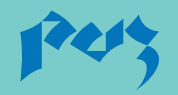

Prensas Universitarias de Zaragoza 
MIMBRES DE UN PAÍS

Sociedad civil y sector no lucrativo en Aragón 


\section{MIMBRES DE UN PAÍS \\ Sociedad civil y sector \\ no lucrativo en Aragón}

Grupo de Estudios Sociales y Económicos del Sector No Lucrativo (GESES)

Ana Bellostas Pérez-Grueso Carmina Marcuello Servós

Chaime Marcuello Servós

José Mariano Moneva Abadía

\section{prest}

Prensas Universitarias de Zaragoza 


\section{FICHA CATALOGRÁFICA}

MIMBRES de un país : sociedad civil y sector no lucrativo en Aragón / Grupo de Estudios Sociales y Económicos del Sector No Lucrativo (GESES), Ana Bellostas Pérez-Grueso ... [et al.]. — Zaragoza : Prensas Universitarias de Zaragoza, 2002

234 p. ; $22 \mathrm{~cm}$. - (Ciencias Sociales ; 48)

ISBN 84-7733-607-5

1. Economía social-Aragón. 2. Organizaciones no lucrativas-Aragón. I. Grupo de Estudios Sociales y Económicos del Sector No Lucrativo (GESES). II. Bellostas Pérez-Grueso, Ana. III. Título. IV. Serie: Ciencias Sociales (Prensas Universitarias de Zaragoza) ; 48

$334.012 .46(460.22)$

No está permitida la reproducción total o parcial de este libro, ni su tratamiento informático, ni la transmisión de ninguna forma o por cualquier medio, ya sea electrónico, mecánico, por fotocopia, por registro u otros métodos, ni su préstamo, alquiler o cualquier forma de cesión de uso del ejemplar, sin el permiso previo y por escrito de los titulares del Copyright.

(C) Ana Bellostas Pérez-Grueso, Carmina Marcuello Servós, Chaime Marcuello Servós y José Mariano Moneva Abadía

(C) De la presente edición, Prensas Universitarias de Zaragoza

1. a edición, 2002

Ilustración de la cubierta: José Luis Cano

Colección Ciencias Sociales, n. ${ }^{\circ} 48$

Director de la colección: José Manuel Latorre Ciria

Editado por Prensas Universitarias de Zaragoza

Edificio de Ciencias Geológicas

C/ Pedro Cerbuna, 12

50009 Zaragoza, España

Prensas Universitarias de Zaragoza es la editorial de la Universidad de Zaragoza, que edita e imprime libros desde su fundación en 1542.

Impreso en España

Imprime: Cometa, S.A.

D.L.: Z-2512-2002 


\section{PRÓLOGO}

A lo largo de estos últimos tres años hemos podido desarrollar nuestra investigación gracias a la colaboración desinteresada de un buen número de personas y entidades.

Una parte de la investigación cualitativa se realizó de modo informal —al uso de la antropología más clásica-, mediante conversaciones, visitas y participación en actos diversos, en entidades distintas, en los diferentes contextos del país anotando y registrando los acontecimientos, discursos e imaginarios socialmente compartidos. Otra parte de la investigación se hizo de modo formal concertando entrevistas en profundidad, reuniendo grupos de discusión e indagando en los materiales de distintas ONL aragonesas.

Como agradecimiento y recuerdo, queremos destacar algunas de estas personas y entidades: Federico Abizanda, M. ${ }^{a}$ Carmen Almudévar, José Bada, José L. Batalla, Jesús Bayego, María Bellostas, Teresa Broto, Carmen Cornago, Ana M. ${ }^{a}$ Cortés, Antón Eito, José L. Fandos, Manuel Hernández Laplana, Chema Fernández Turrado, J. A. Ferrer, Asún García, Julio Gavín, Elena Gil, Francisco José González, Ángel Gutiérrez, Carmen Jiménez, Marga Julve, Paloma Lafuente, Luis Muñoz, Cristina Navarro, Luis Nogué, Enrique Nogueras, Paco Pérez Giner, Pablo Plo, Mares Rodríguez, Manena Sancho, Javier Serrano..., ACOPAL, Acción Solidaria Aragonesa, Amigos de Serrablo, Asociación Española de Sociocybernética, Cáritas (Huesca-Teruel), CODEF, Cruz Roja Huesca, FAEA, Fundación ADUNARE, JOC, Fundación Rey Ardid.

También queremos agradecer el tiempo y la dedicación a todas las asociaciones y fundaciones que nos facilitaron sus datos a través de la 
encuesta, así como a los responsables de los registros por su amabilidad, paciencia y tiempo. Entre ellos, Isabel Mansilla Arnal, María Teresa García Ruiz, Joaquín Gimeno Pérez, María Teresa Serrate, Francisco de Vera y Pinilla, el equipo de trabajo del Registro de Asociaciones Deportivas de Aragón, Registros de Asociaciones de Zaragoza, Huesca y Teruel, Registro de Cooperativas de Aragón y Registro de Fundaciones de Aragón. 


\title{
PRESENTACIÓN
}

\author{
La gota de agua participa de la grandeza del océano, \\ aunque ella no lo sepa. \\ Pero apenas se empeñe en separarse de él, \\ se secará por completo.
}

Gandhi, 118

\begin{abstract}
Para mí, el poder político no es un fin, sino uno de los medios que permite a los hombres mejorar sus condiciones de vida en todos los planos. El poder político es lo que permite dirigir los asuntos de un país, por medio de los delegados de la nación. Si las ruedas del engranaje de la vida nacional alcanzasen tal grado de perfección que le permitiesen funcionar automáticamente, no sería necesario tener delegados. Sería entonces un estado de anarquía ilustrada. En ese país, cada uno sería su propio amo. Se dirigiría a sí mismo, sin molestar para nada a sus vecinos. Por consiguiente, el estado ideal es aquel en que no hay ningún poder político. De ahí la afirmación tan conocida de Thoreau de que el mejor de los gobiernos es aquel que gobierna menos
\end{abstract}

Gandhi, 199

Este libro es el resultado de dos años largos de un trabajo interdisciplinar en equipo del Grupo de Estudios Sociales y Económicos del Sector No (GESES) de la Universidad de Zaragoza.. Gracias a un proyecto financiado por el Gobierno de Aragón —a través del CONSI+D_*** hemos atendido el análisis del impacto de este ámbito, que indiscutiblemente es cada vez más relevante en nuestra vida cotidiana. Al igual que en otras sociedades avanzadas, su importancia es múltiple y variada tanto en lo que afecta a su dimensión económica, a su dimensión social e incluso a su dimensión política.

* <http://www.unizar.es/geses>.

* «Estudio de la eficacia económica y social del sector privado no lucrativo aragonés» (P26/98). 
Nos referimos a un sector considerado «emergente» y que se suele denominar no lucrativo o también Tercer Sector o Economía Social. Cualquiera de estas acepciones acarrea controversias, matices y acentos a considerar. $\mathrm{Al} \mathrm{mar-}$ gen de ello, yendo más allá de los detalles terminológicos, nuestro objetivo ha sido estudiar la realidad social de la que esos términos intentan hacerse cargo. Por eso, hemos querido conocer en profundidad las características cuantitativas y cualitativas del sector en nuestro país, en Aragón. Estas páginas ofrecen una parte de la información y materiales recabados durante nuestra investigación. Ahora presentamos sus elementos más significativos.

Por eso, éste es un texto que quiere ser fundamentalmente divulgativo, sin perder el rigor académico y científico del trabajo que subyace. Está dirigido a todas aquellas personas interesadas en la materia, bien para reflexionar, bien por estar vinculados, bien por pura curiosidad. Pero además, este libro quiere llenar el vacío existente sobre el sector en los estudios actuales de la economía y de la sociedad aragonesa.

Como ya se sabe, Aragón es un país de contrastes y paradojas. Si miramos al mapa encontramos un extenso territorio, vacío de habitantes en su mayor parte. Despoblado. Desierto y, sin embargo, tendiendo a la masificación en torno a la metrópoli del Ebro, Zaragoza.

Mientras tanto, al sur y al norte, paisajes y horizontes callados. Pueblos que guardan silencio porque nadie corre por sus calles. Casas cerradas $y$, muchas de ellas, a punto de caer, sin más futuro que el recuerdo. Paradojas de un país donde se afianzan las inercias generales de la sociedad española. A la par, se mantienen ritmos propios arraigados en décadas y siglos pasados, en los cuales el tejido social se desleía por causa de la emigración a lugares con mejores condiciones de vida.

Contrastes porque la sociedad aragonesa acoge en su seno la quinta ciudad española muestra, por otro lado, las cifras de densidad de población más bajas - y clamorosas - de Europa. Estadísticas diáfanas y, al mismo tiempo, engañosas. Porque, como sucede con la renta per cápita, la distribución de los cálculos hace que, en el mismo territorio, la riqueza de quienes viven bien se reparta aparentemente en las comarcas donde realmente los servicios escasean y los recursos son inexistentes. ${ }^{1}$

1 La aportación estimada de Aragón al PIB español en 1999, según datos del INE, es de 3,24\%, mientras que el porcentaje de población aragonesa con respecto al total en 1998 es del 2,97 \%; la superficie aragonesa representa el 9,4\%; la densidad de nuestra población regional es de $24,8 \mathrm{hab} . / \mathrm{km}^{2}$, en contraste con la densidad española: $78,8 \mathrm{hab} / \mathrm{km}^{2}$. 
Un país paradójico cuya capital es paradigma de la contradicción: motor de su economía y del conjunto del valle del Ebro, agujero negro de la migración interna y espacio de creciente dinamismo social. Un país por vertebrar y del que se perciben grandes potencialidades... pendientes de concretarse en acciones y prácticas que les den forma.

Aragón es una comunidad autónoma que, pese a sus sombras, tiene en sí una riqueza enorme: sus gentes, su "capital humano». Quienes consiguen resistir a la tentación - y necesidad - de salir fuera para buscar mejores posibilidades han ido articulando una sociedad plural, activa y multiforme.

Por eso, si atendemos a las gentes que forman la sociedad aragonesa, y vamos más allá de sus estereotipos contradictorios, nos encontramos con auto-imágenes y modelos sociales de referencia opuestos. Por una parte, y con claras connotaciones poco deseables, el aragonés destaca por su tendencia cainita al desprecio de lo propio, a la incuria colectiva por lo común... Se dice que éstas son expresión del individualismo y de la falta de interés por las empresas compartidas. Sin embargo, por el lado positivo, encontramos imágenes que destacan una gran habilidad para los pactos, sinceridad en los compromisos, nobleza en los comportamientos, tenacidad y constancia de cara a la consecución de metas. Ambas visiones operan en la vida cotidiana de la sociedad aragonesa. Con ellas y desde ellas se articulan procesos de acción colectiva. Así, existen agrupaciones de ciudadanos y ciudadanas de este país que han ido tejiendo un modo de relaciones sociales variado, plural, multiforme, vertebrando, con los recursos disponibles, las nuevas formas de sociedad civil aragonesa; inventando siempre un presente complejo y poco fácil.

Este libro se sitúa en ese ámbito, con el objetivo anteriormente reseñado de estudiar las llamadas organizaciones no lucrativas (ONL) de la sociedad aragonesa. Con ello nos sumamos ${ }^{2}$ a una corriente de investigación internacional y de actualidad que ha ido cuajándose durante la última década. Fruto de ella son dos publicaciones recientes, la primera, Global Civil Society, coordinada por Lester Salamon y publicada por el Center for

2 Hemos participado en diferentes conferencias de International Society for ThirdSector Research (ISTSR) con los trabajos C. Marcuello y Ch. Marcuello $(1998,2000)$ y C. Marcuello y Urbina (1998). 
Civil Society Studies, de la Johns Hopkins University (Salamon et al., 1999a). La segunda es un trabajo particular dentro del mismo marco de la anterior: El sector no lucrativo en España, dirigida por José Ignacio Ruiz Olabuénaga $(2000 a)$, que ha sido publicada por la Fundación BBV. Anteriormente la Fundación Encuentro presentó ¿Existe sociedad civil en España?, obra coordinada por Joan Subirats (1999). Un último libro, presentado por Fundación Tomillo, es Empleo y trabajo voluntario en las $O N G$ de acción social, publicado por el Ministerio de Asuntos Sociales (Fundación Tomillo, 2000).

A partir de esas referencias, en nuestro caso comenzamos retomando un asunto todavía abierto, como es la definición de los límites del sector. Es un proceso dialéctico donde transitamos del plano conceptual al fenoménico — de los conceptos a los acontecimientos...-. Así, este primer apartado insiste en la cuestión conceptual para posibilitar lo que hemos concebido como una fenomenología del sector no lucrativo en Aragón. En este punto, partimos a la vez de los dos ámbitos para intentar explicar y comprender mejor la realidad compleja y multiforme que nos ocupa, ofreciendo una tipología de síntesis y adaptada al caso aragonés. En segundo lugar, siguiendo el mismo método, continuamos indagando y aclarando el marco jurídico mediante el cual se articula el sector. Para ello revisamos la legislación del Estado, la propia de nuestra comunidad autónoma y establecemos una comparación con el resto de comunidades autónomas. En tercer lugar, pasamos a considerar el sector no lucrativo aragonés propiamente dicho, comenzando con el análisis de los datos existentes en los registros oficiales en lo que afecta a las fundaciones y asociaciones. Seguimos con la descripción de las características de ambas y de los elementos más destacados de cada uno de los dos colectivos. En cuarto lugar, aunque en continuidad con el capítulo anterior, profundizamos en los subsectores de actividad tanto de las asociaciones como de las fundaciones aragonesas. En quinto lugar, terminamos con las conclusiones de la investigación. 


\section{CAPÍTULO I NI SÓLO GOBIERNO, NI SÓLO MERCADO: EL SECTOR NO LUCRATIVO ARAGONÉS}

A lo largo del siglo pasado la sociedad aragonesa, de forma similar a la española, ha protagonizado una transformación estructural en todos sus ámbitos; en muchos de ellos, tan silenciosa como profunda. Se ha recorrido un camino que transita de unas estructuras tradicionales pre-modernas a otras completamente distintas, inmersas en dinámicas que van más allá de la modernidad e industrialización y llegan, en la actualidad, a parámetros equiparables al modelo europeo de desarrollo — tan anhelado hace apenas dos décadas-, e incluso alcanzan cotas de bienestar comparables con cualquier ciudad de primer rango dentro de la Unión Europea. Sin embargo, también es cierto que, mientras tanto, siguen coexistiendo situaciones totalmente opuestas dentro del mismo territorio aragonés.

A pesar de esas contradicciones —en paralelo a la evolución señalada-, la sociedad aragonesa, y en ella el sector no lucrativo, ha experimentado un importante crecimiento en las últimas décadas. Es similar a lo ocurrido en España y a lo sucedido internacionalmente. El sector que se llama no lucrativo ha multiplicado su incidencia en la vida cotidiana, en foros especializados de científicos sociales, políticos, «mercados» y también en la opinión pública. Sobre todo, porque ha incrementado considerablemente su presencia en distintos sectores de actividad económica y social. Esto es consecuencia de un aumento tanto de la dimensión global del sector como del número y tamaño de las organizaciones que lo configuran. De hecho, éstas no han dejado de crecer en los años más recientes. 


\section{I.1. De la sombra a la luz propia}

El sector no lucrativo se mueve y crece recurriendo tanto a nuevas como a viejas formas de actuación, abarcando actividades tradicionales — cultura, educación, salud - incorporando nuevas aportaciones — ciencia, tecnología, cooperación al desarrollo- y adaptándose a las nuevas circunstancias —ocio, deporte- En cada país se concreta y vertebra con arreglo a las características propias de su idiosincrasia y de su historia particular. En todos, aparece como rasgo común la presencia creciente en el imaginario social y el incremento de actividad del sector.

Así, encontramos que la descripción del sector se formula desde distintas perspectivas ideológicas y teóricas, sean socialdemócratas o neoliberales, conservadoras o progresistas... Textos y autores destacan la relevancia social y económica de las ONL (Rose-Ackerman, 1996) e insisten en el hecho de que estas organizaciones son un indicador de la madurez existente en el seno de una sociedad (Drucker, 1993; Subirats, ed., 1999). Los movimientos ciudadanos, las asociaciones y organizaciones populares son una muestra de la riqueza de la sociedad civil y reflejo de sus estructuras, de sus redes y de su dinamismo societario. Las redes de las ONL hablan directamente de la vitalidad y versatilidad tanto de una sociedad como de su economía. Por eso, se detecta un teorema implícito: en la medida en que se disponga de un entramado de ONL variado, dinámico y activo, se posibilita una mayor autonomia, capacidad de organización y riqueza social del sistema social y su ciudadanía. ${ }^{3}$ Precisamente porque son organizaciones que surgen desde la "a-filiación» de intereses compartidos y como respuesta de los ciudadanos a su propia diversidad de necesidades socialmente construidas.

Sin embargo, es relativamente reciente la investigación sobre el sector no lucrativo. Sigue haciendo falta profundizar en el conocimiento del sector, en general, y de las características de las organizaciones, en particular. Ello tampoco es casual: tal circunstancia se debe en buena medida a la tendencia de las ciencias sociales por atender al sector lucrativo y a la Administración pública como puntos de enfoque prioritarios.

3 Muy relacionado con las últimas teorías sobre capital social (ver <www.bancomundial.>). 
En el caso aragonés, resalta todavía más esa laguna de investigación y reflexión. Hasta hoy la única fuente son las propias entidades que han divulgado su trabajo en sus campos particulares de acción, pero que no permiten obtener una visión agregada de él. Sólo algún caso esporádico (Subirats, ed., 1999; Gutiérrez Resa y Garcés Ferrer, 1999) y poco habitual rompe parcialmente la tendencia, como por ejemplo, al presentar repertorios (Ayuntamiento de Zaragoza, 2000 y 2001) ${ }^{4}$ de organizaciones donde desarrollar actividades solidarias o de voluntariado. Afortunadamente, en los últimos tiempos la falta de información aludida se va remediando, y, con toda probabilidad, es previsible que estemos bien pronto en el extremo opuesto: abundancia de publicaciones, intereses múltiples y crecientes por el sector, divulgación mayor de sus actividades, reflexiones, foros de discusión, jornadas...

Por otra parte, hemos de situar el sector no lucrativo aragonés en el contexto de España y, desde ahí, establecer las comparaciones pertinentes. En este sentido, contamos con el estudio de Ruiz Olabuénaga (2000a), publicado por la Fundación BBV en colaboración con la Universidad Johns Hopkins. Así, para España estima el número de ONL en las cuales 253 309, dan trabajo a más de medio millón de trabajadores remunerados y mueven más de un millón de voluntarios regulares. Estos datos representan un $4 \%$ del PIB y, en términos de empleo ${ }^{6}$ sobre la población activa, suponen un 4,5\%. Comparando España con el resto de los 22 países considerados en Global Civil Society, el empleo generado por el Tercer Sector se sitúa en el undécimo lugar.

En el mismo informe se resalta que en España las ayudas públicas recibidas por este sector son inferiores al conjunto de países analizados -28 de todo el mundo, entre los que figuran la mayoría de los miembros de la UE, Estados Unidos y Japón-. Dichas ayudas representan un $32,1 \%$ en el caso español, frente al $42 \%$ de la media global y el 55,6\% de la media europea. De esta forma, en España los ingresos privados procedentes de las cuotas alcanzan el $49,1 \%$ y el procedente de las donaciones el $18,8 \%$.

4 Desde la institución del Justicia de Aragón hay un informe sobre el voluntariado social en Aragón de 1994.

5 Sin incluir el empleo agrícola.

6 Ver <www.ciriec.es> 
El sector no lucrativo español se sitúa en valores cercanos a otros países europeos. Así, el informe muestra cómo España disfruta de un sector no lucrativo que comparte cifras, elementos y características similares a Alemania, Austria y Francia (Salamon y Anheier, 1999b). Estos rasgos comunes se traducen, principalmente, en un modelo de sector no lucrativo donde predominan los servicios sociales. Son países que tienen como clave común la amplia influencia católica. Sin embargo, por diferentes razones, ésta ha ido debilitando su presencia, sobre todo en la educación, aunque sigue predominando en los servicios sociales. En lo que se refiere al empleo dentro del sector no lucrativo, en España se concentra en los servicios de atención social y, al igual que en Francia, se detecta una importante presencia de ONL en la educación.

Otro elemento a destacar es el dinamismo del sector. En términos de actividad, las ONL españolas superan tanto al sector público como al sector privado lucrativo. También — según el informe de la Universidad Johns Hopkins_, se estima que internacionalmente, entre 1990 y 1995 , el crecimiento del empleo fue de un $23 \%$ en el sector no lucrativo, frente al $6 \%$ de media para el resto de los sectores. Estos datos reflejan la importancia global del sector.

Por tanto, considerando estas magnitudes del sector no lucrativo podemos afirmar que se trata de un sector muy dinámico, que representa una parcela importante en la economía y la vida social. Sin embargo, quedan pendientes algunas aclaraciones ante preguntas $y$ dudas como las siguientes: ¿Qué es el sector no lucrativo?, ¿qué son las organizaciones no lucrativas?, ¿cuáles son sus actividades principales?, y sobre todo, ¿qué interés tiene el que se estudien en profundidad estas entidades?

El propósito del presente capítulo es responder tales cuestiones y reflexionar adecuando las respuestas a la realidad aragonesa. Aunque necesariamente hemos de atender a las tendencias generales, hemos delimitado nuestro objeto de estudio a Aragón. No obstante, somos conscientes de que, como toda delimitación, tiene sus limitaciones, problemas y asuntos pendientes de ser relacionados con el contexto general donde se insertan. Por eso, en la medida de lo posible, siempre estaremos haciendo referencia a casos y datos más allá del marco aragonés para poder comprender mejor el fenómeno particular que aquí nos ocupa. 


\section{I.2. ¿De qué estamos hablando? Economía Social vs. Tercer Sector}

El sector no lucrativo y las organizaciones que lo forman (las ONL) ha sido y sigue siendo considerado desde diferentes enfoques y tratamientos a la hora de definirlo y acotarlo. ${ }^{7}$

En primer lugar —si atendemos a la evolución de las investigaciones sobre él-, encontramos que hasta la década de los setenta no cabe hablar de una investigación dedicada al estudio de las ONL como un sector con identidad propia en la economía de una sociedad (Hansmann, 1987). Estas organizaciones ocupaban un espacio en la vida cotidiana de la sociedad, pero - aunque la realidad de las ONL existía — no habían sido tenidas en cuenta como un conjunto formal con características comunes. Se percibían como agentes aislados que trabajaban separadamente en ámbitos como el sanitario, servicios sociales, educación, cultura, etc. (Young, 1992). La década de los setenta fue el punto de partida en el estudio de este tipo de entidades, al considerar que constituían un sector de organizaciones que comparten una serie de características y que difieren del sector empresarial y del sector público (Weisbrod, 1975 y 1986).

Aun así, a comienzos de la década de los noventa las contribuciones sobre el estudio de las ONL estaban todavía en sus inicios, tanto a nivel internacional como en España (Mertens, 1999; Ruiz Olabuénaga, 2000a). Pero es en ese período donde podemos decir que se reconoce que las particularidades propias de las ONL necesitan de un estudio específico, que actualmente se encuentra en una fase incipiente de formulación y delimitación de contenidos, metodologías, estrategias de análisis y evaluación de prácticas.

En segundo lugar —en lo que afecta a la conceptualización teórica-, se emplea gran diversidad de términos para denominar a estas organizacio-

7 Ver el volumen monográfico de Economistas, n. 83 (2000), donde se plantea todavía la discusión sobre el concepto de sector no lucrativo, y el capítulo 1 de Ruiz Olabuénaga (2000a). Los trabajos de Barea (2000), Casado (2000) y C. Marcuello (2000) se dedican a las cuestiones de delimitación y definición del sector no lucrativo y las organizaciones no lucrativas. Ver también Barea y Monzón (1996), Defourny (1996), Rodríguez y Monserrat (1996) y Sajardo Moreno (1996a y 1996b). 
nes y a la panoplia de actividades que realizan. Podemos considerar que también son el reflejo de esta diversidad y de la necesidad de ponerse de acuerdo las propias entidades no lucrativas, las instituciones públicas y la visión académica. Suele utilizarse la denominación de sector no lucrativo, pero también encontramos otras, como, por ejemplo: sector de beneficencia, sector independiente, sector voluntario (Rodríguez y Montserrat, 1996), organizaciones voluntarias (Casado, 1992; Funes Rivas, 1994), organizaciones no gubernamentales (Subirats, 1992), sector asociativo, sector no lucrativo (Serra Martín, 1990), entidades sin fines de lucro (Barea y Monzón, 1996), Tercer Sector (Cabra de Luna y Lorenzo, 1993), etc. En realidad, cada denominación pone el acento en alguno de los aspectos que caracterizan a estas organizaciones $y$, tomadas conjuntamente, nos acercan al concepto de ONL como síntesis de todos ellas.

En tercer lugar — para definir los límites de las ONL—, encontramos dos corrientes teóricas que ofrecen respuestas a qué es el sector. Una, denominada enfoque de la Economía Social —de tradición europea, continental-, y otra enfoque del Tercer Sector — de tradición anglosajona(Defourny, 1994; Sajardo Moreno, 1996a y 1996b). Ambas corrientes tratan de aportar su visión y clarificar un concepto que todavía no está cerrado y al que las dos corrientes se están acercando paulatinamente. Pero cada una de ellas lo hace subrayando las particularidades de su perspectiva. Según el enfoque europeo, el sector de Economía Social «está compuesto por sociedades, principalmente cooperativas, mutuas y asociaciones cuya ética traduce los siguientes principios: finalidad de servicio a los miembros o a la colectividad, más que de beneficio, autonomía de gestión, procesos de decisión democrática, primacía de las personas y del trabajo sobre el capital en el reparto de beneficios» (Defourny, p. 1994, 24). ${ }^{8}$ El enfoque anglosajón propone que el Tercer Sector está compuesto "por aquellas organizaciones formalmente constituidas, de carácter privado, con autogobierno, que incorporan fundamentalmente trabajadores voluntarios esto es, no asalariados-, organizaciones que pueden obtener beneficios, pero no pueden distribuirlos entre sus propietarios o miembros, sino que deben invertirlos en la actividad de la entidad» (Salamon y Anheier, 1994; Salamon et al., 1999).

8 Ver también Barea (2000). 
Con lo dicho, vemos dos divergencias claras entre ambas corrientes. La primera diferencia conceptual se concentra en los aspectos vinculados con la gestión interna y en los modelos de toma de decisiones de las entidades. Esto es, si se atiende al enfoque de Economía Social, las fundaciones quedan excluidas, puesto que no tienen obligación de cumplir con unos procesos democráticos dentro de sus modos de decisión. Es el patronato quien decide. Los socios pueden ser escuchados, pero nunca dispondrán de ejercer un voto que modifique las decisiones tomadas. Una fundación, hay que recordar, es un patrimonio adscrito a un fin, y el patronato es el único órgano de toma de decisiones válido, junto con el protectorado ejercido por la Administración pública. Es decir, no existe una asamblea de socios ni una junta directiva elegida democráticamente por éstos. Tal característica, para algunos — desde el enfoque de la Economía Social—, ha sido suficiente para excluir las fundaciones de este sector. En la actualidad, desde las distintas instituciones relacionadas con la Economía Social, la figura de las fundaciones se está incluyendo como una más.

La segunda discrepancia - considerando el enfoque anglosajón del Tercer Sector- es la exigencia de personal voluntario en «todas» las organizaciones no lucrativas. Evidentemente, esta restricción significa que dos grupos fundamentales para la Economía Social —las cooperativas y las mutuas - quedan excluidos, ya que son entidades constituidas a partir de unas figuras jurídicas en las que, por lo general, la presencia del voluntariado no existe. ${ }^{?}$

A pesar de estos puntos de controversia — aparentemente irreconciliables-, entre ambos enfoques hay más consonancias que disonancias. De hecho, el elemento común de las dos corrientes es la consideración de «lo no lucrativo» como factor de distinción para delimitar el universo de estas organizaciones.

Finalmente, siguiendo la argumentación anterior podemos encontrar otro elemento común al conjunto de ONL. Desde un punto de vista económico vemos que las ONL se definen por estar sujetas a una restricción

9 En el caso aragonés, la reciente Ley de Cooperativas de Aragón crea dos nuevos tipos, las cooperativas de iniciativa social y las cooperativas de servicios sociales, que probablemente puedan dar lugar a la participación de voluntariado, dadas sus especiales características. 
legal que prohíbe distribuir beneficios o excedentes a los individuos que tienen capacidad de control sobre la organización (sean miembros asociados, directores, administradores...). No se limita la generación de beneficios, sino que se impide expresamente la apropiación privada de éstos por los miembros de la entidad, exigiéndose, en cambio, que los excedentes reviertan en la financiación de futuros servicios. ${ }^{10}$ Es decir, las ONL no se crean para la obtención de beneficios monetarios individuales de sus miembros - como es el caso de las empresas o sociedades-, sino para la consecución de unos fines en los que predomina el interés general frente al interés particular.

Éste es un rasgo común a todas las ONL aunque no suficiente para definirlas, por lo que habrá que incorporar otros elementos distintivos que en el apartado siguiente se van a desarrollar.

\section{I.3. Una propuesta de definición}

Si tenemos en cuenta que las corrientes ortodoxas de la ciencia económica analizan el comportamiento humano — desde el enfoque de la producción y distribución tanto de bienes como de servicios en la sociedad-, y asumen como paradigma básico de conducta la persecución del interés particular, entonces es conveniente revisar esa postura altruista de las ONL. De hecho, el interés individual se relaciona con la maximización de las ganancias monetarias que reciben los individuos a través de las actividades que realizan, pero también puede relacionarse con todo aquello que el individuo considera deseable para sí mismo o para el bienestar común. Cuando esto último ocurre, las personas pueden participar en actividades de producción o intercambio, sin que ello les reporte a cambio beneficios personales directos. A partir de esta distinción hablamos de actividades humanas no lucrativas y de actividades humanas lucrativas. Y decimos que una actividad humana es no lucrativa cuando quien la realiza no recibe una contrapartida explícita de quien se beneficia de ella. Mientras que actividad lucrativa es aquella por la cual quien la realiza, recibe a cambio una contrapartida explícita.

10 Hansmann (1980). En este trabajo habla de los "patrons», esto es, todas aquellas personas con capacidad de decisión y control en las ONL. 
Así, al igual que una organización puede crease para facilitar la consecución de un lucro particular y explícito para todos aquellos que forman parte de ella (desde el trabajador que ve en la organización una forma de obtener un salario por su trabajo, hasta el inversor que contempla la organización como un vehículo para incrementar el valor de su patrimonio financiero), también puede hacerse por altruismo. Por eso, si la acción colectiva de las organizaciones que permiten obtener un lucro explícito a sus miembros se muestra más eficaz para ese fin que la acción individual, de igual modo las personas interesadas en llevar a cabo actividades altruistas pueden considerar más eficaz realizarlas a través de una organización que a través de su acción individual. Dicho de otra forma, las organizaciones no nacen condicionadas por el fin que mueve a quienes participan en ellas, sino por la eficacia en la consecución de dichos fines, en comparación con una actuación individualista en el «océano» del mercado (Ch. Marcuello, 1996).

Dado que la organización es un soporte de la actividad para producir bienes y servicios, no cabe atribuirle, como a tal, fines y objetivos, pues estos atributos son particulares de las personas. No puede, por tanto, hablarse de organizaciones lucrativas y no lucrativas en términos de los fines que persigue el soporte o vehículo de ciertas actividades económicas, sino en términos de los fines que mueven a aquellos miembros de la organización con derecho a decidir sobre su continuidad o terminación, así como sobre las políticas y reglas generales de funcionamiento interno. De esta forma, hablaremos de organización lucrativa cuando la acción colectiva se desarrolla en un soporte institucional donde los participantes buscan mayoritaria o exclusivamente el lucro personal, a través de contrapartidas explícitas a cambio de lo que aportan a la acción colectiva concreta. Por el contrario, la organización no lucrativa será aquella que vertebra a propietarios de recursos, los cuales, en una parte significativa, no condicionan la aportación de recursos a una contrapartida explícita, y en la que, en todo caso, los propietarios con derechos esenciales de decisión no pueden apropiarse privadamente de los excedentes de la acción colectiva.

En función de lo dicho y para que las organizaciones tengan mayor eficacia, se requiere que éstas posean personalidad jurídica, es decir, capacidad para asumir derechos y obligaciones frente a terceros, al igual que se reconoce esa capacidad jurídica a las personas físicas. La protección legal 
de los derechos y deberes contraídos por las organizaciones exige cierta estandarización o normalización de las formas jurídicas que aquellas pueden adoptar. De otro modo, si existiera libertad absoluta para diseñar las normas que regulan las relaciones entre la organización como nexo jurídico y los que interaccionan con ella, la eficacia del sistema jurídico se vería sensiblemente mermada. Por eso, cuando una acción colectiva quiere elegir el soporte jurídico que le permite asumir derechos y obligaciones, ha de hacerlo recurriendo a las formas jurídicas tipificadas por el derecho del país donde se crea. En el capítulo siguiente analizaremos las distintas formas jurídicas bajo las cuales se pueden llevar a cabo colectivamente actividades no lucrativas en Aragón y en España.

Por otra parte, la variedad de intereses y objetivos con los que los individuos crean estas organizaciones nos obliga a realizar una distinción previa a la clasificación que expondremos en el apartado siguiente. El criterio propuesto se basa en los conceptos de actividad no lucrativa y actividad lucrativa, mencionados anteriormente. A partir de esta distinción y según cuál sea el soporte institucional en que se apoyan las actividades, podemos formular una tipología de organizaciones y actividades (ver tabla I.1):

1) La actividad lucrativa realizada a través de organizaciones lucrativas tiene como soporte habitual las empresas o sociedades privadas, mediante las cuales los miembros de la organización buscan la maximización del beneficio monetario particular.

2) La utilización de la organización no lucrativa para desarrollar actividades lucrativas permite a los individuos llevar a cabo las actividades con el fin de obtener algún tipo de compensación personal o de mejora del bienestar de los miembros de la organización.

TABLA I.1

CONCEPTUALIZACIÓN DE ORGANIZACIÓN NO LUCRATIVA

\begin{tabular}{|l|l|l|}
\hline Organización/actividad & Actividad lucrativa & Actividad no lucrativa \\
\hline Organización no lucrativa & $\begin{array}{l}\text { 2) Mutualismo, cooperativas } \\
\text { cajas de ahorros }\end{array}$ & 3) Asociaciones, fundaciones \\
\hline Organización lucrativa & 1) Sociedades mercantiles & $\begin{array}{l}\text { 4) Actividades de acción social } \\
\text { empresarial }\end{array}$ \\
\hline
\end{tabular}

FUENTE: Elaboración propia a partir de Marcuello (1996 y 2000) 
3) La intersección entre actividad no lucrativa y organización no lucrativa es propia de organizaciones creadas para llevar a cabo actividades que favorecen el bienestar general cuyo fin es producir beneficios públicos o externos a los miembros de la organización. ${ }^{11}$

4) Las actividades no lucrativas de las empresas y organizaciones con afán de lucro son las que se encuadran en el terreno de la acción social de la empresa, incipiente en el caso español y mucho más desarrollada en el mundo anglosajón.

Por tanto, considerando esta tipología, así como las contribuciones de la Economía Social y del Tercer Sector - aunque queden elementos por aquilatar-, la definición propuesta del sector no lucrativo quiere ofrecer una concepción amplia de las ONL. Entendemos que el sector no lucrativo está formado por aquellas organizaciones legalmente reconocidas - dejamos fuera el entramado de grupos informales sin legalizar, independientemente de su labor o repercusión-, de carácter privado, con auto-gobierno, donde los derechos de decisión y control residen en los miembros de la entidad, que podrán contar con trabajadores o voluntarios, donde la clave principal radica en la limitación a la apropiación de los posibles excedentes de la actividad y cuyos fines abarcan asuntos de «asistencia social, cívicos, educativos, culturales, científicos, deportivos, sanitarios, de cooperación para el desarrollo, de defensa del medio ambiente, de fomento de la economía social o de la investigación", como se dice en la Ley 30/1994 de Fundaciones, en el artículo 42 del título II.

Atendiendo ahora a las figuras jurídicas, el conjunto de ONL produce beneficios sociales externos, ${ }^{12}$ pero en sentido estricto son las asociaciones y fundaciones el conjunto de entidades donde confluye el interés altruista de los que las crean con la figura jurídica que las desarrolla. En un

11 Ver la clasificación de Monserrat (1991), en donde distingue entre ONL de proyección interna y ONL de proyección externa; la primera se asimilaría con la opción 2 de esta clasificación y la segunda con la opción 3.

12 La Diputación General de Aragón, en función de sus competencias en esta materia, declara de interés social la promoción, estímulo y desarrollo de las cooperativas y sus organizaciones representativas dentro de su territorio. Dada la importancia que tiene el movimiento cooperativo dentro del sistema económico-social de la Comunidad Autónoma, adoptará en sus programas de actuación las medidas necesarias para promover la constitución y el desarrollo de cooperativas y el mejor cumplimiento de sus objetivos. 
sentido más amplio, las cooperativas, mutuas y cajas de ahorros son las entidades donde las personas que las crean tienen un interés particular que se articula a través de ellas. En este segundo caso, la doctrina del derecho español establece las cooperativas y las mutualidades que cumplen el requisito de la inexistencia de lucro subjetivo, al no distribuir las ganancias entre sus miembros, de forma que podrían ser consideradas organizaciones sin fines lucrativos de interés particular. A estas dos figuras hay que añadir el caso de las cajas de ahorro, que, dentro del ordenamiento jurídico, según la Ley 31/1985, de 2 de agosto, de Regulación de las Normas Básicas sobre Órganos Rectores de las Cajas de Ahorro, se configuran como entes de carácter social, ajenos al lucro mercantil, que operan en unos mercados financieros cada vez más competitivos, para mantener su capacidad de ahorro y la eficacia de su servicio a la economía nacional. No son consideradas entidades públicas sino privadas; además, el beneficio neto después de impuestos se destina a reservas y a la obra social.

\section{I.4. Los límites de la definición: fronteras difusas}

Hasta aquí hemos señalado una serie de propuestas que se refieren a una realidad cargada de complejidad, difícil de estudiar y sintetizar en una única definición. Los elementos revisados parten de un grupo de entidades en las que la búsqueda de un beneficio monetario no es su objetivo ni su razón de ser. De ellas podemos constatar su existencia y apreciarlas en las diversas facetas de la vida social. Como observación podemos comprobar que su elemento común es la ausencia — prohibición— del reparto del beneficio monetario obtenido. Los intereses perseguidos son muy variados. Alcanzarán distintos ámbitos y colectivos ciudadanos, desde la sociedad en general hasta un grupo restringido de personas.

Si atendemos a las obras de las ONL como organizaciones sociales, vemos que son el reflejo de la sociedad civil organizada más allá de la lógica del mercado. Su racionalidad responde a criterios donde tanto lo político como lo social —en una visión amplia — son el substrato de unas actividades que también inciden en los procesos económicos de la sociedad. Precisamente desde tal dimensión, la economía intenta explicar la existencia de este conjunto de organizaciones sin afán de lucro recurriendo a la 
división de la sociedad en tres sectores: sector público, sector privado lucrativo y sector no lucrativo (Weisbrod, 1975 y 1986).

$\mathrm{Al}$ sector público se adscriben las entidades de titularidad pública — vinculadas a las administraciones del Estado...- que, a pesar de perseguir también un interés general y no repartir dividendos, no presentan las características de independencia y de titularidad privada. El sector lucrativo remite al ámbito de las organizaciones que se dedican a actividades que tienen como fin obtener beneficios para los propietarios de la organización.

Esta distinción, en principio, refleja tres sectores claramente separados en la perspectiva de la economía. Sin embargo, la realidad presenta unas fronteras difusas y permeables entre los tres sectores, de forma que existen instituciones ligadas al sector público que cada vez tienen mayor independencia y que actúan como agentes similares a una ONL, aunque conservan sus lazos con dicho sector. A su vez, persisten empresas de difícil ubicación, dado su compromiso con la comunidad donde actúan. Por ejemplo, las "empresas de inserción»: bajo la figura de una sociedad limitada se crean empresas que compiten en el mercado y buscan beneficios, pero cuya principal finalidad es la inserción social y profesional de personas excluidas del mercado de trabajo; la obtención de beneficios es exclusivamente para asegurar la supervivencia del proyecto y la inserción de las personas.

Así pues, nos topamos con realidades que muestran unos resultados, unos procesos, unas acciones en que la propia vitalidad social va modificando y moldeando sus límites, entendiendo que éstos deben adaptarse al avance de la propia sociedad. Gráficamente:

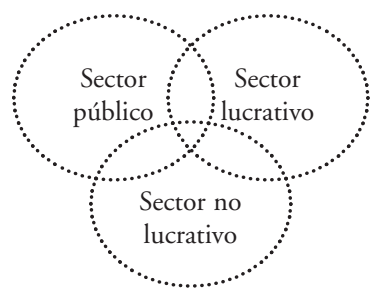

Estamos ante una parcela de la realidad de nuestra sociedad en la que todavía queda bastante por consolidar. Los fenómenos sociales son difíciles de acotar, más cuando hablamos de procesos de cambio o de innova- 
ción. Las ONL han ido sedimentando unas formas de proceder y de estar en el mundo; por eso hemos de estar abiertos a posibles evoluciones y cambios de este ámbito. No ofrecemos una definición cerrada porque nos limitaría enormemente: preferimos adoptar un enfoque donde se asume que existen unos elementos comunes que están enriquecidos por los cambios que suceden constantemente, lo que nos permite ser más coherentes aún a costa de ser menos operativos.

Dejamos para otro momento el debate que se origina al articular la sociedad en tres sectores.

\section{I.5. Una clasificación de las ONL: un camino por recorrer}

Metodológicamente, las diferencias de enfoques y perspectivas en la definición de las ONL dan lugar a tipologías o clasificaciones que buscan sistematizar y ordenar la diversidad.

Dentro de estas clasificaciones podemos citar las procedentes del ámbito académico y las de ámbito institucional. Entre las propuestas catalogadas en el ámbito académico destacan las formuladas por Monserrat (1991), Alberich (1994), Ruiz Olabuénaga (1994) y Casado, dir. (1995). Alternativamente, entre las consideradas dentro del ámbito institucional destacan las aportaciones del Ministerio de Asuntos Sociales, presentada por la Dirección General de Fomento de la Economía Social.

Algunas de las obras que destacan por su aportación en la delimitación del sector no lucrativo, y que no hemos tenido ocasión de comentar hasta ahora, son las de Hansmann (1980), Douglas (1987) y Weisbrod (1988), que serán objeto de exposición en desarrollos posteriores.

Hansmann (1980) propone una clasificación de las organizaciones no lucrativas atendiendo a dos criterios: 1) la procedencia de los ingresos y 2) el sistema de control en la organización.

1) Según la procedencia de los ingresos, distingue dos tipos de organizaciones: si las entidades obtienen los ingresos fundamentalmente de donaciones y/o subvenciones, ya sean privadas o públicas, las denomina organizaciones no lucrativas «donativas» («donative 
nonprofit»); si los ingresos provienen principalmente de las ventas de bienes o servicios, las denomina organizaciones no lucrativas «comerciales» («commercial nonprofit»).

2) De acuerdo con el tipo de control efectuado sobre la organización, distingue entre las entidades en las que el control final (el poder para elegir al equipo de directores) está en manos de los que la sostienen económicamente (donantes o usuarios), y las que denomina organizaciones no lucrativas mutuales («mutual nonprofits»); el último grupo comprende aquellas organizaciones en las que los equipos directivos son estables, permanecen en el tiempo y tienen cierta independencia de los asociados: organizaciones no lucrativas empresariales («entrepreneurial nonprofits»).

La intersección de los dos criterios da lugar a la tipología que se presenta en tabla I.2, junto con algunos ejemplos ilustrativos de los cuatro casos resultantes.

El resto de las clasificaciones parten de la proyección de las actividades de las organizaciones no lucrativas, y con ellas se obtienen resultados con matices diferentes. Weisbrod (1988) considera que existe una gran variedad de organizaciones no lucrativas, pero pueden ser clasificadas en tres grupos principales, atendiendo a su mayor o menor grado de similitud con las empresas privadas y con el sector público. Dicha similitud se concreta en un "índice de colectividad", que resulta de poner en relación la financiación de cualquier organización y el tipo de servicios que suministra (ver tabla I.3).

TABLA I.2

CLASIFICACIÓN DE ONL PROPUESTA POR HANSMANN (1980)

\begin{tabular}{|l|l|l|}
\hline \multirow{2}{*}{$\begin{array}{l}\text { Según la procedencia } \\
\text { de los ingresos }\end{array}$} & \multicolumn{2}{|c|}{ Según el tipo de control } \\
\cline { 2 - 3 } & \multicolumn{1}{|c|}{ Mutuales } & \multicolumn{1}{c|}{ Empresariales } \\
\hline Donativos & clubes políticos & museos \\
\hline Comerciales & $\begin{array}{l}\text { asociaciones de consumidores } \\
\text { asociaciones del automóvil }\end{array}$ & $\begin{array}{l}\text { hospitales } \\
\text { servicios educativos } \\
\text { residencias de ancianos }\end{array}$ \\
\hline
\end{tabular}


TABLA I.3

CLASIFICACIÓN DE ORGANIZACIONES NO LUCRATIVAS PROPUESTA POR WEISBROD (1988)

\begin{tabular}{|l|l|}
\hline Privadas & Públicas \\
\hline Comerciales & Colectivas de confianza \\
\hline
\end{tabular}

Las ONL privadas comprenden las organizaciones que Weisbrod denomina "comerciales o de propietarios». La ONL actúa como instrumento para generar beneficios a sus constituyentes, ya sean empresas privadas o personas individuales. Dentro de ellas se incluyen las asociaciones comerciales y todo tipo de clubes y asociaciones que buscan beneficiar a sus propios miembros, como cooperativas de producción, mutualidades, cámaras de comercio, etc.

Los dos tipos de ONL públicas son organizaciones no lucrativas colectivas («nonprofit colectives») y organizaciones no lucrativas de confianza («nonprofit trust»). Las organizaciones no lucrativas colectivas son aquellas que ofertan servicios de carácter público a personas que no intervienen en las actividades de financiación de la organización. Las actividades de estas organizaciones apenas se distinguen de las agencias estatales. Las organizaciones no lucrativas de confianza suministran una combinación de bien privado y protección al consumidor. Estas entidades venden servicios, al igual que las incluidas en el primer tipo, pero dichos servicios se dirigen a personas cuyo nivel de información o su capacidad para obtener información sobre las características, calidad y cantidad de los servicios, es bastante inferior a la del resto de los bienes y servicios que suelen consumir.

La clasificación de ONL propuesta por Douglas (1987) también hace hincapié en la restricción de no distribución de beneficios, pero la considera insuficiente para aproximarnos adecuadamente a la gran variedad de organizaciones existentes y para describir su naturaleza. En su propuesta de clasificación, el universo de las organizaciones no lucrativas está dividido en tres grandes tipos ${ }^{13}$ (tabla I.4).

13 Esta clasificación es muy similar a la propuesta por Hall (1987). 
TABLA I.4

CLASIFICACIÓN DE ORGANIZACIONES NO LUCRATIVAS (DOUGLAS, 1987)

\begin{tabular}{|l|l|}
\hline Tipología & Ejemplos \\
\hline 1) Org. de bienes públicos & Entidades filantrópicas \\
2) Org. de beneficio mutuo & Asociaciones deportivas, profesionales \\
3) Org. de acción política & Grupos de presión, partidos políticos \\
\hline
\end{tabular}

La clase «organizaciones de bienes públicos» la integran aquellas que suministran bienes públicos a terceros utilizando fondos privados para su financiación; en cierto sentido, son o pueden considerarse una alternativa al Estado; además, su oferta es de gran diversidad, de forma que el Estado incluso puede comprar los servicios que ofrecen. Las «organizaciones de beneficio mutuo» incluyen a las ONL que se crean para proporcionar bienes públicos en exclusividad para sus propios miembros. Las «organizaciones de acción política» persiguen conseguir beneficios indirectos a través de su influencia en las políticas estatales.

Finalmente, en coherencia con la definición propuesta de ONL, hemos adoptado la clasificación realizada por Salamon y Anheier (1992 y 1994) y Salamon et al. (1999). No se trata tanto de buscar comportamientos genéricos de las organizaciones no lucrativas, como de proporcionar un catálogo de actividades con el fin de facilitar su cuantificación en las estadísticas económicas. Esta aportación destaca por el rigor y la relación exhaustiva de actividades que comprende: un total de 10 grupos y alrededor de 200 subgrupos.

Presentamos los rasgos generales de los 13 grandes grupos de actividad y en el anexo (pp. 31-40) detallamos los diferentes subgrupos. En la medida en que se traten los distintos tipos de entidades del sector no lucrativo aragonés se utilizará esta clasificación. 


\section{Cultura y ocio}

Fomento de la cultura y ocio desde manifestaciones artísticas, sin discriminar por edad ni sexo al individuo receptor del servicio. Se incluyen medios de comunicación, arte, museos, zoos, clubes deportivos, clubes recreativos y sociales.

\section{Deporte}

Promoción del deporte tanto aficionado como de competición, en todas las modalidades, sean o no olímpicas.

\section{Educación, formación e investigación}

Formación e investigación. Actuaciones de promoción, gestión y apoyo de servicios de educación e investigación.

4. Salud

Atención sanitaria, hospitalaria y de ambulatorio, y asistencial-sanitaria a todos los estratos sociales, servicios de salud mental, rehabilitación...

5. Servicios sociales

Organizaciones e instituciones que proporcionan servicios sociales a la población general o a un grupo determinado de la población: infancia, juventud, familia, discapacitados, ancianos, autoayuda.

6. Medio ambiente

Fomento del cuidado del medio ambiente, proyectos de detección de problemas, formulación de soluciones y mejoras y divulgación.

7. Desarrollo comunitario

Organizaciones que promueven programas y proveen de servicios para favorecer el desarrollo económico y el bienestar social de la sociedad. Se incluyen asociaciones de vecinos y fomento del empleo.

8. Derechos civiles

Organizaciones y grupos que trabajan para proteger y promover los derechos civiles y dedicados a intereses sociales y políticos de carácter general, o a actuaciones especiales y que ofrecen servicios legales.

9. Intermediarios filantrópicos y promoción del voluntariado

Organizaciones de carácter filantrópico que promueven el desarrollo de organizaciones para actividades de interés general, así como el fomento y gestión del voluntariado.

10. Cooperación internacional

Organizaciones que promueven el intercambio intercultural con otros países y la ejecución de programas para el desarrollo y bienestar de otros países, y que proporcionan ayuda de emergencia en situaciones de crisis.

\section{Religiosas}

Organizaciones que promueven creencias religiosas, y grupos relacionados y auxiliares de dichas organizaciones.

12. Profesionales

Defensa y regulación de intereses de profesionales, de negocios y laborales.

13. Otros fines

Otros fines no clasificados.

FUENTE: Salamon y Anheier (1992) 


\section{Anexo. Clasificación internacional de las organizaciones no lucrativas (ICNPO)}

\section{Grupo 1: Cultura y OCiO}

Organizaciones y actividades en campos genéricos y especializados de la cultura y del ocio.

\subsection{Cultura}

\section{Medios y comunicación}

Producción y difusión de la información y de la comunicación; incluye emisoras de radio y estaciones de TV, editoriales de libros, de diarios, de periódicos y de boletines de noticias, productoras de cine y bibliotecas.

Artes gráficas, diseño, cerámica

Producción y difusión de artes gráficas y de diseño; incluye sociedades fotográficas, escultura, pintura, actividades gráficas, centros de dibujo y diseño y asociaciones arquitectónicas.

\section{Actividades artísticas}

Realización de actividades en centros, compañías de teatro, y de asociaciones dedicadas a actividades artísticas; incluye teatros, danza, ballet clásico, ópera, orquestas, corales y bandas y grupos de música.

Sociedades históricas, literarias y humanísticas

Promoción y defensa de las humanidades, preservación del patrimonio histórico y cultural de acontecimientos históricos; incluye sociedades dedicadas a la difusión de la historia, a la poesía y sociedades literarias, asociaciones difusoras de lenguas vivas y muertas, idiomas oficiales, dialectos..., promoción de la lectura, organización de memoriales, fondos conmemorativos y asociaciones.

Museos

De temática genérica y museos especializados dedicados a difundir el arte, la historia, la ciencia, la cultura y la tecnología.

Parques zoológicos y acuarios

\subsection{Ocio}

\section{Clubes deportivos}

Organización de deporte para aficionados, entrenamiento, tratamientos de salud deportiva y servicios y competiciones deportivas. 
Ocio y clubes sociales

Organización de recursos recreativos y de servicios a los individuos y a las comunidades.

\subsection{Clubes de servicios}

Organizaciones que prestan servicios a sus afiliados y a las comunidades locales en general.

\section{GRUPO 2: EDUCACIÓN E INVESTIGACIÓN}

Organizaciones y actividades que administran, proporcionan, promueven, dirigen, utilizan y mantienen la educación y la investigación.

\subsection{Educación primaria y secundaria}

Educación elemental, primaria y secundaria

\subsection{Educación universitaria y especializada}

Educación universitaria y especializada, grados académicos superiores

\subsection{Resto del área educativa}

Escuelas técnicas y de difusión profesional

Dedicadas a la formación técnica y profesional, con el objetivo de proporcionar salidas laborales.

Educación de adultos y de formación continua

Instituciones destinadas a proporcionar educación y preparación adicional al sistema educativo oficial.

\subsection{Investigación}

Investigación médica

Investigación en el campo médico; incluye la investigación sobre enfermedades específicas, o disciplinas médicas.

Ciencia y tecnología

Investigación en ciencias bioquímicas y físicas, ingeniería y tecnología.

Ciencias sociales, estudios politicos

Investigación y análisis en ciencias y áreas sociales, incluida la investigación en ciencias políticas. 


\section{GRUPO 3: SALUD}

Las organizaciones con actividad en el ámbito sanitario que ofrecen cuidado médico general, y los servicios especializados, administración de los servicios de sanitarios y de los servicios de fomento de la salud.

\subsection{Hospitales y rehabilitaciones}

Hospitales

Sobre todo, asistencia médica y tratamiento del hospitalizado.

\section{Rehabilitación}

Cuidado médico del enfermo y terapia de rehabilitación a los individuos que sufren de disfunciones físicas debido a lesiones, defectos genéticos o enfermedades, que requieran fisioterapia intensiva o formas similares de cuidado.

\subsection{Residencias asistenciales}

Residencias asistenciales

Cuidado de enfermos convalecientes, asistencia residencial, así como servicios primarios de cuidado médico; incluye los hogares para los ancianos que precisen asistencia y clínicas asistenciales en general.

\subsection{Asistencia psiquiátrica}

\section{Hospitales psiquiátricos}

Cuidado y tratamiento del paciente mentalmente enfermo.

\section{Tratamiento de la salud mental}

Tratamiento ambulatorio del paciente mentalmente enfermo; incluye centros de salud mentales comunitarios y hogares intermedios.

\section{Intervención en situaciones críticas}

Aparte de asistencia y asesoramiento a personas que padecen crisis mentales agudas, incluye prevención y socorro a suicidas y víctimas de malos tratos y agresiones sexuales.

\subsection{0 otros servicios médicos}

\section{Educación de la salud pública y de la salud}

Promoción de la salud y educación sanitaria; incluye la investigación de agentes nocivos para la salud, cursos de formación de primeros auxilios y servicios de planificación familiar. 
Tratamiento de la salud, sobre todo paciente no internado

Organizaciones que proporcionan sobre todo servicios médicos de ambulatorio a pacientes no internados; por ejemplo, atención domiciliaria.

\section{Servicios médicos de rehabilitación}

Cuidado terapéutico del paciente no internado; incluye los centros naturistas, clínicas de yoga y otros establecimientos terapéuticos.

\section{Servicios médicos emergencia}

Servicios a las personas en situaciones de emergencia; incluyen servicios ambulatorios y cuidado paramédico de emergencia, programas de shock/trauma y programas de salvamento; servicios de ambulancias.

\section{Grupo 4: SERVICIOS SOCIALES}

Organizaciones e instituciones que prestan servicios sociales a una comunidad o población en general.

\subsection{Servicios sociales}

Bienestar de la infancia, servicios a la infancia

Cuidado de los niños, servicios de adopción, centros de desarrollo del niño; incluyen centros infantiles de guardería.

\section{Servicios a la juventud y bienestar de la juventud}

Servicios a la juventud; incluyen servicios de prevención de la delincuencia y del embarazo en adolescentes, centros de juventud y clubes juveniles, programas del trabajo para la juventud.

Ayuda a la familia

Servicios a las familias; incluyen educación familiar, apoyo a separados, divorciados..., apoyo a la familia.

Servicios para los discapacitados

Servicios para los discapacitados; incluye hogares de acogida, con excepción de clínicas de reposo; transporte, ocio y otros servicios especializados.

\section{Servicios para los ancianos}

Organizaciones que proporcionan cuidado geriátrico; incluye servicios a domicilio, medios de transporte, ocio, comedores y otros servicios dirigidos a la tercera edad. 


\section{Otros servicios sociales}

Programas y servicios de apoyo al individuo no considerados anteriormente; incluye los grupos de ayuda, asesoramiento personal, y financiero.

\subsection{Asistencia preventiva y emergencias}

Prevención y control de problemas

Organizaciones que trabajan para prevenir, predecir, controlar y aliviar los efectos de desastres, educar o preparar de otra manera a individuos para que hagan frente a los efectos de desastres, o proporcionar atención a las víctimas del desastre; incluye los cuerpos de bomberos, los servicios de rescate y los voluntarios.

Centros de acogida

Organizaciones que proporcionan cobijo al emigrante; incluye la ayuda a inmigrantes y cobertura temporal.

Ayuda del refugiado

Organizaciones que proporcionan alimento, ropa, abrigo y servicios a los refugiados y a los inmigrantes.

\subsection{Ayuda a los capas de población económicamente desfavorecidas}

Apoyo económico

Organizaciones que proporcionan ayuda económica y otros servicios directos a las personas con bajos niveles de renta.

\section{Ayuda material}

Organizaciones que proporcionan alimento, ropa, transporte y otras formas de ayuda; incluye comedores y centros de distribución de ropa.

\section{Grupo 5: Medio Ambiente}

Organizaciones que fomentan y que proporcionan servicios destinados a la conservación ambiental, el control y la prevención de la contaminación, la educación y la salud ambiental, y la protección de animales.

\subsection{Entorno}

\section{Disminución y control de la contaminación}

Organizaciones que promueven un aire y un agua limpia, la disminución de la contaminación, la prevención de ruidos, el control de las radiaciones, de los residuos peligrosos y de las sustancias tóxicas, el tratamiento de los desechos sólidos y programas de reciclado y de reducción del agujero de la capa de ozono. 
Conservación y protección de los recursos naturales

Preservación y conservación de recursos naturales, incluyendo la tierra, el agua, la energía y los recursos de la tierra para uso general y disfrute público.

Parques naturales y espacios abiertos

Jardines botánicos, arboledas, programas hortícolas y servicios del paisaje; incluye las organizaciones que promueven campañas de embellecimiento, programas para preservar los parques, espacios verdes y abiertos en zonas urbanas o rurales y programas de embellecimiento de la ciudad y de la carretera.

\subsection{Animales}

Protección y cuidado de los animales

Protección y atención de animales; incluye centros de acogida de animales.

Preservación y protección de la fauna

Preservación y protección de la fauna; incluye reservas naturales y refugios.

Servicios veterinarios

Hospitales para animales y servicios que proporcionan ayuda a las explotaciones agrarias y a los animales domésticos.

\section{Grupo 6: SeRVICIOS Cívicos}

Organizaciones que promueven programas y que proporcionan servicios de ayuda y mejora de relaciones cívicas y de bienestar económico y social de la sociedad.

\subsection{Desarrollo económico, social y comunitario}

De vecinos o comunitarias

Organizaciones que trabajan para mejorar la calidad de vida dentro de las comunidades.

\section{De desarrollo económico}

Programas y servicios para mejorar la infraestructura y la capacidad económica de una comunidad; incluye iniciativas para la creación de edificios, de diverso tipo de infraestructura (caminos), programas emprendedores, y ayuda de consultoría técnica o de gestión de este tipo de programas, organizaciones rurales del desarrollo. 
De desarrollo social

Organizaciones que trabajan para mejorar la infraestructura y la capacidad institucional para paliar problemas sociales y mejorar el bienestar público en general.

\subsection{Vivienda}

De viviendas

Desarrollo, construcción, gestión, alquiler con opción a compra, financiación y rehabilitación de viviendas.

Ayuda a la vivienda

Organizaciones que proporcionan vivienda, servicios jurídicos y asesoramiento relacionados con la vivienda.

\subsection{Formación y empleo}

Programas de aprendizaje

Organizaciones que proporcionan e imparten programas de formación laboral.

Asesoramiento en temas laborales

Formación profesional y asesoramiento.

Talleres ocupacionales

Destinados a la creación de empleo, así como a la formación en puestos laborales.

\section{GRUPO 7: LEY, DEFENSA Y POLÍTICA}

Organizaciones y grupos que trabajan para proteger y defender los derechos civiles, o abogan por los intereses sociales y políticos de distritos electorales generales o especiales, ofrecen servicios jurídicos y promueven seguridad pública.

\subsection{Derechos civiles y su defensa}

Organizaciones de defensa

Organizaciones que protegen los derechos y promueven los intereses de grupos de población específicos; por ejemplo, colectivos afectados físicamente, ancianos, niños y mujeres.

De derechos civiles

Organizaciones que trabajan para proteger o para preservar libertades civiles individuales y derechos humanos. 
Étnicas

Organizaciones que velan por los intereses, o proporcionan servicios a miembros que pertenecen a una etnia específica.

Cívicas

Programas y servicios para potenciar los derechos civiles.

\subsection{Servicios jurídicos}

Servicios jurídicos

Servicios jurídicos, asesoramiento y ayuda en la resolución de conflictos jurídicos.

Prevención de la delincuencia y seguridad pública

Prevención de la delincuencia, promoción de la seguridad y medidas preventivas entre ciudadanos.

\section{Rehabilitación de delincuentes}

Programas y servicios destinados a la reinserción de delincuentes: en libertad condicional, en régimen abierto..., alternativas de la prisión.

Ayuda a la víctima

Servicios de ayuda y asesoramiento a víctimas de hechos delictivos.

De protección al consumidor

Protección de los derechos del consumidor, y mejora del control y de la calidad del producto.

\subsection{Organizaciones políticas}

Partidos y organizaciones politicas

Organizaciones que realizan propuestas ideológicas sobre cuestiones relativas a la organización, gestión y administración de la actividad pública y, en general, socio-económica.

GRUPO 8: INTERMEDIARIOS FILANTRÓPICOS Y PROMOCIÓN DEL VOLUNTARIADO

Organizaciones filantrópicas y organizaciones que promueven la captación de recursos y voluntarios. 


\subsection{Intermediarios filantrópicos y promociones del voluntariado}

\section{Promoción y ayuda del voluntariado}

Las organizaciones que reclutan, forman y canalizan voluntarios hacia otras organizaciones, y promueven el voluntariado entre la ciudadanía.

Organizaciones de captación de fondos

Organizaciones colectivas de captación de fondos.

\section{GRUPO 9: ACTIVIDADES INTERNACIONALES}

Organizaciones que promueven la mayor comprensión intercultural entre gente de diversos países y pasados históricos, que proporcionan ayuda ante emergencias y que promueven el desarrollo y el bienestar en el extranjero.

\subsection{Actividades internacionales}

Programas de intercambio y cooperación cultural

Programas y servicios diseñados para animar el intercambio y la cooperación cultural mutuos internacionalmente.

Organizaciones de cooperación al desarrollo

Programas y proyectos que promueven el desarrollo social y económico en el extranjero.

Organizaciones internacionales para ayuda de emergencia

Organizaciones que recogen, canalizan y proporcionan ayuda a otros países en situaciones de desastre o de emergencia.

Derechos humanos y organizaciones internacionales de paz

Organizaciones que promueven y vigilan los derechos humanos y la paz en el ámbito internacional.

\section{GRUPO 10: RELIGIÓN}

Organizaciones que promueven la creencia religiosa y que administran servicios y rituales religiosos; incluye las iglesias, mezquitas, sinagogas, templos, seminarios, monasterios e instituciones religiosas similares, además de asociaciones relacionadas y afines de tales organizaciones. 


\subsection{Congregaciones religiosas y asociaciones}

\section{Congregaciones}

Iglesias, sinagogas, templos, mezquitas, monasterios, seminarios y organizaciones similares que administran servicios y rituales religiosos.

Asociaciones de congregaciones

Asociaciones y delegaciones de congregaciones religiosas y de organizaciones que utilizan y que promueven creencias, servicios y rituales religiosos.

\section{GRUPO 11: DE NEGOCIOS, ASOCIACIONES PROFESIONALES Y SINDICATOS}

Organizaciones que promueven, regulan y salvaguardan los intereses de empresarios, profesionales y empleados.

\subsection{Asociaciones profesionales y sindicatos}

Agrupaciones empresariales

Organizaciones que trabajan para promover, regular y salvaguardar los intereses de diferentes agrupaciones empresariales; por ejemplo, asociaciones de agricultores, asociaciones de comerciantes.

De profesionales

Organizaciones que promueven, regulan y protegen los intereses de los profesionales.

\section{Sindicatos}

Organizaciones que promueven, protegen y regulan los derechos y los intereses de los trabajadores.

\section{GRUPO 12: OTROS}




\section{CAPÍTULO II \\ LOS CIMIENTOS LEGALES DE LAS ONL: MARCO JURÍDICO}

Cuando calificamos al conjunto de este sector de nuestra sociedad como no lucrativo, estamos usando una denominación en negativo que no aclara lo que son tanto el propio sector como sus organizaciones. Las llamamos - se llaman - ONL, pero queda mucho por decir de lo que son, representan y hacen. Necesitamos perfilar más y mejor sus propios elementos de distinción.

Una de las vías para ello es recurrir a la legislación vigente. En este capítulo nos vamos a referir a las figuras jurídicas que son susceptibles de formar parte del sector no lucrativo ya definido en el anterior. Encontramos que asociaciones y fundaciones son las que la propia Ley 30/1994 de Fundaciones e Incentivos Fiscales a la Participación Ciudadana en Actividades de Interés General define como entidades sin fines no lucrativos, aunque, además, existen otras figuras particulares que, por sus características, no son iguales entre sí, ni con el resto de entidades (ONCE, Cruz Roja, Cáritas...), ${ }^{14} \mathrm{y}$ a las cuales debemos sumar las cooperativas, las mutuas y cajas de ahorros.

Estamos ante un marco jurídico complejo donde es difícil valorar la situación global de las ONL, ya que se incorporan figuras diversas con su propio marco y casos especiales que añaden más complejidad. En este capítulo proponemos un breve recorrido por el marco regulador español, para

14 Ver Casado, dir. (1995). 
ahondar en el caso de Aragón y ofrecer posibles orientaciones de futuro; al final nos referimos al resto de las comunidades autónomas.

\section{II.1. Legislación estatal: el marco común}

Dentro del derecho español, el término asociación tiene rango genérico, engloba una gran diversidad de formas asociativas: «todo fenómeno que suponga un grupo de personas reunidas en forma permanente y dotado de una organización se estima como acogido al término asociación». ${ }^{15}$ De acuerdo con este modo de expresar el concepto de asociación, todas las organizaciones que realizan actividades económicas, ya sean lucrativas o no lucrativas, están incluidas en él.

Con una conceptualización de partida tan amplia, el ordenamiento jurídico debe desarrollar un tratamiento diferente para cada uno de los fenómenos asociativos surgidos desde la sociedad, que por otra parte, durante muchas décadas, tuvo cercenada la participación ciudadana y la libertad de asociación: raíces e historia que no se deben olvidar a la hora de analizar el presente de las ONL en nuestro país.

Las organizaciones que llevan a cabo actividades económicas se recogen en las distintas figuras asociativas enumeradas en el artículo 35 del Código Civil, donde se distinguen: 1) las corporaciones, asociaciones y fundaciones de interés público reconocidas por la ley; 2) las asociaciones de interés particular, sean civiles, mercantiles o industriales, a las que la ley concede personalidad propia distinta de la de cada uno de sus asociados. De esta forma, en el código se distingue entre las personas jurídicas públicas (corporaciones) ${ }^{16} \mathrm{y}$ las personas jurídicas privadas, bien sean de interés público (asociaciones y fundaciones), o de interés privado (sociedades civiles y mercantiles).

15 Reflejado por López-Nieto (1987).

16 Las corporaciones están consideradas como personas jurídicas públicas, por lo que las características de independientes y privadas no son propias de dichas entidades. Un caso específico son los colegios profesionales, que se rigen por el marco regulador de corporaciones de derecho público, a lo cual se añade que para ejercer determinadas profesiones es obligatoria la inscripción. Debido a estas características, excluimos del sector no lucrativo este tipo de entidades, aunque mantenemos a la ONCE por ser un caso especial dentro de las corporaciones y por tener los rasgos esenciales de una ONL. 
Así las cosas y de acuerdo con esta distinción, la idea de actividad no lucrativa la podemos relacionar con la expresión interés general, y la de actividad lucrativa con la de interés particular. Esto supone que interpretamos la expresión interés general como interés o utilidad de todos, en contraposición a los intereses privados o personales. Dicho de otro modo, resaltamos que se actúa para favorecer a terceros, o se persiguen finalidades supra-individuales, o se trabaja por un fin o ideal desinteresado. El interés particular se referirá, en cambio, a un núcleo limitado de personas. En la reflexión de López-Nieto (1987) sobre la diferencia entre la figura de la sociedad y de la asociación se argumenta más extensamente esta relación. Para ello, parte de la distinción entre interés particular e interés general expresado en el Código Civil.

Según López-Nieto, la asociación es «una unión de personas que ponen en común sus conocimientos, su actividad [...], mientras que la sociedad es un contrato por el cual varias personas se unen para poner una cosa en común y repartir sus beneficios». De aquí se deducen tres consecuencias que acentúan las diferencias entre las dos figuras:

— En la sociedad existe una aportación o participación valorables económicamente e imputables a los socios; en la asociación no.

- En la sociedad las relaciones entre los socios son por razón de las cosas comunes; en la asociación las relaciones son estrictamente personales.

- En la sociedad se persigue un fin de ganancia individual y, por tanto, la participación de los socios en los beneficios debe producirse sobre la base de recíprocas proporciones preestablecidas; en la asociación no.

Por consiguiente, la diferencia fundamental estriba en que en las asociaciones no existe reparto del beneficio obtenido entre los asociados, es decir, lucro subjetivo, ${ }^{17}$ mientras que en las sociedades se distribuyen los beneficios entre sus miembros.

17 En la terminología jurídica se distingue el lucro subjetivo del lucro objetivo. El lucro objetivo o lucro social es la obtención de beneficio sin distribución entre los asociados. El lucro subjetivo o lucro de los socios es la obtención de beneficios y distribución de las ganancias entre los miembros asociados. Por tanto, en la asociación puede existir lucro, pero sólo cuando se entiende como lucro subjetivo. 
Sin embargo, como señala Aguiar de Luque ${ }^{18}$ (1984), «la distinción que efectúa el Código Civil ha sido objeto de crítica, manteniéndose al respecto que ni puede considerarse de interés público a toda asociación que no persiga el reparto de beneficios, ni el interés particular equivale siempre a la persecución de un fin lucrativo». Es decir, la expresión interés público no recoge toda la realidad asociativa, ya que el código cita como asociaciones de interés particular únicamente las sociedades civiles, mercantiles e industriales; de forma que podría deducirse que todas las restantes asociaciones deben cumplir el requisito de interés general, cuando, por ejemplo, asociaciones deportivas o asociaciones de vecinos deberían ser consideradas como de interés particular y, sin embargo, no persiguen la distribución de beneficios entre sus miembros.

Por tanto, a pesar de las dificultades que plantea la interpretación de las expresiones interés particular e interés general, las figuras del ordenamiento jurídico que consideramos como organizaciones, no lucrativas son las asociaciones, las fundaciones y las corporaciones a las que por sus especiales características añadimos las mutualidades, cooperativas y cajas de ahorros.

En el capítulo anterior ya planteábamos esta distinción desde los modos de hacer de las propias entidades y catalogábamos como ONL de interés general las asociaciones y fundaciones, mientras que incluíamos dentro de las ONL de interés particular a las cooperativas, mutualidades y cajas de ahorros. El análisis del ordenamiento jurídico nos permite perfilar mejor esta distinción. De momento, encontramos que en el caso de las cooperativas se ha creado una nueva figura - cooperativas de iniciativa social—, ${ }^{19}$ que debería ser incluida entre las de interés general. Asimismo, la complejidad del entramado legal de las asociaciones nos lleva a dedicar un espacio específico a partidos políticos y sindicatos.

Partiendo de lo dicho en el capítulo anterior, entendemos que el sector no lucrativo está formado por aquellas organizaciones legalmente reconocidas - dejamos fuera el entramado de grupos informales sin legalizar, independientemente de su labor o repercusión-, de carácter privado, con autogobierno, donde los derechos de decisión y control residen en los miembros de la entidad, que podrán contar con trabajadores o voluntarios,

18 Citado en López-Nieto (1987).

19 Ley de Cooperativas de Aragón 9-1998 y Ley 27-1999 de Cooperativas. 
donde la clave principal radica en la limitación a la apropiación de los posibles excedentes de la actividad y cuyos fines abarcan desde asuntos de «asistencia social, cívicos, educativos, culturales, científicos, deportivos, sanitarios, de cooperación para el desarrollo, de defensa del medio ambiente, de fomento de la economía social o de la investigación", como se expresa en la Ley 30/1994 de Fundaciones, en el artículo 42 del título II.

Ahora continuamos exponiendo los rasgos generales derivados de la legislación estatal sobre las entidades que entendemos que forman parte del sector no lucrativo, diferenciando las de interés general y las de interés particular.

\section{II.1.1. Asociaciones}

Respecto de las asociaciones, el marco legal es, cuando menos, complicado. Hasta que en marzo de 2002 se aprueba la Ley 1/2002 de Derecho de Asociación no existía un marco adaptado a la Constitución que regulara las asociaciones. Hasta entonces, la Ley general de Asociaciones por la que se regían todavía una gran parte de estas asociaciones databa de 1964. En concreto, la Ley 191/1964, de 24 de diciembre, de Asociaciones, y el Decreto 1440/65, de 20 de mayo, donde se establecen normas complementarias para las asociaciones. Junto a esto y debido a las deficiencias generadas por el desfase entre la ley y los cambios sociales, se han creado una serie de leyes y decretos que tratan de paliarlas. El resultado es un entramado legal muy poco efectivo.

El marco general donde se recoge el derecho de asociación es el artículo 22 de la Constitución, en los siguientes términos: 1) se reconoce el derecho de asociación; 2) las asociaciones que persigan fines o utilicen medios tipificados como delito son ilegales; 3) las asociaciones constituidas al amparo de este artículo deberán inscribirse en un registro a los solos efectos de publicidad; 4) las asociaciones sólo podrán ser disueltas o suspendidas en sus actividades en virtud de resolución judicial motivada; 5) se prohiben las asociaciones secretas y las de carácter paramilitar.

Este precepto se encuentra en la sección 2, "De los derechos fundamentales y de las libertades públicas», del capítulo II del título primero, y, a tenor de los previsto en el artículo 53 del mismo cuerpo legal, el derecho de asociación debe ser regulado por ley, que forzosamente ha de ser ley 
orgánica (art. 81.1), y cualquier ciudadano puede recabar su tutela ante los tribunales ordinarios por un procedimiento basado en los principios de preferencia y sumariedad y, en su caso, a través del recurso de amparo ante el Tribunal Constitucional.

A pesar de los años transcurridos desde la entrada en vigor de la Constitución, nos encontramos que hasta el año 2002 no existía una ley orgánica "post-constitucional» que desarrollara este derecho.

No obstante, en la Ley 30/1994, de 24 de noviembre, se modifica el artículo 4 de la Ley 191/1964, sobre declaración de Utilidad Pública y el Real Decreto 1786/1996, de 19 de julio, sobre procedimientos relativos a asociaciones de utilidad pública regula las asociaciones de utilidad pública y especifica, entre otros requisitos para la concesión de esta condición por parte del Consejo de Ministros, los tipos de fines a los que tienen que orientar sus actividades: «de asistencia social, cívicos, educativos, culturales, científicos, deportivos, sanitarios, de cooperación para el desarrollo, de defensa del medio ambiente o de fomento de la economía o de la investigación, de promoción del voluntariado, o cualesquiera otros de naturaleza análoga».

En definitiva, nos están remitiendo a fines o actuaciones acordes con la tipología propia de actividades principales de cualquier ONL, que hemos desarrollado en el capítulo I del presente libro. De esta forma se establece una orientación teleológica para las asociaciones similar a la establecida para las fundaciones: ejercicio de actividades destinadas a objetivos de interés general, en contraposición a las que persiguen intereses privados o personales. Paralelamente, en la legislación marco sobre asociaciones, y en línea con la Ley 30/1994, no se prohibe expresamente que este tipo de entidades puedan realizar, al menos como actuaciones secundarias, actividades de carácter mercantilista.

En la tendencia evolutiva que se experimenta en el ámbito jurídico cuando nos referimos al concepto asociación, López-Nieto (1987) establece características adicionales: la asociación comporta una unión permanente de personas físicas, que está dirigida a servir un fin común, definido por el objeto asociativo, exento de lucro.

Esta unión de personas o voluntades se rige por unas normas que permiten consensuar decisiones sobre pautas de actuación para lograr los objetivos asociativos, que se concretan como establece el artículo 11 de la 
Ley $1 / 2002$. De esta forma, la legislación establece y conceptúa la asociación como una entidad administrativamente organizada en estratos con diferentes capacidades de decisión y responsabilidades, con el objeto de facilitar la gestión socio-económica de la entidad. Dentro de esta organización destaca como órgano supremo la asamblea general, cuyo funcionamiento está regido por el principio de adopción de acuerdos por mayoría (democracia interna), lo que confiere a la asociación un régimen democrático en la toma de decisiones. Este régimen de funcionamiento democrático queda reiterado en la redacción del artículo 11.

Por otro lado, aunque no queda expreso en la redacción de la normativa jurídica, las asociaciones pueden ser multiactivas, lo que significa que implícitamente pueden desarrollar actividades de carácter mercantilista, en paralelo con otras no lucrativas. La legislación fiscal así lo comprende, y ésta es la justificación de por qué el título II de la Ley 30/1994 hace extensiva la redacción del régimen fiscal de exenciones parciales en la tributación del impuesto de sociedades, donde se contempla a las asociaciones como sujeto pasivo.*

En definitiva, las asociaciones se entienden como organizaciones creadas desde la confluencia de voluntades de personas físicas y jurídicas, dirigidas a actuaciones de interés general, con actividades principales comprendidas en el compendio relacionado en el capítulo I de este tratado, pero con capacidad para generar, aunque sea de forma esporádica, rendimientos lucrativos.

La dificultad de convivir hasta el 2002 con una ley pre-constitucional se ha ido paliando con la proliferación de normativa para aquellas asociaciones no contempladas en la Ley de 1964, y, por ello, podemos distinguir asociaciones bajo el régimen jurídico general y asociaciones bajo regímenes jurídicos especiales (Casado, dir., 1995, p. 26 y ss.).

\section{II.1.1.1. Asociaciones bajo el régimen jurídico general}

Son aquellas regidas por la Ley de Derecho de Asociación de 2002, del que todavía no se ha publicado un reglamento que la desarrolle cuando se redacta este texto. Las asociaciones que se incluyen, según el artícu-

* En el momento de publicar este libro se ha presentado un proyecto de ley de mecenazgo que mejora la situación fiscal de las asociaciones y fundaciones. 
lo 1 , son «todas las asociaciones que no tengan fin de lucro y que no estén sometidas a un régimen asociativo específico». Quedan excluidas expresamente en la propia ley:

- Las sociedades civiles, sociedades mercantiles, industriales y laborales, las cooperativas, mutualidades, las comunidades de propietarios y corporaciones.

- Asociaciones que no se rigen por la ley: «las asociaciones constituidas para fines exclusivamente religiosos por las iglesias, confesiones y comunidades religiosas» (art. 1, pto. 3) y cualesquiera otras asociaciones reguladas por leyes especiales.

Estarían incluidas las benéficas, protectoras de animales y plantas, investigación, culturales, juveniles, arte, consumidores, servicios sociales y cooperación al desarrollo. En este último caso, el Real Decreto 1033/1986, de 25 de abril, creó un registro público para las entidades que realicen sus actividades en el campo de la acción social además del Registro General.

\section{II.1.1.2. Asociaciones de regímenes jurídicos especiales}

Tienen una notoria independencia legal y se inscriben en registros especiales. Son asociaciones políticas, sindicales, empresariales, deportivas,$^{20}$ religiosas, y asociaciones de estudiantes. ${ }^{21}$

A continuación vamos a destacar algunas de las principales características de los partidos políticos, sindicatos y asociaciones empresariales, haremos una breve reflexión sobre las entidades religiosas.

Los partidos políticos, tradicionalmente considerados una variante de asociación política, son regulados por la Ley Orgánica 6/2002, de 27 de junio. Estas organizaciones son la expresión de la libertad de ejercicio de los derechos civiles y políticos recogidos en la Constitución Española, cuyas actuaciones podrían concretarse en hacer efectivo un plan ideológico sobre cuestiones relativas a la organización, gestión y administración de

20 Ley 10/1990, de 15 de octubre, del Deporte, título III, sobre las asociaciones deportivas.

21 Ley Orgánica 8/1985, de 3 de julio, del Derecho a la Educación, art. 7 para las asociaciones de estudiantes no universitarios, y Ley Orgánica 11/1983, de 25 de agosto, de Reforma Universitaria, art. 27.5 para las de estudiantes universitarios. 
la actividad pública y, en general, socio-económica. En cuanto a su independencia y capacidad de auto-gestión de sus recursos económicos, dadas las restricciones establecidas en la Ley Orgánica 3/1987, de 2 de julio, sobre la financiación de los partidos políticos, que la reciente Ley Orgánica 6/2002 no modifica, podría entenderse que sus decisiones se encuentran limitadas. No obstante, las limitaciones se centran en la percepción de fondos y financiación privada, restricción que entendemos determinada por el claro espíritu democrático de que el poder político no esté en manos de lobbies económicos. De hecho, una vez establecidos los montantes presupuestarios, es la junta general y, en última instancia, el comité ejecutivo los agentes que deciden plenamente, dentro de los límites de la legislación vigente, la disposición de los recursos financieros.

El artículo 7 de la Constitución Española reconoce expresamente a los sindicatos de trabajadores y asociaciones empresariales como los agentes sociales encargados de la defensa y promoción de los intereses económicos y sociales de los trabajadores y empresarios, respectivamente. La Ley Orgánica 11/1985, de 2 de agosto, pilar legislativo en la regulación de estas organizaciones, establece como requisito básico que debe regir su estructura y funcionamiento el talante democrático. Asimismo se les reconoce personalidad jurídica y plena capacidad para la auto-gestión de sus recursos; de hecho, en ambos casos se les asigna el rango de asociación.

En estos momentos, desde el registro dependiente de la Dirección General de Asuntos Religiosos, perteneciente al Ministerio de Justicia, se estima que existen en España 899 entidades religiosas relacionadas con confesiones consideradas minoritarias. Entre las organizaciones vinculadas con la Iglesia católica, la cifra se eleva a 11081 entidades, incluyendo asociaciones, cofradías, hermandades, órdenes y congregaciones religiosas, además de 153 fundaciones canónicas. Así, el artículo 2 del Real Decreto 142/1981, de 9 de enero, define el término generalista entidad religiosa cmo aquellos sujetos afectos a la inscripción en el Registro de Entidades Religiosas, y cita las siguientes organizaciones:

1. Las iglesias, confesiones y comunidades religiosas.

2. Las órdenes, congregaciones e institutos religiosos.

3. Las entidades asociativas religiosas constituidas como tales en el ordenamiento de las iglesias y confesiones.

4. Sus respectivas federaciones. 
De esta forma, observamos que detrás del concepto de entidad religiosa se recoge un amplio abanico de estructuras organizativas que es preciso estudiar con algo de detenimiento para avanzar en nuestro análisis. En primer lugar, señalaremos que en el tercer orden de la clasificación se concentran bajo el término entidades asociativas formas jurídicas como asociaciones y fundaciones de corte religioso y canónico. Con independencia del motor ideológico de sus actividades, son entidades que, jurídicamente, forman parte consustancial del Tercer Sector. En esta línea, las federaciones que se constituyan al amparo de confesiones religiosas serán tratadas al finalizar el presente apartado con el resto de federaciones. En consecuencia, en este apartado nos centraremos en evaluar si las iglesias, confesiones, comunidades, órdenes, congregaciones e institutos religiosos forman parte de nuestro sector no lucrativo. Para ello acudiremos a las referencias recogidas en la Ley Orgánica 7/1980, de 5 de julio, de libertad religiosa, donde su artículo 6.1. establece expresamente que serán entes considerados con plena autonomía y capacidad para organizar y gestionar la organización y funciones, sin que se imponga la exigencia de regímenes democráticos en la toma de decisiones ni estructuras previas que permitan deducir esta característica. Por otra parte, es difícil precisar si el fomento de las creencias religiosas, practicar actos de culto, ofrecen asistencia religiosa, conmemorar festividades, celebrar ritos, impartir enseñanza, proporcionar enseñanza religiosa y moral de acuerdo con las convicciones de la confesión o iglesia correspondiente, etc., lo podemos identificar con una actividad prioritariamente no lucrativa, como se ha definido en el capítulo primero de este libro. Por todo ello, concluimos que, de todas las entidades religiosas comprendidas como tales desde la perspectiva jurídica, sólo son agentes componentes del Tercer Sector las asociaciones y fundaciones religiosas, que suelen ser creadas para fomentar actividades de corte no lucrativo, diseñadas y ejecutadas dentro del ámbito de la confesión o iglesia que fomenta y avala la relación asociativa.

\section{II.1.2. Fundaciones}

A mediados de los años noventa, dentro del panorama jurídico español adquiere una relevancia destacada la figura de la «fundación» con la entrada en vigor de la Ley 30/1994, norma que regula el nacimiento, la 
vida organizativa y administrativa y la extinción de una fundación.* Esta ley surge como vehículo destinado a estimular la creación y a proteger las iniciativas y el libre ejercicio de fundar, derecho reconocido en el artículo 34 de nuestra Constitución. Para comprender mejor el papel de estas entidades y su origen, nos valen las palabras del profesor Tomás y Valiente: «ni sociedad civil contra Estado, ni propiedad individualista, sino colaboración Estado-sociedad, derecho a fundar como derecho de libertad del propietario y propiedad delimitada por su función social [...] y en la intersección entre ambos vectores [...] surge la fundación».

Así las cosas, la ley referida concibe las fundaciones como organizaciones constituidas sin ánimo de lucro que, por voluntad de sus creadores, tienen afectado su patrimonio a la realización de fines de interés general (art. 1.1). De esta concepción se derivan tres implicaciones:

- Ausencia del ánimo de lucro. Este requisito debe ser entendido en sus justos términos: «una fundación no puede nunca ser considerada como medio apto para la obtención de ganancias destinadas a actividades distintas a las de interés general».

No obstante, es evidente que, para hacer frente a ciertas obligaciones de interés común, la fundación tendrá que realizar, al menos ocasionalmente, actividades económicas. Incluso, en estas situaciones, la ley exige al patronato el óptimo de rentabilidad.

- Carácter duradero de la afectación patrimonial. Esta circunstancia implica que el patrimonio debe permanecer y dar la oportunidad a la fundación para que se cumplan los objetivos perseguidos desde la actividad de interés general. No obstante, no se invalida el hecho de que la fundación tenga un carácter temporal y una pervivencia preestablecida en el tiempo.

- Afectación teleológica al interés general. De hecho, las fundaciones son un fenómeno expresivo de la autonomía de la voluntad privada para potenciar, junto con el poder público, atenciones de talante social y de general interés de grupo, a veces determinados y, en otras ocasiones, algo más indeterminados.

* En el momento de publicar este libro se ha presentado un nuevo proyecto de ley de fundaciones. 
Para poder analizar el panorama fundacional español es necesario precisar, aunque sea de forma somera y sintética, el contenido de la Ley 30/1994. La Ley se compone de dos partes:

En primer lugar, el título I, donde se desarrollan el régimen general y las normas de carácter sustantivo dirigidas a regular la actividad administrativa de las fundaciones —el nacimiento (su constitución, escritura, estatutos, la dotación y creación del patrimonio...), las incidencias en el ejercicio de sus actividades (variaciones patrimoniales, aplicación de medios a fines, fusiones...) y su extinción - y el régimen contable de estas entidades, que es una particularización del régimen general propio de las sociedades mercantiles a las peculiaridades de las fundaciones. Esta primera parte tiene una aplicación extensiva para todo tipo de fundaciones, con las siguientes limitaciones:

a) Las fundaciones laborales preexistentes constituidas en virtud de convenio colectivo entre organizaciones empresariales y sindicales deberán ser objeto de un futuro tratamiento legal específico. Mientras tanto, se les aplica la Ley 30/1994.

b) La ley se aplicará sin perjuicio de lo establecido en acuerdos y convenios respecto a fundaciones creadas o fomentadas por confesiones religiosas, sus iglesias o comunidades.

c) Esta ley no es de aplicación a fundaciones del patrimonio nacional. ${ }^{22}$

En segundo lugar, el título II de la Ley 30/1994 establece un régimen de carácter fiscal con el fin de regular las obligaciones tributarias propias de ciertas entidades sin fines de lucro, como fundaciones inscritas en el registro correspondiente y asociaciones declaradas de utilidad pública, incluidas las fundaciones del patrimonio histórico.

Volviendo a la parte sustancial de nuestra argumentación, queda claro que, para poder constituirse un conjunto de voluntades en fundación, es necesario que su actividad principal esté dirigida a la inexistencia de lucro, entendida jurídicamente como la ausencia de reparto de beneficios a los dirigentes, fundadores y partícipes de la entidad. Esta premisa no implica la prohibición expresa de que una entidad de este tipo dedique sus esfuerzos, en calidad de actuación secundaria, a realizar actividades de corte mer-

22 Salvo en lo que se refiere al régimen fiscal de las aportaciones lucrativas efectuadas a su favor. 
cantil, entendiendo como tal aquella no exenta de tributación en rentas netas obtenidas. Con ello, el panorama de fundaciones se concreta y distribuye en cuatro tipologías:

1. Fundaciones que disfrutan de la exención fiscal de la totalidad de las explotaciones económicas (visto en el art. 48, apartado segundo, de la Ley 30/1994), porque cumplen con los requisitos del artículo 42.1 de la Ley 30/1994 (disfrute del régimen tributario de las entidades sin fines de lucro establecido en la Ley 30/1994).

2. Fundaciones en las que sólo se extiende la exención fiscal prevista en la Ley 30/1994 a la actividad que constituye su objeto social o fundacional, así como a los incrementos patrimoniales derivados de un título gratuito, pero no a los rendimientos de las explotaciones económicas.

3. Fundaciones que por realizar sólo prestaciones gratuitas gozan de una exención total en sus actividades y, además, de un incentivo fiscal adicional (ver art. 55 de la Ley 30/1994).

4. Fundaciones que no reúnen los requisitos del artículo 42.1 de la Ley 30/1994 y, por lo tanto, no pueden disfrutar del régimen fiscal establecido en ella. Su regulación corresponde al capítulo XV, del título VIII, de la Ley 43/1995, del impuesto sobre sociedades.

La posible liberalidad de realización de actividades mercantiles es respetada desde la legislación vigente, sin que esta circunstancia implique que las entidades no lucrativas puedan concebir como su actividad principal aquella que escape a las presentadas en el artículo 2 de la ley, en los siguientes términos:

[...] de asistencia social, cívicos, educativos, culturales, científicos, deportivos, sanitarios, de cooperación para el desarrollo, de defensa del medio ambiente o de fomento de la economía o de la investigación, de promoción del voluntariado, o cualesquiera otros de naturaleza análoga.

Otro aspecto destacado e imprescindible es la necesidad de que exista un patrimonio afectado a la realización de la voluntad del fundador o fundadores. El derecho a fundar está reconocido en la sentencia 49/1988 del Tribunal Constitucional como una manifestación más de la autonomía de la voluntad respecto a los biene, en virtud de la cual una persona puede disponer libremente de su patrimonio, incluso creando una persona jurídica para asegurar los fines deseados de interés general. 
En consecuencia, el fundador es el creador de la fundación, que puede ser una persona física o jurídica o varias. El fundador dicta las reglas, dentro de las limitaciones establecidas por la ley, para constituir la fundación, para el desarrollo de la actividad fundacional e, incluso, para su extinción. La voluntad del fundador está explícita en la carta constitucional y en los estatutos de la fundación, si bien el fundador no puede eludir los imperativos legales establecidos en la Ley 30/1994.

El fundador tiene que reunir los siguientes requisitos:

- Si es una persona física, debe tener capacidad para obrar y para disponer gratuitamente de los bienes y derechos que supongan la dotación fundacional.

- Si es una persona jurídica y la fundación es de carácter asociativo debe contar con el acuerdo expreso de la junta general o asamblea de socios; si la fundación es de carácter institucional, debe contar con el acuerdo de su órgano rector.

De cualquier forma, se explicita que las fundaciones pueden surgir tanto por iniciativas privadas como por iniciativas de organismos públicos. De aquí surge una segunda clasificación:

1. Fundaciones de iniciativa privada, cuyo fundador puede ser una persona física o jurídica, regulada por el derecho mercantil o civil.

2. Fundaciones de iniciativa pública, donde la voluntad de fundar emana de entes regulados por el derecho público.

En nuestra sociedad sociedad hay muchos ejemplos de fundaciones de iniciativa pública. Éstas no deben confundirse con la reciente figura de la fundación pública sanitaria, regulada por la Ley 15/1997, que nace para dotar de mayor independencia y descentralizar los hospitales dependientes del INSALUD, y ante la incapacidad político-social y legal para otorgarles la figura de fundaciones, consorcios o sociedades estatales. Tal incapacidad está básicamente originada por la naturaleza estatutaria de su plantilla de trabajadores y su difícil reconversión al régimen de contratación laboral. Esta circunstancia provoca que su gestión en recursos humanos no sea plena, y, por lo tanto, el patronato carece de soberanía para aplicar políticas de despidos e incentivos. 
Llegados a este punto, debemos cuestionarnos si es necesario incorporar como característica adicional a una fundación regida desde la Ley 30/1994 la ostentación de gestión plena, con reconocimiento explícito jurídico. Remitiéndonos al articulado de esta ley se clarifica, en las referencias expresas al concepto de patronato y funciones, las responsabilidades jurídicas de sus miembros, que se presentan como el órgano que establece las pautas efectivas que regirán con plena capacidad de decisión el funcionamiento de la fundación y velará, en definitiva, por el cumplimiento de los fines fundacionales. De esta forma, consideramos que las fundaciones públicas sanitarias no pueden catalogarse en el conjunto de fundaciones ni asimilarse con fundaciones de iniciativa pública, que están dotadas de plena capacidad de la toma de decisiones.

En cuanto a la referencia efectuada a su afectación teleológica o finalista de su actividad principal, resulta gratificante comprobar que en la Ley 30/1994 se realiza el esfuerzo de establecer puntos de encuentro con las tendencias doctrinales, dado que se establece una acotación en fines que, a pesar de su talante generalista, confluye con las propuestas realizadas en el capítulo primero.

Como conclusión, solamente consideramos las fundaciones que surgen por iniciativa de entidades regidas por ramas del derecho privado, mientras que no incluimos a aquellas cuya voluntad de fundar se genera desde entes regulados por el derecho público. La razón fundamental se debe a que en la definición de ONL se exige, además de que sea autogestionadas, que proceda de la iniciativa privada.

\section{II.1.3. Cooperativas}

La Constitución Española, en su artículo 129.2, «dispone que los poderes públicos promoverán eficazmente las diversas formas de participación en las empresas y fomentarán, mediante una legislación adecuada, las sociedades cooperativas».

En el artículo 1.1 de la Ley 27/1999, de 16 de julio, de cooperativas, se concibe este tipo de entidades como una asociación de personas cuyo objetivo fundamental es la realización de actividades empresariales, encaminadas a satisfacer sus necesidades y aspiraciones económicas y sociales, 
con estructura y funcionamiento democrático. De esta conceptualización se desprende lo siguiente:

- Como personas jurídicas que son, este tipo de entidades tienen una autonomía plena para gestionar sus recursos económicos y humanos.

- Además, deben disponer de forma efectiva de una estructura organizativa que responda a una distribución de responsabilidades y capacidades de decisión. De hecho, en el capítulo IV de la Ley 27/1999 se definen y establecen los requisitos básicos de funcionamiento de los órganos de las entidades, como la asamblea general, el consejo rector, la intervención y el comité de recursos.

- Adicionalmente, y como se señala en el artículo 1.1 de la ley mencionada, se anticipa que las decisiones que se adopten responderán a un régimen democrático, que es uno de los pilares básicos en los que se apoya posteriormente el legislador para regular las funciones y capacidades de los órganos de la entidad.

Asimismo, el marco legal hace referencia a que las cooperativas deben regirse por los principios cooperativos postulados por la Alianza Cooperativa Internacional. ${ }^{23}$ La Alianza Cooperativa Internacional (ACI) expone, a través de la Declaración sobre la Identidad Cooperativa la definición, los valores y los principios cooperativos que identifican a una organización como cooperativa. Reproducimos a continuación su planteamiento.

Declaración sobre la Identidad Cooperativa (ACI)

Definición

Una cooperativa es una asociación autónoma de personas que se han unido de forma voluntaria para satisfacer sus necesidades y aspiraciones económicas, sociales y culturales en común, mediante una empresa de propiedad conjunta y de gestión democrática.

Valores

Las cooperativas están basadas en los valores de la autoayuda, la autorresponsabilidad, la democracia, la igualdad, la equidad y la solidaridad. En la tradición de sus fundadores, los socios cooperativos hacen suyos los valores éticos de la honestidad, la transparencia, la responsabilidad y la vocación social.

$23<$ <ww.coop.org>, 2001. 
Principios cooperativos

Los principios cooperativos son pautas mediante las cuales las cooperativas ponen en práctica sus valores.

Primer principio: adhesión voluntaria y abierta

Las cooperativas son organizaciones voluntarias, abiertas a todas las personas capaces de utilizar su potencial y dispuestas a aceptar las responsabilidades de ser socio, sin discriminación social, política, religiosa, racial o de sexo.

Segundo principio: festión democrática por parte de los socios

Las cooperativas son organizaciones gestionadas democráticamente por los socios, los cuales participan activamente en la fijación de sus políticas y en la toma de decisiones. Los hombres y mujeres elegidos para representar y gestionar las cooperativas son responsables ante los socios. En las cooperativas de primer grado, los socios tienen iguales derechos de voto (un socio, un voto), y las cooperativas de otros grados están también organizadas de forma democrática.

Tercer principio: participación pconómica de los socios

Los socios contribuyen equitativamente al capital de sus cooperativas y lo gestionan de forma democrática. Al menos parte de ese capital normalmente es propiedad común de la cooperativa. Por lo general, los socios reciben una compensación, si la hay, limitada sobre el capital entregado. Como condición, los socios asignan los excedentes para todos o alguno de los siguientes fines: el desarrollo de su cooperativa, posiblemente mediante el establecimiento de reservas, de las cuales una parte por lo menos serían no distribuibles; el beneficio de los socios en proporción a sus operaciones con la cooperativa; y el apoyo de otras actividades aprobadas por los socios.

Cuarto principio: autonomía e independencia

Las cooperativas son organizaciones autónomas de autoayuda, gestionadas por sus socios. Si firman acuerdos con otras organizaciones, incluidos los gobiernos, o si consiguen capital de fuentes externas, deben hacerlo en términos que aseguren el control democrático por parte de sus socios y mantengan su autonomía cooperativa.

Quinto principio: educación, formación e información

Las cooperativas proporcionan educación y formación a los socios, a los representantes elegidos, a los directivos y a los empleados para que puedan contribuir de forma eficaz al desarrollo de sus cooperativas. Ellas informan al gran público, especialmente a los jóvenes y a los líderes de opinión, de la naturaleza y beneficios de la cooperación.

Sexto principio: cooperación entre cooperativas

Las cooperativas sirven a sus socios lo más eficazmente posible y fortalecen el movimiento cooperativo trabajando conjuntamente mediante estructuras locales, nacionales, regionales e internacionales.

Séptimo principio: interés por la comunidad

Las cooperativas trabajan para conseguir el desarrollo sostenible de sus comunidades mediante políticas aprobadas por sus socios. 
La interpretación de estos principios cooperativos indica que existe una limitación clara a la distribución del beneficio, por lo que entendemos que son ONL y las clasificamos como de interés particular; además, sus actuaciones tienen efectos externos de los que se beneficia la sociedad en general. La clasificación como ONL de interés particular se debe a que, atendiendo a los antecedentes legislativos señalados, de hecho, esta unión de personas se dirige originariamente a atender las necesidades de los individuos directamente implicados en este tipo de entidades con el fin fundamental de realizar actividades que atiendan sus necesidades económicas y sociales.

No obstante, en esta ley se desarrolla una casuística de posibles tipos de cooperativas —algunas de ellas claramente orientadas a atender intereses individuales desde la ejecución de actividades mercantiles-, como las cooperativas de trabajo asociado, las cooperativas de viviendas, las cooperativas de explotación comunitaria de la tierra y las cooperativas de servicios, las cooperativas de transportistas, las cooperativas de seguros, las cooperativas sanitarias, las cooperativas de enseñanza y las cooperativas de crédito, entre otras. $\mathrm{Si}$ analizamos el objeto y las normas aplicables de cooperativas como las de iniciativa social, donde se expresa que tienen que ser entidades sin ánimo de lucro, las de consumidores y usuarios, para las que entre sus objetivos se establece atender la educación, formación y defensa de los derechos de sus socios en particular y de los consumidores en general, o, en su caso, las agrarias, para las que se define como uno de sus fines la mejora de la población agraria y el desarrollo del mundo rural, podemos afirmar que estos tres tipos pueden ser susceptibles de ser considerados como ONL de interés general.

\section{II.1.4. Mutualidades}

Las mutuas son concebidas como asociaciones de personas o mutualistas, sin carácter capitalista o sin ánimo de lucro. ${ }^{24}$ La naturaleza de asociación que tiene la mutualidad conlleva la capacidad de los mutualistas, que son los propios beneficiarios de la previsión, para decidir sobre el fun-

24 Real Decreto 2486/1988, de 20 de noviembre de 1998, por el que se aprueba el Reglamento de Ordenación y Supervisión de los Seguros Privados, y Real Decreto 2615/1988, de 4 de diciembre, por el que se aprueba el Reglamento de Entidades de Previsión Social. 
cionamiento de la entidad. El asociado se convierte así en asegurador y asegurado al mismo tiempo, teniendo por ello la facultad de autogestionarse.

La concepción personalista de las mutualidades hace que todos los mutualistas tengan los mismos derechos políticos y de representación, con independencia de sus aportaciones o sus derechos económicos frente a la entidad. De esta forma, queda garantizado un régimen de toma de decisiones democrático en el funcionamiento de este tipo de persona jurídica.

El principio de solidaridad es el pilar básico del nacimiento del movimiento mutualista de previsión social y, de hecho, puede decirse que éste es el fundamento y la razón de ser del mutualismo. De ahí que tradicionalmente las mutualidades se hayan considerado entidades que actúan sin ánimo de lucro, característica consustancial a su naturaleza y creación.

De hecho, su carácter no lucrativo lo corrobora la actividad principal de toda mutualidad, es la previsión y cobertura de riesgos, que, en términos generales, coincide casi en su totalidad con el campo de acción protectora de la Seguridad Social, y que es compartida con otros sistemas privados de previsión. Esta actividad principal ha sido tradicionalmente combinada con actuaciones de carácter secundario de naturaleza benéfico-social, en ámbitos como la salud, la tercera edad y la mejora de la calidad de vida, como ratificó el Congreso Español de Mutualidades (Barcelona, 1991). Por ello que podríamos considerar que las mutualidades están dirigidas a satisfacer mayoritariamente el interés particular de sus miembros, y, en consecuencia, puede afirmarse que las mutualidades de previsión social son ONL de interés particular.

\section{II.1.5. Cajas de ahorro}

La Ley 31/1985, de 2 de agosto, de Regulación de las Normas Básicas sobre Órganos Rectores de las Cajas de Ahorro las define en su prólogo como «entes de carácter social [...] ajenas al lucro mercantil [...], que operan en unos mercados financieros cada vez más competitivos». No son consideradas entidades públicas sino privadas; además, el beneficio neto después de impuestos se destina a reservas y a la obra benéfico-social. Ésta puede ser propia o en colaboración, «de modo que las mismas se orienten 
hacia la sanidad pública, la investigación, enseñanza y cultura o los servicios de asistencia social y que los beneficios de ellas derivados se extiendan especialmente al ámbito regional de actuación de la Caja». ${ }^{25}$

Desde el punto de vista de la regulación, el marco estatal ha sido ampliamente completado por la normativa autonómica desde 1985. Son instituciones altamente reguladas y cuyo rasgo principal de identificación es la obra social. Desde nuestro punto de vista, la existencia de esta obra social es la aplicación directa de la prohibición del reparto de beneficios, necesaria para considerar una entidad como no lucrativa. Asimismo, son entidades privadas y autogestionadas, aunque el desarrollo de la normativa sobre sus órganos de gobierno incorpora en un porcentaje elevado (42\% en Aragón) a representantes de la Administración pública, lo cual supone un control directo sobre sus actuaciones.

Como institución, encontramos que su origen tiene un marcado carácter social, tanto por la existencia de una obra benéfico-social como por la orientación de su actividad financiera hacia segmentos de la población con menores recursos. En la actualidad la actuación de las cajas en los mercados financieros es difícil de distinguir de la de los bancos, y es el resultado de una evolución del propio sistema financiero, por lo que podemos encontrar que la vertiente financiera ha cobrado mayor relevancia en los fines de estas entidades, quedando en segundo término y condicionado el papel de la obra social. En otras palabras, la actividad «comercial» es superior a la actividad "social», por lo que nos encontramos con entidades que presentan una dualidad en sus fines. Sin embargo, es indudable que las características relacionadas con la prohibición del reparto de excedentes, así como el hecho de ser una entidad privada y autogestionada, son propias de las ONL, aunque evidentemente no encontramos que entre sus recursos humanos haya voluntarios.

\section{II.2. Legislación aragonesa sobre el sector no lucrativo}

Con la aprobación del Estatuto de Autonomía de Aragón en la Ley Orgánica 8/1982, de 10 de agosto, y sus posteriores modificaciones reco-

25 Real Decreto 2290/1977, de 27 de agosto, por el que se regulan los órganos de gobierno y las funciones de las Cajas de Ahorros, art. 22. 
gidas en la Ley Orgánica 6/1994, de 24 de marzo, y en la Ley Orgánica 5/1996, de 30 de diciembre, nuestra comunidad, Aragón, accedió a la autonomía por la vía del artículo 143 de la Constitución. Esta circunstancia originó que la Comunidad Autónoma de Aragón ampliara sus competencias en diversas materias, confiriéndole la potestad legislativa, reglamentaria y ejecutiva en diversas cuestiones. En relación con aspectos que afectan a este estudio, hay que indicar que el proceso de transferencias reconoce competencias, de muy diverso calibre, a la Comunidad Autónoma de Aragón en las siguientes materias:

- Fundaciones privadas de carácter docente, cultural, artístico, benéfico, asistencial y similares que desarrollen principalmente sus funciones en Aragón.

- Asociaciones privadas de carácter docente, cultural, artístico, benéfico, asistencial y similares que desarrollen principalmente sus funciones en Aragón.

- Cooperativas.

— Mutualidades no integradas en la Seguridad Social.

- Cajas de ahorros.

No obstante, hemos señalado que el grado de las competencias transferidas de acuerdo con cada una de las personas jurídicas presentadas no es el mismo. En la temática que nos afecta, la competencia legislativa está reconocida en el artículo 35 de la Ley Orgánica 5/1996, donde, en su punto 4, establece que corresponderá a la Comunidad Autónoma la competencia exclusiva en la «conservación, modificación y desarrollo del Derecho Civil aragonés, sin perjuicio de las competencias exclusivas del Estado [...]».

Asimismo, observamos que en el proceso de transferencias nuestra Comunidad Autónoma no tiene, por muy diversos motivos, competencias reconocidas para algunas de las entidades que hemos considerado en apartados anteriores, cuya potestad legislativa y procedimental dependen directamente del Gobierno central, ni para las entidades religiosas, cuya regulación, por convenio con el Estado español, depende de la autoridad eclesiástica.

Con el panorama general descrito en esta parte introductoria, nos proponemos exponer en los siguientes apartados los avances efectuados desde las Cortes Generales y el Gobierno de Aragón en todas las materias 
citadas, de acuerdo con las capacidades reconocidas por las leyes orgánicas que determinan sus competencias autonómicas.

La legislación aragonesa ha desarrollado un marco propio para algunas de las figuras jurídicas específicas del sector no lucrativo, como luego detallaremos, aunque en otras todavía está pendiente. En tales casos, mientras tanto, se guía por la legislación estatal que sirve de referencia.

El proceso ha venido marcado por el ritmo de las transferencias del Gobierno central a la Comunidad Autónoma de Aragón en cada materia. Así, en 1983 se produce el traspaso de las competencias a la Comunidad Autónoma de Aragón en materia de cajas de ahorros. ${ }^{26}$ En 1994 se transfieren las competencias en materia de asociaciones ${ }^{27}$ y mutualidades ${ }^{28} \mathrm{y}$ en 1995 se realizan las de fundaciones ${ }^{29}$ y cooperativas. ${ }^{30}$

\section{II.2.1. La regulación jurídica aragonesa en materia de asociaciones}

La Ley Orgánica 9/1992, de 23 de diciembre, encarga a nuestra Comunidad Autónoma la función ejecutiva de la legislación estatal en aspectos tales como las asociaciones aragonesas. Este encargo se recoge posteriormente, y en los mismos términos, en la Ley Orgánica 6/1994 (modificación del art. 37 del Estatuto de Autonomía) y en la Ley Orgánica 5/1996 (art. 39, donde se modifica el art. 37 anteriormente reseñado), y es desarrollado en el Real Decreto 1054/1994, de 20 de mayo, sobre traspaso de funciones y servicios de la Administración del Estado a la Comunidad Autónoma de Aragón en materia de Asociaciones. De esta forma, pretende-

26 Decreto 93/1983, de 25 de octubre, por el que se regulan las competencias de la Comunidad Autónoma de Aragón en materia de cajas de ahorros.

27 Real Decreto 1054/1994, de 20 de mayo, sobre traspaso de funciones y servicios de la Administración del Estado a la Comunidad Autónoma de Aragón en materia de asociaciones.

28 Real Decreto 1050/1994, de 20 de mayo, sobre traspaso de funciones y servicios de la Administración del Estado a la Comunidad Autónoma de Aragón en materia de mutualidades de previsión social no integradas en la Seguridad Social.

29 Real Decreto 569/1995, de 7 de abril, sobre la competencia exclusiva que, en virtud del artículo 35.1.27 del Estatuto de Autonomía, corresponde en materia de fundaciones a Aragón.

30 Real Decreto 567/1995, de 7 de abril, sobre traspaso de funciones y servicios de la Administración del Estado a la Comunidad Autónoma de Aragón en materia de cooperativas, calificación y registro administrativo de sociedades anónimas laborales y programas de apoyo al empleo. 
mos poner de manifiesto la actual incapacidad del Gobierno de Aragón para legislar en materia de asociaciones; en consecuencia, sólo tenemos la posibilidad de centrarnos en los avances realizados desde el Gobierno de Aragón en aspectos de carácter procedimental.

En este sentido, el Real Decreto 1054/1994, de 20 de mayo, explicita que la Comunidad Autónoma de Aragón asume las siguientes funciones:

- Registro de todas las asociaciones que desarrollen principalmente sus actividades y tengan establecido su domicilio dentro del territorio aragonés.

— Ejercicio de la función de publicidad registral respecto a dichas asociaciones.

En relación con la función registral, debemos reconocer el esfuerzo que se está llevando a cabo desde el Gobierno autonómico, que en estos momentos está gestionando tres registros de asociaciones. En primer lugar, el Registro de Asociaciones Deportivas de Aragón, creado por el Decreto 102/1993, de 7 de septiembre, incorporado y dependiente del Departamento de Cultura y Educación, e incardinado en la Dirección General de Deportes.

En segundo lugar, otro registro dependiente del Gobierno aragonés es el Registro de Asociaciones de Consumidores y Usuarios, desarrollado desde el Decreto 38/1997, de 8 de abril, del Gobierno de Aragón, dependiente de la Dirección General de Consumo.

El Registro General de Asociaciones, presentado en tercer lugar por ser el más importante en atribución funcional, se crea con el Decreto 13/1995, de 7 de febrero, del Gobierno aragonés. Este registro asume las funciones realizadas, hasta las transferencias en materia de asociaciones, por los registros provinciales existentes en los gobiernos civiles y dependientes del Registro Nacional de Asociaciones del Ministerio del Interior. El Registro General se configura como registro único, con una unidad central en el Servicio de Relaciones Institucionales, dependiente a su vez del Departamento de Presidencia y Relaciones Institucionales y las unidades registrales de Huesca y de Teruel sitas en las delegaciones territoriales.

De este registro general de asociaciones se excluye la inscripción de partidos políticos, las confesiones religiosas, los sindicatos y organizaciones sindicales, las asociaciones sindicales profesionales, los colegios profe- 
sionales, las asociaciones empresariales y profesionales, las agrupaciones de interés económico y ciertas asociaciones deportivas.

El Registro de Asociaciones Deportivas de Aragón y el Registro de Consumidores y Usuarios custodian los expedientes de sendos tipos de asociaciones y mantienen una comunicación directa con el Registro General de Asociaciones. De hecho, como establece el Decreto 13/1995, el Registro de Asociaciones Deportivas tiene que comunicar al Registro General las inscripciones que efectúe. Por su parte, y en sentido inverso, el Decreto 38/1997, establece como requisito para inscribir una entidad en el Registro de Asociaciones de Consumidores y Usuarios que haya sido previamente inscrita en el Registro General.

Básicamente, los hechos motivo de inscripción son la constitución, las modificaciones estatutarias, las incorporaciones de una asociación, y la posterior baja, si la hubiera, a una federación, la apertura de delegaciones, la disolución y, en su caso, la declaración de utilidad pública de toda aquella asociación preinscrita en cada uno de los registros antes mencionados.

En definitiva, podemos indicar que el Gobierno de Aragón ha atendido los encargos de desarrollo procedimental en materia de asociaciones, a fin de cumplir de la legislación estatal marco, y que destaca la actual ausencia de potestad para legislar en materia de asociaciones.

Sin embargo, hay que resaltar la iniciativa de la comunidad referida $\mathrm{a}^{31}$ «la declaración de interés social para entidades privadas sin ánimo de lucro con actuaciones en el área social». Con lo cual, de nuevo aparece el concepto de entidades sin ánimo de lucro en sentido amplio, de forma que se incluyen tanto asociaciones como otro tipo de entidades sin especificar. Esto lo podemos interpretar como una forma abierta y amplia de entender las entidades sin ánimo de lucro —o cierta despreocupación...-. O, si se quiere, también es una iniciativa que posibilita un reconocimiento social a la actividad desarrollada por las entidades de «interés social», y puede servir como garantía de cara a la sociedad aragonesa del aval que supone el control público sobre estas entidades.

31 Decreto 7/1999, de 9 de febrero, del Gobierno de Aragón por el que se regula la declaración de interés social para entidades privadas sin ánimo de lucro con actuaciones en el área social, publicado en el $B O A$ de 19 de febrero de 1999. 


\section{II.2.2. Las fundaciones de iniciativa privada en el panorama jurídico aragonés}

Con las transferencias asignadas a nuestra comunidad autónoma, se confiere al Gobierno de Aragón potestad legislativa, reglamentaria y ejecutiva en cuestiones relacionadas con fundaciones, como se constata en el artículo 35.27 de la Ley Orgánica 5/1996.

El traspaso de funciones y servicios en materia de fundaciones se desarrolla por el Gobierno de Aragón en los términos redactados en el Decreto $276 / 1995$, de 19 de diciembre. En dicho decreto se crea el protectorado y el registro de este tipo de entidades, y se aporta una descripción puntual de las funciones atribuidas a los servicios asignados a cada dirección general, servicio y sección que componen la estructura orgánica del protectorado de fundaciones aragonés.

De acuerdo con la redacción del Decreto 276/1995, y el posterior Decreto 184/1997, de 18 de noviembre, el Protectorado con ámbito territorial de la Comunidad Autónoma de Aragón, así como la gestión del registro de estas entidades, corresponde al Departamento de la Presidencia y Relaciones Institucionales. Como protectorado, a este departamento se le asignan funciones propias, así como la distribución de actividades entre distintas direcciones generales, servicios y secciones dependientes de las anteriores.

En concreto, el Departamento de la Presidencia y Relaciones Institucionales se ve auxiliado en los temas relativos a fundaciones por uno de los órganos directivos que dependen de él, la Dirección General de Interior, creada por el Decreto 181/1999, de 28 de septiembre. Concretamente, en la estructura de esta dirección general, es el Servicio de Régimen Jurídico y Registros el encargado de ejercitar, entre otras tareas, el registro de fundaciones.

De esta forma, el protectorado aragonés está presente en cuatro momentos en la vida de toda fundación, cuyo ámbito de actividad se centralice dentro de nuestra comunidad autónoma: en la constitución de la fundación, en la rendición de sus cuentas, en las alteraciones en su composición administrativa y en otro tipo de circunstancias que no obedecen a los casos anteriores pero que resultan igualmente de relieve. Adicional- 
mente, y sin ánimo de profundizar en los aspectos que reseñamos, el Gobierno de Aragón debe ejercer no sólo un control legalista, sino además la prestación de un apoyo de asesoramiento técnico a este tipo de entidades y la evaluación y publicidad de los beneficios sociales que reportan tales entes, y, en consecuencia, la creación de una vía de captación de fondos para realizar sus actividades, en detrimento de la solicitud de subvenciones y otras ayudas gubernamentales.

De todos los aspectos comentados observamos, a título preliminar, que, si bien en materia de fundaciones el Gobierno de Aragón tiene capacidad para elaborar su propia ley aragonesa, aún no ha acometido dicha tarea, y mientras tanto las fundaciones de nuestra Comunidad Autónoma se rigen por la legislación estatal marco: la Ley 30/1994. Lo que sí han abordado los políticos aragoneses es la elaboración de decretos donde se atienden los requerimientos procedimentales relativos al ejercicio del protectorado y de registro.

\section{II.2.3. Avances en la legislación de cooperativas, mutualidades y cajas de ahorros en Aragón}

La última modificación del Estatuto de Autonomía, la Ley Orgánica 5/1996, en su artículo 35, atribuye potestad legislativa al Gobierno de Aragón en materia de cooperativas y entidades asimilables, mutualidades no integradas en la Seguridad Social y cajas de ahorros, así como instituciones de crédito cooperativo. Hasta la fecha, nuestro Gobierno autonómico ha atendido la elaboración legislativa de todos los entes presentados, menos de las mutualidades.

En relación con los logros alcanzados por la Comunidad Autónoma de Aragón sobre cooperativas, hay que indicar que nuestro Gobierno autonómico elabora la Ley 9/1998, de 20 de diciembre, donde se desarrollan todos los aspectos relacionados con las sociedades cooperativas de Aragón. Esta ley, como se explicita en su preámbulo introductorio, pretende utilizar la capacidad legislativa en materia de cooperativas para afianzar y recuperar los principios de este tipo de asociacionismo en nuestra Comunidad Autónoma, participar en la adaptación de la legislación autonómica a las directrices europeas y diseñar un modelo cooperativista acorde y efectivo con la actual realidad aragonesa. 
Esta ley adopta fórmulas y novedades que responden a los preceptos establecidos en la ley estatal, pero mejora y agiliza aspectos para facilitar la vida administrativa y la supervivencia económica de las cooperativas de menor tamaño, como permitir sustituir el consejo rector por dos o tres rectores.

En el caso de las cooperativas, destaca la introducción de dos nuevas figuras especiales, lo que supone una confirmación de la definición presentada en el capítulo anterior. Estas figuras son las cooperativas de iniciativa social y de servicios sociales.

Las cooperativas de iniciativa social, se dice en la ley, «son aquellas Cooperativas de Trabajo Asociado que tienen por finalidad principal el apoyo, la promoción y el desarrollo de colectivos que, por sus peculiares características, precisen de una especial atención en orden a conseguir su bienestar y su plena integración social y laboral, a través de la prestación de servicios y el desarrollo de actividades empresariales de carácter asistencial, educativo, de prevención, integración e inserción. Para que una Cooperativa sea considerada como de Iniciativa Social, deberá constar en sus Estatutos la ausencia de ánimo de lucro y, en caso de producirse resultados positivos, éstos no podrán ser repartidos entre los socios, dedicándose a la consolidación y mejora de la finalidad prevista; asimismo, las aportaciones obligatorias de los socios al capital social no podrán devengar interés alguno, sin perjuicio de su posible actualización. Las aportaciones voluntarias devengarán, como máximo, el interés básico del Banco de España. También constará el carácter gratuito del desempeño de los cargos del Consejo Rector, sin perjuicio de las compensaciones económicas que procedan por los gastos en el desempeño de sus funciones como tales, y las retribuciones de los socios trabajadores y de los trabajadores por cuenta ajena no podrán superar el ciento cincuenta por ciento de las retribuciones que, en función de la actividad y categoría profesional, establezca el convenio colectivo aplicable a los trabajadores por cuenta ajena del sector».

Las cooperativas de servicios sociales, también según la propia ley aragonesa, "son aquellas que procuran la atención social a sus miembros, pertenecientes a colectivos de disminuidos físicos, psíquicos o sensoriales, menores, ancianos con carencias familiares o económicas y grupos marginados de la sociedad, facilitándoles bienes y servicios para su subsistencia y desarrollo». 
A partir de esta iniciativa, podemos considerar que desde las Cortes aragonesas se confiere a la figura jurídica de la cooperativa un papel destacado para el desarrollo de actividades no lucrativas y que, por tanto, estas nuevas entidades desempeñarán un papel similar al de las asociaciones y fundaciones. Y ello porque sus fines tienen rango de interés general o de bienestar común - superando las fronteras de los intereses individuales - y porque la prohibición del reparto del beneficio queda también expresada, junto con la gratuidad de los cargos de tipo gestor. Sin embargo, se niega la posibilidad de que las aportaciones obligatorias reciban algún tipo de remuneración, a diferencia del resto de cooperativas, mientras que las aportaciones voluntarias sí pueden percibirla.

Siguiendo con las cooperativas, dado el interés que tiene para Aragón el desarrollo del cooperativismo, creemos conveniente recoger literalmente el fragmento de la Ley de 1998:

Se declara de interés social para la Diputación General de Aragón la promoción, estímulo y desarrollo del cooperativismo dentro de su territorio. Esto implica el compromiso de adoptar medidas que promuevan la constitución, desarrollo y mejor cumplimiento de sus objetivos.

Para la Comunidad Autónoma de Aragón el concepto «sin ánimo de lucro» propuesto en esta ley de cooperativas se acota diciendo que "podrán ser calificadas como entidades sin ánimo de lucro las sociedades cooperativas que gestionen servicios de interés colectivo o de titularidad pública, cuando renuncien expresamente en sus Estatutos a acreditar a sus socios retornos cooperativos y dediquen los eventuales saldos positivos a su reinserción en la cooperativa».

Para finalizar reseñaremos los avances legislativos en materia de cajas de ahorros en Aragón. La reforma experimentada recientemente por la Ley 1/1991, de 4 de enero, que ha dado como resultado la Ley 4/2000, de 28 de noviembre, destaca, desde nuestro punto de vista, por el acento que el Gobierno de Aragón ha puesto en el ejercicio de obras y acciones sociales. De todos es conocida la amplia tradición e impacto que tienen en la sociedad aragonesa las inversiones en actividades culturales, asistenciales, deportivas, recreativas..., llevadas a cabo por nuestras cajas de ahorros con su obra social, que proviene del excedente anual no distribuible por definición legal. En la nueva ley se destaca que «las Cajas de Ahorro han tenido una importante evolución, incrementándose su importancia eco- 
nómica y social. Esto exige que sus normas de actuación respondan en cada momento a las necesidades que se plantean, y en este sentido se modifica la regulación de las Cajas de Ahorro en Aragón». Las principales actuaciones de la ley se refieren a los órganos rectores y a la gestión de la obra social. Con respecto a esta última se acaba de desarrollar en la Orden de 5 de abril de 2001, donde se establecen las directrices de la obra social y cultural de las cajas de ahorros en el ejercicio 2001. Las principales incidencias y efectos de esta ley se incorporan en el apartado dedicado expresamente a las cajas de ahorros aragonesas.

La reforma efectuada supone que desde estas entidades se fomenten e incluso se erijan como motor de iniciativas para satisfacer necesidades novedosas, además de las tradicionalmente atendidas, como son la sanidad pública, la investigación, la innovación y el fomento y desarrollo de aspectos socioeconómicos propios de nuestra región. No obstante, en su artículo 28 bis destaca la potestad que se asigna el Gobierno de Aragón para establecer una tipificación de necesidades prioritarias detectadas en nuestra región, con el ánimo de reconducir las iniciativas de las cajas de ahorro. De hecho, se reconoce a estas entidades la libertad para que decidan, bajo un régimen democrático, el destino final de sus inversiones en obra social, aunque la Orden de 5 de abril de 2001, en la que se establecen las directrices de la obra social y cultural de las cajas de ahorros en el ejercicio 2001 supone un elevado control de la capacidad de actuación de las cajas en materia de asignación de su obra social.

Esta nueva regulación implica, como se detalla en el anexo, lo siguiente:

Cuarta: En la Obra Social y Cultural en colaboración tendrán carácter prioritario las actividades realizadas con el Gobierno de Aragón. Y Quinta: Las obras en colaboración con el Gobierno de Aragón se coordinarán con el Departamento responsable en materia de Economía. Posteriormente, lo acordado se materializará en convenios específicos con cada Departamento u Organismo implicado.

Para finalizar, en el último apartado exponemos un anexo legislativo con las referencias más relevantes sobre las figuras jurídicas comentadas en este capítulo. 


\section{II.3. Anexo legislativo}

\section{II.3.1. Legislación Estatal}

- Ley Orgánica 8/1982, de 10 de agosto, de Estatuto de Autonomía de Aragón.

- Ley Orgánica 6/1994, de 24 de marzo, de reforma del Estatuto de Autonomía de Aragón.

- Ley Orgánica 5/1996, de 30 de diciembre, de reforma de la Ley Orgánica 8/1982, de 10 de agosto, de Estatuto de Autonomía de Aragón, modificada por la Ley Orgánica 6/1994, de 24 de marzo de reforma de dicho estatuto.

En relación con las asociaciones españolas:

- Constitución Española, art. 9-2. ${ }^{\circ}, 22$ y 48.

- Código Civil, art. 28, 35-39 y 41.

— Ley 1/2002, de 26 de marzo, de Derecho de Asociación.

- Ley 191/1964, de 24 de diciembre, de Asociaciones.

- Decreto 1440/1965, de 20 de mayo, por el que se dictan las normas complementarias de la Ley de Asociaciones de 24 de diciembre.

— Orden de 10 de julio de 1965 por el que se regula el funcionamiento de los registros de asociaciones.

- Decreto 713/1977, de 1 de abril, que regula la denominación de las asociaciones y el régimen jurídico de sus promotores.

— Ley 54/1978, de 4 de diciembre, de partidos políticos.

— Ley Orgánica 7/1980, de 5 de julio, de libertad religiosa.

- Real Decreto 142/1981, de 9 de enero, donde se regula el Registro de entidades religiosas.

- Ley Orgánica 11/1985, de 2 de agosto, de libertad sindical, modificada por la Ley Orgánica 14/1994 y la Ley 11/1994.

— Ley Orgánica 3/1987, de 2 de julio, sobre financiación de partidos políticos.

- Real Decreto 397/1988, de 22 de abril, que regula la inscripción registral de las asociaciones juveniles.

- Ley 30/1994, de 24 de noviembre, que modifica art. 4 de la Ley 191/1964, de declaración utilidad pública.

— Real Decreto 1786/1996, de 19 de julio, sobre procedimientos relativos a asociaciones de utilidad pública. 
- Real Decreto 397/1988, de 22 de abril, sobre la inscripción registral de las asociaciones juveniles.

- Real Decreto 1252/1999, de 16 de julio, de modificación parcial del Real Decreto 1835/1991, de 20 de diciembre, sobre federaciones deportivas españolas y registro de asociaciones deportivas.

- Real decreto 2211/1995, de 28 de diciembre, por el que se modifica el Real Decreto 825/1990, de 22 de junio, sobre el derecho de representación, consulta y participación de los consumidores y usuarios a través de sus asociaciones.

En relación con las fundaciones españolas:

- Constitución Española, art. 34.

- Ley 30/1994, de 24 de noviembre, de fundaciones y de incentivos fiscales a la participación privada en actividades de interés general.

- Real Decreto 765/1995, de 5 de mayo, por el que se regula determinadas cuestiones del regímenes de incentivos fiscales a la participación privada en actividades de interés general.

— Real Decreto 316/1996, de 23 de febrero, Reglamento del Registro de Fundaciones de Competencia Estatal.

En relación con las cooperativas en España:

- Ley 27/1999, de 16 de julio, de cooperativas.

— Ley 6/1998, de 13 de mayo, de regulación del funcionamiento de las secciones de crédito de las cooperativas.

— Orden de 7 de febrero de 1996 por la que se reducen las aportaciones al fondo de garantía de depósitos en las cooperativas de crédito.

— Orden de 23 de julio de 1997 por la que se desarrolla el Reglamento de la Ley de Ordenación de los Transportes Terrestres en materia de Cooperativas de Transportistas y Sociedades de Comercialización.

- Ley de Cooperativas de Crédito 13/1989, de 26 de mayo.

- Ley 20/1990, de 19 de diciembre, de Régimen Fiscal de Cooperativas.

- Real Decreto 84/1993, de 22 de enero, reglamento de desarrollo de la ley de cooperativas de crédito.

En relación con las mutualidades:

— Ley 33/1984, de 2 de agosto, de Ordenación de los Seguros Privados. 
— Orden de 9 de abril de 1987, por el que se desarrolla el Reglamento de Entidades de Previsión Social.

— Ley 8/1987, de 8 de junio, de regulación de los planes y fondos de pensiones.

- Real Decreto 1307/1988, de 20 de septiembre, por el que se aprueba el Reglamento de Planes y Fondos de Pensiones.

- Real Decreto 2486/1988, de 20 de noviembre, por el que se aprueba el Reglamento de Ordenación y Supervisión de los Seguros Privados.

- Real Decreto 2615/1988, de 4 de diciembre, por el que se aprueba el Reglamento de Entidades de Previsión Social.

- Real Decreto 1993/1995, de 7 de diciembre, por el que se aprueba el Reglamento sobre Colaboración de las Mutuas de Accidentes de Trabajo y Enfermedades Profesionales de la Seguridad Social.

En relación con las cajas de ahorros en España: ${ }^{32}$

— Real Decreto 2290/1977, de 27 de agosto, por el que se regulan los órganos de gobierno y las funciones de las cajas de ahorros.

- Ley $31 / 1985$, de 2 de agosto, sobre órganos rectores.

- Ley 13/1992, de 1 de junio, de recursos propios de las entidades financieras.

- Real Decreto 1343/1992, de 6 de noviembre, por el que se desarrolla la Ley 13/1992, de 1 de junio, de recursos propios y supervisión en base consolidada de las entidades financieras.

\section{II.3.2. Legislación autonómica de Aragón}

En relación con las asociaciones:

- Estatuto de Autonomía de Aragón, art. 37-1.

- Decreto 87/1983, de 27 de septiembre, de la Diputación General de Aragón, por el que se crea el Registro General de Asociaciones Deportivas y se establece el régimen de aprobación de las de ámbito exclusivamente regional.

- Decreto 56/1984, de 30 de julio, de la Diputación General de Aragón, por el que se regulan las federaciones deportivas aragonesas.

32 Para una selección de normativa ver <www.ceca.es>. 
— Ley 4/1993, de 16 de marzo, del deporte en Aragón.

- Decreto 102/1993, de 7 de septiembre, de la Diputación General de Aragón, por el que se regula el Registro General de Asociaciones Deportivas de Aragón.

- Real Decreto 1054/1994, de 20 de mayo, sobre traspaso de funciones y servicios de la Administración del Estado a la Comunidad Autónoma de Aragón en materia de asociaciones.

- Decreto 181/1994, de 8 de agosto, de la Diputación General de Aragón, por el que se regulan las federaciones deportivas aragonesas.

- Decreto 13/1995, de 7 de febrero, de la Diputación General de Aragón, por el que se regula el Registro de Asociaciones de la Comunidad Autónoma de Aragón.

- Decreto 23/1995, de 17 de agosto, del Gobierno de Aragón, por el que se aprueba la regulación de las asociaciones deportivas.

- Decreto 38/1997, de 8 de abril, del Gobierno de Aragón, por el que se crea el Registro de Asociaciones de Consumidores y Usuarios de la Comunidad Autónoma de Aragón.

— Decreto 7/1999, de 9 de febrero, del Gobierno de Aragón, por el que se regula la declaración de interés social para entidades privadas sin ánimo de lucro con actuaciones en el área social.

— Orden de 18 de marzo de 1999, del Departamento de Sanidad, Bienestar Social y Trabajo, por la que se desarrolla el Decreto 7/1999, de 9 de febrero, que regula la declaración de interés social para entidades privadas sin ánimo de lucro con actuaciones en el área social

En relación con las fundaciones:

- Decreto 140/1985, de 6 de noviembre, de la Diputación General de Aragón, por el que se crea el Registro de Asociaciones Culturales, Fundaciones Culturales y Entidades Análogas cuyas actividades básicas y principales no rebasen el ámbito territorial de Aragón. Decreto 276/1995, de 19 de diciembre.

- Corrección de errores del Decreto 276/1995, de 19 de diciembre, de la Diputación General de Aragón, por el que se regulan las competencias en materia de fundaciones y se crea el Registro de Fundaciones.

- Decreto 276/1995, de 19 de diciembre, de la Diputación General de Aragón, por el que se regulan las competencias en materia de fundaciones y se crea el Registro de Fundaciones. 
- Decreto 99/1995, de 9 de mayo, de la Diputación General de Aragón, por el que se asignan al Departamento de Presidencia y Relaciones Institucionales las competencias transferidas por la Administración del Estado a la Comunidad Autónoma de Aragón en materia de fundaciones.

— Orden de 16 de abril de 1996, del Departamento de Presidencia y Relaciones Institucionales, por la que se regula el funcionamiento del Registro de Fundaciones de la Comunidad Autónoma.

- Corrección de errores de la Orden de 16 de abril de 1996, del Departamento de Presidencia y Relaciones Institucionales, por la que se regula el funcionamiento del Registro de Fundaciones de la Comunidad Autónoma.

— Real Decreto 276/1995, de 19 de diciembre, por el que se regulan las competencias en materia de fundaciones y se crea el Registro de Fundaciones en Aragón.

- Real Decreto 569/1995, de 7 de abril, sobre la competencia exclusiva que, en virtud del artículo 35.1.27 del Estatuto de Autonomía, le corresponde en materia de fundaciones a Aragón.

- Orden de 23 de mayo de 1995, del Departamento de Presidencia y Relaciones Institucionales, por la que se da cumplimiento a lo preceptuado en el Decreto 99/1995, de 9 de mayo, de la Diputación General de Aragón, por el que se asignan las competencias transferidas por la Administración del Estado a la Comunidad Autónoma de Aragón en materia de fundaciones a este Departamento.

— Orden de 24 de julio de 1996, del Departamento de Presidencia y Relaciones Institucionales, por la que se da publicidad al acuerdo del Gobierno de Aragón, por el que se designan los miembros de los patronatos de las fundaciones docentes.

— Orden de 24 de julio de 1996, del Departamento de Presidencia y Relaciones Institucionales, por la que se da publicidad al acuerdo del Gobierno de Aragón, por el que se designan los miembros de los patronatos de las fundaciones benéfico-asistenciales.

— Orden de 28 de marzo de 1996, del Departamento de Sanidad, Bienestar Social y Trabajo, por la que se designan representantes de dicho departamento en el patronato de las fundaciones benéfico-asistenciales cuyo gobierno y representación tiene encomenda- 
dos la Administración Pública de la Comunidad Autónoma de Aragón.

— Orden de 6 de mayo de 1996, del Departamento de Educación y Cultura, por la que se delega la presidencia del patronato de las fundaciones cuyo gobierno y representación tenga asignada la Administración de la Comunidad Autónoma y estén adscritas a este Departamento.

- Decreto 184/1997, de 18 de noviembre del Gobierno de Aragón, de estructura orgánica del Departamento de Presidencia y Relaciones Institucionales.

- Decreto 181/1999, de 28 de septiembre, de la Presidencia del Gobierno de Aragón, por el que se establece la estructura orgánica de la Presidencia.

- Orden de 21 de junio de 2000, del Departamento de Presidencia y Relaciones Institucionales, por la que se dispone la publicación en el Boletin Oficial de Aragón del acuerdo de la Diputación General designando los miembros de los patronatos de las fundaciones docentes y benéfico-asistenciales.

En relación con las cooperativas:

- Real Decreto 567/1995, de 7 de abril, sobre traspaso de funciones y servicios de la Administración del Estado a la Comunidad Autónoma de Aragón en materia de cooperativas, calificación y registro administrativo de sociedades anónimas laborales y programas de apoyo al empleo.

— Ley 9/1998, de 22 de diciembre, de Cooperativas de Aragón.

En relación con las cajas de ahorros:

- Ley 4/2000, de 28 de noviembre, de cajas de ahorros de Aragón.

- Ley 1/1991, de 4 de enero, reguladora de las cajas de ahorros en Aragón.

- Decreto 93/1983, de 25 de octubre de 1983, por el que se regulan las competencias de la Comunidad Autónoma de Aragón en materia de cajas de ahorros.

— Orden de 12 de noviembre de 1984, del Departamento de Economía y Hacienda, por el que se fijan los coeficientes de reparto entre las cajas de ahorros aragonesas respecto de la suscripción de emisiones calificadas por la Comunidad Autónoma de Aragón. 
- Decreto 58/1986, de 20 de mayo, de la Diputación General de Aragón, por el que se desarrolla la Ley 31/1985, de 2 de agosto, de regulación de las normas básicas sobre órganos rectores de las cajas de ahorros.

- Corrección de errores del Decreto 58/1986, de 20 de mayo, de la Diputación General de Aragón, por el que se desarrolla la Ley 31/1985, de 2 de agosto, de regulación de las normas básicas sobre órganos rectores de las cajas de ahorros.

— Corrección de errores del Decreto 56/1986 de 20 de mayo, de la Diputación General de Aragón, por el que se desarrolla la Ley 31/1985, de 2 de agosto, de regulación de las normas básicas sobre órganos rectores de las cajas de ahorros.

- Orden de 17 de octubre de 1988, del Departamento de Economía, por la que se aprueban los Estatutos de la Federación Aragonesa de Cajas de Ahorros.

- Orden de 5 de abril de 2001, del Departamento de Economía, Hacienda y Empleo, por la que se dispone la publicación del acuerdo del Gobierno de Aragón, de 27 de marzo de 2001, por el que se establecen las Directrices de la obra social y cultural de las cajas de ahorros en el ejercicio 2001.

En relación con las mutualidades:

- Real Decreto 1050/1994, de 20 de mayo, sobre traspaso de funciones y servicios de la Administración del Estado a la Comunidad Autónoma de Aragón en materia de mutualidades de previsión social no integradas en la Seguridad Social.

- Decreto 144/1994, de 21 de junio, de la Diputación General de Aragón, por el que se asignan al Departamento de Bienestar Social y Trabajo las competencias transferidas por la Administración del Estado a la Comunidad Autónoma de Aragón en materia de mutualidades de previsión social no integradas en la Seguridad Social.

\section{II.3.3. Legislación en el resto de comunidades autónomas}

Aunque es una cuestión importante y en la cual se ha de profundizar, entendemos que en este momento de nuestro trabajo de investigación sólo podemos presentar la relación de actuaciones legales realizadas en materia de 
las distintas figuras jurídicas comentadas (asociaciones, fundaciones, cooperativas, cajas de ahorros y mutuas) en el resto de comunidades autónomas.

Queda para otra ocasión el estudio comparado de la realidad del Tercer Sector en el conjunto de las comunidades autónomas españolas. Aunque ya se han avanzado trabajos, éstos no se han realizado con el enfoque que planteamos.

En relación con las asociaciones:

- Cataluña: Ley 7/1997, de 18 de junio, de Asociaciones de Cataluña.

- País Vasco: Ley 3/1988 de 12 de febrero, de asociaciones.

En relación con las fundaciones:

- Cataluña: Ley 5/2001, de 2 de mayo, de fundaciones de Cataluña.

- Canarias: Ley de fundaciones Canarias, Ley 2/1998, de 6 de abril.

— Galicia: Ley de Fundaciones "de interés gallego", Ley 7/1983, de 22 de junio, modificada por la Ley 11/1991, de 8 de noviembre.

- Madrid: Ley 1/1998, de 2 de marzo, de fundaciones de la Comunidad de Madrid.

- Navarra: Compilación Foral de Navarra, modificada por la Ley 1/1973, de 1 de marzo.

- País Vasco: Ley de fundaciones del País Vasco, Ley 12/1994, de 17 de junio.

- Valencia: Ley 8/1998, de 9 de diciembre, de Fundaciones de la Comunidad Valenciana.

En relación con las cooperativas:

— Ley 3/1995, de 2 de marzo, de modificación de la Ley 11/1985, de Cooperativas de la Comunidad Valenciana.

— Ley foral 12/1996, de 2 de julio, de cooperativas de Navarra.

- Ley 5/1998, de 18 de diciembre, de cooperativas de Galicia.

— Ley 2/1998, de 26 de marzo, de sociedades cooperativas de Extremadura.

- Ley 2/1999, de 31 de marzo, de sociedades cooperativas andaluzas.

— Ley 4/1999, de 30 de marzo, de cooperativas de la Comunidad de Madrid.

— Ley 4/2001, de 2 de julio, de cooperativas de La Rioja. 
En relación con las cajas de ahorros:

- Ley Foral 7/1987, de 21 de abril, de Navarra.

- Ley 3/1991, de 8 de noviembre, de cajas de ahorros del País Vasco.

- Decreto-Legislativo 1/1994, de 28 de julio, texto refundido de cajas de ahorros de Castilla-León.

- Decreto-Legislativo 1/1994, de 28 de julio, texto refundido de cajas de ahorros de Cataluña.

- Ley 8/1994, de 23 de diciembre, de cajas de ahorros de Extremadura.

- Ley 5/1994, de 23 de junio, por la que se modifica la Ley 5/1992, de 15 de julio, de cajas de ahorros de Madrid.

- Ley 1/1995, de 30 de enero, por la que se modifica la Ley 13/1990, de 26 de julio, de cajas de ahorros de Canarias.

- Ley 4/1996, de 31 de mayo, de cajas de ahorros de Galicia.

— Ley 4/1997, de 10 de julio, de cajas de ahorros de Castilla-La Mancha.

— Ley 4/1997, de 16 de junio, de modificación de la Ley de la Generalidad Valenciana 1/1990, de 22 de febrero, sobre cajas de ahorros.

— Ley 3/1998, de 1 de julio, de cajas de ahorros de la región de Murcia.

- Ley 15/1999, de 16 de diciembre, de cajas de ahorros de Andalucía.

- Ley 2/1999, de 18 de febrero, de modificación de la Ley 1/1990, de 12 de marzo, por la que se regulan los órganos rectores de las cajas de ahorro con sede social en la Comunidad Autónoma de Cantabria.

— Ley 2/2000, de 23 de junio, de cajas de ahorro, Comunidad Autónoma del Principado de Asturias. 


\section{CAPÍTULO III \\ LA REALIDAD DEL SECTOR NO LUCRATIVO EN ARAGÓN: LAS ORGANIZACIONES NO LUCRATIVAS DE INTERÉS PARTICULAR}

Aunque todos sabemos que es difícil atrapar cualquier realidad social - por sus características intrínsecas de mutabilidad, pluriformidad, irrepetibilidad...-, lo es más si hablamos de organizaciones de la sociedad civil como éstas, que responden a factores dispares y complejos. Sin embargo, en este caso creemos que es posible y necesario proporcionar unas cuantas claves de la realidad del sector no lucrativo, a día de hoy, en Aragón. Son datos que en breve habrán de ser revisados - estamos ante un sector socialmente sumamente dinámico y vital—, pero al menos fijan una imagen de referencia a partir de la cual seguir investigando en este ámbito.

Nuestro punto de arranque lo hemos establecido con la definición propuesta en el primer capítulo. Ahora continuamos la tarea de la descripción - tanto cuantitativa como cualitativa-, junto con una valoración de las características básicas del sector no lucrativo aragonés. Pero conviene recordar que hemos planteado una distinción entre aquellas entidades que, bajo la denominación general de no lucrativas, se catalogan como de interés general y aquellas cuyos rasgos son propios de entidades de interés particular.

En este capítulo analizamos las organizaciones no lucrativas de interés particular. Éstas son un conjunto de entidades que provocan reacciones contradictorias en la opinión pública y en la percepción que se tiene 
de ellas desde la ciudadanía. Para muchas personas resulta extraño que una cooperativa o una caja de ahorros se presenten «legalmente» como una organización que no busca el enriquecimiento y cuyo fin último no es el lucro de sus integrantes. Sin embargo, si se acepta la definición propuesta al comienzo, son ONL y forman parte del sector no lucrativo de nuestra comunidad autónoma. ${ }^{33}$

A continuación veremos cuáles son sus características y los datos más destacados para poder comprender mejor su particular modo de ser ONL primando un interés particular. Primero nos centraremos en el conjunto de las cooperativas y, en segundo lugar, abordaremos las cajas de ahorro. ${ }^{34}$

\section{III.1. Las cooperativas en Aragón}

Para quienes conocen esta parcela de nuestra sociedad, es evidente que las cooperativas son mucho más que unas organizaciones con intereses económicos en el mercado. Las cooperativas recogen en sí mismas una larga tradición que plantea las relaciones sociales de un modo distinto a la mera búsqueda de beneficios monetarios. Incluso ven en el sector cooperativo una vía de acción y de participación ciudadana, en la cual convergen tanto la dimensión económica y social como la dimensión política.

Su punto de partida se distingue de las organizaciones lucrativas en la definición de un modelo de relaciones que no está en función del capital o de la propiedad de los medios de producción. Son las personas las que se agrupan para conseguir mediante un modelo de interrelación e interacción colectiva la solución a las necesidades particulares. Plantean una gestión económica al servicio de los individuos desde la apuesta por la participación de los socios cooperativistas.

Y el punto de llegada al que se encaminan también es distinto de las empresas lucrativas. No se trata sólo de ganar más para tener más. El bene-

33 Otros trabajos ya las incorporan, como Ruiz Olabuénaga (2000a).

34 No hemos abordado las mutualidades por las dificultades en cuanto a la búsqueda de información suficiente sobre ellas, aunque consideramos que es otro grupo de entidades que necesariamente se debería valorar. 
ficio no es sólo el lucro de los sujetos implicados en la entidad. Al menos, en los discursos con los que explican su realidad, aparece la necesidad de generar tejido social en forma de un entramado de relaciones cooperativas donde se modela el conjunto de la sociedad hacia los valores de la participación, la solidaridad y la cooperación.

En nuestra investigación hemos constatado que los discursos sobre este sector reflejan que cualquier cooperativa es una entidad multifacética, en que se pueden destacar unos cuantos elementos, a saber: $a$ ) es una forma de organización en la que unas personas se asocian para satisfacer en común aquellas necesidades que consideran pertinentes; $b$ ) es una empresa en tanto que opera en un sector de la economía; $c$ ) es un medio de participación ciudadana que transciende lo puramente mercantil; $d$ ) es un mecanismo de creación de redes sociales; $e$ ) es una herramienta de arraigo de población en zonas y sectores dispares..., entre otras.

Pero también queda claro que las cooperativas no son organizaciones de caridad que pretendan generar relaciones asistenciales, ni son entidades dedicadas a la beneficencia. Surgen porque unas personas se asocian para buscar mediante la acción cooperativa satisfacer sus fines. Entre ellos no está excluido el beneficio económico ni el lucro particular. Pero, a diferencia de las organizaciones lucrativas habituales, la remuneración de los cooperativistas «en ningún caso sería en función de un capital. O sea, es un principio general del cooperativismo que la remuneración ni el derecho de voto jamás será en función del capital que se tenga. El derecho de voto será un socio un voto como principio general y, en todo caso, en caso de que no sea un socio un voto, se podrá establecer una ponderación o una diferencia en función del grado de utilización de los servicios cooperativizados del socio. Pero siempre el capital estará desterrado como principio de regulación interna».

La Alianza Cooperativa Internacional expresamente dice que los valores que deben guiar a las cooperativas son: «auto-ayuda, la auto-responsabilidad, la democracia, la igualdad, la equidad y la solidaridad. En la tradición de sus fundadores, los socios cooperativos hacen suyos los valores éticos de la honestidad, la transparencia, la responsabilidad y la vocación social».

Con esas claves se han desarrollando las pautas generales de actuación, y desde ellas se distingue un modo de ser más cercano al espíritu 
general del sector no lucrativo que a su contrario. Las cooperativas son un modo de hacer sociedad, más que un mero instrumento de participación en el mercado capitalista para conseguir más dinero como beneficio final.

Quizá por eso mismo se da la paradoja de que han sido bien vistas por las tendencias políticas de casi todo signo: «de siempre, las cooperativas, desde hace años han estado protegidas, especialmente protegidas, en todo... han tenido una especial fiscalidad, un especial fomento por parte de la Administración». En la Monarquía, en la República, en el franquismo y en la democracia actual, la legislación ha tenido en cuenta el cooperativismo. En cada época, con sus propios acentos; pero, en general, valorando el carácter colaborativo de estas organizaciones como un camino para la mejora de la sociedad.

$\mathrm{Si}$ atendemos al tiempo que nos corresponde, esta parcela de la economía social aragonesa se encuentra en un período de cambio y transformación. Además de la necesidad permanente de adaptación a la realidad socioeconómica, ahora el elemento principal viene dado por la nueva definición del marco jurídico. Todavía es relativamente reciente la elaboración y aprobación de la legislación actual de cooperativas aragonesas. La nueva ley de cooperativas - Ley 9/1998, de 22 de diciembre, de Cooperativas de Aragón - sostiene en su prólogo una interesante afirmación: «se declara de interés social para la Diputación General de Aragón la promoción, estímulo y desarrollo del cooperativismo dentro de su territorio. Esto implica el compromiso de adoptar medidas que promuevan la constitución, desarrollo y mejor cumplimiento de sus objetivos».

El primer dato que hay que tener en cuenta y recalcar es que nos encontramos en una fase de cambio y adaptación. Por eso, la situación actual de los registros - y los datos que pueden ofrecer - respecto de la materia es transitoria. La justificación es obvia: el conjunto de cooperativas que tienen su registro en la comunidad aragonesa deben adaptarse a la nueva ley.

Por otra parte, es un período crucial para la actualización del registro de cooperativas, puesto que en un plazo relativamente corto - unos dos años- se podrá conocer con mayor precisión cuáles de estas cooperativas están activas, así como los datos básicos que permitan caracterizarlas, desde socios y capital social hasta sector de actividad.

Dadas las circunstancias en las que estamos, y siendo conscientes de su dificultad, en este apartado proponemos un modesto análisis desde los 
datos existentes en el registro y otras fuentes consultadas (INE, 2000), así como desde las entrevistas realizadas a expertos en este campo.

La nueva ley aragonesa, en su preámbulo, sostiene que:

La Constitución Española, en su artículo 129.2, dispone que los poderes públicos promoverán eficazmente las diversas formas de participación en las empresas y fomentarán, mediante una legislación adecuada, las sociedades cooperativas. Por otra parte, el Estatuto de Autonomía de Aragón establece, en su artículo 35.1.23, la competencia exclusiva de la Comunidad Autónoma en materia de cooperativas. Esta competencia fue transferida a la Comunidad Autónoma de Aragón por la Ley Orgánica 9/1992, proceso que se completó mediante el Real Decreto 567/1995, sobre traspaso de funciones y servicios de la Administración del Estado a la de esta Comunidad Autónoma. Sobre la base de esta normativa, y al objeto de fomentar la creación de sociedades cooperativas en Aragón, se dicta la presente Ley.

El modelo cooperativo entendemos que cumple, al menos, dos papeles, uno como referente organizativo y otro como actor socioeconómico. En ambos casos tiene una importante función en la vertebración de la economía y la sociedad de nuestra comunidad, que se ha traducido en que el papel que ha desempeñado y sigue desempeñando es comportarse como factor de progreso de las zonas rurales.

En esos contextos - mayoritarios en Aragón-, este modelo es creador de riqueza y empleo, determina el mantenimiento de los modos de vida particulares y de los referentes culturales locales, y articula un tipo de asociación de voluntades de especial relevancia social, que se caracteriza por la solidaridad y la participación de los socios en la toma de decisiones.

También hay que recordar que en la última década el movimiento cooperativista, en general, y el cooperativismo aragonés, en particular, ha conocido profundas transformaciones. Éstas no deben provocar un distanciamiento respecto de los valores y principios cooperativos tradicionalmente considerados. Ni se debe claudicar en favor de ciertos «valores» imperantes como consecuencia y exigencia de una concepción alicorta de la eficacia en la gestión mediante criterios empresariales. Además, tampoco se ha de renunciar a planteamientos básicos, máxime cuando la incorporación de España a la Unión Europea exige un importante cambio normativo que permita afrontar la nueva situación del mercado europeo. El reto del presente es conseguir que se mantengan y consoliden los principios cooperativos, a la vez que se mejora la eficacia en la gestión de las cooperativas. 
La nueva ley aragonesa pretende actualizar la legislación cooperativa existente y recoger las peculiaridades de la realidad cooperativa de nuestra comunidad autónoma.

\section{III.1.1. Número de cooperativas y distribución geográfica}

Como ya hemos dicho, las cooperativas de Aragón se distribuyen de forma mayoritaria en el medio rural aragonés. Esto no es óbice para que también existan grandes cooperativas e iniciativas en el ámbito urbano. En cualquier caso, el nuevo marco jurídico probablemente permita abrir espacios para el cooperativismo en campos menos habituales y más diversificados, si bien ésta es una posibilidad que irá muy ligada a la difusión de las potencialidades y ventajas que ofrece dicha forma de organización.

Con los datos disponibles, en este momento nos encontramos con un total de 1831 cooperativas constituidas en Aragón. Éstas se distribuyen de forma muy desigual en el conjunto del territorio. Así, tenemos que la provincia de Zaragoza agrupa el $68,87 \%$, la de Teruel el $18,24 \%$ y la de Huesca el 12,89 \% (tabla III.1).

Es necesario partir de la premisa de que existen cooperativas que están legalmente constituidas y que siguen en el registro, pero que apenas tienen actividad o vida organizativa. Por eso es preciso distinguir entre las cooperativas que están activas y las que no. ${ }^{35}$ Con ese elemento presente, podemos estimar que en Aragón existen 1149 cooperativas activas y en

TABLA III.1

COOPERATIVAS CONSTITUIDAS EN ARAGÓN EN EL AÑO 2000

(Censo electoral, elecciones marzo de 2000)

\begin{tabular}{|l|c|c|c|c|c|c|c|}
\hline \multirow{2}{*}{} & \multirow{2}{*}{} & \multicolumn{2}{|c|}{ Huesca } & \multicolumn{2}{c|}{ Teruel } & \multicolumn{2}{c|}{ Zaragoza } \\
\cline { 3 - 9 } & \multirow{2}{*}{ Aragón } & Número & $\begin{array}{c}\text { \% sobre } \\
\text { Aragón }\end{array}$ & Número & $\begin{array}{c}\text { \% sobre } \\
\text { Aragón }\end{array}$ & Número & $\begin{array}{c}\text { \% sobre } \\
\text { Aragón }\end{array}$ \\
\hline Cooperativas & 1.831 & 236 & 12,89 & 334 & 18,24 & 1.261 & 68,87 \\
Cooperativas activas (est) & 1.149 & 138 & 12,01 & 196 & 17,06 & 815 & 70,93 \\
\hline
\end{tabular}

FUENTE: Registro de Cooperativas de la Diputación General de Aragón y elaboración propia

35 A partir de los registros, aquellas que no se han adaptado a la ley de 1987 o no presentan ninguna actividad y que desde el registro se consideran inactivas. 
funcionamiento. Esto supone una pérdida por el camino de un total de 682 entidades. Es decir, aproximadamente un $63 \%$ de las cooperativas constituidas están activas. Los porcentajes de distribución por provincia varían mínimamente. Sólo es destacable la pérdida en términos relativos de la provincia de Huesca.

Por otra parte, según los datos del INE (2000), se considera que en el sector cooperativo español para el año 1999 existen 23456 cooperativas. Con lo cual, si nos permitimos establecer comparaciones de número de cooperativas — siempre con la prudencia debida a la hora de comparar unidades que no son homogéneas en tamaño, etc.-, el porcentaje de las cooperativas de Aragón respecto del total de España sería de un 5,4\%. Esto, en comparación con el peso relativo de la población aragonesa en la española, que es de un 2,9\%, revela que el peso del cooperativismo aragonés no es nada despreciable. En tal sentido, Aragón duplica prácticamente el número de cooperativas por cada mil habitantes $(0,99$ frente a un 0,59 a nivel estatal).

En lo que respecta a la distribución de las cooperativas aragonesas en el propio territorio aragonés, nos encontramos con que la provincia de Teruel muestra el valor más destacado: de medio punto por encima de la provincia de Zaragoza y uno de diferencia con la de Huesca. Aquí se rompe el tópico del refrán y se observa que en Teruel las cooperativas se han convertido en un mecanismo de arraigo y de supervivencia.

TABLA $\| I .2$

NÚMERO DE COOPERATIVAS Y POBLACIÓN ARAGONESA

(Los datos de los registros están actualizados hasta noviembre de 2000)

\begin{tabular}{|l|c|c|c|c|}
\hline Población & Aragón & Huesca & Teruel & Zaragoza \\
\hline $\begin{array}{l}\text { Población total } \\
\text { Población }>18 \text { años }^{b}\end{array}$ & 1.183 .234 & 204.956 & 136.840 & 841.438 \\
$\begin{array}{l}\text { Número de cooperativas/ } \\
\text { por cada 1000 hab. }\end{array}$ & $0,019.679$ & 178.747 & 118.381 & 722.551 \\
$\begin{array}{l}\text { Número de cooperativas/ } \\
\text { por cada 1000 hab. mayor } \\
\text { de } 18 \text { años }\end{array}$ & 1,13 & 0,77 & 1,66 & 1,13 \\
\hline
\end{tabular}

a Censo de población 1996

b Censo electoral, elecciones marzo de 2000.

FUENTE: Registro de Cooperativas de la Diputación General de Aragón, INE 
Además, si distinguimos las capitales del resto de la provincia, encontramos que se corrobora lo dicho al comienzo: es fuera de las ciudades principales donde se ubican la mayoría de las cooperativas aragonesas.

TABLA III.3

DISTRIBUCIÓN DE LAS COOPERATIVAS ACTIVAS DIFERENCIANDO CAPITAL DE PROVINCIA Y RESTO DE LA PROVINCIA

(Los datos de los registros están actualizados hasta noviembre de 2000)

\begin{tabular}{|l|c|c|c|c|c|c|}
\hline \multirow{2}{*}{} & \multicolumn{2}{|c|}{ Huesca } & \multicolumn{2}{c|}{ Teruel } & \multicolumn{2}{c|}{ Zaragoza } \\
\cline { 2 - 7 } & Capital & $\begin{array}{c}\text { Resto } \\
\text { de la provincia }\end{array}$ & Capital & $\begin{array}{c}\text { Resto } \\
\text { de la provincia }\end{array}$ & Capital & $\begin{array}{c}\text { Resto } \\
\text { de la provincia }\end{array}$ \\
\hline Número & 29 & 109 & 27 & 169 & 387 & 428 \\
\% sobre el total de Aragón & 2,52 & 9,49 & 2,35 & 14,71 & 33,68 & 37,25 \\
$\%$ sobre la provincia & 21,01 & 78,99 & 13,78 & 86,22 & 47,48 & 52,52 \\
\hline
\end{tabular}

FUENTE: Registro de Cooperativas de la Diputación General de Aragón y elaboración propia

\section{III.1.2. Clasificación de las actividades de las cooperativas}

Como las cooperativas son organizaciones que tienen elementos peculiares, se hace obligatorio revisar y adaptar la clasificación propuesta para las ONL de interés general. Tomada tal cual la formulamos en su momento, ahora no es suficiente.

En este caso, la ley aragonesa de cooperativas establece una tipología propia para el conjunto del sector cooperativo en Aragón. Por razones obvias es la que hemos adoptado en este apartado. No obstante, la clasificación propuesta en el primer capítulo sigue siendo válida para las cooperativas denominadas de iniciativa social. Éstas, de acuerdo con la ley, pueden tener como finalidad «el apoyo, la promoción y el desarrollo de colectivos que, por sus peculiares características, precisen de una especial atención en orden a conseguir su bienestar y su plena integración social y laboral, a través de la prestación de servicios y el desarrollo de actividades empresariales de carácter asistencial, educativo, de prevención, integración e inserción». En este nuevo tipo de cooperativa introducido en Aragón se ha de ubicar, por tanto, la clasificación propuesta. 
Los tipos de cooperativas que se contemplan y definen en la Ley 9/1998, de 22 de diciembre, de Cooperativas de Aragón son los siguientes:

\section{Cooperativas de trabajo asociado}

Asocian principalmente a personas físicas que, mediante su trabajo, realizan cualquier actividad económica o social de producción de bienes o servicios destinados a terceros.

- Cooperativas de enseñanza de trabajo asociado: Agrupan a profesores, personal no docente y de servicios con objeto de desarrollar actividades docentes en sus distintos niveles, etapas y modalidades, pudiendo realizar también actividades extra-escolares, conexas y complementarias a las mismas.

- Cooperativas de iniciativa social: Dedicadas a proporcionar apoyo, promoción y desarrollo de colectivos que, por sus peculiares características, precisen de una especial atención a fin de conseguir su bienestar y su plena integración social y laboral, a través de la prestación de servicios y el desarrollo de actividades empresariales de carácter asistencial, educativo, de prevención, integración e inserción.

\section{Cooperativas de servicios}

Asocian a personas físicas y/o jurídicas, titulares de explotaciones industriales o de servicios, y a profesionales que ejercen su actividad por cuenta propia. Tienen por objeto la prestación de suministros y servicios en común y la ejecución de operaciones tendentes al mejor funcionamiento de las actividades empresariales o profesionales de sus socios, que no puedan atribuirse a ninguna otra clase de cooperativas.

\section{Cooperativas agrarias}

Asocian a titulares de explotaciones agrícolas, ganaderas o forestales. También podrán asociar a otras cooperativas, sociedades agrarias de transformación, comunidades de regantes y aquellas personas jurídicas que, agrupando a titulares de explotaciones agrarias, realicen actividades empresariales afines a las de la propia cooperativa. Tienen por finalidad la prestación de servicios y suministros, la producción, transformación y comercialización de los productos obtenidos y, en general, 
cualesquiera operaciones y servicios tendentes a la mejora económica o técnica de las explotaciones de sus socios o de la cooperativa, así como de las condiciones económicas y sociales del ámbito en que desarrollen su actividad.

\section{Cooperativas de explotación comunitaria de la tierra}

Asocian a titulares de explotaciones agrarias que ceden sus derechos sobre éstas a la cooperativa, pudiendo prestar también su trabajo en ella.

\section{Cooperativas de consumidores y usuarios}

Adquisición y/o producción de bienes y servicios para el consumo y uso como destinatarios finales de los socios y de quienes con ellos convivan habitualmente. También procurarán la información y defensa de los intereses legítimos de consumidores y usuarios.

- Cooperativas de servicios sociales: Son aquellas cooperativas de consumo que procuran la atención social a sus miembros, pertenecientes a colectivos de disminuidos físicos, psíquicos o sensoriales, menores, ancianos con carencias familiares o económicas y grupos marginados de la sociedad, facilitándoles bienes y servicios para su subsistencia y desarrollo.

\section{Cooperativas de viviendas}

Procurar, exclusivamente para sus socios, viviendas, servicios o edificaciones complementarias, así como su rehabilitación, pudiendo organizar el uso y disfrute de los elementos comunes y regular su administración, conservación y mejora.

\section{Cooperativas de crédito}

Fomento y captación del ahorro en cualquiera de sus modalidades para atender las necesidades de financiación de sus socios y terceros comprendidos en su ámbito de actuación.

\section{Cooperativas de seguros}

Tienen por objeto el ejercicio de la actividad aseguradora en cualquiera de las ramas admitidas en derecho. 
- Cooperativas sanitarias: Son aquellas cooperativas de seguros cuyo objeto es asegurar los riesgos relativos a la salud de sus socios o asegurados y de los beneficiarios de éstos.

\section{Cooperativas escolares}

Tienen como finalidad formar a los alumnos de centros de enseñanza en los principios y práctica cooperativos. Su actividad consistirá en procurar a sus socios, en las mejores condiciones posibles de calidad y precio, los bienes y servicios necesarios para su desarrollo educativo y cultural.

La definición y descripción anterior de los distintos tipos de cooperativas es en sí misma bastante clara. Ahora bien, de todos modos queremos comparar la clasificación inicial de las ONL y las clases de cooperativas según la nueva ley. En el cuadro III.1 se puede comprobar que entre ambas tipologías existen numerosos vínculos y conexiones.

\section{CUADRO III.1}

\begin{tabular}{|c|c|}
\hline Clase de cooperativa & Clasificación $O N L$ \\
\hline Cooperativas de trabajo asociado & Otras o profesionales \\
\hline $\begin{array}{l}\text { Cooperativas de enseñanza de trabajo aso- } \\
\text { ciado }\end{array}$ & Educación \\
\hline Cooperativas de iniciativa social & $\begin{array}{l}\text { Depende de los fines cualquiera } 13 \text { tipos } \\
\text { propuestos }\end{array}$ \\
\hline Cooperativas de servicios & $\begin{array}{l}\text { Dependiendo del sector de servicios, otras o } \\
\text { profesionales }\end{array}$ \\
\hline Cooperativas agrarias & Otras o profesionales \\
\hline $\begin{array}{l}\text { Cooperativas de explotación comunitaria de la } \\
\text { tierra }\end{array}$ & Otras o profesionales \\
\hline Cooperativas de consumidores y usuarios & Derechos civiles \\
\hline Cooperativas de servicios sociales & Servicios sociales \\
\hline Cooperativas de viviendas & Desarrollo comunitario \\
\hline Cooperativas de crédito & Otras o profesionales \\
\hline Cooperativas de seguros & \\
\hline Cooperativas sanitarias & Salud \\
\hline Cooperativas escolares & Enseñanza \\
\hline
\end{tabular}


TABLA III.4

NÚMERO DE COOPERATIVAS ACTIVAS EN ARAGÓN CLASIFICADAS

POR TIPO DE COOPERATIVA

(Los datos de los registros están actualizados hasta noviembre de 2000)

\begin{tabular}{|l|r|r|}
\hline Tipo de cooperativa & Número & $\%$ \\
\hline Agrarias y agrarias $2 .^{\circ} \mathrm{G}$ & 247 & 21,50 \\
Consumo & 25 & 2,18 \\
Crédito & 5 & 0,44 \\
Enseñanza & 4 & 0,35 \\
Explotación comunitaria de la tierra & 9 & 0,78 \\
Iniciativa social & 2 & 0,17 \\
Servicios & 18 & 1,57 \\
Trabajo asociado & 621 & 54,05 \\
Transportistas & 19 & 1,65 \\
Vivienda & 199 & 17,32 \\
Total & 1.149 & 100,00 \\
\hline
\end{tabular}

FUENTE: Registro de Cooperativas de la Diputación General de Aragón y elaboración propia

En lo que afecta a esta parte del análisis del Tercer Sector aragonés y la presentación de sus datos más relevantes, hemos seguido la clasificación recogida en los registros del Gobierno de Aragón hasta la fecha. Éstos, a su vez, como están en fase de actualización, todavía no siguen las pautas descritas en el nuevo marco legal. Así, por ejemplo, encontramos entre los tipos de cooperativas las denominadas de "transportistas", las cuales no aparecen en la nueva ley de cooperativas; pero, debido a que el Registro Aragonés de Cooperativas todavía no ha actualizado las ya existentes, se mantiene la clasificación antigua.

Una vez realizadas las aclaraciones anteriores, entendemos que es interesante resaltar algunos de los datos que la tabla III.4 recoge. Primero, vemos que las cooperativas de trabajo asociado son las más numerosas en nuestra comunidad, ya que representan el 54,05\% del total. Le siguen en un puesto también relevante las cooperativas agrarias, con un $21,50 \%$, y, en tercer lugar, las cooperativas de viviendas, con un 17,32 \%. El resto de actividades se reparten en porcentajes pequeños el aproximadamente $10 \%$ restante.

Si revisamos las peculiaridades de esta distribución en cada una de las provincias, nos encontramos con algunas variaciones. Por ejemplo, en el caso de Huesca el tipo de cooperativa más destacado es el dedicado a la actividad agraria. Suponen el 40,58 \% del total de la provincia. A continuación 
se sitúan las dedicadas a la vivienda, con un 29,71\%, y, en tercer lugar, las de trabajo asociado, con un 19,57 \%, lo que supone un pequeña alteración del orden para el conjunto de Aragón. Las características de la provincia de Huesca hacen pensar que el peso del sector agrario y la distribución de la población llevan a introducir este tipo de estructura, al menos hasta el presente. Y como elementos también destacados, aunque con valores muy pequeños, hemos de señalar los casos de las cooperativas de consumo, con $3,62 \%$, las de transportistas, con un 2,90\%, y las de servicios, con un $2,17 \%$. De las tres, las dos primeras encajan en el contexto general de la provincia, donde ambos sectores de actividad han estado ligados a las estrategias de vida cotidiana de la población.

TABLA III.5

NÚMERO DE COOPERATIVAS EN HUESCA CLASIFICADAS POR TIPO DE COOPERATIVA

(Los datos de los registros están actualizados hasta noviembre de 2000)

\begin{tabular}{|l|c|c|}
\hline Tipo de cooperativa & Número & $\%$ \\
\hline Agrarias y Agrarias 2. ${ }^{\circ} \mathrm{G}$ & 56 & 40,58 \\
Consumo & 5 & 3,62 \\
Crédito & 1 & 0,72 \\
Enseñanza & 1 & 0,72 \\
Explotación comunitaria de la tierra & 0 & 0,00 \\
Iniciativa social & 0 & 0,00 \\
Servicios & 3 & 2,17 \\
Trabajo asociado & 27 & 19,57 \\
Transportistas & 4 & 2,90 \\
Vivienda & 41 & 29,71 \\
Total & 138 & 100,00 \\
\hline
\end{tabular}

FUENTE: Registro de Cooperativas de la Diputación General de Aragón y elaboración propia

En el caso de la provincia de Teruel nos encontramos con una situación más similar al conjunto de la Comunidad Autónoma, con la salvedad del incremento del peso relativo de las cooperativas agrarias en la distribución de la provincia. Así, vemos que en primer lugar se encuentran las cooperativas de trabajo asociado, con un 43,88\%, después las agrarias, con un 37,24 \%, y en tercer lugar las de viviendas, con un 12,24\%. Respecto de los grupos menos numerosos, destacaremos las de consumo, con un $2,55 \%$. De nuevo, el peso de la actividad agraria en la provincia se manifiesta con el porcentaje de las cooperativas de este sector, aunque destaca el primer lugar de las de trabajo asociado. 
TABLA III.6

NÚMERO DE COOPERATIVAS EN TERUEL CLASIFICADAS

POR TIPO DE COOPERATIVA

(Los datos de los registros están actualizados hasta noviembre de 2000)

\begin{tabular}{|l|r|r|}
\hline Tipo de cooperativa & Número & $\%$ \\
\hline Agrarias y agrarias 2. ${ }^{\circ} \mathrm{G}$ & 73 & 37,24 \\
Consumo & 5 & 2,55 \\
Crédito & 1 & 0,51 \\
Enseñanza & 1 & 0,51 \\
Explotación comunitaria de la tierra & 1 & 0,51 \\
Iniciativa social & 0 & 0,00 \\
Servicios & 3 & 1,53 \\
Trabajo asociado & 86 & 43,88 \\
Transportistas & 2 & 1,02 \\
Vivienda & 24 & 12,24 \\
Total & 196 & 100,00 \\
\hline
\end{tabular}

FUENTE: Registro de Cooperativas de la Diputación General de Aragón y elaboración propia

TABLA III.7

NÚMERO DE COOPERATIVAS EN ZARAGOZA CLASIFICADAS

POR TIPO DE COOPERATIVA

(Los datos de los registros están actualizados hasta noviembre de 2000)

\begin{tabular}{|l|r|r|}
\hline Tipo de cooperativa & Número & $\%$ \\
\hline Agrarias y agrarias 2. ${ }^{\circ} \mathrm{G}$ & 118 & 14,48 \\
Consumo & 15 & 1,84 \\
Crédito & 3 & 0,37 \\
Enseñanza & 2 & 0,25 \\
Explotación comunitaria de la tierra & 8 & 0,98 \\
Iniciativa social & 2 & 0,25 \\
Servicios & 12 & 1,47 \\
Trabajo asociado & 508 & 62,33 \\
Transportistas & 13 & 1,60 \\
Vivienda & 134 & 16,44 \\
Total & 815 & 100,00 \\
\hline
\end{tabular}

FUENTE: Registro de Cooperativas de la Diputación General de Aragón y elaboración propia

La tabla III.7 nos muestra el caso de la provincia de Zaragoza. Aquí se repite en parte el modelo general de Aragón. En el primer puesto destacan por encima del resto las cooperativas de trabajo asociado, con un $62,33 \%$. Más alejadas, aunque con un número elevado sobre el total de Aragón, se encuentran las cooperativas de viviendas, lo cual es bastante lógico, dado 
que es la provincia donde más se construye. Sin embargo, llama la atención que las cooperativas de transportistas no sean más numerosas y estén más presentes en una zona del valle del Ebro donde siempre se resalta su posición estratégica para las comunicaciones e intercambios de mercancías.

\section{III.1.3. Evolución temporal en la creación de las cooperativas aragonesas}

Los cambios producidos por el nuevo marco legal todavía están demasiado recientes para que se perciban efectos tangibles y notorios en el sector del cooperativismo aragonés. Si los hay, comenzarán a ser palpables a partir de la actualización del nuevo sistema de registros.

Si consideramos la década de los noventa como período de referen$\mathrm{cia}^{36}$ para ver la evolución temporal del sector, nos encontramos con una evolución desigual en la constitución de cooperativas. Al comienzo de la década el crecimiento es lento pero sostenido, comportándose de forma irregular — a la baja - y con tendencia a la estabilización para la segunda mitad de la década.

TABLA III.8

COOPERATIVAS CONSTITUIDAS EN ARAGÓN DURANTE EL PERÍODO 1990-1999

\begin{tabular}{|l|c|c|c|c|}
\hline \multirow{2}{*}{ Año } & \multicolumn{2}{|c|}{ Aragón } & \multicolumn{2}{c|}{ España } \\
\cline { 2 - 5 } & $N .^{\circ}$ de cooperativas & \% total en Aragón & $N .^{\circ}$ de cooperativas & $\%$ total España \\
\hline 1990 & 47 & 7,56 & 1.729 & 7,08 \\
1991 & 50 & 8,04 & 1.583 & 6,48 \\
1992 & 70 & 11,25 & 2.186 & 8,95 \\
1993 & 74 & 11,90 & 3.146 & 12,88 \\
1994 & 67 & 10,77 & 3.304 & 13,53 \\
1995 & 69 & 11,09 & 3.106 & 12,72 \\
1996 & 52 & 8,36 & 2.814 & 11,52 \\
1997 & 63 & 10,13 & 2.555 & 10,46 \\
1998 & 62 & 9,97 & 2.036 & 8,34 \\
1999 & 68 & 10,93 & 1.958 & 8,02 \\
Total & 622 & 100 & 24.417 & 100 \\
\hline
\end{tabular}

FUENTE: Anuario de estadísticas laborales y de asuntos sociales, Ministerio de Trabajo y Asuntos Sociales, 2000

36 Hasta esa fecha no hay datos suficientes para cuantificar adecuadamente el total de cooperativas existentes. 
TABLA III.9

EVOLUCIÓN DE LA CONSTITUCIÓN DE COOPERATIVAS POR PROVINCIAS EN ARAGÓN, 1990-1999

\begin{tabular}{|l|c|r|r|r|r|r|}
\hline \multirow{2}{*}{ Periodo } & \multicolumn{2}{|c|}{ Huesca } & \multicolumn{3}{c|}{ Teruel } & \multicolumn{2}{c|}{ Zaragoza } \\
\cline { 2 - 7 } & Número & \multicolumn{1}{c|}{$\%$} & Número & $\%$ & Número & $\%$ \\
\hline 1990 & 8 & 8,99 & 14 & 11,76 & 25 & 6,04 \\
1991 & 9 & 10,11 & 7 & 5,88 & 34 & 8,21 \\
1992 & 13 & 14,61 & 19 & 15,97 & 38 & 9,18 \\
1993 & 16 & 17,98 & 10 & 8,40 & 48 & 11,59 \\
1994 & 9 & 10,11 & 9 & 7,56 & 49 & 11,84 \\
1995 & 5 & 5,62 & 11 & 9,24 & 53 & 12,80 \\
1996 & 8 & 8,99 & 13 & 10,92 & 31 & 7,49 \\
1997 & 4 & 4,49 & 14 & 11,76 & 45 & 10,87 \\
1998 & 4 & 4,49 & 12 & 10,08 & 46 & 11,11 \\
1999 & 13 & 14,61 & 10 & 8,40 & 45 & 10,87 \\
& & & & & & \\
Total & 89 & 100 & 119 & 100 & 414 & 100 \\
\hline
\end{tabular}

FUENTE: Anuario de estadísticas laborales y de asuntos sociales, Ministerio de Trabajo y Asuntos Sociales, 2000

Así, en este período se han creado en Aragón 622 cooperativas, que representan el 2,6\% de las constituidas en España. Con respecto a la cifra inicial, un $5,4 \%$, este porcentaje desciende notablemente, lo que nos proporciona un dato más realista de la situación.

Si atendemos a la evolución por provincias — tabla III.9- nos encontramos con unos comportamientos similares en las tres, aunque con algunos matices. En los casos de Zaragoza y Huesca se observa que la primera mitad de la década de los noventa es de creación constante de entidades. Los números son modestos, pero muestran un incremento paulatino en la evolución. En el caso de Teruel, para esta misma fase, nos encontramos con bastantes altibajos aunque en términos absolutos los resultados son superiores a los de Huesca. En la segunda mitad, sin embargo, el flujo de creación de nuevas entidades se estabiliza e incluso tiende a la baja en la provincia de Huesca, con un repunte en el año 1999.

La representación gráfica de la evolución de las cooperativas aragonesas para este período nos muestra de forma más clara lo apuntado anteriormente. 
GRÁFICA III.1

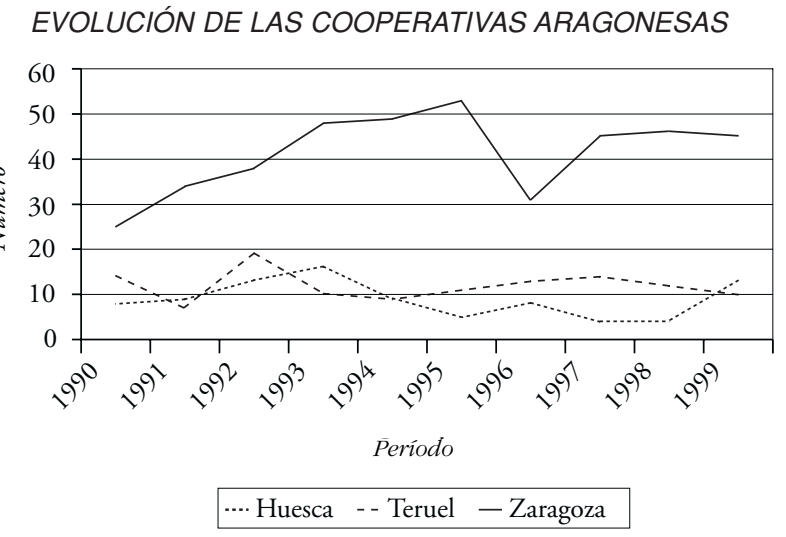

Una conjetura que planteamos es la posible correlación entre tiempos de crisis y constitución de cooperativas. Es conocido por todos que la crisis económica es más profunda en los años 92 y 93 y que se inicia una recuperación económica a partir de 1994 . En períodos así, donde cualquier iniciativa es complicada, es más difícil salir adelante de forma personal. Por eso nos parece más propicio buscar iniciativas en común, como las cooperativas, que esperar a soluciones individuales.

\section{III.1.4. Las personas: socios cooperativistas}

En todas las entidades del sector no lucrativo lo importante son las personas que las constituyen y vertebran. Después insistiremos especialmente en este punto en lo que afecta a las fundaciones y las asociaciones. Sin embargo, en el mundo de las cooperativas existe un valor añadido, quizá heredero de la tradición primigenia del pensamiento cooperativista. Las personas que se implican en este tipo de proyectos suelen tener como punto de convergencia la motivación del esfuerzo compartido y la consciencia de que en común es más factible alcanzar los objetivos propuestos.

La finalidad de las cooperativas podrá ser más o menos lucrativa, más o menos altruista, más o menos general..., pero en todos los casos lo que pone a disposición de la sociedad es un modo de proceder. En ese modus operandi es donde se transciende la acción cotidiana para convertirse en un 
modo de hacer sociedad. La economía se construye con un paradigma distinto, e incluso las relaciones humanas se articulan como un mecanismo emancipador y proactivo. Las claves son la implicación en los objetivos comunes y la participación como forma de acción.

Aunque pueda sonar extraño, el cooperativismo es una forma avanzada y evolucionada de practicar el voluntariado. Es decir, las personas que se implican en una cooperativa lo hacen como pleno ejercicio de su voluntad y con la intención de compartir su esfuerzo personal con otros socios implicados en el mismo proyecto. El interés propio es un subproducto del interés común. Si lo de todos no mejora y crece, lo particular tampoco lo hace. Quizá por eso, nuestro tiempo sea una época difícil para las ideas cooperativas.

De hecho, con los datos disponibles, el número de personas implicadas en las cooperativas aragonesas es más bien bajo, aunque estemos dentro de los parámetros generales de la sociedad española.

Durante la década de los noventa el número de socios iniciales — aquellos que han constituido inicialmente las cooperativas aragonesas- representa un $2,5 \%$ de los socios a nivel estatal. Si lo relacionamos con la población aragonesa el 0,5\% de ésta se ha implicado en proyectos cooperativistas durante dicha década, lo cual es un valor similar para España en su conjunto, un $0,59 \%$.

TABLA III.10

SOCIOS INICIALES DE LAS COOPERATIVAS CONSTITUIDAS EN ARAGÓN DURANTE EL PERÍODO 1990-1999

\begin{tabular}{|l|c|c|c|c|}
\hline \multirow{2}{*}{ Año } & \multicolumn{2}{|c|}{ Aragón } & \multicolumn{2}{c|}{ España } \\
\cline { 2 - 5 } & $N .^{\circ}$ de socios & \% en Aragón & $N .^{\circ}$ de socios & \% en España \\
\hline 1990 & 479 & 8,05 & 19.308 & 8,22 \\
1991 & 411 & 6,90 & 18.540 & 7,89 \\
1992 & 667 & 11,20 & 22.091 & 9,41 \\
1993 & 1073 & 18,02 & 35.700 & 15,20 \\
1994 & 521 & 8,75 & 25.091 & 10,68 \\
1995 & 596 & 10,01 & 20.096 & 8,56 \\
1996 & 842 & 14,14 & 21.729 & 9,25 \\
1997 & 496 & 8,33 & 31.422 & 13,38 \\
1998 & 528 & 8,87 & 23.950 & 10,20 \\
1999 & 340 & 5,71 & 16.940 & 7,21 \\
Total & 5.953 & 100 & 234.867 & 100 \\
\hline
\end{tabular}

FUENTE: Anuario de estadísticas laborales y de asuntos sociales, Ministerio de Trabajo y Asuntos Sociales, 2000 
TABLA III.11

EVOLUCIÓN DEL NÚMERO DE SOCIOS EN LAS NUEVAS COOPERATIVAS CONSTITUIDAS EN ARAGÓN DURANTE 1990-1999

\begin{tabular}{|l|c|r|r|r|r|r|}
\hline \multirow{2}{*}{ Periodo } & \multicolumn{2}{|c|}{ Huesca } & \multicolumn{2}{|c|}{ Teruel } & \multicolumn{2}{|c|}{ Zaragoza } \\
\cline { 2 - 7 } & Número & $\%$ & Número & $\%$ & Número & $\%$ \\
\hline 1990 & 59 & 7,62 & 159 & 11,80 & 261 & 6,81 \\
1991 & 59 & 7,62 & 61 & 4,53 & 291 & 7,60 \\
1992 & 139 & 17,96 & 128 & 9,50 & 400 & 10,44 \\
1993 & 181 & 23,39 & 66 & 4,90 & 826 & 21,56 \\
1994 & 56 & 7,24 & 56 & 4,15 & 409 & 10,68 \\
1995 & 104 & 13,44 & 68 & 5,04 & 424 & 11,07 \\
1996 & 41 & 5,30 & 520 & 38,58 & 281 & 7,33 \\
1997 & 37 & 4,78 & 113 & 8,38 & 346 & 9,03 \\
1998 & 44 & 5,68 & 115 & 8,53 & 369 & 9,63 \\
1999 & 54 & 6,98 & 62 & 4,60 & 224 & 5,85 \\
Total & 774 & 100 & 1.348 & 100 & 3.831 & 100 \\
\hline
\end{tabular}

FUENTE: Anuario de estadísticas laborales y de asuntos sociales, Ministerio de Trabajo y Asuntos Sociales, 2000

Si atendemos a la distribución del número de socios por provincias — como se presenta en la tabla III.11—, y lo relacionamos con la población de cada provincia, las tasas de participación en proyectos cooperativistas varían de forma importante. En el caso de la provincia de Huesca desciende al 0,38\%. Mientras que en la provincia de Teruel se produce un incremento muy relevante hasta un $0,99 \%$. En Zaragoza se mantiene cercano a la media estatal, con un $0,46 \%$.

GRÁFICA III.2

\section{EVOLUCIÓN DE SOCIOS EN COOPERATIVA}

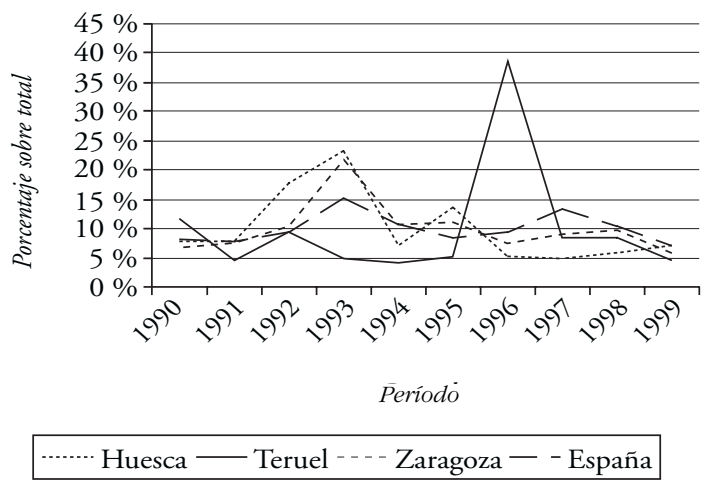


En definitiva, las personas, con su esfuerzo, son quienes crean, desarrollan y llevan adelante las organizaciones, lo cual es más obvio en el sector cooperativo. En este caso «lo más importante no es el dinero que se pone sino las ganas de trabajar, los medios que se pongan de trabajo y las personas». Por la misma razón las cooperativas en Aragón desempeñan un papel fundamental en el mundo rural y en las pequeñas poblaciones de nuestro país. Las cooperativas han permitido poner en marcha estrategias de supervivencia «en aquellas zonas donde hay pequeñas empresas, donde los recursos son limitados y, por lo tanto, cualquier actividad económica con la forma tradicional de empresa, digamos de capital, pues es más difícil». Quizá esto ha hecho que su importancia sea mayor en el medio rural, y, por provincias, en Teruel y Huesca, en términos relativos, mucho más relevante que en Zaragoza.

\section{III.2. Las cajas de ahorro aragonesas}

Dentro de este apartado dedicado a las ONL de interés particular, hemos de abordar el fenómeno de las cajas de ahorro. Como tales, su historia es rica, densa y extensa. ${ }^{37}$ La perspectiva de análisis desde un enfoque centrado en el sector no lucrativo nos lleva a considerar estas organizaciones de un modo poco habitual, puesto que nos interesa su carácter altruista y sin ánimo de lucro. Un enfoque que, por otra parte, parece menos relevante que los planteamientos actuales de interés político y primacía de los resultados en el mercado, por encima de cualquier otra consideración.

En el caso que nos ocupa, la primera puntualización se refiere a la definición del nuevo marco jurídico. La nueva ley aragonesa sobre cajas de ahorros - Ley 4/2000, de 28 de noviembre, de reforma de la Ley 1/1991, de 4 de enero, de las Cajas de Ahorros en Aragón- formula una serie de indicaciones sobre las cajas de ahorros referentes a la obra social y la composición de los órganos rectores.

En su preámbulo se dice que «desde la entrada en vigor de la Ley 1/1991, las cajas de ahorro han tenido una importante evolución, incrementándose su importancia económica y social. Esto exige que sus normas de actuación respondan en cada momento a las necesidades que se plantean, y

37 Ver García Roa (1994), Carbó y Coello (1997), Carbó y Rodríguez (1998), Titos Martínez (1998), Maroto (1999). 
en este sentido se modifica la regulación de las Cajas de Ahorro en Aragón». Lo cual no hace sino confirmar dos hechos conocidos: que las cajas son unas entidades fundamentales en la economía aragonesa, y que el control de su gestión y la posibilidad de intervenir directamente en ellas es un aspecto donde también se traslucen las pugnas de fuerzas e intereses políticos.

La cajas, desde su fundación, no buscan repartir dividendos entre sus accionistas, primero porque no los tienen y segundo porque se pensaron para otros fines. Los objetivos sociales de las cajas han sido siempre su principal signo de distinción. Pero dicha particularidad además de haber pasado por grandes transformaciones tanto en sus principios de acción como de legitimación, ha tenido que adaptarse a las circunstancias propias de cada época. De esta realidad también se hace cargo la nueva legislación. Por eso dice: «respecto a la obra social y cultural, y sin merma de la libertad con la que las cajas pueden operar en este aspecto esencial, se establecen criterios que permitan lograr un servicio a la sociedad adecuado a los tiempos actuales y, al mismo tiempo, se aborda de forma más unitaria su régimen jurídico». Se anticipa un punto que más adelante veremos al comentar algunos de los artículos de la ley: se incrementa el control sobre la obra social al servicio de la sociedad, preparando una mayor intervención política en lo que hasta hora eran acciones más o menos independientes.

Con esa misma lógica, también se da un paso para obligar a cualquier otra caja con implantación e intereses en el mercado aragonés — evitando la sangría de unos ahorros cuyos beneficios sociales se iban a los territorios de las sedes principales - a revertir sus «excedentes» en obras sociales. Así, se señala en el preámbulo que «se amplía la obligación de sostenimiento de las obras sociales y culturales a las cajas de ahorro con presencia en Aragón, pero sin domicilio social en esta Comunidad, que deberá ser proporcional al volumen de recursos captados en territorio aragonés».

Este tipo de argumentación está preparando una apuesta por el compromiso de las cajas como entidades de ahorro especiales con el desarrollo de la Comunidad Autónoma. Y esto sí que supone un paso más en la consolidación y explicitación de unas vías de acción que han estado en otros momentos menos claras. Así, se entiende el texto del artículo 4.1 cuando dice:

Las Cajas de Ahorro con domicilio social en la Comunidad Autónoma de Aragón tendrán como actividad principal el fomento del ahorro, y orientarán sus actuaciones a la consecución de fines de interés público para contribuir al desarrollo social y económico de Aragón, así como a su equilibrio territorial. 
Ese compromiso con el desarrollo social y económico de Aragón, podía suponerse o considerarse obviamente ligado a la historia de las cajas, pero en el nuevo contexto de deslocalización, expansión y fusiones en los mercados financieros, las pautas señaladas por la nueva ley vienen a reforzar una estrategia de vinculación de las entidades con la sociedad de la que obtienen sus recursos y de la que gestionan sus ahorros. Por eso también, en coherencia, podemos leer en el artículo 28.2:

Cuando una Caja con domicilio social en la Comunidad Autónoma de Aragón actúe habitualmente en más de una comunidad autónoma, la dotación de la obra social y cultural para cada uno de los territorios de su actuación se adaptará a las necesidades específicas de desarrollo socioeconómico de dichos territorios.

Las cajas ni deben ni pueden comportarse como unas entidades financieras que buscan un lucro desmedido para enriquecer a los suyos, prescindiendo de consideraciones como las que ahora se establecen.

Se propone, por tanto, un modo de proceder que hace que se vincule a la sociedad de la que se obtienen los recursos financieros - ahorrosuna parte equivalente de lo que estas entidades deben destinar a obra social. Para que quede claro, así lo expresa el artículo 28.3:

Las Cajas de Ahorro que operen en el territorio de la Comunidad Autónoma de Aragón sin tener su domicilio social en el mismo han de efectuar inversiones o gastos en obra social y cultural en Aragón, destinando a tal efecto, como mínimo, la parte proporcional del presupuesto anual de la obra social y cultural en función de los recursos ajenos captados de esta Comunidad Autónoma con respecto al total de la entidad.

Y, como decíamos antes, dando mayor entrada a la intervención política en esas actuaciones se redacta el artículo 28 bis.2:

El Gobierno de Aragón establecerá las directrices y prioridades en relación con la obra social y cultural e indicará las principales necesidades y carencias sobre las que se debe actuar, respetando, en el marco previamente definido, la libertad de cada Caja para decidir el destino concreto de las inversiones.

Así, estas ONL especiales de nuestra sociedad, pasan a un grado mayor de control de la clase política, lo cual podemos interpretarlo como una cuestión lógica y coherente con el sistema democrático en el que vivimos. En este momento, vista la realidad, no deja de ser más que un mecanismo de cooptación y de control de las cajas (poder económico...) por parte del Gobierno de turno (poder político). 
Esta tendencia se consolida, además, con la distribución de cuotas de representación en los consejos de administración de las cajas. Basta ver el reparto que se propone en el artículo 45.1, según el cual el $42 \%$ de dichos consejos procederá de las instituciones públicas, ayuntamiento y gobierno autónomo. Se puede argüir que ello es beneficioso para la ciudadanía, puesto que son sus cargos electos quienes después obran en consecuencia. Pero algunos pueden interpretarlo como un mecanismo de perpetuación en el poder de quienes ya están. Ambas interpretaciones son posibles. El artículo referido dice:

La representación de los sectores a que se refiere el artículo anterior se distribuirá de la forma que a continuación se establece:

a) El $41 \%$ del total de los Consejeros Generales será elegido en representación de los impositores de las Cajas de Ahorro.

b) El $7 \%$ de tales Consejeros será elegido en representación directa del personal de plantilla de la Caja.

c) El $21 \%$ de los Consejeros Generales será elegido en representación de la Comunidad Autónoma de Aragón.

d) El $21 \%$ de los Consejeros Generales será elegido en representación de los Ayuntamientos de la zona de actuación de la Caja.

e) El $10 \%$ de los Consejeros Generales será elegido en representación de las entidades o personas fundadoras de la Caja.

La participación individual en el consejo es un cargo que no lleva asociado una remuneración con la que beneficiarse particularmente. Como está escrito en la norma correspondiente: «en el ejercicio de las funciones de los miembros de los órganos de gobierno de las Cajas de Ahorro, con excepción del Presidente del Consejo de Administración, no se podrán originar percepciones distintas de las dietas por asistencia y desplazamiento». ${ }^{38}$ Pero sí que es evidente que el peso específico de las personas que lo forman puede inclinar las decisiones del consejo en función de criterios y líneas de actuación muy distintas entre sí. Y, como nos han señalado algunas voces críticas con este sistema, también sería pertinente, en algunos casos, revisar el importe de esas dietas y otra serie de prestaciones que pueden resultar contradictorias con el fondo de la norma.

38 Ley 31/1985, de 2 de agosto, de regulación de las normas básicas sobre órganos rectores de las cajas de ahorros (BOE número 190, de 9 de agosto de 1985). 


\section{III.2.1. Número de cajas de ahorros y distribución geográfica}

La nueva ley indica que se deben considerar como cajas aragonesas las que tenga su domicilio social en Aragón, esto es, Caja de Ahorros de la Inmaculada e Ibercaja. Pero si partimos de los artículos dedicados a la obra social en la nueva ley de cajas, podemos comprender y delimitar mejor la incidencia de las cajas en la sociedad aragonesa.

Evidentemente, basta con recorrer algunas calles de Aragón para constatar que hay un número mayor de cajas en esta comunidad. Operan y son visibles a través de sus oficinas. $Y$ de todos es conocido el casi refrán que dice «en pueblo rico, cajas y bancos», por alusión directa a la presencia de las entidades financieras en aquellos lugares de nuestra geografía donde abunda el dinero.

Conviene recordar que el artículo 28.3 obliga a las cajas de otras comunidades autónomas a «reinvertir» proporcionalmente en obra social el ahorro aragonés. A día de hoy sabemos que dichas cajas, en general, se ajustan al marco jurídico. Sin embargo, no podemos estimar la cantidad de la que se trata ni tenemos datos oficiales desglosando estas partidas para el amplio conjunto de entidades afectadas. En cualquier caso, no pretendemos ser los vigilantes de la legalidad ni saber si destinan fondos a esta comunidad o a otra. Lo que queremos conocer es la capacidad de creación de servicios de las organizaciones analizadas en el conjunto de la comunidad. El indicador de la obra social destinada nos permitiría suponer dicha capacidad por su ubicación en Aragón.

Para examinar esta cuestión, lo primero que hay que resaltar, aunque sea conocido y evidente, es que las Cajas de Ahorros con la casa matriz en Aragón son Caja de Ahorros de la Inmaculada e Ibercaja. Ambas tienen una larga trayectoria en la comunidad.

La Caja de Ahorros de la Inmaculada fue fundada en 1905; según sus propios documentos, es «una entidad de ahorro sin ánimo de lucro. Por ello, los beneficios que obtiene en su gestión durante el ejercicio los destina, una vez cubiertas las reservas y atendidas las obligaciones fiscales, a su Obra Social. Una Obra Social moderna, renovada y sensible a las necesidades asistenciales, docentes, formativas, culturales, de investigación y deportivas de Aragón, nuestra tierra, y comprometida con la conservación de su patrimonio histórico-artístico y de su medio ambiente. Así, a través 
de sus obras sociales, la CAI revierte en la sociedad los recursos que recibe de ella, participa en el desarrollo de Aragón y contribuye a mejorar la calidad de vida de todos sus ciudadanos». ${ }^{39}$ Resalta con estas palabras la propuesta de relación entre la entidad y la sociedad aragonesa. En definitiva, es igual que las demás, pero en su perfil insisten en aquello de «Aragón es nuestra tierra».

Ibercaja, más antigua en el país, se define a sí misma como «una Institución de crédito de carácter benéfico-social [que] fue fundada en 1873 comenzando sus actividades en $1876 » .{ }^{40} \mathrm{Si}$ continuamos ahondando en la entidad, podemos ver su auto-posicionamiento:

Aunque Ibercaja desarrolla su actividad en el terreno financiero, desde su fundación un marcado carácter social es consustancial a sus objetivos. La Caja, en un afán permanente por ofrecer solución a las necesidades sociales que no están suficientemente cubiertas por la acción de la Administración pública u otros entes, ha trabajado también por lograr el bienestar de la comunidad, niños, jóvenes y mayores que radican en su zona de actuación.

TABLA III.12

CAJAS DE AHORROS Y NÚMERO DE OFICINAS CON PRESENCIA EN ARAGÓN, 1999

\begin{tabular}{|l|c|c|c|c|}
\hline Cajas de ahorros & Huesca & Teruel & Zaragoza & Total \\
\hline CAI & 20 & 17 & 152 & 189 \\
Ibercaja & 102 & 92 & 228 & 422 \\
Bancaja & - & - & 4 & 4 \\
BBK & - & - & 3 & 3 \\
Caixa Galicia & - & - & 4 & 4 \\
Caja Badajoz & - & - & 1 & 1 \\
Caja Cataluña & 1 & 1 & 8 & 10 \\
Caja Duero & - & - & 4 & 4 \\
Caja España & 2 & 1 & 4 & 7 \\
Caja Madrid & 4 & 1 & 17 & 22 \\
Caja Navarra & - & - & 3 & 3 \\
Caja Pamplona & 1 & - & - & 1 \\
Caja Penedés & 5 & - & - & 5 \\
Caja Rioja & - & - & 1 & 1 \\
La Caixa & 10 & 4 & 51 & 65 \\
Total & 145 & 116 & 480 & 741 \\
\hline
\end{tabular}

FUENTE: Elaboración propia a partir de la CECA y Informe Anual de Ibercaja y CAl, 1999

39 Página web de la CAI: <www.cai.es>,2002.

40 Informe Anual 1999, Ibercaja. 
En este apunte se acota la relación inicial entre esta institución y la sociedad en la que se inserta. Como en las demás cajas, el compromiso social con la comunidad es su signo de distinción y su objetivo, lo cual se preocupa de recalcar la propia institución:

Los principios que definen la actividad de la Entidad desde su origen son la familia y los valores de la comunidad, el fomento del ahorro y la contribución al desarrollo económico y social de la zona de actuación [...] A través de su Obra Social busca la defensa del medio ambiente, la conservación del patrimonio histórico-artístico, la integración social, la formación y el fomento del empleo y la difusión de la cultura.

Si esto se cumple, entonces estamos ante una ONL que transciende el espíritu de su sector de actuación para preocuparse por hacer que la comunidad donde se inserta esté cada vez mejor. Aspecto este que es común al sector general de las cajas de ahorro. No son simples entidades de crédito: su espíritu y sus principios transcienden el mercado capitalista para humanizar la economía y las relaciones sociales. Otra cosa es lo que después se plasma en la realidad. Quizá es tiempo para hacer una auditoría social ${ }^{41}$ en profundidad de unas organizaciones con peso e importancia fundamental en la sociedad aragonesa, en particular, y en la sociedad española, en general.

TABLA III.13

DISTRIBUCIÓN DE LA RED DE OFICINAS DE CAI E IBERCAJA EN ARAGÓN, 1999

\begin{tabular}{|l|c|c|c|}
\hline Provincia & CAI & Ibercaja & Total \\
\hline Huesca & 20 & 102 & 122 \\
Teruel & 17 & 92 & 109 \\
Zaragoza & 152 & 228 & 380 \\
Aragón & 189 & 422 & 611 \\
\hline
\end{tabular}

FUENTE: Informe Anual 1999, CAI, e Informe Anual 1999, Ibercaja

En cualquier caso, estas dos cajas son ampliamente conocidas en la Comunidad Autónoma, han dejado y siguen dejando su impronta en la vida económica, social y política de Aragón. En el caso de Ibercaja,

41 Moneva y Ch. Marcuello (2001). 
también ha mantenido una política de ampliación de sus actividades y de expansión territorial. Este aspecto es un punto de diferenciación entre ambas, pues el desarrollo de la CAI se ha realizado dentro de las fronteras territoriales aragonesas. Su opción queda, incluso, inicialmente constreñida al ámbito de Zaragoza, para después crecer al resto de la comunidad aragonesa. Si nos fijamos en la tabla III.13 en el número de oficinas por provincias, observamos algunas diferencias importantes en cuanto a la presencia de las dos cajas a través de su red comercial.

El peso de Ibercaja es claramente mayor que el de la CAI. Las circunstancias históricas hicieron que esto haya sido así, pero también las decisiones de sus gestores, que desde hace ya tiempo han hecho una apuesta por convertirla en una caja de referencia en el conjunto de la CECA y en las zonas de influencia del entorno de Aragón. Así lo demuestra su presencia en el conjunto de España: mientras que la CAI sólo posee en 1999 la oficina de rigor en la capital del Estado Ibercaja mantiene en el mismo año 472 oficinas fuera de Aragón.

TABLA III.14

DISTRIBUCIÓN DE LA RED DE OFICINAS DE CAI

E IBERCAJA EN EL RESTO DE ESPAÑA, 1999

\begin{tabular}{|l|c|c|}
\hline Otras provincias & CAI & Ibercaja \\
\hline Albacete & & 1 \\
Alicante & & 5 \\
Barcelona & & 19 \\
Burgos & & 3 \\
Castellón & & 10 \\
Girona & & 1 \\
Guadalajara & & 58 \\
La Rioja & & 110 \\
Lleida & 1 & 45 \\
Madrid & & 162 \\
Navarra & & 12 \\
Soria & & 3 \\
Tarragona & & 2 \\
Toledo & & 33 \\
Valencia & & 472 \\
Total & 1 & \\
\hline
\end{tabular}

FUENTE: Informe Anual 1999, CAl, e Informe Anual 1999, Ibercaja 
En consecuencia, Ibercaja tiene una política de expansión territorial bastante evidente y que encaja con anteriores denominaciones. Recuérdese que era la Caja de Ahorros y Monte de Piedad de Zaragoza, Aragón, Rioja y Guadalajara. Estos territorios, con ese orden (110 oficinas en La Rioja y 58 en Guadalajara) y sumados a su expansión hacia el Mediterráneo (33 oficinas en Valencia) y a Madrid (162 oficinas) definen la presencia fundamental de la entidad en el conjunto de España. En los casos de Soria, Tarragona y Navarra, que están en la zona de influencia de Zaragoza, es evidente que las cajas locales se han encargado de controlar el sector con una presencia desigual de Ibercaja, con oficinas estratégicamente ubicadas.

Si contrastamos el peso de las dos cajas aragonesas en el conjunto del sector español de cajas de ahorro, nos encontramos con algunos datos interesantes. Por ejemplo, viendo la tabla III.15 y a pesar de que demográficamente pintamos poco en el conjunto de España, las cajas aragonesas están en la parte alta de la cuota de mercado

TABLA III.15

CAJAS DE AHORROS EN ESPAÑA. DISTRIBUCIÓN

DEL NÚMERO DE OFICINAS EN EL CONJUNTO, 1999

\begin{tabular}{|l|c|c|}
\hline Comunidad autónoma & Número de cajas & Número de oficinas \\
\hline Andalucía & 6 & 2.702 \\
Aragón & 2 & 741 \\
Asturias & 1 & 220 \\
Baleares & 2 & 447 \\
Canarias & 2 & 421 \\
Cantabria & 1 & 207 \\
Castilla-León & 6 & 834 \\
Castilla-La Mancha & 2 & 1.365 \\
Cataluña & 10 & 4.452 \\
Com. Valenciana & 4 & 1.708 \\
Extremadura & 2 & 545 \\
Galicia & 1 & 1.032 \\
Madrid & 2 & 1.978 \\
Murcia & 2 & 474 \\
Navarra & 3 & 312 \\
País Vasco & 1 & 632 \\
La Rioja & - & 249 \\
Ceuta y Melilla & 49 & 12 \\
Total & & 18.331 \\
\hline
\end{tabular}

FUENTE: Confederación Española de Cajas de Ahorros (CECA, 1999) 
III.2.2. Clasificación de las actividades de la obra social de las cajas de ahorros

Independientemente de la extensión y amplitud de la red de cada una de las entidades, el punto fundamental — donde se sustenta la razón de ser de cualquiera de las dos cajas aragonesas- es su obra social. Como ya hemos señalado, no son simples bancos pensados para ganar dinero y lucrarse con los beneficios de los juegos financieros. Las cajas no están en nuestra sociedad para especular y ganar más mercado con el fin único del rendimiento económico. Las cajas surgieron para romper con el capitalismo oligárquico imperante en España, especialmente para evitar la perversidad de la usura y de unos mercados financieros controlados por unos pocos grupos aristocráticos renuentes al cambio del statu quo.

La obra social es, por tanto, el punto crucial donde cada caja tiene que mostrar su compromiso con la sociedad, asunto que, con el nuevo marco jurídico, está en vías de redefinición y posiblemente de cambio. De momento, con los datos disponibles, tenemos las tablas III.16, III.17 y III.18, que nos presentan los recursos económicos gestionados. También es cierto que sólo son cifras que hablan de dinero y nada de su impacto social. Damos por supuesto que a mayor volumen de fondos destinados, más resultados socialmente contrastables. Pero esto es una simple suposición, que debe ser evaluada. A medida que el nuevo marco jurídico dé paso a la intervención política en las pautas de las obras sociales, será más necesario auditar socialmente los resultados de los fondos destinados.

TABLA III.16

DISTRIBUCIÓN DE LOS RECURSOS DE LA CAI POR ÁREAS DE ACTIVIDAD EN 2000, 1999 Y 1998, EN MILLONES DE PESETAS

\begin{tabular}{|l|r|r|r|r|r|r|}
\hline \multirow{2}{*}{ Área de Actividad } & \multicolumn{2}{|c|}{$2000^{a}$} & \multicolumn{2}{c|}{1999} & \multicolumn{2}{c|}{1998} \\
\cline { 2 - 7 } & Número & \multicolumn{1}{c|}{$\%$} & Número & $\%$ & Número & $\%$ \\
\hline Área cultural & 473,4 & 29,61 & 470,8 & 37,21 & 545,7 & 47,24 \\
Área deportiva & 16,9 & 1,06 & 19,5 & 1,54 & 15,6 & 1,35 \\
Área docente & 127,6 & 7,98 & 114,3 & 9,03 & 115,4 & 9,99 \\
Área investigación & 75,4 & 4,72 & 49,8 & 3,94 & 28,2 & 2,44 \\
Área formación profesional & 128,8 & 8,06 & 154,3 & 12,19 & 140,1 & 12,13 \\
Área asistencial y sanitaria & 613,9 & 38,40 & 305,7 & 24,16 & 160,8 & 13,92 \\
Amortizaciones inmovilizado & 162,8 & 10,18 & 150,9 & 11,93 & 149,4 & 12,93 \\
Total & 1598,8 & 100 & 1265,3 & 100 & 1155,2 & 100 \\
\hline
\end{tabular}

a Presupuesto.

FUENTE: Elaboración propia a partir del Informe Anual 1999 y 1998, CAI 
TABLA III.17

DISTRIBUCIÓN DE LOS RECURSOS DE IBERCAJA POR ÁREAS DE ACTIVIDAD EN 2000, 1999 Y 1998, EN MILLONES DE PESETAS

\begin{tabular}{|l|r|r|r|r|r|r|}
\hline \multirow{2}{*}{ Área de actividad } & \multicolumn{2}{|c|}{$2000^{a}$} & \multicolumn{2}{c|}{1999} & \multicolumn{2}{c|}{1998} \\
\cline { 2 - 7 } & Número & $\%$ & Número & $\%$ & Número & $\%$ \\
\hline Área cultural & 2394,0 & 47,88 & 2247,0 & 53,46 & 1806,0 & 47,53 \\
Área docente & 650,0 & 13,00 & 660,0 & 15,70 & 555,0 & 14,61 \\
Área asistencial y sanitaria & 986,0 & 19,72 & 866,0 & 20,60 & 989,0 & 26,03 \\
Área medio ambiente & 420,0 & 8,40 & 430,0 & 10,23 & 319,0 & 8,39 \\
Previsiones nuevas actividades & 550,0 & 11,00 & & & 131,0 & 3,45 \\
Total & 5000,0 & 100,00 & 4203,0 & 100,00 & 3800,0 & 100,00 \\
\hline
\end{tabular}

a Presupuesto.

FUENTE: Elaboración propia a partir del Informe Anual 1999 y 1998, CAI

TABLA III.18

DISTRIBUCIÓN DE LOS RECURSOS DE LAS CAJAS DE AHORROS ESPAÑOLAS POR ÁREAS SOCIALES EN 1998, EN MILLONES DE PESETAS

\begin{tabular}{|l|r|r|}
\hline Área de actividad & \multicolumn{1}{|c|}{ Pesetas } & $\%$ \\
\hline Área cultural & $57.358,7$ & 48 \\
Área docente & $23.700,2$ & 19,9 \\
Área sanitaria & $3.186,4$ & 2,7 \\
Área asistencial & $32.406,2$ & 27,1 \\
Área investigación & $2.747,8$ & 2,3 \\
Total & $119.399,3$ & 100 \\
\hline
\end{tabular}

FUENTE: Memoria Obra Social 1998, CECA

Hasta el momento nos encontramos con que las dos cajas aragonesas están orientadas de forma divergente, ya que CAI opta por quedarse en Aragón, mientras que Ibercaja ha decidido seguir creciendo más allá de las fronteras originales. No obstante, existen similitudes de fondo de las áreas de ejecución de cada obra social, ya que cada una de ellas tiene su propia impronta social. En el caso de Ibercaja, se concentran en cuatro áreas que incluyen elementos de los desagregados en CAI. De éstas destaca por su relativa innovación el peso del medio ambiente, aunque sea de modo superficial y más como una moda en lo aparente que como algo que sea así en el resto de la entidad. ${ }^{42}$ La obra social de la CAI no

42 A este respecto, como valoración rápida, si una entidad realmente se compromete con un área de actuación tiene que ser coherente tanto en lo explícito como en lo implícito, es decir, en aquello que "dona" y en aquello donde hace negocio... Una auditoría social daría cuentas de lo que decimos. 
considera como elemento separado la cuestión del medio ambiente, si bien es cierto que tiene programas ${ }^{43}$ de actuación en ese sentido. Esto es similar a lo que sucede con la investigación y la formación profesional, en este caso con categoría propia y como apuesta modesta de la CAI. Al contrario que en el organigrama de Ibercaja, aquí aparecen como actividades incluidas en otras áreas y sin un marco propio de ejecución.

Mirando en conjunto al sector, se observa que el comportamiento de las cajas aragonesas es paralelo al del resto de España, al menos con los datos de 1998. Así, encontramos el predominio del área cultural en todo el Estado, seguida de la asistencia y sanidad, para culminar con el docente.

\section{III.2.3. Evolución de la obra social de las cajas de ahorros}

Actualmente, la legislación vigente es la que marca las cantidades destinadas por las cajas a la realización de su obra social. En este sentido, las variaciones que se han dado con el paso del tiempo no son un dato sobre el que podamos aportar mucho, salvo reclamar una mayor cuantía como ciudadanos y como impositores o usuarios de estas entidades.

TABLA III.19

EVOLUCIÓN EN PORCENTAJE DE LA DISTRIBUCIÓN DE LOS RECURSOS A LA OBRA SOCIAL POR LA CAI, 1990-2000

\begin{tabular}{|c|c|c|c|c|c|c|c|c|c|c|c|}
\hline Área de actividad & 1990 & 1991 & 1992 & 1993 & 1994 & 1995 & 1996 & 1997 & 1998 & 1999 & $2000^{x}$ \\
\hline Área cultural & 32,71 & 34,70 & 22,68 & 30,74 & 34,76 & 52,02 & 43,90 & 36,26 & 47,24 & 37,21 & 29,61 \\
\hline deportiva & 2,28 & 0,76 & 1,14 & 2,39 & 1,99 & 1,03 & 1,28 & 1,62 & 1,35 & 1,54 & 1,06 \\
\hline Área docente & 4,80 & 5,17 & 3,16 & 5,82 & 5,64 & 6,83 & 6,63 & 7,66 & 9,99 & 9,03 & 7,98 \\
\hline Área invest & 4,91 & 4,07 & 1,95 & 4,93 & 3,12 & 2,94 & 4,46 & 4,89 & 2,44 & 3,94 & 4,72 \\
\hline Área formación profesional & 26,19 & 23,18 & 57,82 & 28,58 & 29,39 & 15,96 & 8,14 & 13,67 & 12,13 & 12,19 & 8,06 \\
\hline Área as & 20,55 & 21,80 & 5,61 & 11,78 & 9,83 & 7,61 & 21,52 & 22,37 & 13,92 & 24,16 & 38,40 \\
\hline Amortizacion inmovilizado & 8,56 & 10,33 & 7,64 & 15,77 & 15,27 & 13,61 & 14,07 & 13,52 & 12,93 & 11,93 & 10,18 \\
\hline Total ${ }^{b}$ & 619 & 698,3 & 912,2 & 653 & 782 & 983,2 & 1008,9 & 1034,7 & 1155,2 & 1265,3 & 1598,8 \\
\hline
\end{tabular}

a Presupuesto.

b En millones de pesetas.

FUENTE: Elaboración propia a partir de los informes anuales de 1990, 1991,1992, 1993 y 1994, CAI

43 Un ejemplo es la colaboración con la fundación en defensa del quebrantahuesos. 


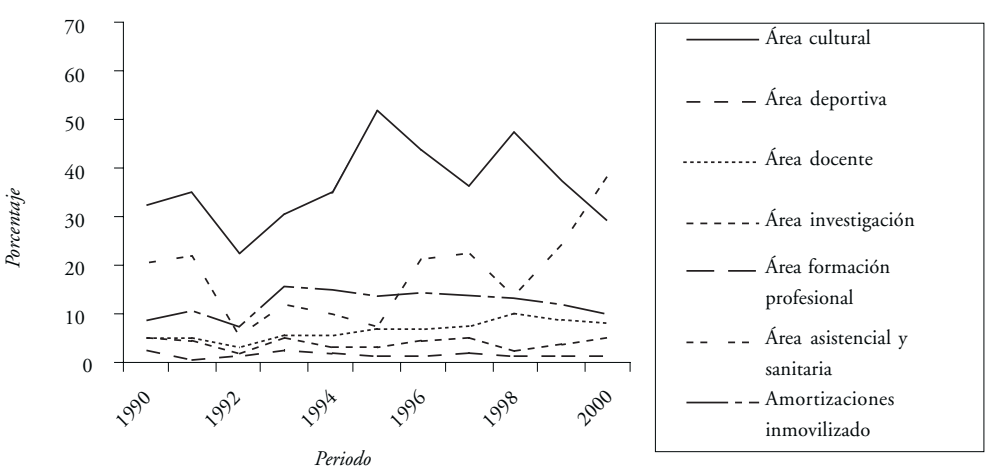

Sin embargo, sí que nos parece más interesante ver la distribución de los recursos a lo largo del tiempo en la obra social tanto de la CAI como de Ibercaja. Las tablas III.19 y III.20 detallan las cifras para cada una de ellas. En primer lugar vemos las de CAI, para la década de los noventa.

La gráfica III.3 nos permite aclarar visualmente la evolución de los valores que recogen las tablas.

TABLA III.20

EVOLUCIÓN EN PORCENTAJE DE LA DISTRIBUCIÓN DE LOS RECURSOS A LA OBRA SOCIAL POR IBERCAJA, 1990-2000

\begin{tabular}{|l|c|c|c|c|c|c|c|c|c|c|c|}
\hline Área de Actividad & 1990 & 1991 & 1992 & 1993 & 1994 & 1995 & 1996 & 1997 & 1998 & 1999 & $2000^{2}$ \\
\hline Área cultural & 48,28 & 48,35 & 50,67 & 54,28 & - & - & - & 53,77 & 47,53 & 53,46 & 47,88 \\
Área cultural y formación & - & - & - & - & 67,80 & 73,02 & 68,67 & & & & \\
Área docente & 10,92 & 15,99 & 12,89 & 10,98 & - & - & - & 12,50 & 14,61 & 15,70 & 13,00 \\
Área asistencial & 26,44 & 22,30 & 22,85 & 21,53 & 20,61 & 16,39 & 17,28 & 20,93 & 26,03 & 20,60 & 19,72 \\
Área sanitaria & 11,99 & 11,26 & 8,30 & 7,20 & 6,21 & 5,27 & 5,28 & - & - & - & - \\
Área medio ambiente & - & - & - & - & - & - & - & 4,43 & 8,39 & 10,23 & 8,40 \\
Otras: obra en colaboración & & & & & & & & & & & \\
$\quad$ no especificada & 2,38 & 2,10 & 5,30 & 6,02 & 5,39 & 5,32 & 8,77 & 8,37 & 3,45 & - & 11,00 \\
Total & 1.218 & 1.332 & 1.265 & 1.612 & 1.708 & 1879 & 1950 & 3000 & 3800 & 4203 & 5000 \\
\hline
\end{tabular}

a Presupuesto.

b En millones de pesetas.

FUENTE: Elaboración propia a partir de los informes anuales de 1990, 1991,1992, 1993 y 1994, CAI 
A continuación ofrecemos los mismos datos para el caso de Ibercaja, donde, además se pueden ver los años donde se modifican las áreas de la obra social.

La gráfica III.4 es más expresiva y permite captar con más facilidad la evolución que las dos tablas anteriores.

GRÁFICA III.4

EVOLUCIÓN OBRA SOCIAL IBERCAJA

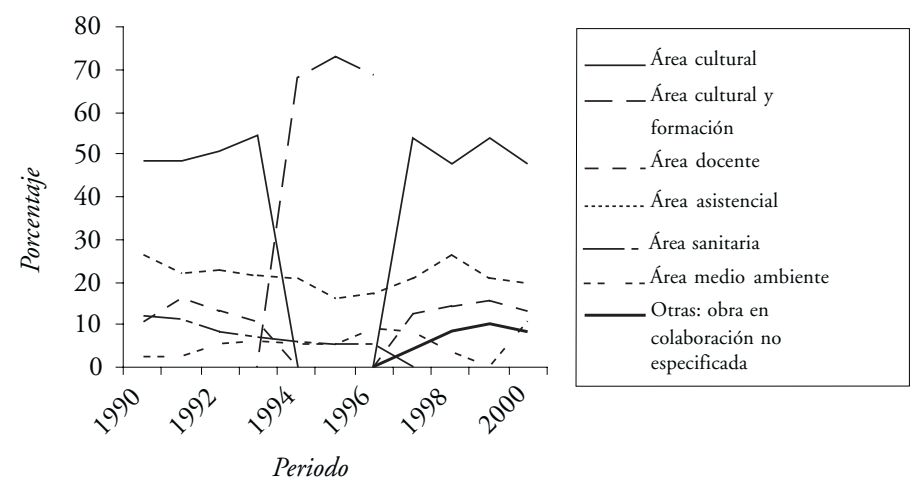

\section{III.2.4. Las personas}

Comparadas con las otras ONL, el peso específico de las personas implicadas en estas entidades es de un tipo distinto a las asociaciones, fundaciones y cooperativas. Las cajas tienen muy institucionalizados sus ritmos. Son organizaciones cuya burocracia interna ya garantiza su vida propia. Se convierten en sistemas estructurados donde el individuo común tiene un papel poco relevante, aunque, como repetimos desde el comienzo, son las personas las que configuran y dan forma a la entidad. En ambos casos - CAI e Ibercaja —, los impositores y usuarios tenemos poco margen de maniobra. No pasamos de ser meros clientes que interesan en cuanto proporcionan una cuota de mercado... y poco más.

El peso fundamental recae en los cuadros de gestión dentro del gran conjunto de trabajadores de la entidad. La estructura interna de estas entidades es jerarquizada y con pocos resquicios para la participación democrática asamblearia en la toma de decisiones. La nueva vía de participación fijada por la ley aragonesa tampoco ha abierto cauces que rompan con los moldes y pautas establecidas. 
Si vemos los datos para cada una de ellas nos encontramos con la diferencia de tamaño más importante de ambas cajas, además del volumen de negocio que mueven.

En el caso de CAI, el total de empleados asciende a 1225. Además de la Asamblea General, formada por los representantes fijados por la nueva legislación aragonesa en la materia, el Consejo de Administración está formado por diecisiete consejeros y la Comisión de Control por nueve miembros.

Respecto de la segunda caja, Ibercaja, tiene un total de empleados de 3734. Supone más del triple que en el caso anterior y representa una de las «empresas» más destacadas de nuestra comunidad. Los puestos de trabajo que ocupan esas personas se distribuyen geográficamente según muestra la tabla III.21.

TABLA III.21

DISTRIBUCIÓN GEOGRÁFICA DE LA PLANTILLA DE IBERCAJA, 1999

\begin{tabular}{|l|r|r|}
\hline Zonas & Número & \multicolumn{1}{c|}{$\%$} \\
\hline Huesca & 297 & 7,95 \\
Teruel & 219 & 5,87 \\
Zaragoza & 916 & 24,53 \\
Departamentos Centrales & 632 & 16,93 \\
Aragón & 2.604 & 55,28 \\
Comunidad Autónoma de la Rioja & 263 & 7,04 \\
Comunidad Autónoma de Navarra & 45 & 1,21 \\
Provincia de Burgos & 15 & 0,40 \\
Provincia de Soria & 12 & 0,32 \\
Zona norte & 335 & 8,97 \\
Provincia de Guadalajara & 194 & 5,20 \\
Comunidad Autónoma de Madrid & 654 & 17,51 \\
Provincia de Toledo & 7 & 0,19 \\
Zona centro & 855 & 22,90 \\
Provincia de Barcelona & 97 & 2,60 \\
Provincia de Girona & 3 & 0,08 \\
Provincia de Lleida & 119 & 3,19 \\
Provincia de Tarragona & 36 & 0,96 \\
Cataluña & 255 & 6,83 \\
Provincia de Albacete & 3 & 0,08 \\
Provincia de Alicante & 19 & 0,51 \\
Provincia de Castellón & 45 & 1,21 \\
Provincia de Valencia & 158 & 4,23 \\
Valencia & 225 & 6,03 \\
\hline
\end{tabular}

FUENTE: Informe Anual 1999, Ibercaja 
TABLA III.22

ASAMBLEA GENERAL DE IBERCAJA, 1999

\begin{tabular}{|l|r|}
\hline & Número \\
\hline Consejeros Generales en representación de los impositores & 60 \\
Circunscripción de Huesca & 8 \\
Circunscripción de Teruel & 7 \\
Circunscripción de Zaragoza & 29 \\
Circunscripción de La Rioja & 8 \\
Circunscripción de Guadalajara & 4 \\
Circunscripciones de Barcelona, Girona y Lleida & 2 \\
Circunscripciones de Valencia, Navarra, Tarragona, & 2 \\
$\quad$ Castellón, Soria, Burgos, Alicante y Toledo & 15 \\
Consejeros Generales en representación de la Entidad Fundadora & 11 \\
Consejeros Generales en representación del Personal & 71 \\
Consejeros Generales en representación de Corporaciones Municipales & 157 \\
Total & \\
\hline
\end{tabular}

FUENTE: Informe Anual 1999, Ibercaja

En lo que respecta a los órganos de gobierno básicos de Ibercaja, encontramos que la Asamblea General está formada por 157 consejeros, como se puede ver en la tabla III.22. El de Administración está formado por 19 consejeros y la Comisión de Control por 9 miembros.

\section{III.2.5. Datos económicos}

Para terminar, ahora sólo queremos recordar algunos datos que son relevantes para valorar la importancia de estas ONL de interés particular. Si tomamos el caso de la caja aragonesa de mayor tamaño, vemos que el volumen de negocio de Ibercaja asciende a 2560611 millones de pesetas en 1999 , con un crecimiento del 10,41 \%. Éste es el total de los recursos que la caja administra de sus clientes. En el año 1999, el beneficio después de impuestos fue de 20562 millones de pesetas, con un incremento de un $8,67 \%$. La dotación a la obra social fue de 5000 millones.

En esta línea es destacable el fuerte incremento del activo experimentado por Ibercaja en el ejercicio 1999, aproximadamente un $15 \%$ (pasando de 1760738 a 2021146 millones de pesetas), lo que se debe en gran parte al aumento de las inversiones crediticias (de 1086596 millones de pesetas a 1257708 , un $15 \%$ aproximadamente). 
Conjuntamente, se observa una ligera disminución de la rentabilidad económica (el beneficio neto sobre activos totales medios es en 1998 de 1,21, mientras que en el año 1999 es de 1,11) y de la rentabilidad sobre recursos propios (el beneficio neto sobre recursos propios pasa de 17,51 en 1998 a 17,24 en 1999).

Un dato detectado es el incremento de productividad por empleado, medido en beneficio antes de impuestos sobre número de empleados; éste ha pasado de 6,05 a 6,61.

En el segundo caso, el volumen de negocio de la CAI se sitúa en 659457 millones de pesetas en 1999. El crecimiento con respecto al año anterior fue del 2,31\%. El beneficio después de impuestos ascendió a 7183 millones, lo que supone un incremento del 6,54\%. La dotación a la obra social fue de 1600 millones.

En relación con Ibercaja, el crecimiento del activo ha sido más modesto en los dos ejercicios observados, de forma que ha pasado de 644559 millones de pesetas en 1998 a 659457 en el año 1999 (un 2,3\%). No obstante, las inversiones crediticias sí que se han incrementado de forma importante, pasando de 373980 millones de pesetas a 415277 en el año 1999 (un 11 \%).

De la misma forma que Ibercaja, la CAI ha sufrido un ligero descenso en las dos ratios de rentabilidad más significativas. Así, la rentabilidad económica ha pasado de 1,17 a 1,13 , y la rentabilidad sobre recursos propios ha descendido en 1999 a 12,91, desde el 13,7 del año 1998.

Por último, en relación con la productividad por empleado, medida por el beneficio antes de impuestos sobre el número de empleados, podemos señalar que la CAI ha pasado de 8,4 en 1998 a 8,56 en 1999, lo que mantiene un tendencia de incremento, basada en una mayor productividad que Ibercaja.

De los datos económicos de ambas entidades se desprende que tanto Ibercaja como CAI se encuentran en una excelente posición y saneamiento financiero, así como que, independientemente de sus políticas de entidad, ambas recogen una gran parte del ahorro y de los créditos de familias y empresas aragonesas.

Estamos, pues, ante dos ONL cuyo impacto social, económico y político en Aragón es más que relevante. Se convierten en piezas clave de la vertebración del país, de nuestra vida cotidiana y del futuro. 


\section{CAPÍTULO IV \\ LA REALIDAD DEL SECTOR NO LUCRATIVO EN ARAGÓN: LAS ORGANIZACIONES NO LUCRATIVAS DE INTERÉS GENERAL}

En el conjunto de las organizaciones no lucrativas de interés general hemos incluido las figuras jurídicas de asociaciones y fundaciones. ${ }^{44}$ En un análisis preliminar observamos claras diferencias en las actividades desarrolladas por las fundaciones y las asociaciones. Dichas diferencias no atañen sólo a su ordenamiento y personalidad jurídica — como quedó constatado en el capítulo anterior-, sino también a su modus operandi, esto es a su modo de proceder o dicho de otro modo, a su cultura de actuación.

Las asociaciones deben perseguir - al igual que las fundacionesfines de interés social en un sentido amplio, como se expresa en la Ley 30/1994 de Fundaciones, en el artículo 42 del título II: «asistencia social, cívicos, educativos, culturales, científicos, deportivos, sanitarios, de cooperación para el desarrollo, de defensa del medio ambiente, de fomento de la economía social o de la investigación». Pero, a diferencia de las fundaciones, las asociaciones tienen como principal factor de funcionamiento el capital humano aportado por sus socios que en las fundaciones es secundario. Éstas necesitan un patrimonio mínimo para su constitución que tiene adscritos los fines perseguidos por la fundación. La asociación depo-

\footnotetext{
44 Considerando la nueva ley de cooperativas aragonesas, se deberían incluir aquí las cooperativas de iniciativa social y las de servicios sociales, pero en el momento de realizar el estudio solamente se cuenta con tres de iniciativa social y ninguna de servicios sociales.
} 
sita en la asamblea general de socios las decisiones fundamentales para su funcionamiento, y en ella cada socio tiene un voto.

Las asociaciones y, a partir de éstas, el movimiento asociativo reflejan el dinamismo de una sociedad. El capital humano de las primeras es un contrapunto del capital social ${ }^{45}$ de la segunda. En suma, muestran la capacidad que tiene el conjunto de la ciudadanía de organizarse y dar cauce a sus propuestas ante la vida en sociedad, ya sean demandas, necesidades, urgencias o preocupaciones puramente diletantes. Vistas desde fuera se manifiestan como un entramado de relaciones sociales que se mueven al ritmo que los sujetos implicados van trazando. Por eso en sus acciones, resultados y concreciones sociales definen un reservorio de riqueza de la sociedad en cuestión. A mayor capacidad organizativa y a mayor capacidad de respuesta colectiva, mayor capital social disponible..., más personas implicadas. Las fundaciones también pueden ser y organizarse de modo similar a una asociación, aunque los requisitos básicos ${ }^{46}$ determinan que sean menos. Por eso encontramos aproximadamente más de diez mil asociaciones frente a 183 fundaciones.

Así pues, cuando nos planteamos el diseño del trabajo de campo consideramos que debíamos mantener una clara distinción entre las distintas figuras jurídicas, en especial las asociaciones y las fundaciones. Desechamos reunir en un mismo cuestionario ambas realidades — aunque el horizonte ha sido una misma estrategia de investigación-, porque contábamos con trabajos anteriores donde ya habíamos observado que el tratamiento analítico tiende a producir conclusiones poco claras y en ocasiones sesgadas. Por ello, optamos por estudiar los dos tipos de entidades de forma independiente, sin renunciar a las comparaciones que resulten enriquecedoras para conocer el sector no lucrativo en Aragón.

Es más, al separar las asociaciones del ámbito de las fundaciones, acentuamos un objetivo, esto es, concretar si existen diferencias de comportamiento entre las asociaciones y las fundaciones aragonesas. Paralelamente, el análisis nos permitirá observar comportamientos específicos en

45 Estamos en un período en el cual se está reflexionando sobre los conceptos de capital social (Moneva y Ch. Marcuello, 2001).

46 Un patrimonio mínimo de un millón de pesetas en el caso aragonés y que los patronos hagan realidad la voluntad de los fundadores sin poder modificarla. 
cada uno de los ámbitos. La estructura seguida para el análisis previo de los datos procedentes de los registros se ha fijado en los siguientes elementos:

- Número y distribución geográfica.

- Clasificación.

- Evolución temporal de la creación de estas organizaciones.

No hay muchas más alternativas, puesto que éstas son las únicas variables disponibles en los registros. Cuando se constituye una asociación, se incorporan al registro los siguientes datos: denominación, fines de la entidad, fecha de creación y domicilio, así como el presupuesto inicial. Es decir, el análisis de los datos desde los registros limita las posibilidades de profundizar en este sector. Para superar tales limitaciones ha sido necesario realizar una encuesta, ${ }^{47}$ junto con entrevistas en profundidad y grupos de discusión, a las entidades aragonesas, tanto fundaciones como asociaciones, con el objeto de incorporar nuevos elementos que nos permitan trazar a través de la cuantificación una parte de las características de este sector.

El estudio de la distribución geográfica servirá para detectar concentraciones de entidades por sectores geográficos y, de acuerdo con las características propias de cada zona, plantear y/o descartar posibles interacciones con otros factores, como la cuestión demográfica, que expliquen la existencia de asociaciones y fundaciones en dicho entorno.

Alternativamente, la valoración de la actividad realizada en Aragón por este tipo de actores sociales nos ayudará a conocer no sólo las iniciativas en términos generales, sino las demandas y necesidades de carácter cultural, deportivo, asistencial, educativo..., que la sociedad aragonesa muestra, denuncia y pretende atender desde su tercer sector.

En cuanto a la valoración de los cambios producidos con el paso del tiempo y a la evolución social, consideramos que son indicadores del dinamismo de estas entidades en la sociedad aragonesa.

47 La muestra de asociaciones de las que se dispone de información es de 194 y es representativa del total de asociaciones para un intervalo de confianza del $95,5 \%$ y un error de estimación del $7 \%$. La muestra de fundaciones es de 16 de un total de 183 entidades, lo que representa un $8,7 \%$. No es representativa de la población de fundaciones, por lo que se tratará como una aproximación. 
Para completar la descripción cuantitativa del sector asociativo, nos detendremos en los resultados de la encuesta realizada a las asociaciones aragonesas. A partir de esta encuesta queremos aproximarnos y estimar el tamaño del sector asociativo. Así, en primer lugar nos referimos al alcance geográfico de estas entidades a través de la valoración de los lugares, ya sea desde el propio municipio o en el ámbito internacional, donde desarrollan sus programas de actuación. Seguidamente, dedicamos una especial atención a las personas que están relacionadas con la vida de las entidades: 1) Los socios, como grupo de personas que constituyen el soporte fundamental para que existan las entidades. 2) Los receptores o usuarios, como razón de ser de estas organizaciones - a través de los cueles podemos ver su incidencia social-. 3) El colectivo de voluntarios y el del personal contratado. Finalmente, los datos económicos sobre ingresos, gastos e infraestructura son fundamentales para conocer el impacto económico de estas asociaciones.

\section{IV.1. Las asociaciones aragonesas}

Si pretendemos describir la realidad de dichas organizaciones, una pregunta de partida es cuántas hay y cómo se reparten en este extenso y despoblado territorio aragonés. Es un planteamiento común y repetido: vivimos bajo el encantamiento de las cifras y de la cuantificación. Pero es la manera más aceptada de hacernos cargo del peso social que tienen. Por eso, dado que queremos realizar una descripción de las asociaciones en Aragón, uno de los elementos a tener en cuenta es el análisis de la concentración geográfica de la actividad de las asociaciones por provincias.

\section{IV.1.1. Número de asociaciones y distribución geográfica}

Los datos proporcionados desde los registros son poco descriptivos y es difícil acotar en qué provincia centraliza cada asociación sus actividades o, al menos, el mayor porcentaje de sus proyectos. Por eso, nos hemos visto obligados a asignar la actividad asociativa a la provincia en la que se ha realizado su domiciliación. Como resultado, en la tabla IV.1 se aprecia que la mayoría de este tipo de actividades se desarrolla, obviamente, en la provincia de Zaragoza y, de forma destacada, en su capital. 
TABLA IV.1

NÚMERO DE ASOCIACIONES CONSTITUIDAS

(Los datos de los registros están actualizados hasta noviembre de 2000)

\begin{tabular}{|l|c|c|c|c|c|c|}
\hline Aragón & \multicolumn{2}{|c|}{ Huesca } & \multicolumn{2}{c|}{ Teruel } & \multicolumn{2}{c|}{ Zaragoza } \\
\hline Número & Número & \% Aragón & Número & $\%$ Aragón & Número & $\%$ Aragón \\
\hline 11969 & 1937 & 16,18 & 1307 & 10,92 & 8725 & 72,90 \\
\hline
\end{tabular}

FUENTE: Registros de asociaciones de Zaragoza, Huesca y Teruel

Esta composición responde, básicamente, a la estructura demográfica de Aragón. Pero son datos que no nos permiten decir mucho más sobre la realidad del sector. De hecho, es muy aventurado ofrecer alguna conclusión relevante a partir del único dato del número de entidades. Así las cosas, lo que esto significa es que no sabemos nada de los recursos utilizados, tamaño, alcance o número de beneficiarios, por lo que cualquier observación basada exclusivamente en el número debe tomarse con mucha precaución.

Ése, y no otro, es el sentido de los índices de densidad asociativa en los que se calcula el número de asociaciones en función de la población de referencia. Sólo nos muestran una primera impresión de la realidad social, que, en esta ocasión, se encuentra por encima de la media, ya que en 1996 se sitúa para España en torno a 4,5 asociaciones por cada mil habitantes. Una posible explicación de esta importante diferencia es que los registros están incluyendo entidades que no están activas y distorsionan notablemente el resultado que ya hemos comentado.

TABLA IV.2

NÚMERO DE ASOCIACIONES CONSTITUIDAS Y POBLACIÓN ARAGONESA, 2000

\begin{tabular}{|c|c|c|c|c|}
\hline Población & Aragón & Huesca & Teruel & Zaragoza \\
\hline Población total $^{a}$ & 1.183 .234 & 204.956 & 136.840 & 841.438 \\
\hline Población mayor de 18 años ${ }^{b}$ & 1.019 .679 & 178.747 & 118.381 & 722.551 \\
\hline $\begin{array}{l}\text { Número de asociaciones } \\
\text { por cada } 1.000 \text { hab. }\end{array}$ & 10,1 & 9,5 & 9,6 & 10,4 \\
\hline Número de asociaciones & & & & \\
\hline por cada 1.000 hab. mayor de 18 años & 11,7 & 10,8 & 11,0 & 12,1 \\
\hline
\end{tabular}

a Censo de población 1996

b Censo electoral, elecciones marzo de 2000.

FUENTE: Registros de asociaciones de Zaragoza, Huesca y Teruel; INE 
TABLA IV.3

DISTRIBUCIÓN DE LAS ASOCIACIONES CONSTITUIDAS, DIFERENCIANDO CAPITAL DE PROVINCIA Y RESTO DE LA PROVINCIA

(Los datos de los registros están actualizados hasta noviembre de 2000)

\begin{tabular}{|l|c|c|c|c|c|c|}
\hline \multirow{2}{*}{} & \multicolumn{2}{|c|}{ Huesca } & \multicolumn{2}{c|}{ Teruel } & \multicolumn{2}{c|}{ Zaragoza } \\
\cline { 2 - 7 } & Capital & $\begin{array}{c}\text { Resto de la } \\
\text { provincia }\end{array}$ & Capital & $\begin{array}{c}\text { Resto de la } \\
\text { provincia }\end{array}$ & Capital & $\begin{array}{c}\text { Resto de la } \\
\text { provincia }\end{array}$ \\
\hline Número & 1541 & 396 & 288 & 1019 & 5792 & 2933 \\
\% sobre el total de Aragón & 12,87 & 3,31 & 2,41 & 8,51 & 48,39 & 24,50 \\
\% sobre la provincia & 79,56 & 20,44 & 22,04 & 77,96 & 66,38 & 33,62 \\
\hline
\end{tabular}

FUENTE: Registros de asociaciones de Zaragoza, Huesca y Teruel

Más allá de esas cuestiones, sí que se observan algunos detalles de interés. Por ejemplo, si nos fijamos en la tabla IV.3, se percibe que Aragón tiene una densa trama de asociaciones desplegadas tanto dentro como fuera de las capitales provinciales. Además de la distorsión que provoca Zaragoza, en Teruel y Huesca se ve que la vida asociativa está activa y dinámica. A medida que vayamos entrando en materia podremos ir precisando más rasgos.

Por eso ahora sólo conviene destacar la distribución discordante dentro de las provincias aragonesas. En Huesca está totalmente polarizada la presencia de asociaciones en la capital, con un $80 \%$. En Teruel el $78 \%$ de las asociaciones se encuentran fuera de la capital de la provincia. En Zaragoza se produce una redistribución más equilibrada: el $66 \%$ de las asociaciones se ubica en la capital y el $34 \%$ en el resto de la provincia. Todo ello confirma la percepción de las gentes y las valoraciones de las personas implicadas en cada caso.

Por un lado, hemos constatado que las asociaciones del mundo rural aragonés tienden a ser distintas según los contextos orográficos. Los tópicos que distinguen entre la montaña y el llano, la ribera y el resto, la estepa, los somontanos y los valles definen modos de acción que, a pesar de los cambios experimentados, mantienen estructuras de funcionamiento social desde las cuales se construyó el cliché. Los propios actores resaltan algunos estereotipos que no necesariamente coinciden con la realidad, pero que existen y funcionan en el imaginario colectivo. Por ejemplo, en el caso de Teruel se habla de dos universos distintos: la provincia rica y la provincia pobre. Unos atribuyen a otros mayor riqueza y con ello más actividades y capacidades para auto-organizarse. Otros achacan la inactividad 
de una ciudad y su entorno a una clase funcionaria que constituye una ciudad de burócratas poco dada a las innovaciones y muy resistente a la generación de dinámicas asociativas. Sin embargo, quizá estamos asistiendo o llegando a un momento de cambio con la Plataforma Teruel Existe. Sólo desde este aire nuevo y fresco, parecen romperse inercias de resignación desolada que han ido arraigándose a medida que los pueblos y su vida se marchaban a otros lugares. A la parte rica de la provincia se le atribuyen unas inercias seculares de actividad económica y social independientes de estímulos externos, lo cual tampoco está lejos de la percepción que tienen de sí mismos sus habitantes. Alcañiz y su área de influencia presentan unas estructuras vitales distintas del resto de la provincia.

En los núcleos rurales que se mantienen vivos también se percibe un modo de interactuar distinto del urbano: «el tipo de gente a mí me parece distinta, la de Teruel ciudad a la gente de los pueblos». Esos signos de distinción se traducen en tendencias asociativas que dinamizan las entidades con modos de comportamiento opuestos: mientras unos «tienden a acumular protagonismos», otros buscan «solucionar cosas juntos». Ambas percepciones se solapan con las visceralidades propias de los núcleos de población pequeños, donde las estructuras de control social son mayores. El reto, de todas maneras, es dar vida a las actividades comunes y planificar para no multiplicar esfuerzos. Quizá el mejor resumen del consenso sobre la cuestión aparece en una de las entrevistas, cuando se dice que «la tarea a hacer es ayudar a la gente que está ahí a descubrir que, si hay algún futuro, pasa por aglutinar en torno a cabeceras comarcales, y aglutinar con un esquema que no machaquemos a los núcleos pequeños, sino que descubramos el potencial que cada núcleo pequeño tiene. Pero no todos; es decir, no hay ningún problema en que para una comarca se planifique una piscina en el pueblo más pequeño, porque, si en Sanidad eso es posible, por qué no en ocio: eso es difícil. Ningún pueblo tiene por sí mismo potencial para tener un equipo de nada, bueno pero juntos a lo mejor sí, puede salir un equipo y llevar a los chavales todas las semanas a competir a los juegos escolares de Teruel, o de Alcañiz o de tal...».

En el caso de la provincia de Huesca, la tradición distingue las gentes de la tierra llana de los montañeses. Éstos mantienen una dosis importante del recelo secular de una sociedad acostumbrada a sobrevivir en un medio duro. Pero también vemos ejemplos muy interesantes de entidades 
que han sido capaces de generar dinámicas de movilización social de largo alcance. Uno de los casos paradigmáticos lo encontramos en la asociación Amigos de Serrablo. No sólo ha conseguido superar con creces los fines de la organización, sino que ha ido más allá de sí misma construyendo un entramado de valores simbólicos que han servido para recrear una identidad colectiva, que después se reproduce en procesos de acción colectiva como el que se genera en torno a una actividad lúdico-deportiva como el cicloturismo de la Quebrantahuesos.

$\mathrm{Al}$ igual que Teruel, Huesca capital tiene un porcentaje muy elevado de funcionarios, pero las inercias sociales son más plurales y activas que en el primer caso. Sin embargo, los actores sociales insisten en algo que también aparecía en la otra provincia: lo que importa son las personas. Y si rastreamos detrás de cada una de las organizaciones, vemos un grupo o incluso a veces un par de personas que son quienes han apostado por un ideal hasta llevarlo a la práctica. En eso el ejemplo de Amigos de Serrablo también es revelador: el impacto de la entidad excede con mucho los recursos humanos y financieros disponibles. Después volveremos sobre el capital humano, las personas que dan vida a las asociaciones, en particular, y a las ONL, en general.

\section{IV.1.2. Clasificación de las actividades de las asociaciones}

En las 11969 organizaciones oficialmente registradas y constituidas ${ }^{48}$ en Aragón nos encontramos con un repertorio de actividades amplio y plural como la propia sociedad aragonesa. Para captar de los perfiles de las asociaciones y de su importancia relativa, es útil establecer una tipología de las asociaciones en función de su actividad. Este criterio se asigna considerando sus objetivos asociativos y, en algunos casos, solapándose con las prácticas reales de las organizaciones.

En la tabla IV.4 se resumen estas claves siguiendo los trece códigos de actividad con los cuales se registran oficialmente las asociaciones. A primera vista, lo que se observa es un predominio de las actividades culturales, de ocio y deportivas por encima de todas las demás, seguidas de un

48 Tras depurar el registro de las entidades duplicadas y ya disueltas y sabiendo que muchas de estas entidades pueden no estar activas. 
grupo numeroso de organizaciones cuyas actividades principales están inscritas en el apartado que corresponde a la educación, formación e investigación, junto con las denominadas de servicios sociales. En el polo opuesto quedan las organizaciones vinculadas a asuntos filantrópicos y las de cooperación internacional — las popularmente conocidas como ONGD-, seguidas de las religiosas y las de salud.

TABLA IV.4

NÚMERO DE ASOCIACIONES CONSTITUIDAS EN ARAGÓN CLASIFICADAS POR TIPO DE ACTIVIDAD

(Los datos de los registros están actualizados hasta noviembre de 2000)

\begin{tabular}{|c|l|r|r|r|r|r|r|r|r|}
\hline \multirow{2}{*}{ Código } & \multirow{2}{*}{ Actividad } & \multicolumn{2}{|c|}{ Aragón } & \multicolumn{2}{|c|}{ Huesca } & \multicolumn{2}{|c|}{ Teruel } & \multicolumn{2}{|c|}{ Zaragoza } \\
\cline { 2 - 8 } & \multicolumn{2}{|c}{$N^{\circ}$} & \multicolumn{1}{c|}{$\%$} & \multicolumn{1}{|c|}{$N .^{\circ}$} & $\%$ & $N .^{\circ}$ & $\%$ & $N^{\circ}$ & $\%$ \\
\hline 1 & Cultura y ocio & 4.047 & 33,81 & 788 & 40,68 & 714 & 54,63 & 2545 & 29,17 \\
2 & Deportivas & 2.523 & 21,08 & 224 & 11,56 & 15 & 1,15 & 2284 & 26,18 \\
3 & Educación, formación e investigación & 1.388 & 11,60 & 221 & 11,41 & 185 & 14,15 & 982 & 11,26 \\
4 & Salud & 114 & 0,95 & 4 & 0,21 & 5 & 0,38 & 105 & 1,20 \\
5 & Servicios sociales & 1.463 & 12,22 & 268 & 13,84 & 228 & 17,44 & 967 & 11,08 \\
6 & Medio ambiente & 183 & 1,53 & 37 & 1,91 & 12 & 0,92 & 134 & 1,54 \\
7 & Desarrollo comunitario & 631 & 5,27 & 237 & 12,24 & 85 & 6,50 & 309 & 3,54 \\
8 & Derechos civiles, políticos y legales & 462 & 3,86 & 76 & 3,92 & 20 & 1,53 & 366 & 4,19 \\
9 & Intermediarios filantrópicos y del voluntariado & 26 & 0,22 & 17 & 0,88 & 0 & 0,00 & 9 & 0,10 \\
10 & Cooperación internacional & 54 & 0,45 & 2 & 0,10 & 1 & 0,08 & 51 & 0,58 \\
11 & Religiosas & 141 & 1,18 & 4 & 0,21 & 30 & 2,30 & 107 & 1,23 \\
12 & Profesionales & 605 & 5,05 & 37 & 1,91 & 12 & 0,92 & 556 & 6,37 \\
13 & Otros fines & 317 & 2,65 & 22 & 1,14 & & & 295 & 3,38 \\
& & & & & & & & \\
& Total & 11.969 & 100 & 1937 & 100 & 1.307 & 100 & 8.725 & 100 \\
\hline
\end{tabular}

FUENTE: Registros de asociaciones de Zaragoza, Huesca y Teruel

Si esto lo hacemos en función de las provincias, podemos observar que en el caso de Huesca se introducen algunas modificaciones relevantes respecto de los puestos destacados. Junto a lo dicho para el conjunto, aquí se incorporan las organizaciones de desarrollo comunitario con un peso específico importante, las cuales, junto con las de servicios sociales, resaltan detrás de las culturales.

En el caso de Teruel también se producen algunos cambios significativos. Si bien prevalecen las asociaciones del campo de la cultura y el ocio $(54,63 \%)$, las deportivas quedan relegadas al extremo opuesto con un $1,15 \%$, mientras que las de servicios sociales destacan especialmente con un $17,44 \%$, seguidas por las de educación, con un $14,15 \%$. 
Y por último, en el caso de Zaragoza, destacan unos cuantos cambios respecto del perfil general propios de la concentración de actividades de la capital de Aragón. Por un lado, el alto número de organizaciones deportivas y el peso de las profesionales (aquí están todas, exceptuando las 49 de Huesca y Teruel).

Así pues, los datos proporcionados desde los registros nos muestran que la vida asociativa en Aragón se concentra en actividades de carácter cultural, seguidas por las deportivas y, en menor medida, en la ejecución de actividades de educación, formación y servicios sociales.

Si comparamos las características obtenidas de los registros con los datos de nuestra encuesta, observamos en la tabla IV.5 que existe una concentración de asociaciones en los sectores de cultura, ocio y deporte, lo que coincide con los datos del registro.

Sin embargo, atendiendo a los recursos, tanto humanos como económicos, que las entidades dedican al desarrollo de sus programas se manifiesta una corrección importante de los porcentajes iniciales, que se refiere básicamente a la disminución de la importancia del sector cultural en un $13 \%$ y el incremento de otros subsectores, como medio ambiente y desarrollo comunitario.

TABLA IV.5

CLASIFICACIÓN DE LAS ENTIDADES DE LA MUESTRA DE ASOCIACIONES ATENDIENDO A LA FINALIDAD BÁSICA, 1999

\begin{tabular}{|l|c|c|c|}
\hline Tipo de actividad & N.o entidades & \% entidades & \% de recursos destinados \\
\hline Cultura y ocio & 88 & 45,36 & 31,42 \\
Deportivas & 37 & 19,07 & 18,73 \\
Educación e investigación & 8 & 4,12 & 4,91 \\
Salud & 11 & 5,67 & 7,02 \\
Servicios sociales & 17 & 8,76 & 6,59 \\
Medio ambiente & 3 & 1,55 & 3,33 \\
Desarrollo comunitario & 8 & 4,12 & 4,70 \\
Cooperación internacional & 6 & 3,09 & 2,43 \\
Religiosas & 6 & 3,09 & 13,04 \\
Derechos civiles & 2 & 1,03 & 2,03 \\
Profesionales & 1 & 0,52 & 0,10 \\
Intermediarios filantrópicos & 0 & 0 & 0,34 \\
Otras de interés general & 6 & 3,09 & 5,36 \\
Total & 194 & 100,00 & 100,00 \\
\hline
\end{tabular}


En consecuencia, no existe una correspondencia exacta entre el número de asociaciones y los recursos destinados a ellas, lo que probablemente se debe a que algunas actividades exigen un mayor esfuerzo económico y social que otras. Este hecho es importante a la hora de valorar la efectividad y eficacia de las citadas entidades.

Tomando como base de actividad principal de las asociaciones los datos que ofrecemos en la tabla IV.5, hemos constatado que una gran parte de la muestra realiza más de una actividad, de forma que en la tabla IV.6 las observaciones derivadas de este hecho totalizan 405. La muestra indica que existe una finalidad básica, pero que, como media, las asociaciones actúan en 2,08 campos. Esto nos permite resaltar la versatilidad, dinamismo y apertura de dichas entidades. Es decir, si consideramos cada campo de actividad desarrollada por una entidad como si fuera una organización independiente, se duplica el número de entidades y se corrigen los porcentajes. Así, se observa que cultura y deporte siguen siendo los subsectores donde se concentra el mayor número de entidades, pero se incrementa porcentualmente en algunos casos destacados como desarrollo comunitario y medio ambiente.

TABLA IV.6

CLASIFICACIÓN DE LAS ENTIDADES DE LA MUESTRA CONSIDERANDO CADA CAMPO COMO UNA ENTIDAD, 1999

\begin{tabular}{|l|r|r|r|r|r|r|r|r|}
\hline \multirow{2}{*}{ Tipo de actividad } & \multicolumn{2}{|c|}{ Aragón } & \multicolumn{2}{|c|}{ Huesca } & \multicolumn{2}{c|}{ Teruel } & \multicolumn{2}{|c|}{ Zaragoza } \\
\cline { 2 - 9 } & Núm. & $\%$ & Núm. & $\%$ & Núm. & $\%$ & Núm. & $\%$ \\
\hline Cultura y ocio & 111 & 27,41 & 17 & 47,22 & 18 & 75,00 & 53 & 39,55 \\
Deportivas & 65 & 16,05 & 2 & 5,56 & 1 & 4,17 & 34 & 25,37 \\
Educación e investigación & 30 & 7,41 & 1 & 2,78 & 0 & 0,00 & 7 & 5,22 \\
Salud & 32 & 7,90 & 2 & 5,56 & 2 & 8,33 & 7 & 5,22 \\
Servicios sociales & 32 & 7,90 & 5 & 13,89 & 1 & 4,17 & 11 & 8,21 \\
Medio ambiente & 28 & 6,91 & 1 & 2,78 & 0 & 0,00 & 2 & 1,49 \\
Desarrollo comunitario-cívico & 41 & 10,12 & 2 & 5,56 & 1 & 4,17 & 5 & 3,73 \\
Cooperación internacional & 17 & 4,20 & 3 & 8,33 & 0 & 0,00 & 3 & 2,24 \\
Religiosas & 15 & 3,70 & 0 & 0,00 & 1 & 4,17 & 5 & 3,73 \\
Derechos civiles & 2 & 0,49 & 1 & 2,78 & - & 0,00 & 1 & 0,75 \\
Profesionales y de negocios & 2 & 0,49 & 0 & 0,00 & 0 & 0,00 & 1 & 0,75 \\
Intermediarios filantrópicos & 4 & 0,99 & 0 & 0,00 & 0 & 0,00 & 1 & 0,75 \\
Otras de interés general & 26 & 6,42 & 2 & 5,56 & 0 & 0,00 & 4 & 2,99 \\
Total & & & & & & & & \\
\end{tabular}

FUENTE: Elaboración propia 
Si analizamos esta clasificación por provincias, encontramos que en Zaragoza y Huesca el subsector de cultura y ocio sigue siendo predominante, mientras que el de deporte es más importante en Zaragoza que en Huesca y Teruel. Por otro lado, el subsector de servicios sociales alcanzan mayor importancia en Zaragoza y Huesca, y el de cooperación internacional en Huesca. En cuanto a Teruel, hay que destacar la importancia relativa del subsector cultura: alcanza el $75 \%$.

\section{IV.1.3. Evolución temporal en la creación de las asociaciones}

Por otra parte, para ahondar en las características del sector asociativo aragonés es necesario atender a la relación entre creación de asociaciones y paso del tiempo.

Si anteriormente decíamos que el conjunto de las ONL refleja la vitalidad y riqueza de la sociedad de referencia, ahora encontramos un punto de enfoque donde precisamente poder contrastarlo. Cuando los ciudadanos y las ciudadanas promueven organizaciones con las que articular sus objetivos compartidos, estamos asistiendo a un proceso de generación de riqueza colectiva. Es un proceso que fragua con el paso del tiempo, al hacerse historia. En ese evolucionar, el espacio público, el espacio ciudadano se modifica, se hace fermento cívico y se convierte en escaparate de las dinámicas sociales. Las iniciativas individuales se aglutinan mediante procesos de afiliación y asociación constituyendo organizaciones capaces de vertebrar esas voluntades y de dar cauce a las demandas de cada momento histórico.

El espacio público en la sociedad aragonesa ha estado circunscrito a las pautas generales del contexto español. Mientras el régimen franquista imponía su particular modo de entender los procesos de participación social, las iniciativas públicas estuvieron lastradas por el peso del aparato estatal. Esta rémora sigue lastrando los modelos de referencia y el lenguaje de muchas personas de nuestro tiempo, aunque afortunadamente las rutas de participación y organización ciudadana abiertas por las distintas asociaciones han permitido que los intereses generales y las iniciativas públicas ya no sean sólo un monopolio del Estado como entidad tutelante y tutora de la creatividad de sus «súbditos». Hoy la ciudadanía aragonesa ha dado muestras fehacientes de su capacidad de 
organizar distintas entidades que, bajo el modelo jurídico de asociación, dan expresión tanto a sus intereses más particulares como a los de más trascendencia colectiva. El espacio público aragonés, lo público en Aragón, se ha ido haciendo grande cada vez que las personas creaban una de estas ONL.

Las dos tablas que siguen nos muestran una tendencia creciente en la constitución de asociaciones aragonesas, en las que se ve un incremento claro desde la transición democrática hasta nuestros días. Con dos salvedades: por un lado, en la última mitad de los años noventa se produce una ligera caída; por otro, en el caso de las provincias de Teruel y Huesca es mucho más evidente.

La tabla IV.7 presenta la evolución en las cifras totales para el conjunto de Aragón. Son datos estructurados en cortes de tiempo quinquenales, con la excepción de la década de los años setenta, que se presenta en una sola unidad.

Si observamos los datos por provincias, se constata que Huesca y Teruel, con una trayectoria demográfica decreciente, tienden a superar en sus iniciativas ciudadanas el ritmo de la provincia dominante. Al respecto estamos preparando un mapa en el que establecemos relaciones entre zonas del país, densidad de población y número de asociaciones constituidas lo que permitirá elaborar un índice de densidad asociativa.

TABLA IV.7

EVOLUCIÓN DE LA CREACIÓN DE ASOCIACIONES EN ARAGÓN (Los datos de los registros están actualizados hasta noviembre de 2000)

\begin{tabular}{|l|r|r|r|r|r|r|r|r|}
\hline \multirow{2}{*}{ Periodo } & \multicolumn{2}{|c|}{ Aragón } & \multicolumn{2}{c|}{ Huesca } & \multicolumn{2}{c|}{ Teruel } & \multicolumn{2}{c|}{ Zaragoza } \\
\cline { 2 - 9 } & Núm. & \multicolumn{1}{c|}{$\%$} & Núm. & $\%$ & Núm. & $\%$ & Núm. & $\%$ \\
\hline Hasta 1969 & 662 & 5,53 & 41 & 2,12 & 32 & 2,45 & 589 & 6,75 \\
$1970-1979$ & 1295 & 10,82 & 164 & 8,47 & 122 & 9,33 & 1009 & 11,56 \\
$1980-1984$ & 1342 & 11,21 & 207 & 10,69 & 154 & 11,78 & 981 & 11,24 \\
$1985-1989$ & 2165 & 18,09 & 263 & 13,58 & 255 & 19,51 & 1647 & 18,88 \\
$1990-1994$ & 3177 & 26,54 & 385 & 19,88 & 289 & 22,11 & 2.503 & 28,69 \\
$1995-1999$ & 2832 & 23,66 & 705 & 36,40 & 401 & 30,68 & 1726 & 19,78 \\
2000 & 496 & 4,14 & 172 & 8,88 & 54 & 4,13 & 270 & 3,09 \\
Total & 11969 & 100,00 & 1937 & 100,00 & 1.307 & 100,00 & 8725 & 100,00 \\
\hline
\end{tabular}

FUENTE: Registros de asociaciones de Zaragoza, Huesca y Teruel 
Por otra parte, si observamos las gráficas en las que se representa para cada provincia la evolución en el tiempo de la creación de organizaciones en función de sus tipos de actividad, las interpretaciones son inmediatas.

Por ejemplo, para el caso de Huesca vemos en dos imágenes la evolución. En una primera aproximación — gráfica IV.1 (A)—, percibimos con claridad que las entidades vinculadas al área de cultura mantienen un recorrido ascendente que arranca ya de 1979. Muestran un ritmo continuo y muy por encima del resto de las actividades (total, 768). En esa línea nos encontramos también con las deportivas, que lo hacen desde 1995, hasta alcanzar un número de 224. También vemos que las vinculadas a actividades educativas presentan un crecimiento constante hasta 1999. En ese año se igualan con las de deporte, desarrollo comunitario, e incluso se ven superadas por los servicios sociales. En línea ascendente, pero con unos valores más modestos, están las entidades de derechos civiles, las cuales comienzan a crecer desde 1984 llegando hasta un total de 76.

GRÁFICA IV.1 (A)

EVOLUCIÓN DE LAS ASOCIACIONES CREADAS EN HUESCA:

CULTURA, DEPORTE, EDUCACIÓN, SERVICIOS SOCIALES, DESARROLLO COMUNITARIO Y DERECHOS CIVILES

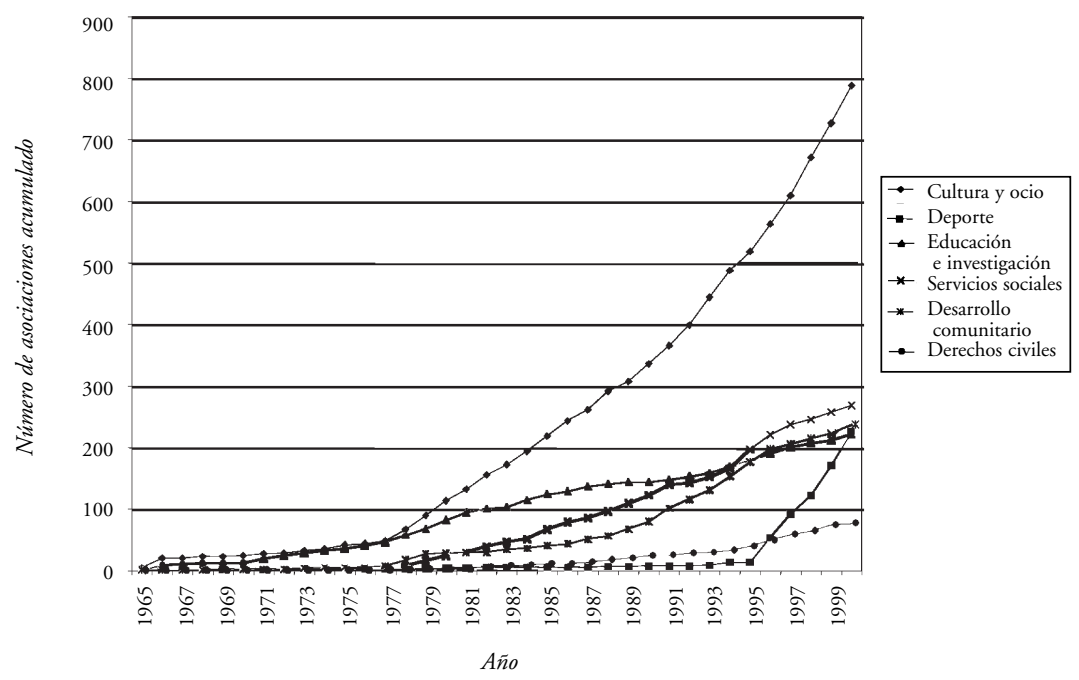


En un segundo cuadro, dentro de la misma provincia de Huesca - gráfica IV.2 (B) —, observamos que el resto de actividades también tiene una fase ascendente, pero dentro de unos valores menos amplios. Las asociaciones de medio ambiente toman fuerza desde 1983 y alcanzan las 37. Lo mismo mismo sucede con las profesionales, que surgidas en 1987 llegan a idéntico número, 37. En otros ámbitos, como el de la cooperación Internacional, el despegue se produce en 1995, hasta totalizar 17. Quedan en un plano muy secundario las denominadas intermediarios filantrópicos, las de salud y las religiosas, con 4 cada grupo.

Para el caso de Teruel — gráfica IV.2 (A)—, vemos algunos elementos concordantes con la situación anterior de Huesca. En la primera representación, el elemento más obvio es la evolución de las entidades vinculadas a actividades culturales. Su presencia y número se incrementa paulatinamente desde 1979 hasta llegar a un total de 714. En un segundo puesto, las organizaciones del ámbito de los servicios sociales y las de educación llevan una trayectoria similar, y alcanzan, respectivamente, las 185 y las 228 . Siguen con valores más alejados las entidades de desarrollo comunitario (20), al igual que las de derechos civiles (20) y, algo menos, las deportivas (15).

GRÁFICA IV.1 (B)

EVOLUCIÓN DE LA CREACIÓN DE ASOCIACIONES EN HUESCA:

MEDIO AMBIENTE, SALUD, INTERMEDIARIOS FILANTRÓPICOS,

COOPERACIÓN INTERNACIONAL, RELIGIOSAS, PROFESIONALES Y OTRAS

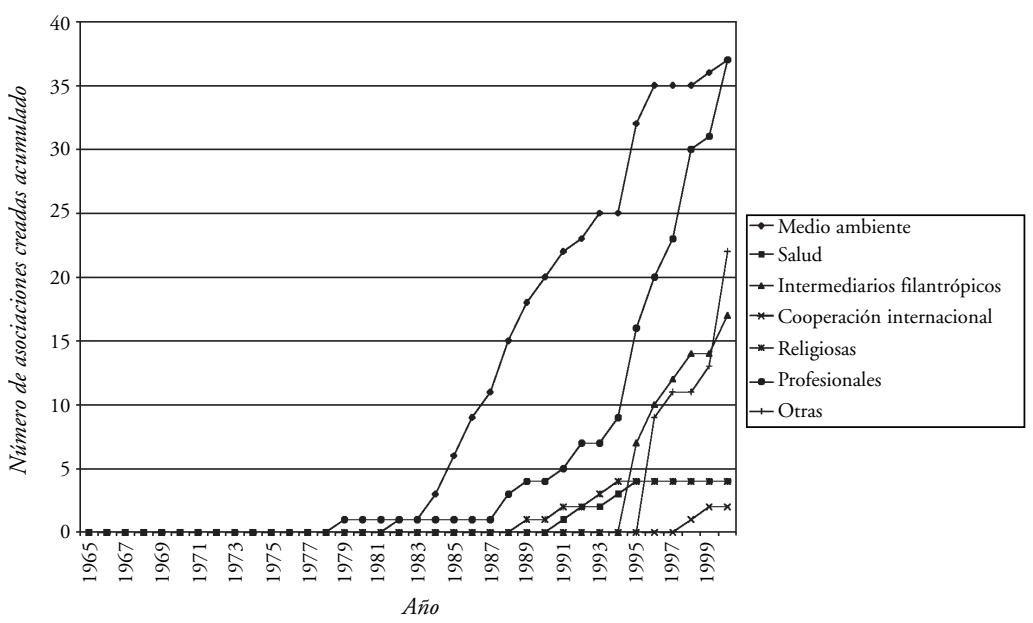




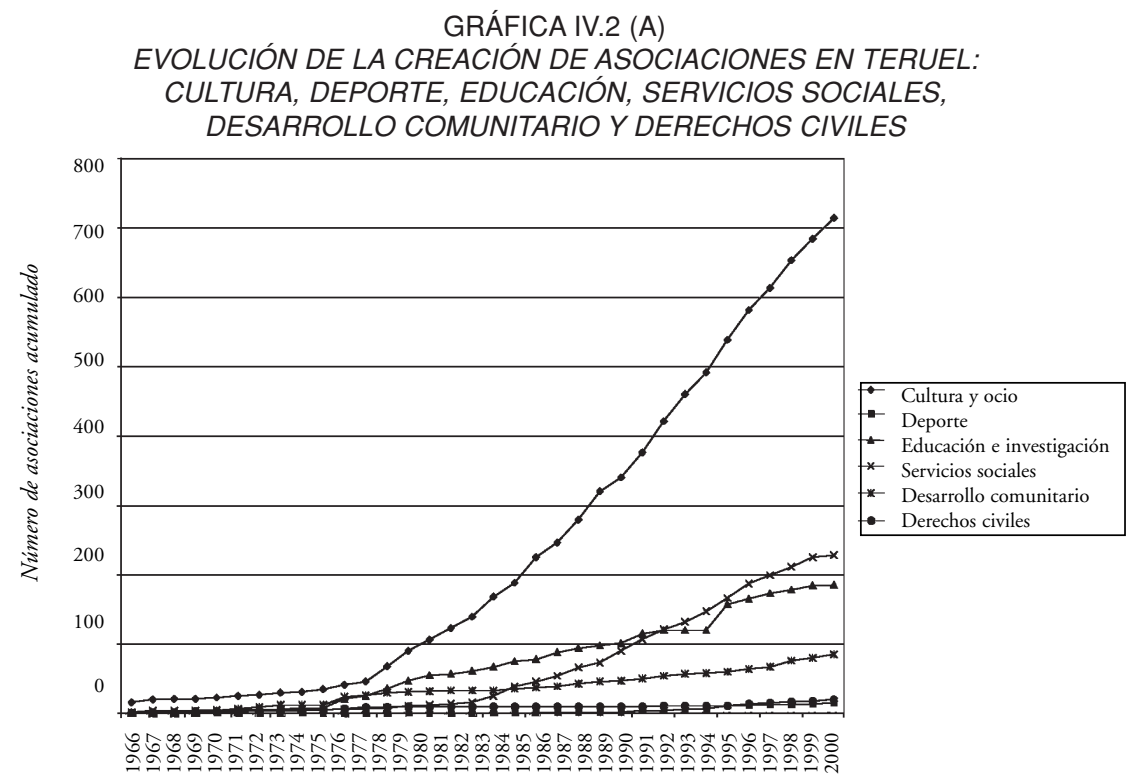

Año

En la segunda representación — gráfica IV.2 (B) — vemos que las entidades religiosas empiezan su desarrollo en 1985 alcanzan un total de 30. La trayectoria de las de medio ambiente es más irregular: comienza en 1988 y llegan a 12. Este mismo valor es el de las profesionales, también de forma irregular, cuyo inicio arranca de 1979. Las de salud surgen en 1995 y ascienden a 5, algo más que el único caso en el ámbito de cooperación internacional. Las dedicadas a intermediarios filantrópicos no existen.

En el caso de Zaragoza — gráfica IV.3 (A) —, se repiten algunos puntos. La Constitución de 1978 y la apertura democrática de la sociedad son el punto de partida en la transformación de la sociedad. Esto se verá de forma destacada en las entidades culturales, al igual que para el deporte y educación —respectivamente 2544, 2295 y 967 entidades-. $\mathrm{Si}$ nos fijamos en las organizaciones de servicios sociales, la fecha es 1988 
GRÁFICA IV.2 (B)

EVOLUCIÓN DE LA CREACIÓN DE ASOCIACIONES EN TERUEL:

MEDIO AMBIENTE, SALUD, INTERMEDIARIOS FILANTRÓPICOS,

COOPERACIÓN INTERNACIONAL, RELIGIOSAS, PROFESIONALES

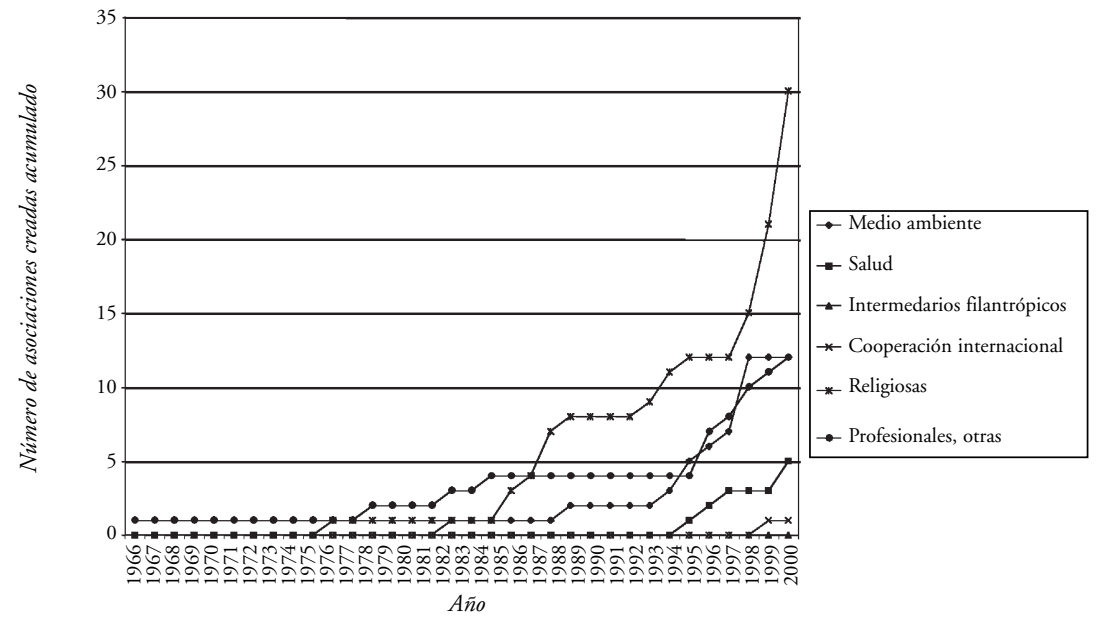

y se equiparan en número en el año 2000 con las de educación, alcanzando ambas un total de 967. Con una trayectoria lenta y similar encontramos las de derechos civiles, con 366, y desarrollo comunitario, con 309.

En una segunda representación — gráfica IV.3 (B)—, vemos algunas particularidades que conviene señalar. Por ejemplo, en el año 1981 se produce el despegue de las organizaciones profesionales, que alcanzan un total de 556. También a partir de esa fecha, aunque por debajo, encontramos las de salud, con un total de 105, las religiosas, con 107, y las de medio ambiente, con 134. A partir de 1995 vemos en un número mucho menor las de cooperación internacional, con un total de 51, y las entidades filantrópicas, de forma testimonial, con 9. 
GRÁFICA IV.3 (A)

EVOLUCIÓN EN LA CREACIÓN DE ASOCIACIONES EN ZARAGOZA:

CULTURA, DEPORTE, EDUCACIÓN, SERVICIOS SOCIALES, DESARROLLO COMUNITARIO Y DERECHOS CIVILES

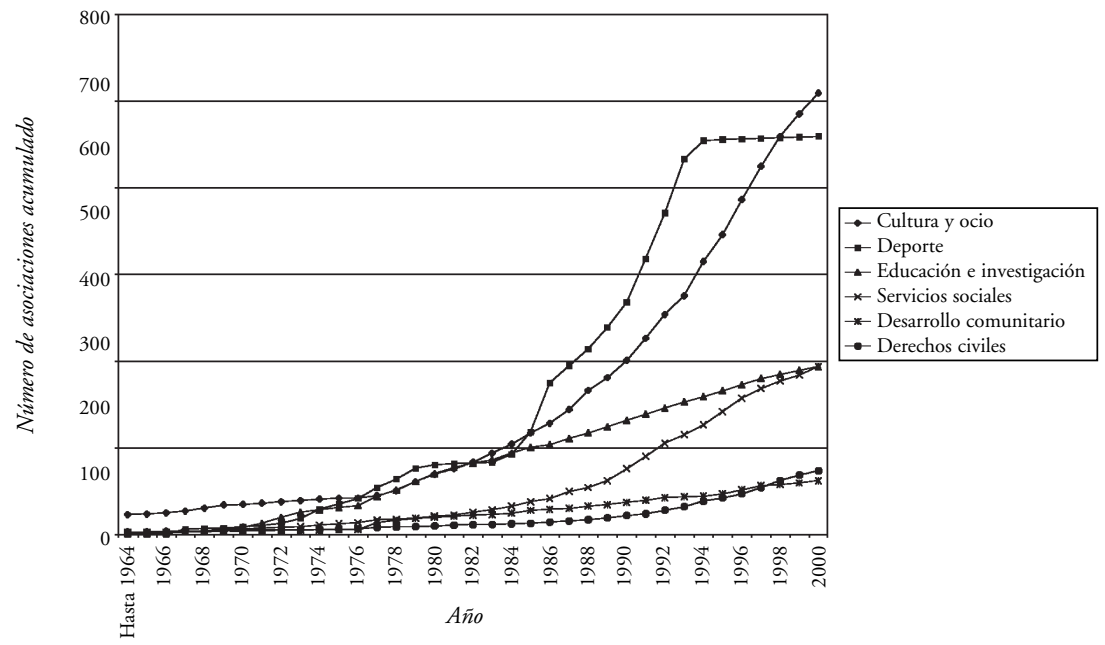

GRÁFICA IV.3 (B)

EVOLUCIÓN EN LA CREACIÓN DE ASOCIACIONES EN ZARAGOZA:

MEDIO AMBIENTE, SALUD, INTERMEDIARIOS FILÁNTRÓPICOS, COOPERACIÓN INTERNACIONAL, RELIGIOSAS, PROFESIONALES, OTRAS

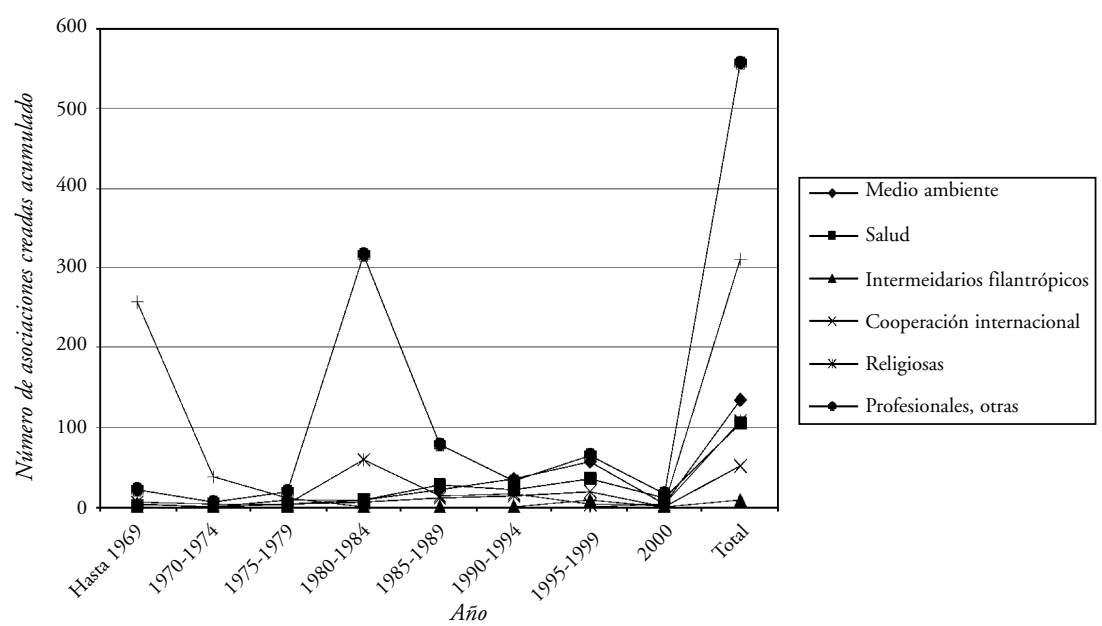




\section{IV.1.4. Ámbito geográfico}

Si hasta el apartado anterior hemos utilizado fundamentalmente los datos disponibles en los registros de la Administración de la Comunidad Autónoma, a partir de ahora nos basamos de forma exclusiva en la encuesta y las entrevistas que realizamos en las asociaciones aragonesas. Con los datos obtenidos presentamos algunas conclusiones para las asociaciones de la encuesta y estimamos la repercusión sobre el conjunto de ellas.

La muestra de entidades de las que se dispone de información es de 194 y es representativa del total de asociaciones. La distribución por provincias de la muestra es la siguiente: 134 pertenecen a la provincia de Zaragoza, 34 a la provincia de Huesca y 26 a la provincia de Teruel. Dicha composición es similar al total de las asociaciones: un 18,56\% pertenecen a Huesca, un $12,37 \%$ a Teruel y un $69,07 \%$ a Zaragoza.

Desde el punto de vista jurídico, el $92 \%$ son asociaciones mientras que el resto son federaciones. La vinculación social es como sigue: 7,7 \% religiosa, $1 \%$ político-sindical y $91,3 \%$ sin adscripción concreta (las describimos como independientes).

TABLA IV.8

ASOCIACIONES QUE DESARROLLAN SUS ACTIVIDADES EN DIFERENTES ÁMBITOS GEOGRÁFICOS

\begin{tabular}{|l|c|c|}
\hline Ámbito geográfico & Núm. de entidades & \% de entidades \\
\hline Un solo ámbito & 137 & 70,6 \\
Dos ámbitos & 22 & 11,3 \\
Tres ámbitos & 22 & 11,3 \\
Cuatro ámbitos & 11 & 5,7 \\
Cinco ámbitos & 2 & 1,0 \\
Total & 194 & 100,0 \\
\hline
\end{tabular}

FUENTE: Elaboración propia

Si queremos valorar el alcance —entiéndase repercusión, impacto, incidencia social...- de las asociaciones aragonesas, hemos de enfocar nuestra atención al ámbito geográfico propio donde realizan los diversos programas de actuación. Este ámbito geográfico de actividad viene determinado por los distintos entornos sociales donde opera cada entidad. Así, dependiendo de los objetivos de cada organización, vemos que unas se 
centran en el desarrollo de sus programas dentro de un barrio, o un municipio, comarca, provincia, hasta el conjunto de Aragón, e incluso algunas aspiran a tener repercusión estatal e internacional. Por eso, para valorar cada una de las entidades tenemos que poner en relación su ámbito geográfico de actividad —es decir, los diferentes lugares donde trabajan con el tipo de acciones - con sus redes de implicación e impacto social.

La mayoría de las entidades trabajan en un solo ámbito, mientras que un total de 57 se desenvuelven en dos o más de dos ámbitos, destacando, con cifras idénticas, las que operan en dos y tres.

Si profundizamos en el número de programas desarrollados por estas entidades en cada uno de los ámbitos, vemos que predomina el municipio -lógicamente-, con un 36,15\%, y la provincia, con un 25,30\%. Las actuaciones para el conjunto de Aragón son más residuales, con un $4,23 \%$, y lo mismo sucede con las que inciden en un marco estatal e internacional, con un $7,8 \%$ y un $5,3 \%$, respectivamente.

Dadas las características de distribución de la población aragonesa, es bastante coherente el tipo de intereses/objetivos y los ámbitos de actuación de las asociaciones. Los datos que la investigación cualitativa nos ha aportado - como después veremos - también nos remiten a una tendencia a implicarse con lo próximo, que en casi todas las ONL no excluye una preocupación clara por lo que sucede más allá de los propios intereses.

TABLA IV.9

NÚMERO DE PROGRAMAS DESARROLLADOS POR LAS ASOCIACIONES EN LOS DIFERENTES ÁMBITOS GEOGRÁFICOS

\begin{tabular}{|l|c|c|}
\hline Ámbito geográfico & Núm. de programas & \% de programas \\
\hline Barrio & 83 & 7,64 \\
Municipio & 393 & 36,15 \\
Comarca & 147 & 13,52 \\
Provincia & 275 & 25,30 \\
Aragón & 46 & 4,23 \\
Estatal & 85 & 7,82 \\
Internacional & 58 & 5,34 \\
Total & 1.087 & 100,00 \\
\hline
\end{tabular}

FUENTE: Elaboración propia 


\section{IV.1.5. Las personas}

El elemento fundamental de cualquiera de estas entidades es el factor humano. Son las personas que integran cada una de estas asociaciones las que dan vida y ponen en marcha los ritmos asociativos particulares. Por eso nos encontramos con un abanico tan amplio y diverso. Las formas de proceder y actuar son como los propios individuos que compartimos los espacios sociales. Unas se presentan como estructuras dinámicas y versátiles. Otras mantienen ritmos pausados y poco abiertos a la participación de extraños. Incluso podríamos aplicar una equivalencia de tipos de caracteres personales con tipos de gestión de las organizaciones. Ésta es una consideración fundada en la experiencia del trabajo de investigación, tanto en la parte cualitativa (entrevistas y grupos de discusión) como en la cuantitativa (la encuesta).

Así, nos hemos encontrado con que en todas las organizaciones las formas de gestión y acción dependen claramente del tipo de relaciones humanas que mantienen y de la biografia de la entidad. Es precisamente en las relaciones establecidas con el paso del tiempo — desde su gestación hasta su fase de consolidación - donde se van sedimentando modos de ser y formas de canalizar los recursos que aporta cada una de las personas. Lo cual, a su vez, también interacciona con los valores socialmente disponibles.

En algunos casos, al margen de los datos cuantitativos, las experiencias de las personas de más edad hacían referencia a la participación como socio que se integra en una estructura con la intención de ir más allá del pago de una cuota. Se aspiraba a tener voz y voto y a estar «en lo que hiciera falta», lo cual presentaba un grado de compromiso distinto del actual. Pero también encontramos casos donde los más experimentados nos insistían en «las pocas ganas del personal» para acometer tareas desde siempre.

Con todo, sí que nos atrevemos a formular algunas distinciones que han surgido en el proceso de investigación. En este momento, estamos asistiendo a una explosión del voluntario - que arranca desde finales de la década de los años ochenta-. Es una forma de nombrar a aquellas personas que se aproximan a una asociación o a cualquier tipo de actividad social con «la voluntad» de no ser remunerados, lo cual ha sido habitual en la mayoría de las asociaciones aragonesas desde que se fundaron. 
Pero ahora esta distinción, dentro de las asociaciones y de las ONL en general, tiende a diferenciar al socio del voluntario. En algunos casos se convierte en una oposición que viene delimitada por el grado de compromiso de unos y otros, con algunas paradojas, según las entidades, que vamos a describir, dejando a un lado lo que reflejan los estatutos.

En la mayoría de las organizaciones encontramos que son socios aquellas personas que pagan una cuota establecida (socios de cuota). Otras distinguen los grados de sus socios pasando por encima del abono de cuotas, y resaltan que socio es quien, además de estar inscrito en la asociación, promueve la existencia y mantiene la entidad participando en las diversas actividades, está especialmente implicado en éstas, se preocupa por su gestión y acude a las asambleas y otros momentos importantes de la asociación (socios activos).

Por otra parte, las formas en las que se concreta el «voluntario» son dispares. En principio, puede y debe ser un socio activo de la entidad. Pero encontramos organizaciones donde voluntario es alguien que sólo dedica un tiempo puntual y periódico a una tarea coordinada desde la entidad (voluntario de plantilla) asumida y concertada por ambas partes. En otras ocasiones, voluntario es quien se pasea de forma aleatoria por la asociación haciendo aportaciones de todo tipo, tanto de conocimientos cualificados como de mano de obra sin cualificar (voluntario sin compromiso). Existe una modalidad de voluntario ligada a los acontecimientos destacados - tanto por los medios de comunicación como por las campañas de publicidad propias de la entidad-, que es propia de personas que de forma esporádica se implican en un suceso único y particular sin mayor seguimiento (voluntario de ocasión). Otra modalidad de voluntario, que también hemos constatado, es aquella en la que la asociación se convierte en lugar de sentido a veces de terapia personal...-, adonde se acude a relacionarse, salir de la soledad y dar cauce a la necesidad de pertenencia (voluntario por terapia).

Prescindiendo de las etiquetas y tipologías, cada asociación construye sus pautas particulares a la hora de establecer las relaciones entre sus integrantes. Aunque son diversas, el número de opciones realmente existentes es limitado. Por eso nos interesaba organizar sucintamente el cómo y el porqué de estos roles atribuidos y conquistados en el seno de las organizaciones a sus respectivos actores. De forma especial, en una época en la que se promociona el voluntariado - e incluso organizaciones internacionales intentan hacer de ello un reto ciudadano- y crece el prestigio de lo no-gubernamental. 
Dejamos aquí apuntado un debate que hemos detectado en algunas asociaciones respecto de la relación entre socios y voluntarios. Estamos ante una corriente de opinión que insiste en el valor de suyo del voluntariado, mientras que otra posición recalca su perversidad. Para los primeros, no hay duda de los muchos beneficios que genera la acción altruista y voluntaria de cualquier persona que hace algo por los demás. En el segundo caso, sin cuestionar el valor del altruismo, se ponen en duda las formas de participación y se destaca la perversión intrínseca de unas actuaciones que tienden a fomentar «el voluntariado de un día, que no está mal, pero...; si sólo participo un día, difícilmente tengo suficiente capacidad e información para valorar lo que hace la asociación; entonces, ¿en manos de quién están las decisiones? Ésta es la sociedad que queremos?... ¿¿Aquella que fomenta voluntarios tontos y poco problemáticos que dan comida a los pobres y desheredados, pero no se plantean por qué no comen? Vamos, lo de la caridad mal entendida».

En apartados posteriores ahondaremos en la cuestión ahora optamos por continuar presentando los datos de la encuesta realizada en lo que respecta al factor humano de las asociaciones.

\section{IV.1.5.1. Socios}

Como dato a tener en cuenta, se considera que el número de socios es uno de los indicadores del tamaño de las entidades, junto con su número de receptores y los datos económicos de gestión. En este punto queremos destacar el peso de los socios en la definición del sector en el caso aragonés. Por eso, si atendemos al número de socios, se nos ofrece un mapa interesante de participación ciudadana.

El número de socios totales es de 56832 en el conjunto de entidades, aunque la cifra tiene que ser matizada. En principio, de acuerdo con los estudios realizados para España sobre el comportamiento asociativo de la sociedad, se observa que existe una llamada pluri-pertenencia a diferentes asociaciones, por lo que a la hora de valorar esta cifra es necesario efectuar una corrección. ${ }^{49}$

49 Ruiz Olabuénaga (2000a) e Informe FOESSA (1994). 
Es decir, debe aplicarse una ratio de 0,423 entre personas y socios declarados en cada entidad. La aplicación de este porcentaje de pluri-pertenencia se basa en los resultados del sondeo FOESSA de 1994, cuyos resultados se muestran en la tabla IV.11.

TABLA IV.10

NÚMERO DE SOCIOS DE LA MUESTRA EN ARAGÓN POR INTERVALOS DE TAMAÑO Y NÚMERO DE ENTIDADES

\begin{tabular}{|l|c|c|c|c|}
\hline Intervalo de socios & Núm. de entidades & \% de entidades & Núm. de socios & $\%$ de socios \\
\hline Hasta 50 socios & 83 & 42,78 & 1.698 & 2,99 \\
De 51 a 250 & 79 & 40,72 & 10.640 & 18,72 \\
De 251 a 1.000 & 22 & 11,34 & 9.947 & 17,50 \\
Más de 1.000 & 10 & 5,15 & 34.547 & 60,79 \\
Total muestra Aragón & 194 & 100,00 & 56.832 & 100,00 \\
\hline
\end{tabular}

FUENTE: Elaboración propia

TABLA IV.11

PERTENENCIA A LAS ASOCIACIONES DE LOS SOCIOS

\begin{tabular}{|l|c|}
\hline Pertenencia a asociaciones & $\%$ \\
\hline No pertenecen a ninguna & 59,6 \\
Pertenecen a 1 & 22,6 \\
Pertenecen a 2 & 10,1 \\
Pertenecen a 3 & 4,3 \\
Pertenecen a más de 3 & 3,4 \\
\hline
\end{tabular}

FUENTE: Ruiz Olabuénaga (2000a), p. 138, y FOESSA (1994), p. 1237

TABLA IV.12

TASA DE PARTICIPACIÓN EN ASOCIACIONES POR PAÍSES

\begin{tabular}{|l|c|}
\hline Países & $\%$ \\
\hline EE.UU & 75 \\
Finlandia & 72 \\
Holanda & 69 \\
Austria & 67 \\
Suiza & 56 \\
Gran Bretaña & 54 \\
Alemania & 53 \\
España & 36 \\
Italia & 31 \\
Aragón & 49 \\
\hline
\end{tabular}

FUENTE: McDonough, Barnes y López Pina (1984), tomado de Ruiz Olabuénaga (2000a) 
Esta corrección aplicada a la cifra obtenida nos indicaría que estamos ante un conjunto de asociaciones que están sostenidas por un total de 22732 socios. El dato podría contrastarse con las cifras que se presentan respecto a la participación ciudadana en asociaciones, como la que ofrece la tabla IV.12.

Así pues, nos encontramos con que la participación de Aragón en el conjunto de las asociaciones españolas es de un 3,75 y que el índice de asociaciones por habitante es muy elevado - 5,38 - sólo superado por las comunidades autónomas de La Rioja, Navarra y Castilla-León (ver tabla IV.13).

De acuerdo con los datos anteriores y practicando las correcciones necesarias, podríamos estimar que para el conjunto de asociaciones aragonesas estaríamos hablando de un total de unos 380000 socios.

TABLA IV.13

PARTICIPACIÓN DE LA POBLACIÓN ESPAÑOLA EN LAS ASOCIACIONES POR COMUNIDADES AUTÓNOMAS

\begin{tabular}{|l|r|r|r|c|}
\hline Regiones & $\%$ & Asociaciones & Población & $\begin{array}{c}\text { Asoc. por cada } \\
\text { 1000 habitantes }\end{array}$ \\
\hline Andalucía & 15,90 & 27.266 & 7.128 .240 & 3,83 \\
Aragón & 3,70 & 6.345 & 1.180 .172 & 5,38 \\
Asturias & 2,70 & 4.630 & 1.071 .284 & 4,32 \\
Baleares & 1,80 & 3.087 & 729.455 & 4,23 \\
Canarias & 3,80 & 6.516 & 1.563 .164 & 4,17 \\
Cantabria & 1,30 & 2.229 & 526.620 & 4,23 \\
Castilla-La Mancha & 5,20 & 8.917 & 1.694 .031 & 5,26 \\
Castilla-León & 8,20 & 14.062 & 2.509 .768 & 5,60 \\
Cataluńa & 15,40 & 26.409 & 6.065 .527 & 4,35 \\
Comunidad Valenciana & 9,70 & 16.634 & 3.913 .187 & 4,25 \\
Extramadura & 2,70 & 4.630 & 1.075 .264 & 4,31 \\
Galicia & 7,20 & 12.347 & 2.723 .763 & 4,53 \\
Madrid & 10,60 & 18.177 & 5.015 .974 & 3,62 \\
Murcia & 2,90 & 4.973 & 1.084 .394 & 4,59 \\
Navarra & 1,80 & 3.087 & 526.633 & 5,86 \\
País Vasco & 5,90 & 10.118 & 2.069 .201 & 4,89 \\
La Rioja & 0,90 & 1.543 & 260.451 & 5,93 \\
Ceuta & 0,10 & 171 & 71.368 & 2,40 \\
Melilla & 0,10 & 171 & 61.800 & 2,77 \\
& & 171.313 & & \\
\hline
\end{tabular}

FUENTE: Subirats, ed. (1999) y elaboración propia a partir del Registro Nacional de Asociaciones 
TABLA IV.14

NÚMERO DE SOCIOS DE LA MUESTRA EN LA PROVINCIA DE HUESCA POR INTERVALOS DE TAMAÑO Y NÚMERO DE ENTIDADES

\begin{tabular}{|l|c|c|c|c|}
\hline Intervalo de socios & Núm. de entidades & \% de entidades & Núm. de socios & \% de socios \\
\hline Hasta 50 socios & 11 & 30,56 & 186 & 2,30 \\
De 51 a 250 & 8 & 22,22 & 2.374 & 29,32 \\
De 251 a 1000 & 5 & 13,89 & 1.926 & 23,78 \\
Más de 1000 & 2 & 5,56 & 3.612 & 44,60 \\
Total muestra Huesca & 36 & 100,00 & 8.098 & 100,00 \\
\hline
\end{tabular}

FUENTE: Elaboración propia

TABLA IV. 15

NÚMERO DE SOCIOS DE LA MUESTRA EN LA PROVINCIA DE TERUEL POR INTERVALOS DE TAMAÑO Y NÚMERO DE ENTIDADES

\begin{tabular}{|l|c|c|c|c|}
\hline Intervalo de socios & Núm. de entidades & \% de entidades & Núm. de socios & \% de socios \\
\hline Hasta 50 socios & 13 & 52,00 & 277 & 8,83 \\
De 51 a 250 & 9 & 36,00 & 1.094 & 34,89 \\
De 251 a 1000 & 2 & 8,00 & 750 & 23,92 \\
Más de 1000 & 1 & 4,00 & 1.015 & 32,37 \\
Total muestra Teruel & 25 & 100,00 & 3.136 & 100,00 \\
\hline
\end{tabular}

FUENTE: Elaboración propia

TABLA IV.16

NÚMERO DE SOCIOS DE LA MUESTRA EN LA PROVINCIA DE ZARAGOZA POR INTERVALOS DE TAMAÑO Y NÚMERO DE ENTIDADES

\begin{tabular}{|l|c|c|c|c|}
\hline Intervalo de socios & Núm. de entidades & \% de entidades & Núm. de socios & \% de socios \\
\hline Hasta 50 socios & 60 & 44,78 & 1.235 & 2,71 \\
De 51 a 250 & 52 & 38,81 & 7.172 & 15,73 \\
De 251 a 1000 & 15 & 11,19 & 7.271 & 15,95 \\
Más de 1000 & 7 & 5,22 & 29.920 & 65,62 \\
Total muestra Zaragoza & 134 & 100,00 & 45.598 & 100,00 \\
\hline
\end{tabular}

FUENTE: Elaboración propia

Un análisis de la distribución de los socios por provincias — ver tablas IV.14, IV.15 y IV.16 - muestra que se concentran de forma evidente en Zaragoza, y que Teruel es la provincia con menor participación total ( 45 598) en Zaragoza, 8098 en Huesca y 3136 en Teruel-. Evidentemente, los factores demográficos son insoslayables en esta cuestión. 
En relación con el tamaño de las asociaciones en función de sus asociados, es en Teruel donde son mas pequeñas, ya que el $52 \%$ de las asociaciones tiene menos de 50 socios. Podría considerarse una obviedad, pero no lo es. El caso reciente de la Plataforma Teruel Existe está aglutinando — sin pretender ser una organización jurídicamente constituidamuchas más personas que cualquier otra conocida en Aragón — salvo las actuales reivindicaciones en pro de un mejor $\mathrm{PHN}$ - Así pues, mirando al conjunto nos encontramos con que en Huesca dos entidades aglutinan al 44,6\% del total de asociados, en Teruel una el 32,3\% y en Zaragoza siete el 65,62\%, con la cifra nada desdeñable de 29920 personas.

Si bien es cierto que no porque haya más socios mejora la calidad de la organización, una relación directamente proporcional entre peso social y número de miembros; al menos, en cuanto a tamaño y capacidad de financiación propia: como es evidente, a igual cuota, mayor independencia cuantos más asociados. Sin embargo, el tamaño por número de asociados no es directamente proporcional al impacto social de la entidad. Para hablar en esos términos son necesarios varios elementos correctores que han de considerarse para dar una valoración de la relación de una asociación con su entorno.

También podemos hacer un lectura inversa. Una entidad necesita sustentarse en una base social realmente existente. Conocemos más de un caso donde la organización sirve para canalizar las actividades y demandas de un colectivo muy reducido de ciudadanos que, en ocasiones, la usan como plataforma de intereses particulares.

En Aragón, como en otros lugares de España - ya lo hemos señalado-, suele darse una tendencia a la pluri-pertenencia en aquellas personas que valoran las iniciativas cívicas y ciudadanas. Pero también sobreabundan quienes nunca se han implicado en nada, ni tan siquiera en la comunidad de vecinos donde se ven obligados a participar.

Más allá de estas inercias de una sociedad poco vertebrada, en el caso de nuestra Comunidad Autónoma observamos una evolución positiva hacia la creación de redes sociales de participación donde la propia ciudadanía va dando cauce a una amplia y diversa urdimbre social. El tamaño de las entidades en función de su número de asociados es menos relevante que la capacidad de generar redes de intercambio y de convergencia de intereses entre las organizaciones existentes. 


\section{IV.1.5.2. Usuarios}

Como ya hemos apuntado, otro elemento fundamental para evaluar el peso específico de una asociación es el número de receptores o beneficiarios de sus actividades. A partir del número de usuarios de los servicios de estas entidades conocemos la repercusión social, por cuanto nos muestra su capacidad de llegar a las personas y, desde ellas, a las necesidades de la sociedad.

Las tablas que siguen nos ofrecen unos resultados donde apreciamos el impacto - entendido en el sentido anterior- que tienen las organizaciones en el seno de la sociedad.

El dato al que llegamos tras la realización de nuestra investigación — como se refleja en la tabla IV.18 - es de 229113 personas destinatarias o usuarias de la red de asociaciones aragonesas estudiadas. Es una cifra que ha de ser matizada y corregida, puesto que en más de un caso una misma persona hace uso de varias entidades. Como no existe un sistema de recogida de datos que nos los calcule mejor, sólo podemos hablar en términos aproximados y sabiendo que las cifras hablan con las limitaciones indicadas.

TABLA IV.17

NÚMERO DE USUARIOS DE LA MUESTRA EN ARAGÓN POR INTERVALOS DE TAMAÑO Y NÚMERO DE ENTIDADES

\begin{tabular}{|l|c|c|c|c|}
\hline Intervalo de usuarios & Núm. de entidades & \% de entidades & Núm. de usuarios & \% de usuarios \\
\hline Hasta 50 usuarios & 94 & 48,45 & 777 & 0,34 \\
De 51 a 250 & 45 & 23,20 & 5.705 & 2,49 \\
De 251 a 1000 & 31 & 11,34 & 16.879 & 7,37 \\
Más de 1000 & 24 & 5,15 & 205.751 & 89,80 \\
Total muestra Aragón & 194 & 100,00 & 229.113 & 100,00 \\
\hline
\end{tabular}

FUENTE: Elaboración propia

TABLA IV.18

NÚMERO DE USUARIOS DE LA MUESTRA EN LA PROVINCIA DE HUESCA POR INTERVALOS DE TAMAÑO Y NÚMERO DE ENTIDADES

\begin{tabular}{|l|c|c|c|c|}
\hline Intervalo de usuarios & Núm. de entidades & \% de entidades & Núm. de usuarios & \% de usuarios \\
\hline Hasta 50 usuarios & 15 & 41,67 & 62 & 0,17 \\
De 51 a 250 & 7 & 19,44 & 925 & 2,57 \\
De 251 a 1000 & 7 & 19,44 & 4.340 & 12,04 \\
Más de 1000 & 7 & 19,44 & 30.728 & 85,23 \\
Total muestra Huesca & 36 & 100,00 & 36.055 & 100,00 \\
\hline
\end{tabular}

FUENTE: Elaboración propia 
TABLA IV.19

NÚMERO DE USUARIOS DE LA MUESTRA EN LA PROVINCIA DE TERUEL POR INTERVALOS DE TAMAÑO Y NÚMERO DE ENTIDADES

\begin{tabular}{|l|c|c|c|c|}
\hline Intervalo de usuarios & Núm. de entidades & \% de entidades & Núm. de usuarios & \% de usuarios \\
\hline Hasta 50 usuarios & 11 & 45,83 & 160 & 1,30 \\
De 51 a 250 & 6 & 25,00 & 923 & 7,52 \\
De 251 a 1.000 & 5 & 20,83 & 2.692 & 21,93 \\
Más de 1.000 & 2 & 8,33 & 8.500 & 69,25 \\
Total muestra Teruel & 24 & 100,00 & 12.275 & 100,00 \\
\hline
\end{tabular}

FUENTE: Elaboración propia

TABLA IV.20

NÚMERO DE USUARIOS DE LA MUESTRA EN LA PROVINCIA DE ZARAGOZA POR INTERVALOS DE TAMAÑO Y NÚMERO DE ENTIDADES

\begin{tabular}{|l|c|c|c|c|}
\hline Intervalo de usuarios & Núm. de entidades & \% de entidades & Núm. de usuarios & \% de usuarios \\
\hline Hasta 50 usuarios & 68 & 50,75 & 556 & 0,31 \\
De 51 a 250 & 32 & 23,88 & 3.857 & 2,13 \\
De 251 a 1.000 & 19 & 14,18 & 9.847 & 5,45 \\
Más de 1.000 & 15 & 11,19 & 166.523 & 92,11 \\
Total muestra Zaragoza & 134 & 100,00 & 180.783 & 100,00 \\
\hline
\end{tabular}

FUENTE: Elaboración propia

Con las salvedades expresadas, podemos decir que 24 entidades se ocupan de 205751 usuarios, lo que supone el 89,8 \%. Si nos centramos en las provincias, se observa que en Huesca 7 asociaciones atienden al 85,2 \%, en Teruel 2 al 69,3\% y en Zaragoza 15 al 92,1\%.

Para matizar los valores indicados, es necesario plantear la relación que existe entre número de asociados y usuarios de una entidad. En algunos casos, ambas figuras convergen en una misma persona. En otros, la realidad nos habla de unos socios que se reúnen para prestar servicios a otras personas que se benefician de la existencia de la asociación. Entre ambos polos las posibilidades son varias y las situaciones diversas. A continuación proponemos una tipología de los casos. Tenemos entidades (autocentradas) cuyos socios son a su vez los destinatarios finales de la propia organización sabiendo que siempre encontramos factores que redundan en beneficio general de la sociedad-. Por ejemplo, cualquier colegio profesional se comporta como una organización cuyos últimos referentes son los intereses cor- 
porativistas y gremiales de sus asociados. También encaja en este perfil un club filatélico, que suele dedicarse a actividades propias del hobby, sin ir más allá de esa afición. No cabe duda de que su labor es encomiable, aunque sea de un escaso valor añadido para los no interesados.

Otras entidades (semi-centradas) son aquellas que, si bien priman las actividades de los socios cotizantes, tienden a establecer cauces que benefician a otros que no pagan la cuota. Por ejemplo, más de un club deportivo aragonés está formado por unos socios que se prestan a sí mismos un servicio de ocio y de instalaciones para el ejercicio físico. Pero, como son un club pensado para la práctica deportiva y ésta prima por encima de otros criterios, generan unos usuarios o socios deportivos que no son socios de cuota. Algo similar sucede en asociaciones culturales cuyos socios buscan producir con sus aportaciones una dinámica de valores distintos o unas costumbres que vayan más allá de las propias paredes de la entidad.

Otro tipo de organizaciones (semi-externalizadas) son aquellas que, si bien priman con sus objetivos finales al destinatario final o usuario, también atienden de forma secundaria a los propios asociados. Son entidades entre las que encontramos a un buen número de las que prestan servicios de ayuda a colectivos con dificultades del tipo que sea. A veces, las mismas de ayuda mutua, aun pareciendo organizaciones sólo pensadas para los afectados, se comportan como punto de referencia y de dinamismo incluso para quienes no están afectados.

Por último, están las entidades (externalizadas) que priman de manera total y absoluta el enfoque en los destinatarios de su actividad. Al menos sobre el papel, las organizaciones ligadas a temas de cooperación internacional hacen un apuesta por este planteamiento. ${ }^{50}$

\section{IV.1.5.3. Voluntarios y personal contratado}

Las personas hacen las organizaciones. Las organizaciones podrán imponer ciertas dinámicas, pero sin las primeras no hay nada que pensar, hacer o decir. Además de las aportaciones señaladas antes, hemos considerado que a la hora de tratar el tema de las personas debíamos optar por una aproximación amplia. Un elemento de distinción relativamente sencillo

50 Ver también una clasificación similar realizada por Casado, dir. (1995). 
viene dado por la cuestión económico-contractual. Por eso distinguimos, como hacen en la mayor parte de las organizaciones, entre voluntarios y personal contratado. En este segundo colectivo nos encontramos con personas entregadas cuya remuneración no alcanza para cubrir la aportación que realizan cotidianamente. Éstos, en muchos casos, son voluntarios con sueldo de subsistencia. Por otro lado, como definición de referencia entendemos que una persona voluntaria es aquella que está en una organización participando activamente en los proyectos y en las decisiones, tanto si es socio de cuota como si no. Es alguien que se implica con su esfuerzo y su voluntad en la vida de la organización. Los grados son diversos y las modalidades muy variadas.

Sabemos que es un tema donde se han de seguir realizando investigaciones empíricas, para ir precisando a partir de la realidad social las características y particularidades del sector. Es el único camino posible, salvo que se pretenda decir de forma axiomática cómo deberían ser las cosas.

En esta línea, observamos que es necesario contrastar las posiciones existentes respecto del voluntariado y las dinámicas socio-políticas que lo legitiman y/o cuestionan. Es un asunto que, además de sus repercusiones en la vida ciudadana, tiene un futuro aparentemente muy abierto.

Podemos comparar los resultados con el estudio titulado Las organizaciones de voluntariado en la ciudad de Zaragoza (2001) y realizado por el Ayuntamiento de Zaragoza, el cual está elaborado sobre un total de 127 organizaciones consideradas en el sector. De estas entidades 104 son asociaciones y representan una base social de 127955 socios — donde se incluyen los 30000 socios donantes de la Hermandad de Donantes de Sangre- y que suponen un total de 12526 voluntarios, de los que 9089 son socios a su vez. Recientemente se han publicado varios trabajos relativos a la materia (Gutiérrez Resa, 2000; Calle, 2000), que precisamente toman la cuestión de la solidaridad y del voluntariado como elementos centrales de su reflexión.

\section{IV.1.5.3.1. Voluntarios}

En nuestra investigación encontramos que la dispersión observable en número de socios y usuarios se reduce cuando la perspectiva de análisis se enfoca hacia los voluntarios. Aun así, 10 entidades aglutinan a 4090 voluntarios, una cifra destacada aunque por debajo de la que aportan otras 184 entidades, que presentan un total de 4757. 
Si la desglosamos por provincias, vemos que la estructura general se repite. En Huesca, 3 entidades agrupan al 43,8\%; en Zaragoza 6 al $49,7 \%$ y en Teruel, son 4 entidades de menor tamaño de 51 a 100 voluntarios las que concentran el $46,7 \%$.

TABLA IV.21

NÚMERO DE VOLUNTARIOS DE LA MUESTRA EN ARAGÓN POR INTERVALOS DE TAMANOO Y NÚMERO DE ENTIDADES

\begin{tabular}{|l|c|c|c|c|}
\hline Intervalo de voluntarios & Núm. de entidades & \% de entidades & Núm. de voluntarios & \% de voluntarios \\
\hline Hasta 50 voluntarios & 155 & 79,90 & 2.484 & 28,17 \\
De 51 a 100 & 29 & 14,95 & 2.273 & 25,78 \\
Más de 100 & 10 & 5,15 & 4.090 & 46,39 \\
Total muestra Aragón & 194 & 100,00 & 8.817 & 100,00 \\
\hline
\end{tabular}

FUENTE: Elaboración propia

TABLA IV.22

NÚMERO DE VOLUNTARIOS DE LA MUESTRA EN LA PROVINCIA DE HUESCA POR INTERVALOS DE TAMAÑO Y NÚMERO DE ENTIDADES

\begin{tabular}{|l|c|c|c|c|}
\hline Intervalo de voluntarios & Núm. de entidades & \% de entidades & Núm. de voluntarios & \% de voluntarios \\
\hline Hasta 50 voluntarios & 27 & 75,00 & 417 & 27,67 \\
De 51 a 100 & 6 & 16,67 & 430 & 28,53 \\
Más de 100 & 3 & 8,33 & 660 & 43,80 \\
Total muestra Huesca & 36 & 100,00 & 1.507 & 100,00 \\
\hline
\end{tabular}

FUENTE: Elaboración propia

TABLA IV.23

NÚMERO DE VOLUNTARIOS DE LA MUESTRA EN LA PROVINCIA DE TERUEL POR INTERVALOS DE TAMAÑO Y NÚMERO DE ENTIDADES

\begin{tabular}{|l|c|c|c|c|}
\hline Intervalo de voluntarios & Núm. de entidades & \% de entidades & Núm. de voluntarios & \% de voluntarios \\
\hline Hasta 50 voluntarios & 19 & 79,17 & 227 & 32,11 \\
De 51 a 100 & 4 & 16,67 & 330 & 46,68 \\
Más de 100 & 1 & 4,17 & 150 & 21,22 \\
Total muestra Teruel & 24 & 100,00 & 707 & 100,00 \\
\hline
\end{tabular}

FUENTE: Elaboración propia 
TABLA IV.24

NÚMERO DE VOLUNTARIOS DE LA MUESTRA EN LA PROVINCIA DE ZARAGOZA POR INTERVALOS DE TAMAÑO Y NÚMERO DE ENTIDADES

\begin{tabular}{|l|c|c|c|c|}
\hline Intervalo de voluntarios & Núm. de entidades & \% de entidades & Núm. de voluntarios & \% de voluntarios \\
\hline Hasta 50 voluntarios & 109 & 81,34 & 1.840 & 27,87 \\
De 51 a 100 & 19 & 14,18 & 1.513 & 22,91 \\
Más de 100 & 6 & 4,48 & 3.280 & 49,67 \\
Total muestra Zaragoza & 134 & 100,00 & 6.603 & 100,00 \\
\hline
\end{tabular}

FUENTE: Elaboración propia

\section{IV.1.5.3.2. Personal contratado}

Si el campo del voluntariado de las organizaciones es bastante dispar, en éste nos encontramos con importantes dosis de diversidad, aunque más acotadas por las posibilidades legales de contratación. Así, existen desde contratos totalmente precarios con unas condiciones laborales inaceptables fuera del contexto asociativo en el que se producen, hasta todo lo contrario.

Si nos guiamos por las cifras que nos ofrece la encuesta, encontramos que el total de empleos remunerados equivalentes se estima en 264,87 , lo que supone un coste laboral medio en el sector servicios de 3,4654 $4^{51}$ millones de pesetas por puesto de trabajo El número de empleados a jornada completa por el conjunto de la muestra equivale al $46,7 \%$ del gasto dedicado por las entidades al personal contratado, con un total de 917871276 pesetas. En Huesca es de un 16,95\%, en Teruel de un 20,04 \% y en Zaragoza de un $51,91 \%$. Es de destacar que en Zaragoza se concentra el mayor volumen de utilización de personal contratado por las asociaciones.

TABLA IV.25

PERSONAL CONTRATADO EN LAS ASOCIACIONES ARAGONESAS

\begin{tabular}{|l|c|c|}
\hline & Coste del personal & \% sobre total de gastos \\
\hline Total & 917.871 .276 & 46,7 \\
Huesca & 44.042 .042 & 16,95 \\
Teruel & 7.514 .000 & 20,04 \\
Zaragoza & 866.315 .234 & 51,91 \\
\hline
\end{tabular}

FUENTE: Elaboración propia

51 INE (1999). 


\section{IV.1.6. Datos económicos}

\section{IV.1.6.1. Ingresos}

Los ingresos totales que manejan las asociaciones de la muestra ascienden a 1949 millones de pesetas. Hay que tener en cuenta que son solamente 194 entidades las que están gestionando tal volumen de recursos, además de no cuantificar el aporte derivado del valor del trabajo voluntario. Si hacemos una extrapolación de estas cifras para dar un visión general de las asociaciones esta cuantía sería aproximadamente de 50200 millones. $^{52}$

La distribución por provincias nos indica que casi la totalidad de los ingresos se concentran en Zaragoza. Ésta representa un total de 1598 millones, frente a Huesca, con 308 millones, y — con un volumen bastante menor- Teruel, con 43 millones.

En términos generales, los ingresos se presentan en equilibrio entre los recibidos por fuentes privadas, 50,2\%, y los fondos obtenidos de los organismos públicos, 49,8\%.

\begin{tabular}{|c|c|c|}
\hline Concepto & Totales (pts.) & Totales (\%) \\
\hline Recaudación cuotas & 352.350 .620 & 18,08 \\
\hline Venta servicios propios & 445.727 .247 & 22,87 \\
\hline Venta otros servicios & 56.381 .319 & 2,89 \\
\hline Donaciones & 51.068 .247 & 2,62 \\
\hline Mecenazgo & 28.325 .436 & 1,45 \\
\hline Otro tipo financiación priv. & 45.362 .143 & 2,33 \\
\hline Ingresos propios & 979.215 .012 & 50,24 \\
\hline Subv. ayuntamientos & 152.465 .925 & 7,82 \\
\hline Subvd. DGA & 325.805 .582 & 16,72 \\
\hline Subv. fondos europeos & 33.631 .317 & 1,73 \\
\hline Subv. otras inst. públ. & 109.838 .835 & 5,64 \\
\hline Convenios con AA. PP. & 347.790 .629 & 17,85 \\
\hline Ingresos públicos & 969.532 .288 & 49,75 \\
\hline Total & 1.948 .747 .300 & 199,99 \\
\hline
\end{tabular}

FUENTE: Elaboración propia

52 Suponiendo una población activa de unas cinco mil asociaciones. 
TABLA IV.27

INGRESOS POR CONCEPTOS Y POR PROVINCIAS

DE LAS ASOCIACIONES DE LA ENCUESTA, 1999

\begin{tabular}{|c|c|c|c|c|c|c|}
\hline \multirow[b]{2}{*}{ Concepto } & \multicolumn{2}{|c|}{ Huesca } & \multicolumn{2}{|c|}{ Teruel } & \multicolumn{2}{|c|}{ Zaragoza } \\
\hline & Pesetas & $\%$ & Pesetas & $\%$ & Pesetas & $\%$ \\
\hline Recal & 43.890 .3 & 14,27 & 9.027 .000 & 21,08 & 299.433 .320 & 18,73 \\
\hline Venta servicios propios & 2.351 .525 & 0,76 & 17.259 .000 & 40,3 & 426.116 .722 & 26,66 \\
\hline Venta otros servicios & 10.398 .575 & 3,38 & 1.812 .200 & 4,23 & 44.170 .544 & 2,76 \\
\hline Donaciones & 23.772 .509 & 7,73 & 1.268 .000 & 2,96 & 26.027 .738 & 1,63 \\
\hline Mecen & 10.888 .436 & 3,54 & 1.225 .000 & 2,86 & 16.212 .000 & 1,01 \\
\hline Otro tipo financiación priv. & 869.251 & 0,28 & 2.275 .000 & 5,31 & 42.217 .892 & 2,64 \\
\hline Ingresos propios & 92.170 .596 & 29,96 & 32.866 .200 & 76,74 & 854.178 .216 & 53,43 \\
\hline Subv & 89.495 .250 & 29,1 & 1.980 .000 & 4,62 & 60.990 .675 & 3,82 \\
\hline & 52.282 .608 & 17,0 & 3.630 .000 & 8,48 & 269.892 .974 & 16,89 \\
\hline & 7.511 .317 & 2,44 & 300.000 & 0,7 & 25.820 .000 & 1,62 \\
\hline & 48.623 .314 & 15,81 & 4.055 .000 & 9,47 & 57.160 .521 & 3,58 \\
\hline Conciertos con AA. PP. & 17.500 .000 & 5,69 & 0 & 0 & 330.290 .629 & 20,66 \\
\hline Ingresos públicos & 215.412 .489 & 70,03 & 9.965 .000 & 23,27 & 744.154 .799 & 46,56 \\
\hline Total & 307.583 .085 & 100,00 & 42.831 .200 & 100 & 1.598 .333 .015 & 100,00 \\
\hline
\end{tabular}

FUENTE: Elaboración propia

Si nos fijamos en las fuentes de ingresos propios de las asociaciones, vemos que la principal es la venta de servicios $(22,9 \%)$. En segunda posición encontramos las cuotas de los asociados, con un 18,1\%, y, en tercer puesto, las donaciones de particulares y empresas, con un 4,1\%.

Los ingresos derivados del Estado proceden fundamentalmente de los convenios con la Administración central, con un monto del 17,9\%, y de las subvenciones del Gobierno de Aragón, con un 16,7 \%.

Por provincias, en Huesca predomina la financiación estatal, con un $70 \%$, mientras que en Teruel y Zaragoza la financiación propia de las asociaciones alcanza valores desiguales de un $76,7 \%$ y de un $53,4 \%$, respectivamente.

En lo que afecta a las fuentes de ingresos privadas, en Huesca el ingreso más destacado proviene de las cuotas de los asociados, con un 14,3\%, en Teruel de la venta de servicios, con un 40,3\%, y en Zaragoza de las ventas de servicios propios, con un $26,7 \%$

La financiación proveniente de las administraciones públicas se distribuye de modo desigual en las tres provincias. Así, en Huesca predomi- 
nan las subvenciones de los ayuntamientos (29,1\%), mientras que en Teruel priman las subvenciones de otras administraciones $(9,47 \%)$ y en Zaragoza los conciertos con la Administración (20,7 \%).

\section{IV.1.6.2. Infraestructura}

La valoración del activo o inversiones de las asociaciones indica la capacidad de desarrollo de actividades futuras de estas entidades. En conjunto las 194 entidades han invertido un total de 4650 millones.

Por provincias las diferencias son mucho más notables que las encontradas en el apartado anterior: casi la totalidad de este activo se concentra en Zaragoza, 4428 millones, frente a los 23 millones de Huesa y los 7 de Teruel. Esta diferencia tan acusada nos lleva a pensar que quizá el principal patrimonio de Teruel está en las personas, mientras que Zaragoza sigue siendo la que devora y absorbe todo.

TABLA IV.28

VALORACIÓN DEL ACTIVO DE LAS ASOCIACIONES DE LA ENCUESTA, 1999

\begin{tabular}{|l|r|c|}
\hline & Totales (pts.) & Totales (\%) \\
\hline Bienes inmuebles & 2.613 .471 .757 & 56,21 \\
Equipamientos & 782.039 .917 & 16,82 \\
Otro tipo infraestructura & 1.254 .322 .041 & 26,98 \\
Total & 4.649 .833 .715 & 100,00 \\
\hline
\end{tabular}

FUENTE: Elaboración propia

TABLA IV.29

INVERSIONES EN ACTIVO POR CONCEPTOS Y POR PROVINCIAS DE LAS ASOCIACIONES DE LA ENCUESTA, 1999

\begin{tabular}{|l|r|r|r|r|r|r|}
\hline & \multicolumn{2}{|c|}{ Huesca } & \multicolumn{2}{c|}{ Teruel } & \multicolumn{2}{c|}{ Zaragoza } \\
\cline { 2 - 7 } & \multicolumn{1}{|c|}{ Pesetas } & \multicolumn{1}{c|}{ Pesetas } & \multicolumn{1}{c|}{ Pesetas } & \multicolumn{1}{c|}{$\%$} \\
\hline Bienes inmuebles & 166.400 .000 & 77,91 & 1.000 .001 & 13,65 & 2.446 .071 .756 & 55,23 \\
Equipamientos & 44.482 .629 & 20,83 & 4.850 .000 & 66,21 & 732.707 .288 & 16,54 \\
Otro tipo financiación & 2.700 .000 & 1,26 & 1.475 .000 & 20,14 & 1.250 .147 .041 & 28,23 \\
Total & 213.582 .629 & 100,00 & 7.325 .001 & 100,00 & 4.428 .926 .085 & 100,00 \\
\hline
\end{tabular}

FUENTE: Elaboración propia 


\section{IV.1.6.3. Gastos}

Si consideramos los gastos realizados por las asociaciones estudiadas durante el año 1999, observamos que ascienden a 1965 millones de pesetas. Éste es un valor prácticamente ajustado a los ingresos (recuérdese, 1949 millones).

Como indicábamos en los ingresos, esta cuantía se refiere a 194 entidades; atendiendo al número de asociaciones y a los gastos generados podríamos estimar la cuantía total en 50644 millones, si consideramos asociaciones activas unas cinco mil. Si ampliamos el espectro y consideramos activas unas diez mil, entonces estaríamos ante unos 101288 millones de gasto. En comparación con el PIB, las asociaciones aragonesas representarían entre el 1,86 \% y el 3,7\%, en 1999 .

Si desglosamos las partidas de este epígrafe, vemos que destacan por encima de las demás los gastos de personal. Éstos son los que suponen la mayor cantidad, con un 46,7\%, seguidos por los de realización de proyectos, con $27 \%$.

Estos porcentajes se modifican notablemente si los diferenciamos por provincias: Zaragoza tiene unos gastos de personal del $52 \%$, los de Teruel suponen el 20,4\% y los de Huesca el $17 \%$.

El segundo elemento señalado, la realización de proyectos, representa un gasto del $60 \%$ en Huesca, del 29,6 \% en Teruel y del 21,8 \% en Zaragoza.

TABLA IV.30

GASTOS POR CONCEPTOS DE LAS ASOCIACIONES ARAGONESAS, 1999

\begin{tabular}{|l|r|r|}
\hline & Totales (pts.) & Totales (\%) \\
\hline Gastos de personal & 917.871 .276 & 46,70 \\
Gastos de formación & 125.344 .872 & 6,38 \\
Gastos de mantenimiento & 203.587 .642 & 10,36 \\
Gastos de publicaciones & 24.954 .034 & 1,27 \\
Gastos de realización de p. & 531.250 .023 & 27,03 \\
Gastos de gestión y administ. & 77.890 .856 & 3,96 \\
Gastos corrientes & 1.880 .898 .703 & 95,70 \\
Compra de bienes y equip. & 84.615 .214 & 4,30 \\
Total de gastos & 1.965 .513 .917 & 100,00 \\
\hline
\end{tabular}

FUENTE: Elaboración propia 
TABLA IV.31

GASTOS POR CONCEPTOS Y POR PROVINCIAS DE LAS ASOCIACIONES DE LA ENCUESTA, 1999

\begin{tabular}{|l|r|r|r|r|r|r|}
\hline \multirow{2}{*}{ Gastos de... } & \multicolumn{2}{|c|}{ Huesca } & \multicolumn{2}{c|}{ Teruel } & \multicolumn{2}{c|}{ Zaragoza } \\
\cline { 2 - 7 } & \multicolumn{1}{|c|}{ Montante } & \multicolumn{1}{c|}{$\%$} & \multicolumn{1}{c|}{ Montante } & \multicolumn{1}{c|}{ Montante } & \multicolumn{1}{c|}{} \\
\hline personal & 44.042 .042 & 16,95 & 7.514 .000 & 20,40 & 866.315 .234 & 51,91 \\
formación & 2.624 .835 & 1,01 & 8.330 .000 & 22,61 & 114.390 .037 & 6,85 \\
mantenimiento & 41.647 .288 & 16,03 & 3.328 .000 & 9,03 & 158.612 .354 & 9,50 \\
publicaciones & 5.980 .697 & 2,30 & 2.430 .600 & 6,60 & 16.542 .737 & 0,99 \\
realización de p. & 156.250 .953 & 60,13 & 10.910 .400 & 29,62 & 364.088 .670 & 21,82 \\
gestión y administr. & 2.306 .000 & 0,89 & 1.540 .000 & 4,18 & 74.044 .856 & 4,44 \\
Gastos corrientes & 252.851 .815 & 97,31 & 34.053 .000 & 92,43 & 1.593 .993 .888 & 95,52 \\
Compra de bienes y equipo & 6.985 .063 & 2,69 & 2.787 .000 & 7,57 & 74.843 .151 & 4,48 \\
Total de gastos & 259.836 .878 & 100,00 & 36.840 .000 & 100,00 & 1.668 .837 .039 & 100,00 \\
\hline
\end{tabular}

FUENTE: Elaboración propia

\section{IV.2. Las fundaciones aragonesas}

El segundo tipo de organizaciones no lucrativas de interés general que vamos a considerar son las fundaciones. Seguiremos la misma estructura de análisis que en el caso de las asociaciones. Centrados en el registro de partida, presentaremos en primer lugar los subsectores de actividad donde operan las fundaciones de la muestra. En segundo lugar, estudiamos la implicación en el marco de Aragón a partir de los receptores de los servicios de estas entidades. A continuación, analizamos uno de los factores fundamentales, como son los recursos humanos implicados en el desarrollo de la actividad. Finalmente, revisaremos los datos económicos referentes a la procedencia de los ingresos, aplicación de los gastos y la inversión en infraestructura.

\section{IV.2.1. Número de fundaciones y distribución geográfica}

En línea con el recorrido realizado respecto de las asociaciones aragonesas, ahora entraremos en un análisis similar. Como punto de inicio, queremos ver cuál es la concentración de fundaciones en las provincias aragonesas. En las asociaciones planteábamos una correlación entre la concentración demográfica y la creación de entidades; lo mismo haremos con las fundaciones. A partir de los datos medios de la población, observamos en el tabla IV.32 que la mayoría de las fundaciones aragonesas, concretamente el $86 \%$, se encuentran domiciliadas en la provincia de Zaragoza. Sin embargo, esta observación no implica necesariamente que sus actividades se limiten a dicha provincia. 
Sin embargo, esta apreciación permite afirmar que la distribución de fundaciones por provincias no responde a la concentración media de población demográfica, que, como indicamos en páginas precedentes, en la provincia de Zaragoza era de un 70-71 \%, en la provincia de Huesca de un $17-18 \%$ y en la provincia de Teruel de un $12 \%$, datos invariables desde 1985 hasta 1999.

Por otra parte, dado que la figura jurídica de fundación tiene como peculiaridad que su nacimiento depende de una concentración de capital y su supervivencia de la rentabilidad del fondo fundacional, podemos presuponer que existirán más fundaciones en aquellas provincias donde exista o bien mayor concentración de capitales, o bien mayor renta provincial, y, además, se detecte una economía vital, mensurable por la evolución del PIB por provincias.

Una vez más se pone de relieve la inercia centrípeta de Aragón, con una tendencia a la centralización en Zaragoza de la vida —esto es, recursos, personas...- de la Comunidad Autónoma.

TABLA IV.32

NÚMERO DE FUNDACIONES, EN 2000

(Actualizado hasta noviembre de 2000)

\begin{tabular}{|c|c|c|c|c|c|c|}
\hline \multirow{2}{*}{ Aragón } & \multicolumn{2}{|c|}{ Huesca } & \multicolumn{2}{c|}{ Teruel } & \multicolumn{2}{c|}{ Zaragoza } \\
\cline { 2 - 7 } & Número & $\%$ Aragón & Número & $\%$ Aragón & Número & $\%$ Aragón \\
\hline 183 & 18 & 9,84 & 16 & 8,74 & 149 & 81,42 \\
\hline
\end{tabular}

FUENTE: Registro de Fundaciones de la Diputación General de Aragón, Boletín Oficial de Aragón y Centro de Fundaciones (1995)

TABLA IV.33

DISTRIBUCIÓN DE LAS ASOCIACIONES DIFERENCIANDO CAPITAL DE PROVINCIA Y RESTO DE LA PROVINCIA

(Actualizado hasta noviembre de 2000)

\begin{tabular}{|l|c|c|c|c|c|c|}
\hline & \multicolumn{2}{|c|}{ Huesca } & \multicolumn{2}{c|}{ Teruel } & \multicolumn{2}{c|}{ Zaragoza } \\
\cline { 2 - 7 } & Capital & Resto prov. & Capital & Resto prov. & Capital & Resto prov. \\
\hline Número & 9 & 9 & 7 & 9 & 114 & 35 \\
\% sobre el total de Aragón & 4,92 & 4,92 & 3,83 & 4,92 & 62,30 & 19,13 \\
\% sobre la provincia & 50,00 & 50,00 & 43,75 & 56,25 & 76,51 & 23,49 \\
Total de gastos & 259.836 .878 & 100,00 & 36.840 .000 & 100,00 & 1.668 .837 .039 & 100,00 \\
\hline
\end{tabular}

FUENTE: Registro de Fundaciones de la Diputación General de Aragón, Boletín Oficial de Aragón y Centro de Fundaciones (1995) 
IV.2.2. Clasificación de las actividades de las fundaciones de Aragón

En relación con el análisis de las actividades que son habituales en el conjunto del sector fundacional aragonés, la tabla IV.34 nos indica que estas entidades concentran sus esfuerzos mayoritariamente en la atención a objetivos y acciones vinculadas con los servicios sociales. La cifra de referencia que obtenemos en este sector de actividad es de un 47,3\%. En segundo lugar encontramos las dedicadas a cuestiones vinculadas con la educación, con un 18,1\%. En tercer puesto, las fundaciones en el ámbito de la cultura, con un peso de un $11,5 \%$.

Si analizamos los datos por provincias, nos encontramos con que en Huesca - tabla IV.35- las actividades se distribuyen siguiendo la pauta general entre servicios sociales, con un $44,4 \%$, cultura, con un $33,3 \%$, y educación, con un $11,1 \%$.

En el caso de la provincia de Teruel, se concentran en mayor número en el sector de servicios sociales, con un $62,5 \%$, y, en segundo lugar, en cultura, con un $18,8 \%$. El resto se distribuye a partes iguales, $6,25 \%$, entre educación, medio ambiente y desarrollo comunitario, con una entidad en cada caso.

TABLA IV.34

NÚMERO DE FUNDACIONES EN ARAGÓN CLASIFICADAS POR TIPO DE ACTIVIDAD (Actualizado hasta noviembre de 2000)

\begin{tabular}{|c|l|c|c|}
\hline Código & Actividad & Número de entidades & \% de entidades \\
\hline 1 & Cultura y ocio & 21 & 11,54 \\
2 & Deportivas & 1 & 0,55 \\
3 & Educación, formación e investigación & 33 & 18,13 \\
4 & Salud & 2 & 1,10 \\
5 & Servicios sociales & 87 & 47,25 \\
6 & Medio ambiente & 6 & 3,30 \\
7 & Desarrollo comunitario & 12 & 6,59 \\
8 & Derechos civiles, políticos y legales & 0 & 0,00 \\
9 & Intermediarios filantrópicos y del voluntariado & 4 & 2,20 \\
10 & Cooperación internacional & 1 & 0,55 \\
11 & Religiosas & 10 & 5,49 \\
12 & Profesionales & 0 & 0,00 \\
13 & Otros fines & 6 & 3,30 \\
& Total Aragón & 183 & 100,00 \\
\hline
\end{tabular}

FUENTE: Registro de Fundaciones de la Diputación General de Aragón, Boletín Oficial de Aragón y Centro de Fundaciones (1995) 
TABLA IV.35

NÚMERO DE FUNDACIONES EN HUESCA, TERUEL Y ZARAGOZA

CLASIFICADAS POR TIPO DE ACTIVIDAD

(Actualizado hasta Noviembre, 2000)

\begin{tabular}{|c|l|r|r|r|r|r|r|}
\hline \multirow{2}{*}{ Código } & \multirow{2}{*}{ Actividad } & \multicolumn{2}{|c|}{ Huesca } & \multicolumn{2}{|c|}{ Teruel } & \multicolumn{2}{|c|}{ Zaragoza } \\
\cline { 2 - 7 } & Núm. & $\%$ & Núm. & $\%$ & Núm. & $\%$ \\
\hline 1 & Cultura y ocio & 6 & 33,33 & 3 & 18,75 & 12 & 8,05 \\
2 & Deportivas & 1 & 5,56 & 0 & 0,00 & 0 & 0,00 \\
3 & Educación, formación e investigación & 2 & 11,11 & 1 & 6,25 & 30 & 20,13 \\
4 & Salud & 0 & 0,00 & 0 & 0,00 & 2 & 1,34 \\
5 & Servicios sociales & 8 & 44,44 & 10 & 62,50 & 69 & 46,31 \\
6 & Medio ambiente & 0 & 0,00 & 1 & 6,25 & 5 & 3,36 \\
7 & Desarrollo comunitario & 1 & 5,56 & 1 & 6,25 & 10 & 6,71 \\
8 & Derechos civiles, políticos y legales & 0 & 0,00 & 0 & 0,00 & 0 & 0,00 \\
9 & Intermediarios filantrópicos y del voluntariado & 0 & 0,00 & 0 & 0,00 & 4 & 2,68 \\
10 & Cooperación internacional & 0 & 0,00 & 0 & 0,00 & 1 & 0,67 \\
11 & Religiosas & 0 & 0,00 & 0 & 0,00 & 10 & 6,71 \\
12 & Profesionales & 0 & 0,00 & 0 & 0,00 & 0 & 0,00 \\
13 & Otros fines & 0 & 0,00 & 0 & 0,00 & 6 & 4,03 \\
& Total & 18 & & 16 & 100,00 & 149 & 100,00 \\
\hline
\end{tabular}

FUENTE: Registro de Fundaciones de la Diputación General de Aragón, Boletín Oficial de Aragón y Centro de Fundaciones (1995)

Para la provincia de Zaragoza la distribución que hallamos sigue presentando el mismo reparto del conjunto del país: primero las actividades de servicios sociales, con un 46,3\%, segundo, las de educación, con un $20,1 \%$, y en tercer lugar, las de cultura, con un $8 \%$.

El abanico de actividades de las fundaciones que se inscriben en el ámbito del servicio social es diverso y amplio. Las posibilidades son muchas, si bien hay unas líneas en común entre las entidades actualmente existentes. Así, observamos que las concreciones de servicio social vienen determinadas por distintas variables, de las que cabe destacar cuatro. Primera, las edades de los destinatarios —esto es, desde ancianos hasta niños-, de las cuales destaca de modo especial la atención a la infancia. Segunda, la forma o condición de minusvalía de los usuarios, que acotan un determinado tipo de acción. Tercera, la variable de sexo, otorgando especial relieve a las acciones destinadas a la mujer. Cuarta, la inclusiónexclusión social, lo que hace que se trabaje con colectivos en zonas de marginalidad social; en este caso se hace mención expresa de apoyo a las unidades familiares de capas marginales. 
Otra actividad atendida por el sector aragonés de fundaciones es la investigación en campos tecnológicos innovadores y en el ámbito de la salud. Por último, encontramos las dedicadas al desarrollo comunitario, en las que prima el uso de herramientas culturales y formativas, con una especial preocupación por problemas derivados de la falta de trabajo en capas sociales paulatinamente más inactivas.

Si nos fijamos en las ausencias, un detalle destacable es la no existencia en nuestra comunidad autónoma de ninguna de las llamadas organizaciones no gubernamentales de desarrollo (ONGD) con forma jurídica de fundación. Así, se produce la misma circunstancia respecto de entidades con el fin prioritario de protección y fomento profesional (código 12). Este objetivo fundacional se encuentra presente en la constitución de varias fundaciones aragonesas, pero como actividad de carácter secundario.

Otros aspectos a subrayar son la escasa presencia de actividad en el ámbito de la educación, la formación y la investigación entre las fundaciones oscenses, junto con actuaciones orientadas a la salud, característica que también destaca en el caso de Teruel. Por otra parte, la provincia turolense, a pesar de su incalculable riqueza en patrimonio artístico, no suele utilizar la figura de la fundación para gestionar su promoción y mantenimiento (código 14), ni se ha potenciado en dicha zona la creación de ese tipo de entidades para fomentar el desarrollo comunitario.

\section{IV.2.3. Evolución temporal en la creación de las fundaciones}

En relación con la evolución experimentada en el crecimiento de las fundaciones aragonesas — de acuerdo con los datos obtenidos-, los últimos cinco años han marcado un período de alta densidad e intensidad. Concretamente, de las fundaciones consideradas en la actualidad como activas, el $70 \%$ han nacido en el período que media desde la implantación de la Ley 30/1994 hasta nuestros días, como se aprecia en la tabla IV.36.

Los factores que pueden vincularse a esta explosión son de varios tipos. Unos son contextuales, debidos al ambiente de cierta expansión socioeconómica. Sin ser un tiempo de gran bonanza económica, tras la crisis de la primera mitad de la década de los noventa, la segunda ha sido un 
tiempo de expansión relativa. Otros son los derivados de la modificación de la ley y la mejora del marco jurídico, que ha permitido poner en marcha iniciativas de este tipo siguiendo el trazo de la nueva legalidad.

TABLA IV.36

EVOLUCIÓN DE LA CREACIÓN DE LAS FUNDACIONES EN ARAGÓN

(Actualizado hasta noviembre de 2000)

\begin{tabular}{|l|c|c|}
\hline Periodo & Núm. fundaciones & Incremento \\
\hline 1. Antes 1995 & 89 & $1 \%$ \\
2. $1995 / 1996$ & 21 & $24 \%$ \\
3. $1997 / 1998$ & 40 & $36 \%$ \\
4. $1999 / 2000$ & 33 & $22 \%$ \\
\hline
\end{tabular}

FUENTE: Registro de Fundaciones de la Diputación General de Aragón, Boletín Oficial de Aragón y Centro de Fundaciones (1995)

TABLA IV.37

EVOLUCIÓN DE LA CREACIÓN DE LAS FUNDACIONES POR PROVINCIAS (Actualizado hasta noviembre de 2000)

\begin{tabular}{|l|c|c|c|c|c|r|}
\hline \multirow{2}{*}{ Periodo } & \multicolumn{2}{|c|}{ Huesca } & \multicolumn{2}{c|}{ Teruel } & \multicolumn{2}{c|}{ Zaragoza } \\
\cline { 2 - 7 } & Núm. fund. & $\%$ & Núm. fund. & $\%$ & Núm. fund. & $\%$ \\
\hline 1. Antes 1995 & 9 & 1 & 9 & 1 & 71 & 1 \\
2. $1995 / 1996$ & 1 & 11 & 2 & 22 & 18 & 25 \\
$3.1997 / 1998$ & 3 & 30 & 4 & 36 & 33 & 37 \\
$4.1999 / 2000$ & 5 & 38 & 1 & 7 & 27 & 22 \\
\hline
\end{tabular}

FUENTE: Registro de Fundaciones de la Diputación General de Aragón, Boletín Oficial de Aragón y Centro de Fundaciones (1995)

\section{IV.2.4. Las personas}

Como ya decíamos al analizar las asociaciones, el factor humano también es la clave de la mayoría de las fundaciones. Aunque la ley dice que en una fundación lo que prima es el capital que se pone al servicio de un determinado fin, la experiencia nos remite a las personas. Es a partir de la red de relaciones humanas desde donde se vertebra o se anquilosa, se posibilita o se impide, la vida de estas entidades.

En el sector de fundaciones aragonesas nos encontramos con las mismas inercias que en el de asociaciones. Si bien es cierto que hay un matiz 
que transmite un aparente mayor grado de implicación —al menos, económica...- cada una de las organizaciones se ve sometida a los ritmos de las individualidades que las constituyen. Por eso el abanico vuelve a ser variado y diverso, tanto en los objetivos y los planteamientos ideológicos como en la impronta que transmiten a la sociedad.

En el caso de las fundaciones, el peso estructural de la gestión y toma de decisiones pasa por el patronato. En la mayoría de los casos traza las grandes líneas de actuación y la "política» de la entidad. Ejerce como órgano de supervisión y control, para dejar actuar dentro de los límites marcados al equipo gestor de la fundación. Los casos son, como hemos dicho, variados y diversos. Por eso también hay fundaciones que se parecen más a una asociación donde las «bases» participan de la gestión y otras que se alejan completamente, pues queda claro cuál es el orden vertical de jerarquías.

Este aspecto afecta especialmente a la relación con las personas voluntarias que se acercan o colaboran con la entidad. En algunos casos, la implicación con la fundación se ve potenciada por la posibilidad de incorporarse a la marcha de la organización. Si esto no se da, el número de voluntarios y su aportación tiende a ser de una calidad relativa menor, aunque con la salvedad derivada de la vinculación con la población beneficiaria. La variedad de usuarios de las diversas fundaciones es tan amplia como la de las mismas organizaciones.

TABLA IV.38

NÚMERO DE USUARIOS ATENDIDOS POR LAS FUNDACIONES ARAGONESAS DE LA MUESTRA, 1999

\begin{tabular}{|l|c|}
\hline Intervalo de usuarios & Núm. de entidades \\
\hline Hasta 50 usuarios & 11 \\
De 51 a 250 & 1 \\
Más de 250 & 2 \\
Total muestra & 16 \\
\hline
\end{tabular}

FUENTE: Elaboración propia

\section{IV.2.4.1. Usuarios}

Respecto del número de usuarios de las fundaciones — tanto en sentido estricto como si son considerados beneficiarios que reciben sus servicios-, la cifra resultante de nuestra investigación empírica es de 4132 personas. 
En algunos casos, las fundaciones aragonesas realizan actividades que repercuten directamente en el conjunto de la sociedad. Sus objetivos incluso transcienden la nación para beneficiar a todo el planeta, sin distinciones. Otras tienen un horizonte mucho más localizado, lo cual hace que el número de usuarios sea muy elevado.

También se ha de recordar, que, en función de cómo concibamos la noción de usuario, algunas fundaciones amplían el conjunto de destinatarios. Un ejemplo de esto es el caso de la fundaciones con fines educativos. Si consideramos el caso de un colegio concebido como fundación, encontramos casos con más de 1500 alumnos matriculados. El número de usuarios de la fundación puede ser considerado desde distintas perspectivas. Una, el número de estudiantes. Otra, el número de familias. Otra, la suma de padres e hijos... Con ello queda abierta la posibilidad de cuantificar de un modo homogéneo este aspecto de las fundaciones.

\section{IV.2.4.2. Voluntarios y personal contratado}

Respecto del número de voluntarios - tomando como valor de referencia las respuestas dadas por las entidades de la muestra de la investigación-, encontramos que éstas aglutinan a un total de 51 personas. Son voluntarios que están repartidos de forma muy desigual. Solamente seis de estas fundaciones manifiestan tener voluntarios participando en su entidad. Una cifra tan reducida nos hace volver a reflexionar acerca de si la definición de voluntario es algo común para todos, o más bien nos encontramos ante una realidad emergente que está en proceso. Como tarea pendiente queda una revisión particularizada de cada caso más allá de las respuestas a un cuestionario.

Por otro lado, el número de personas contratadas por la fundaciones de la muestra ofrece una cifra que supera la de voluntarios. Estamos hablando de un total de 77 contratos, también distribuidos de forma desigual y con características laborales muy heterogéneas. De las 16 entidades 8 especifican que tienen personal contratado, el cual oscila de una sola persona a 28 .

Por tanto, estos datos nos permiten hablar de una desigual y escasa vertebración de los recursos humanos en el sector. Con toda probabilidad estamos ante un tipo de estructuras organizativas que resultan difíciles de homologar y que, como tales, tienen mucho que recorrer para extenderse 
por la sociedad aragonesa. Ello no significa que no haya destacados ejemplos donde bajo la figura jurídica de la fundación encontramos verdaderos instrumentos de organización social, con numerosas personas implicadas, desde los patronos, pasando por empleados, voluntarios y usuarios.

\section{IV.2.5. Datos económicos: ingresos, infraestructura y gastos}

Como ya hemos indicado, la muestra de fundaciones es de 16 entidades y los datos recabados nos dicen que han obtenido 1066 millones de pesetas de ingresos brutos. Tomando este dato como punto de partida, podríamos estimar que el conjunto de fundaciones aragonesas tendría como ingresos alrededor de unos 12000 millones de pesetas.

Las fuentes de dichos ingresos se reparten según una distribución mixta que corresponde en un $85,7 \%$ a fuentes privadas y en un $14,3 \%$ públicas. Los porcentajes son muy diferentes a los de las asociaciones, que se situaban en torno al 50\% para cada ámbito.

Si consideramos los tipos de ingresos, primero tenemos que destacar las donaciones tanto de patrocinadores como legados (45\%), segundo, la prestación de servicios $(28 \%)$ y, tercero, las cuotas de afiliados, con un porcentaje reducido $(3,7 \%)$.

Respecto de las fuentes públicas, observamos que la primera institución financiadora es el Gobierno de la Comunidad Autónoma de Aragón, con un $7,4 \%$, seguida de diversas Administraciones locales, con un $5,6 \%$. Ambas son las que aportan más recursos al sector, los que proceden de fondos europeos y de la Administración central son muy inferiores.

La inversión realizada por las 16 fundaciones asciende a un total de 1238 millones. La distribución de esta cantidad se hace, primero, en inversiones financieras, con un 37,66 \%, segundo, en infraestructuras diversas, con un 31,63\%, continuando con bienes inmuebles $(22,44 \%)$ y equipamientos $(8,27 \%)$. Como es de esperar, los capitales fundacionales han de estar en una posición relevante, dado que ésa es la clave de esta figura jurídica. Aunque los capitales puestos al servicio de fines no sean muy cuantiosos, la media de ellos sumada a las inversiones en bienes inmuebles hacen que la muestra nos permita hablar de un sector asentado. 
TABLA IV.39

VALORACIÓN DEL ACTIVO DE LAS FUNDACIONES ARAGONESAS DE LA MUESTRA, 1999

\begin{tabular}{|l|c|c|r|r|}
\hline & Totales & Núm. respuesta con cifra & Media & $\%$ \\
\hline Inversiones financieras & 466.311 .526 & 12 & 31.087 .435 & 37,66 \\
Bienes inmuebles & 277.790 .000 & 4 & 18.519 .333 & 22,44 \\
Equipamientos & 102.445 .111 & 8 & 6.829 .674 & 8,27 \\
Otro tipo de infraestructura & 391.645 .000 & 4 & 26.109 .667 & 31,63 \\
Total & 1.238 .191 .637 & & 82.546 .109 & 100,00 \\
\hline
\end{tabular}

FUENTE: Elaboración propia

TABLA IV.40

GASTOS SEGÚN LOS DIFERENTES CONCEPTOS, TOTALES DE LA MUESTRA DE FUNDACIONES Y PORCENTAJE, 1999

\begin{tabular}{|l|r|r|}
\hline Tipo de gasto & \multicolumn{1}{|c|}{ Totales } & \multicolumn{1}{c|}{$\%$} \\
\hline Gastos generados por el patronato & 70.000 & 0,01 \\
Gastos de administración & 21.811 .598 & 4,45 \\
Gastos propios de captación de fondos & 3.800 .000 & 0,78 \\
Gastos de personal & 236.017 .590 & 48,16 \\
Gastos por publicaciones propias & 32.107 & 0,01 \\
Gastos de asesoramiento externo y tramitación & 4.385 .252 & 0,89 \\
Gastos por utilización de inmuebles & 43.057 .302 & 8,79 \\
Gastos por proyectos sociales & 180.900 .000 & 36,91 \\
Total & 490.073 .849 & 100,00 \\
\hline
\end{tabular}

FUENTE: Elaboración propia

En la partida correspondiente a los gastos, la suma de los distintos gastos realizados asciende a un total de 490 millones. Si recordamos la cifra anterior, esto indica que la diferencia entre gastos e ingresos es de 576 millones de saldo positivo.

La distribución de los gastos gira en torno a dos puntos principales. El primero es el que se asigna a personal, con un porcentaje del 48,1\%. En segundo lugar está la realización de proyectos, con un 36,9\%. Los demás asuntos, salvo el uso de inmuebles y gastos de administración, son realmente mínimos. Es llamativa la escasa divulgación de publicaciones propias, así como la poca cantidad de recursos destinados a la captación de fondos. Esto nos sugiere dos lecturas opuestas: o bien una desvinculación de ese tipo de actividad como tarea de las fundaciones, o bien una falta de capacidad para buscar más allá de los cauces ya establecidos en cada una de las entidades. 
TABLA IV.41

INGRESOS SEGÚN LOS DIFERENTES CONCEPTOS: TOTALES Y PORCENTAJE SOBRE LA MUESTRA DE FUNDACIONES, 1999

\begin{tabular}{|l|r|r|}
\hline Tipo de ingreso & \multicolumn{1}{|c|}{ Totales } & \multicolumn{1}{c|}{$\%$} \\
\hline Recaudación en cuotas de afiliados & 39.102 .173 & 3,67 \\
Por prestación de servicios & 298.048 .701 & 27,95 \\
Dotaciones percibidas de patrocinadores & 267.200 .000 & 25,06 \\
Donaciones y legados en forma dineraria o en especie & 220.757 .363 & 20,70 \\
Otro tipo de financiación externa & 88.872 .367 & 8,33 \\
Ingresos corrientes & 913.980 .604 & 85,71 \\
Financiación de subvenciones fondos europeos & 6.216 .471 & 0,58 \\
Financiación de subvenciones Estado central & 8.000 .000 & 0,75 \\
Financiación de subvenciones Comunidad Autónoma & 78.362 .007 & 7,35 \\
Financiación de subvenciones entidades locales & 59.812 .147 & 5,61 \\
Ingresos públicos & 152.390 .625 & 14,29 \\
Total & 1.066 .371 .229 & 100,00 \\
\hline
\end{tabular}

FUENTE: Elaboración propia

\section{IV.2.6. Como acotación y contrapunto}

Las fuentes que hemos utilizado para caracterizar cuantitativamente el número de fundaciones en Aragón proceden del registro de la Diputación General de Aragón, el Centro de Fundaciones y el Boletín Oficial de Aragón. Los únicos datos que incluyen dichas fuentes son el nombre social de la fundación, la fecha de creación, el domicilio y los fines de la fundación. Hemos tenido que buscar otros mecanismos y medios de información, debido a que el Registro de Fundaciones presenta los siguientes aspectos:

- El registro sólo contenía los datos registrales de aquellas fundaciones adaptadas al título I de la Ley 30/1994, sin que quedara constancia de aquellas entidades pendientes de atender requisitos administrativos y, sin embargo, con un auténtico peso social en la Comunidad Autónoma.

- El Registro de Fundaciones no presenta ninguna delegación de fundaciones extranjeras o con ámbito nacional, que, sin embargo, sabemos que operan en nuestra comunidad autónoma con una relevancia expresa en niveles de efectividad social. 
- El registro carece de referencias de fundaciones de tipo religioso, inscritas en el Arzobispado de Zaragoza.

- El registro presenta datos administrativos que, cuando se cotejan con datos reales, ponen de manifiesto una palpable desactualización de la información depositada en el Servicio de Régimen Jurídico y Registros, especialmente en lo referente a domiciliación fundacional.

Ante esta realidad, la base de datos proporcionada por la DGA ha sido completada y actualizada a partir de datos proporcionados por plataformas y coordinadoras, como el Centro de Fundaciones, sin que hasta el momento podamos garantizar haber alcanzado la completitud y exhaustividad deseada.

Los datos de las asociaciones proceden de los registros generales de Zaragoza, Huesca y Teruel, actualizados hasta noviembre de 2000. 


\section{CAPÍTULO V \\ UN ANÁLISIS DE LA FUNCIÓN SOCIAL Y ECONÓMICA DEL SECTOR NO LUCRATIVO EN ARAGÓN}

\section{V.1. Introducción}

En este capítulo, queremos estudiar las ONL acentuando el análisis transversal de tres aspectos: su función social, su funcionamiento interno y su impacto socioeconómico. En los dos anteriores hemos insistido en cuantificar y conocer de qué estamos hablando cuando nos referimos al Tercer Sector.

Uno de los principales resultados es que no tenemos una aproximación exacta al conjunto del sector - y rara vez se tendrá, dadas sus características intrínsecas-, pero sí sabemos que, en la actualidad, la Administración pública, en el caso de las asociaciones, financia en torno al $50 \%$ de sus actividades, a la par que existen diferentes medidas reguladoras y legislativas que afectan a estas entidades. Quizá es el momento de plantear elementos que sirvan de apoyo para valorar la tarea de estas entidades e instrumentos que lo faciliten, tanto para las propias ONL como para la Administración y la sociedad, en general. Por eso son oportunas preguntas como: ¿qué papel desempeñan estas entidades en la sociedad aragonesa?, ¿cuáles son sus modos de hacer?, ¿cuál es el capital social de nuestra comunidad?, ¿cuál es su grado de profesionalización y participación interna?, ¿cómo evaluar sus prácticas, acciones y resultados?, ¿qué grado de transparencia hemos de exigir desde la sociedad aragonesa?, ¿cómo construir los canales de informa- 
ción adecuados? También las relaciones entre la Administración pública y las ONL son una clave fundamental, tanto en la ciudad como en los pueblos del país — ¿estamos construyendo "Zaragón»?- - Y cómo no, la relación entre la empresa y las ONL. Como actores de la sociedad, estas organizaciones ocupan diversas posiciones en todos los ámbitos de la vida ciudadana. Negocian su lugar en el mundo e intervienen desde ellos generando espacios sociales de sentido y legitimidad.

Así, uno de los elementos que en este momento se destaca con más asiduidad es la percepción y atribución colectiva de una mayor versatilidad, agilidad y dinamismo como supuesta muestra de una mayor eficiencia social y económica de las ONL, frente a otro tipo de organizaciones, especialmente la Administración pública o empresas lucrativas.

Ahora ofrecemos unas coordenadas teóricas de partida con las cuales acotar la cuestión de la eficiencia social —más compleja que la eficacia al menor coste que se plantea para la eficiencia económica-, considerando como referencias tanto la literatura existente como los universos simbólicos que las generan socialmente.

Hemos entendido, desde el comienzo, que nos movemos en un sistema social complejo, donde distintos subsistemas dan pie a esferas de legitimación y acción variadas. Los procesos de diferenciación social posibilitan y constriñen los ámbitos de acción y de sentido de las ONL.

Funcionan de forma autónoma como subsistemas abiertos en interacción con otros, pero pueden ser considerados en su conjunto con unos elementos comunes que permitan elaborar una «medición-valoración», utilizando un repertorio de indicadores de eficiencia social ad hoc, elaborados en el trabajo de campo de nuestra investigación.

El horizonte hacia el que apuntamos es tanto el diagnóstico del sector como la propuesta de evaluación prospectiva, entendida como un elemento de definición de grandes líneas donde apostar colectivamente de cara a conseguir lo que Robert Bellah (Bellah et al., 1992) denominaba «Buena Sociedad» o lo que Pérez Adán (2000), siguiendo a Etzioni (1999), llama «Salud Social».

Hemos estudiado, por tanto, la eficiencia y eficacia del sector no lucrativo en Aragón, insistiendo en elementos como su gestión, participación y realidad que generan desde sus diversos campos de actuación cotidiana. 


\section{V.2. Una reflexión sobre los conceptos de eficiencia y eficacia social}

Como hemos visto hasta este punto, el Tercer Sector ocupa una posición relevante en la sociedad aragonesa. Además, las organizaciones del sector incrementan pausada y paulatinamente su presencia y visibilidad social. Como ya hemos dicho, las ONL rechazan el uso de criterios basados en el beneficio propio y exclusivo. También hemos visto que dentro de este universo tienen cabida un sinnúmero de actividades, organizaciones y grupos. Si recordamos apartados anteriores, hemos considerado que las ONL tienen unas peculiaridades que hacen difícil su acomodo en los esquemas tradicionales de distinción de ámbitos. Por un lado, son una parte del sector privado de un sistema social; con esto distinguimos las ONL de la Administración pública —Estado- y del sector privado lucrativo tradicional — mercado- Por otro, para algunos autores (Abrahamson, 1994) se encuentran en el punto medio entre Estado, sociedad civil y mercado de las sociedades del bienestar, en eso que se ha dado en llamar welfare mix.

Ahora continuamos con nuestro análisis del sector no lucrativo aragonés considerando su eficiencia económica y su eficiencia social como entidades sin ánimo de lucro, en un contexto de complejidad social creciente. Respecto de la primera noción, parece que los conceptos y teorías están claros, mientras que para la segunda las cosas son algo diferentes. En trabajos anteriores ${ }^{53}$ hemos revisado la literatura científica sobre la materia, donde constatábamos una ausencia conceptual respecto de la noción de eficiencia social. en unos casos, porque se da por supuesto el significado; en otros, porque se utiliza como un adjetivo más a la hora de calificar organizaciones o actividades sociales sin aclarar de qué se trata.

Sea cual sea la ubicación, lo cierto es que en la actualidad nos encontramos con que se produce un juego ideológico en el cual se utilizan las ONL para reducir el rol del Estado y de sus políticas sociales. El argumento es bastante simple: 1) las ONL son buenas para la sociedad por-

53 En este apartado seguimos lo dicho en Marcuello (1999): The increase of societal complexity, non-profit entities and social efficiency. A Sociocybernetic Approach to a Social Efficiency Concept and its Measurement, Papers, Crete, Meeting, RC51 on Sociocybernetics. Véase también Moneva y Ch. Marcuello (2001). 
que mejoran el desarrollo de ésta y, como 2) estas ONL son socialmente más eficientes que las políticas estatales; 3) por tanto, cualquier sociedad necesita más y más ONL. A la par, observamos un paralelismo: proceso de de-construcción del Estado y promoción del Tercer Sector. El sistema social se está transformando por un camino de re-ingeniería, como si una desconocida mano negra dilapidase las formas de legitimación tradicionales del Estado sacándolo del centro, disolviendo su rol y extendiendo la sensación de impotencia ante la complejidad del mercado y los procesos económicos.

La cuestión de la eficiencia social de las ONL se convierte en un punto neurálgico de nuestra investigación, dado que el contexto general utiliza este referente como criterio de discriminación de acciones y de recursos. Ya hemos dicho que lo público es aquello que es patrimonio del pueblo, es decir, de los ciudadanos y ciudadanas; no es sólo cuestión privativa del Estado. La ciudadanía es quien decide cómo y para qué se han de hacer las cosas..., pero no significa automáticamente que el rol del Estado deba ser soslayado o reducido a la mínima expresión, como parece sugerir la corriente político-económica imperante.

$\mathrm{Al}$ revés, si tomamos en serio la necesidad de gestionar bien las cosas comunes, entonces la eficiencia económica se convierte en obligación inseparable de un balance social. Es decir, si nos imponemos políticas que primen la eficiencia económica, éstas han de ser un correlato de la eficiencia social. Desde nuestro punto de vista, la relación entre lo económico, lo político y lo social es inextricable e ineluctable.

Pero aquí es donde nos topamos con un problema de partida. Si para la eficiencia económica las cosas parecen estar claras y definidas con cierta precisión desde la ciencia económica, al pasar a la eficiencia social nos encontramos con lo dicho antes, y, por tanto, necesitamos definir qué es ésta exactamente. El problema estriba en que la respuesta presenta muchas dificultades. Como punto de arranque, afirmamos que la eficiencia social «es un concepto intersubjetivo y una noción temporalmente dependiente dentro de un sistema social, en el cual los individuos están siempre actuando y reaccionando. Lo que cuenta como eficiencia social en una sociedad compleja es consecuencia de un proceso sistémico mútiple y selectivo, pero puesto en marcha siempre por sujetos o instituciones» (C. Marcuello, 1999). 
Por eso, para encontrar una posible definición de qué es aquello socialmente eficiente, entendemos que son necesarios tres peldaños de un mismo recorrido: ${ }^{54}$

1) auto-definición de la eficiencia social desde los actores sociales como creadores de significado;

2) análisis de sus discursos como conciencia auto-poiética y referencia normativa;

3) propuesta de indicadores para medir su cumplimiento en ONL.

Así, en el caso del concepto de eficiencia social, primero han de ser los sujetos sociales implicados quienes formulen su interpretación del concepto. Es desde el contexto de estudio desde donde se pregunta a los actores sociales — piezas involucradas en la creación de significados del sistema-, para que auto-definan y sean referencia de la creación de significado. En un segundo paso, se han de tomar sus discursos como fuente auto-poiética de conciencia y de referencia normativa de sí mismos y del sistema social donde se insertan. Por último, nuestra tarea es destilar — conjunta y auto-referencialmente- un repertorio de indicadores con los cuales abordar la evaluación de la eficiencia social en las ONL.

54 «El enfoque sociocibernético afirma y acentúa que los valores y significados sociales son siempre una construcción. El conocimiento no está "ahí fuera"; esto supone que los conceptos son productos de un sistema social, esto es, una producción de la comunidad o vecindad científica, entre otros niveles creadores de conceptos. El científico social no es un cazador de conocimiento y de observaciones ajenas a él mismo. Su acto de observación condiciona lo observado. Tanto quien hace ciencia como quien sin pensar más forma parte de un sistema social se encuentran dentro de un marco de referencia con el que interaccionan dialécticamente. Individuo y sistema social son dos asuntos sólo separables en el análisis. Y paradójicos. Por un lado, creamos mundos de palabras, pero siempre llegamos tarde: la sociedad estaba ya ahí. Los sistemas sociales estaban antes. Nadie conoce a Adán y nosotros, como seres humanos, somos consecuencia de un nacimiento de segundo orden: el proceso de socialización. Proceso que no es otra cosa que el modelado del sujeto por parte del sistema social. Es decir, la introyección de orden social en el soporte biológico para consolidar un individuo humano. Incorporamos el orden del sistema social, su cosmología, su Weltanschauung en tanto en cuanto nos hacemos cargo del mundo de significados de ese sistema social. En realidad, sólo somos palabras y tiempo. Somos un conjunto de conceptos averiguando y buscando nuestro horizonte y nuestro sentido. Pero siempre en un sistema de palabras, en un sistema social.» (Marcuello, 1999.) 
Nuestro punto de partida, en el estudio de la eficiencia social de las ONL en Aragón, ha sido buscar cauces de descripción del sistema y de esta noción —eficiencia social— dentro de él.

En primr lugar, delimitamos las coordenadas del universo a estudiar y elaborado un mapa y una recopilación de trayectorias. ${ }^{55}$ Con esas claves iniciales sobre la mesa, hemos pasado a preguntar a las personas implicadas en las redes de ONL existentes en Aragón. En paralelo, también hemos contrastado las mismas preguntas con quienes articulan y generan relaciones significativas en esta parte del sistema social. Los actores han sido elegidos en función de su participación en ONL, y abarcan el conjunto de las referencias políticas, además de la edad y del sexo. Las personas han sido minuciosamente seleccionadas revisando su trayectoria. Son personas activas, nudos importantes de relaciones en el contexto aragonés.

Como intentamos estudiar la práctica real de las ONL, y en ellas su eficiencia social, tenemos que atender al proceso de auto-definición de la eficiencia social a partir de los actores sociales como creadores de significado y como protagonistas de ellas. No queremos una lectura pre-definida de qué debe ser la eficiencia social. Es una noción en diálogo con el presente, carente de un estatuto consolidado en el diccionario. Pero el objetivo es ir dando forma a una definición operativa.

Por eso mismo, consideramos como punto de partida los discursos de las personas implicadas en las ONL y de aquellas que entran en su sub-sistema social. Al optar por esta vía, ponemos a estas organizaciones en un proceso de auto-referencia, pero su centro está fuera de ellas. El sistema social es el marco del sub-sistema multiforme de las ONL. En el momento en que hemos propuesto averiguar a qué se ha de llamar eficiencia social vemos una conexión y una referencia directa a lo común de sus valores sociales. Entendemos que no hay otra posibilidad.

Ante la pregunta qué es la eficiencia social nos hemos encontrado con dos aproximaciones. Una donde la respuesta se ve como algo externo que debería existir y estar homologado para cualquiera. Otra como una cuestión que se piensa, se interpreta y se construye dependiendo de quién habla. En ambos casos, la primera constatación es la falta de una defini-

55 Llamamos trayectorias a los sectores, actividades y recorridos sociales de las diversas modalidades de ONL. 
ción evidente. No es algo obvio. Si a la palabra eficiencia - mayor rendimiento con la menor energía - se le añade el apellido de social, la cuestión se hace menos evidente y más compleja. Dificultad que se incrementa cuando los avances de la investigación se devuelven a los propios actores sociales - feed-back - implicados en el proceso empírico, o cuando se les pregunta hacia dónde apunta, cómo será o cómo debería ser - feed-forward - la respuesta.

Nuestra opción ha sido formular la pregunta anterior sin precisar detalles. Se hace en términos generales. En todos los casos entrevistados la primera reacción tiende a la abstracción. Buscan en su diccionario personal la definición del concepto. Después, la subsiguiente respuesta se plantea desde la experiencia asociativa de esos sujetos con los que se dialoga. Unos ejemplifican directamente su definición desde los casos que han vivido. Otros, sin nombrarlos, relatan lo que sucede en sus ONL.

El abanico de respuestas registradas refleja el espectro ideológico de la sociedad. En cada una de las personas y de las instituciones afloran las maneras de ver la realidad de donde provienen. Es una realidad variada y dispar, donde las ONL son múltiples y diversas. Sólo tienen en común la ausencia de apropiación del beneficio. Pero ni siquiera parten de una interpretación compartida de su rol como instituciones sociales. Lo que las homologa es el mismo sistema burocrático y legislativo en una sociedad que se dice a sí misma democrática.

El sistema social de referencia tiene establecidas unas coordenadas legales y un imaginario social donde sustentarse. Esto se concreta en un sistema social regido por, al menos, tres elementos: el mercado, el consumo constante y la presencia permanente de la tecnología.

El mercado sabemos que rara vez produce resultados socialmente óptimos. El mercado se presenta en su forma ideológica como el mecanismo auto-regulador del intercambio de bienes y servicios en la sociedad. El sistema social se legitima en la justicia del intercambio (pseudo)equitativo de ofertas y demanda. El mercado es el terreno donde se ponen en juego los comportamientos egoístas de los sujetos. Así, se supone que todo y todos nos comportamos maximizando recursos en pos de beneficios.

Ello se produce en un contexto donde el consumo constante es una de las pautas sociales más arraigadas y extendidas. Necesitamos consumir 
y poseer para ser alguien en este sistema social, lo cual va en paralelo a la mercantilización de la vida cotidiana. Se convierte en necesidad, en promesa que moviliza y en referencia por alcanzar. Sólo hace falta esforzarse lo suficiente para poder consumir. Incluso se critica a quienes no entran en las mismas pautas. Sin consumidores no hay productividad que sirva para algo más que para almacenar cacharros.

La técnica y la tecnología son las herramientas que posibilitan el incremento de bienes de consumo. Desde hace dos siglos ha entrado en un proceso exponencial de crecimiento. Primero se presentaba como sueño y garantía de un paraíso fabricado por manos humanas, contra la condena de Adán. Ahora sigue siendo considerada como la solución a los problemas, pero no se sabe bien de quién ni de qué. Como consecuencia de esta primacía, la gestión del sistema social se justifica como una cuestión propia de técnicos y expertos. La técnica y la tecnología se convierten en tecnocracia; junto con la ciencia dan pie a una sabiduría convenciona ${ }^{6}$ y un marco de legitimación que constituye la tecnociencia. ${ }^{57}$

A partir de estos tres elementos, la sociedad como sistema configura modos de actuación. Las ONL están en diálogo con y son parte de ellos, e incluso algunas también se enfrentan. Ante el mercado, las ONL de nuestro estudio se posicionan de tres modos:

1) Como «bomberos o apagafuegos» de aquellas situaciones sociales que el juego de la oferta y de la demanda no atiende...; no se formulan críticas, la tarea prioritaria es poner parches al sistema.

2) Como agentes de control y crítica, promoviendo acciones de intervención estructural que buscan la transformación del orden del sistema social.

3) Se insertan en él sin cuestionar ni paliar: es la arena en la que se juegan su prestigio compitiendo con otros.

Y esto se repite ante el consumo y la tecnología: paliar, transformar o pactar. La sociedad de consumo genera ONL:

56 Recordando la noción de Galbraith en su texto clásico La sociedad opulenta, editado un sinfín de ocasiones.

57 Sobre esta cuestión una referencia obligada es el trabajo de Giorgio Israel (2000): Le jardin du noyer, Seuil, París. 
1) que buscan paliar los problemas de esta «necesidad» de adquisición y gasto;

2) que quieren transformar este modo de actuar;

3) y que se convierten en un objeto más de consumo social.

Para la tecnología es lo mismo.

Las respuestas a la pregunta por la eficiencia social de las ONL también apuntan a estos tres modelos. Encontramos las tres situaciones - paliar, transformar, pactar-, rara vez de manera aislada sino combinadas. En todos los casos se ve el sistema social como algo perfectible, donde las instituciones sociales tienen tareas que realizar más allá de los papeles propios del Estado o de las acciones del mercado.

Además hay que completar el mapa con una perspectiva externa a las ONL. Las coordenadas legales y la burocracia de las Administraciones públicas definen un marco de existencia, de acción y de control de las ONL. No se habla de su eficiencia, salvo en la versión de «organizaciones de interés social». En ese caso —en el contexto aragonés-, se reduce lo social a los espacios de bienestar social, ${ }^{58}$ entendidos en términos de "servicios, prestaciones y actuaciones cuyo objeto sea procurar el acceso de todos los ciudadanos a los diferentes sistemas públicos de acción social». La propia Administración pública otorga el estatuto de ONL de «interés social» en tanto en cuanto desarrollen «servicios o actividades en materia de acción social» y éstos sean de "un alto grado de utilidad», pero siempre para servir de «estímulo para mejorar, en todos los campos y facetas, las prestaciones sociales». Ello limita el amplio número de ONL existentes, y las sitúa en el terreno del pacto con el Estado, pues es éste a través de sus gestores quien decide qué ONL son útiles al sistema social. Entonces la eficiencia social se referirá a aquellos servicios y actividades que suplen al Estado. Se medirá en relación con los problemas que soluciona y los huecos que tapa.

Dentro del sistema social, las ONL constituyen un subsistema creado al considerar como categoría de análisis la gestión y distribución de los

58 En el caso de la legislación aragonesa, el Decreto 7/1999, de 9 de febrero, del Gobierno de Aragón, por el que se regula la declaración de interés social para entidades privadas sin ánimo de lucro con actuaciones en el área social, publicado en el $B O A$ de 19/02/99. 
beneficios de estas entidades. Pero toma cuerpo al constatar que en sus diversos campos de actividad la ausencia de objetivos lucrativos genera intersecciones con todas las actividades sociales. Y precisamente eso hace que la pregunta por la eficiencia social provoque respuestas alejadas de los planteamientos economicistas, del consumismo o la tecnocracia.

Por tanto, la noción de eficiencia social se ha ido construyendo - seguimos en proceso- en las entrevistas realizadas a un mapa de actores inicial. Las respuestas han sido convergentes desde la disparidad. Ante la misma pauta de preguntas, las entrevistas han planteado recorridos muy distintos pero que repiten algunos códigos y conceptos.

¿Qué es la eficiencia social? Las respuestas destacan dos enfoques, uno cuantitativo y otro cualitativo. Lo cuantitativo enlaza con la versión común de la palabra eficiencia - mayor rendimiento con la menor energía- y con la necesidad de medir. Se necesitan «medidas», números, cifras para hablar de eficiencia, incluso de la social. Pero no lo es todo; lo cualitativo remite al componente ideológico — casi visceral— de la idea de lo social.

En el primer caso, situados, por ejemplo, en el terreno sociopolítico, la eficiencia se nos presenta como una noción en función de los resultados - votos- obtenidos. Si lo político se reduce a la cota de poder que se tiene, entonces está claro que es más eficiente aquella campaña electoral que, con menos recursos, lleva a más número de votos conseguidos — supuestamente, más poder-. Pero esto es una reducción economicista que no sirve cuando se trata de «medir» si se cumplen los valores pretendidos por un grupo humano, muchos de los cuales son incomensurables. Por ejemplo, la libertad.

Esto nos lleva a lo cualitativo. Lo social no es reducible al «mercado» ni a un único repertorio de «valores objetivos». La objetividad de lo social y el consenso al respecto es uno de los primeros escollos que debemos superar. Lo social, como mucho, se remite a unos significados reconocidos, compartidos y construidos socialmente. La noción de eficiencia social se liga a las pretensiones de las ONL, de sus integrantes, de la sociedad. Pero en especial aparecen dos aspectos: la relación medios/resultados y el alcance de éstos. Ambos siguen mostrando el peso del cálculo coste-beneficio. Pero no son suficientes. 
A partir de las primeras entrevistas se perfila una respuesta: la sociedad es un valor en sí. Luego, una ONL o cualquier otra institución será eficiente en términos sociales siempre que «haga sociedad». Asociarse y crear redes sociales es un valor, algo positivo y óptimo. Pero entonces el problema es ¿¿de qué modelo de sociedad estamos hablando?, ¿cuál es el modelo de sociedad subyacente? Aquí tenemos un segundo escollo: la sociedad de referencia. En este caso, en las entrevistas ha cuajado como referencia el marco introductorio a la Constitución Española de 1978, ${ }^{59}$ es una versión de la Declaración de los Derechos Humanos de 1948.

Fijado ese referente - también podría darse sin él—, en las entrevistas ha ido cerrándose la noción de «mejor sociedad»: será siempre aquella que sus objetivos son tomados de la propia sociedad. Y en esto la socialización y la integración social son una condición de posibilidad ineludible.

La eficiencia social de las ONL se configura a través de la participación, tanto en la misma sociedad como en la propia ONL. Además, los discursos registrados proponen que ha de ser una cuestión donde el componente altruista de la ONL genere una escala de valor societal. En la medida en que una ONL ofrece resultados que repercuten en «otros» y van más allá de un "para sí» cerrado, podemos hablar de una mayor eficiencia social. Esta distinción nos remite a los objetivos de la ONL y a sus efectos. Pero también necesitamos distinguir qué tipo de vida interna se desarrolla. No todo resultado o actividad es igualmente válido; se ha de atender al procedimiento y a los medios.

Estamos ante una noción dinámica y en proceso, que se da en un contexto de sociedad de mercado y de consumo. Las personas se hacen sujetos individualizados, con tendencias fuertes a la insolidaridad, al aislamiento, al olvido del otro, a la desconexión, a la atomización y a la anomia (Galtung, 1997). Aquellas instituciones sociales que abren cauces de comunicación social están haciendo una mejor sociedad; por tanto, son más eficientes desde el punto de vista social. Los cauces de comunicación se proponen en paridad y en dos planos: respecto del contexto social y respecto de los integrantes de la organización. La vigilancia ha de ser especial en aquellas ONL donde se entregan fondos públicos. Esa vigilancia ha de

59 Aunque para algunos tuvo en su momento elementos cuestionables, el título primero es en el que hay más consensos. 
mirar a los mecanismos de control democrático que tiene y al poder social que representan. Esto remite también a unos indicadores de permeabilidad y de pluralidad.

La noción de eficiencia social nos aparece como una referencia a la sociedad y a los beneficios que reporta la actividad de una organización. En cada tiempo, los acentos resaltarán elementos diferentes; por eso convendrá distinguir los fines propios de cada institución y los intereses de la sociedad.

Pero, como mostraban las personas entrevistadas, esto sucede en una sociedad donde las asimetrías aumentan, donde la integración social se hace más compleja y difícil. Las ONL serán más eficientes en la medida en que colaboren en la solución de esas grietas del sistema social. Sólo se entrará en la valoración de los recursos en el caso de que se puedan comparar instituciones. En esa comparación — toda medida lo es- no sólo tendremos que hablar de dinero o costes, sino también de procesos y participación. Esto es un lugar de divergencia. Algunas personas y ONL entienden que la solución de los problemas sociales es cuestión de justicia, mientras que en el otro extremo es una cuestión de conquista personal y de generosidad — por no hablar de caridad—. La primera posición está asociada a una visión del Estado y de lo público como responsable de la satisfacción total de las necesidades sociales. La segunda insiste en la primacía de la sociedad civil y el papel subsidiario del Estado.

Esta perspectiva olvida otros componentes de «interés social» que van más allá de lo que abarca el paraguas de la «protección social» o del «Estado del bienestar». Hay ONL cuya repercusión y eficiencia social no se cuestiona pero que se inserta en terrenos culturales o identitarios sin pretensiones de entrar en el terreno del bienestar o de la seguridad. Y también construyen sociedad.

Otro elemento es la relación con las Administraciones públicas. De nuevo se repiten las tres estrategias señaladas antes — paliar, transformar, pactar-. En el caso aragonés — podría generalizarse a la Administración española-, todavía pesa una cultura burocrática donde se quieren pocos «interlocutores sociales». Para un grupo importante del funcionariado la multiplicación de ONL es un elemento de preocupación. El tejido social se hace más complejo, menos evidente y con más variables a considerar. Es 
lo que algunos llamaban rescoldos del «partido único», lo cual converge con la capacidad de presión social que reclaman algunas ONL más consolidadas en terrenos diversos. La aparición de nuevas ONL y de nuevos grupos dificulta la representatividad. Se ve como una debilidad aquello que debería ser fuente de dinamismo social. La eficiencia social en estos casos tiende a solaparse con la «incidencia social». Incluso en algunas entrevistas las fases de la conversación discurrían por cauces donde las personas interpeladas los utilizaban indistintamente. La eficiencia social de una ONL parecería entonces ligada a su visibilidad social. A ello se sumaba cierta necesidad de profesionalización y de organización orientada por objetivos. Como si el discurso de la eficiencia ante el mercado tuviera que ser asumido desde el terreno de las ONL. Y la hipótesis se corrobora en algunas de las ONL abordadas.

La pregunta por la eficiencia social se ha convertido en las entrevistas realizadas en una revisión de la propia vida asociativa. Para algunos la cuestión lleva a la medición del altruismo con que se plantean los objetivos de las ONL y con los medios que se utilizan. La eficiencia social tiene que romper con los cálculos monetaristas y economicistas impuestos en el paradigma de la sociedad de mercado. El cálculo del coste-beneficio no puede ser la única variable por considerar. Eso sólo habla de una buena gestión contable, pero no dice nada de su contenido social. Una sociedad está más viva en la medida en que tiene una red de ONL que están vivas y dinámicas. El sistema social densifica sus redes sociales. Aumenta en complejidad y gana en "capital social».

La vida de las ONL también tiene "ciclos biológicos». Podemos equiparar la vida de las ONL a un ser vivo cualquiera: se conciben, nacen, maduran y mueren... Algunas perduran en el tiempo a sus fundadores y dejan un legado a la sociedad, más allá de sus orígenes. En la investigación realizada, la medida de la eficiencia social de las ONL se nos mostraba ligada a la vitalidad de las organizaciones. En una sociedad industrializada, urbana y atravesada por las prisas, una medida de esa eficiencia social era la comunicación, el encuentro y el «verse». La delegación, la eficacia en la gestión con planteamientos de rendimiento por objetivos no era muestra de una mejor sociedad o mayor eficiencia social. Esto es un paradoja, puesto que se pide consecución de objetivos, pero prima más la manera de alcanzarlos. La paradoja se resuelve con 
palabras recogidas en la investigación: «se trata de generar tejido social, más y mejor tejido social».

Y este tejido — estas ONL— será más eficiente en la medida en que aporte ventajas a la sociedad en su conjunto. En tal caso la eficiencia social se equipara con la rentabilidad social, que es distinta del cálculo económico simple. Incluso en la corriente de opinión con un talante más socialdemócrata la eficiencia social de una ONL se manifiesta en tanto en cuanto se inserta en aquellos espacios sociales que son considerados «inútiles en términos económicos», asunto que, por otra parte, desde esa perspectiva, debería ser asumido por el Estado, puesto que el mercado lo rechaza como suyo por «falta de negocio». Entonces encontramos un discurso crítico con las ONL y con todo movimiento no gubernamental que se dedica a sustituir al Estado y a paliar las insuficiencias de los servicios públicos...

Otra lectura, complementaria de la anterior, entiende la eficiencia social con criterios de rendimiento social. Pero los define diciendo lo que no es:

- descoordinación: cuando varias ONL actúan en un mismo espacio, sin comunicación y repitiendo actividades o servicios;

- caridad, frente a una visión de justicia social, que actúa puntualmente en el sistema social para paliar sin soluciones, ni visiones a largo plazo;

- ayuda individual, frente a cambio estructural que implique al conjunto y no a los casos particulares;

- derroche humano de recursos, frente a una conciencia de limitación y austeridad.

En dicha perspectiva, la eficiencia social no es igual a la suma de la eficiencia en términos individuales; no es suficiente el lucro individual como referencia. Pero se trata de una cuestión cargada de posicionamientos ideológicos y políticos.

La investigación nos lleva a lo evidente: no es posible dar una definición de eficiencia social sin rozar el terreno de la ideología. Esto no impide, sin embargo, plantear una mirada sistémica que intente ofrecer una lectura generadora de consenso y de suficiente intersubjetividad para ser considerada objetiva. 


\section{V.2.1. Indicadores de eficiencia social (IES)}

Un reto de nuestra investigación es averiguar qué se entiende por eficiencia social en un sistema social tan concreto y particular como la sociedad aragonesa. Queremos que los resultados de este itinerario nos permitan proponer unos indicadores para medir su cumplimiento en las entidades no lucrativas de nuestro caso de estudio. Tiene el potencial de generar una referencia teórica (concepto) junto con una práctica investigadora (medida).

No tenemos una definición final y cerrada de la noción de eficiencia social, pero sí aproximaciones operativas con las que elaborar un repertorio de indicadores - preguntas - de eficiencia social. Los consensos detectados en la entrevistas nos han señalado algunos aspectos destacables:

a) El estudio de la eficiencia social de las ONL ha de plantearse atendiendo a la diversidad de los casos; por tanto, es necesario contextualizar y revisar cada ONL en su trayectoria y en sus resultados: las actividades, las obras son una muestra de su eficiencia social. Sólo así se pueden evaluar los objetivos de las ONL, en asuntos palpables.

Una vez ubicados en el caso:

b) Se ha de atender a la relación medios-resultados. Esto supone responder a ¿qué se hace, con cuántos recursos y cuántas personas?

c) Pero también se ha de preguntar: ¿Cuál es el alcance? ¿Cuántas personas? ¿Qué repercusión?

Si aceptamos que la sociedad es un valor en sí, entonces:

d) ¿Crea o participa de redes sociales, federaciones, coordinadoras, plataformas...?

e) ¿Cuál es el número de personas que pertenecen o se vinculan a la ONL?

f) ¿Se permite la participación interna? ¿Cómo se lleva a cabo? ¿Cuál es la vida interna?

g) Matizando la cuestión del alcance, ¿`sus resultados repercuten en «otros» o se quedan en un "para sí» cerrado?

b) ¿Cuáles son los procedimientos y los medios utilizados?

i) ¿Se establecen cauces de comunicación social, internos y externos?

j) ¿Cómo se responde a la disensión y la pluralidad?

$k$ ) ¿Es permeable a demandas sociales? 
A esto también añadimos la revisión de las actividades públicas que realiza cada ONL, su tipología, periodicidad y el talante con que lo hace. Quienes han de responder a las preguntas y a sus indicadores son las propias personas integradas en las ONL. En algunos de los elementos señalados, es enriquecedor contar con la opinión de unas respecto de otras dentro del propio sector. Obtenemos una auto-imagen e interpretación de sus afines que nos ofrece una valoración, una medida de su eficiencia social. Pero, como es evidente, toda medida es una cuestión relativa a un patrón de referencia que se toma como unidad. A la eficiencia social planteada en los términos anteriores no es necesario asignarle un valor numérico. Estos indicadores se proponen como una auto-evaluación, donde lo interesante es poner en marcha el proceso de reflexión.

Una ONL presentará mayor eficiencia social si facilita una mejor respuesta afirmativa a los elementos señalados antes. Por tanto, la eficiencia social de una ONL es directamente proporcional a su capacidad para hacer una sociedad mejor, a partir de cauces de comunicación paritaria, pluralidad social e integración social. Aquellas ONL que tiendan a la exclusión, a la fragmentación y a la primacía de la lógica del club como separación en castas generan un modelo social poco eficiente.

Las ONL actúan en un terreno donde lo público y lo privado convergen y, en ocasiones, también se contradicen. La preocupación por la eficiencia social nos lleva, en una primera tentación, al terreno de las cifras y de la cuantificación. Pero no es ése su lugar de más relevancia. La comprensión de la realidad es un asunto más cualitativo, que se traduce en discursos y en valoraciones que remiten a horizontes normativos. Tenemos un objetivo, poner a la gente primero.

\section{V.3. Eficiencia y eficacia del sector no lucrativo en Aragón}

En esta parte del capítulo queremos contrastar los indicadores propuestos en el apartado anterior con un análisis del sector no lucrativo aragonés. Para comenzar, hemos observado algunas pautas comunes en los modelos de gestión. Planteamos una breve reflexión sobre el tamaño y número de las ONL; a continuación hablaremos de la capacidad de creación de redes sociales, así como de la participación y la profesionalización. Finalmente, plantearemos algunas cuestiones sobre la evaluación, la transparencia y la comunicación social. 


\section{V.3.1. Modelos de gestión en las ONL}

Como se podía prever, no hemos encontrado una respuesta única y compartida a la pregunta de cuál es la mejor forma de gestionar una ONL. Aunque sí que hay un punto común para los distintos actores: no existe una receta que se pueda aplicar a todos los casos sin más.

El punto de partida es la diversidad y la heterogeneidad del sector. Son organizaciones que tienen sus peculiaridades, sus personas, sus contextos. Sin embargo, a pesar de ello sí que se bosquejan algunos rasgos o cuestiones de mínimos que deban cumplirse. De hecho, para sus propios actores/gestores sería más fácil tener un modelo de excelencia — -pues, oye, lo copiamos literalmente»—. Pero, para otros, nunca será así, puesto que «las organizaciones las hacemos las personas». Dado que estas organizaciones deben tener fundamentalmente un carácter abierto y participativo - salvo las fundaciones, donde el patronato tiene potestad para delimitar la cuestión-, ya no es trasladable de manera automática lo que en una entidad funciona y da buenos resultados a cualquier otra del sector. Además, también están condicionadas por el tipo de población al que se dirigen y los objetivos que se marca cada organización. En todo caso, hemos encontrado un consenso en este punto: "gestionar sería el cumplimiento de objetivos; el gestor debe cumplir un mandato superior, dado por sus estatutos...».

Pero de nuevo hay que considerar las diferencias y los matices. En el caso de las asociaciones, los estatutos se (re)interpretan en el ejercicio de las asambleas de la entidad. En las fundaciones, es el patronato quien acuerda la política estratégica de la organización. Los gestores después tendrán que ajustarse a estas pautas y líneas de acción.

Ahora bien, nos encontramos tres tipos generales de organizaciones —independientemente del subsector de actividad-, que después condicionan las formas de administración y gestión interna:

- las reivindicativas/denuncia,

- las gestoras de recursos públicos,

- las auto-centradas.

Las dos primeras están en un eje de compromiso e implicación social amplia; la tercera parte de sí y para sí.

Las primeras adoptan un papel reivindicativo y de denuncia. Están en una posición de dinamización social. Su papel es de activación de las estra- 
tegias de concientización social. Uno de los puntos será alertar a la Administración de las necesidades y, por eso mismo, «ser un poco chinches para que la Administración vaya respondiendo a las carencias». Estas organizaciones suelen manejar presupuestos bajos. Se nutren de «activistas, socios..., gente voluntaria», fundamentalmente, y su vitalidad depende de las personas que se disponen a trabajar en y por los fines de la organización. En tal caso, su modelo de gestión tiene una condición fundamental: "que sean respetuosos todos los socios con sus compañeros, y que sean democráticos; poco más se les puede pedir; quizá, quizá que tuvieran autonomía económica». Es decir que pudieran encontrar un mecanismo de autosuficiencia e independencia económica con el cual poder llevar a cabo sus actividades. Puede ser vía cuotas, vía participación voluntaria o vía servicios..., todo para tener el dinero necesario con el cual mantener la estructura. Si dependen de subvenciones y de la Administración, su capacidad de acción estará claramente cercenada, maniatada y, a veces, sesgada. Estarán atados para poder denunciar las múltiples limitaciones, a veces irregularidades y carencias, que padece la Administración: Si dependes de ella o de cualquier otro tipo de poder económico, no pue-
des mantener una postura reivindicativa constante.

Algunos plantean que esta actividad es más propia de las asociaciones, pero no tiene por qué ser así; al menos, debe ser una estrategia compartida entre entidades: unas denuncian, otras gestionan. Por ejemplo, en un mismo barrio una asociación tiene que encargarse de «denunciar y revolver a los agentes sociales, a las administraciones». Desde ese ejercicio, a veces se consiguen unos fondos y recursos que desde una entidad complementaria, bien asociación o bien fundación, se podrían gestionar e intentar aplicarlos para que técnicamente sean más eficientes.

Las segundas son las ONL que gestionan recursos. En este caso, la respuesta a cómo se ha de hacer es polémica y está cargada de debates. Una posición insiste en que la gestión tiene que responder a los patrones y pautas propias cualquier empresa, «o sea, con un criterio de servicio al cliente, de excelencia empresarial...». Tienen la obligación de «hacerlo lo mejor posible, y, desde luego, abandonando viejos clichés de: "Bueno, pues como es un tema social"». Otra, sin embargo, considera que "no se debe caer en la empresarialización de las ONL». Lo cierto es que los recursos «son escasos y hay que optimizarlos todo lo que se pueda». Por eso mismo, uno de 
los retos de las ONL es gestionar correctamente, y para ello primero deben tener muy clara su propia organización. Esto supone definir con precisión cuál es el papel de la entidad en su entorno, del patronato, si lo hay, de los distintos estamentos internos de la organización, de las personas implicadas... Delimitar dónde acaba la intervención de los «órganos políticos» y dónde empieza la de los gestores, cómo se entrelaza la tarea de los gestores asalariados con la de los voluntarios «sin que sea una manera de cubrir puestos de trabajo a coste cero», por ejemplo.

Las terceras serán aquellas ONL centradas en si mismas y para sí. Pueden estar en cualquier ámbito de los descritos en el capítulo anterior. Su gestión es tan variopinta y dispar como las propias entidades. El problema que surge y que algunos sujetos implicados en el sector social de las ONL expresan es que «en Aragón el número de ONG o de entidades sociales es enorme». Lo cual no es sino una percepción subjetiva - que no coincide con los datos existentes - que muestra la preocupación por la ampliación del número de entidades. Esto, además, se suma a que muchas veces surgen para satisfacer intereses particulares «en función de apetencias personales de los gestores, y, entonces al final hay eso; luego poca cultura de colaboración, poca cultura de trabajo en común». Así se crea un problema para el conjunto. Es decir, si cada entidad se plantea las cosas de forma absolutamente propia y particular — bastante común por otra parte-, pero con un enfoque dedicado a la lucha entre ONL, se promueve una competencia poco útil al conjunto de la sociedad. Algunos lo plantean en términos de «miopía, con mucha estrechez de miras, como si fuera un pastel y si viene alguien y se me lleva un trozo, en lugar de pensar " $i v a m o s$ a hacer el pastel más grande!... y tengamos todos un trozo más grande del pastel"...». El incremento del espíritu colaborativo-cooperativo es un reto y una referencia a la hora de hablar de la gestión de las ONL. Incluso aquellas entidades que respondan a la práctica de una afición minoritaria desarrollarán un modelo de gestión de más calidad si se ponen en relación con otras asociaciones, empresas o fundaciones de su entorno.

Los modelos de gestión deben ser evaluados. En las entrevistas y grupos de discusión aparece la tesis siguiente: se ha de responder ante las personas implicadas — socios, usuarios...-, ante las Administraciones públicas que financian actividades - es decir, siempre que exista dinero público—y ante la propia sociedad — por salud social colectiva—. Y recordemos que estos modelos los identificábamos ya en el primer capítulo 
cuando presentábamos las diferentes tipologías de las entidades propuestas a nivel internacional, que ahora vemos reflejadas en el caso aragonés.

El objetivo de una gestión eficiente y comprometida tiene que conducir a una calidad de vida donde se conquistan cotas de disfrute de lo cotidiano que suenan a privilegios de pocos en tiempos pasados. Extender esas posibilidades y la capacidad de romper con las ataduras indeseadas es desarrollar mejor una sociedad. Por eso, el fin de quienes proponen evaluaciones y un control más eficiente de los recursos no apunta a eliminar ONL del mapa. Al contrario, son personas con una historia personal densa las que tienden a resaltar la importancia de "hacer las cosas bien». Sólo así la densidad del tejido social gana en calidad y en futuro. El capital social se vertebra y consolida a medida que las entidades son más capaces, autónomas y eficientes.

$$
\begin{aligned}
& \text { Una postura radical y estúpida es que se cierren. No, lo que planteo es } \\
& \text { que se les oriente y se les enseñe a que hagan las cosas bien... }
\end{aligned}
$$

Lo cual tiene elementos disonantes con lo dicho antes sobre la diversidad y la gestión, pero abre un camino para reconocer que aquellos avances que se conquistan en otros terrenos son susceptibles de ser adaptados al mundo de las ONL. Si las empresas lucrativas han mejorado sus posiciones en el mercado planteando una "estrategia $\mathrm{x}$ » — salvo incoherencias éticas-, la propuesta que aflora es aprender, copiar y mejorar. Pero ésta no es una postura mayoritaria: «para eso habría que cambiar la mentalidad de muchos gestores de ONG, que están en posesión de la verdad absoluta, que creen que no pueden aprender nada de nadie...; somos gente un tanto especial los que nos metemos en estos rollos».

Quizá por esto una pregunta que conviene formular es qué tienen que mejorar las entidades sociales aragonesas para hacer mejor las cosas. Y las respuestas convergen en algunos elementos. Sin embargo, también es cierto que se dibujan dos grandes tendencias. Por un lado, la de las personas que insisten en la gestión mimética — aplicando las salvedades pertinentesrespecto de otros sectores, en especial, el ámbito de las empresas lucrativas. Tal posición gana espacios simbólicos cuando estamos en un entorno de ONL e que el tamaño y las actividades entran en ámbitos donde los límites de su vida cotidiana se difuminan en relación con aquellos sectores del mercado donde operan. Por otro lado, una segunda tendencia acentúa la participación, el compromiso..., más que la gestión por objetivos o la mímesis que defienden las anteriores. Es decir, quieren gestionar y llevar 
bien las cosas de su organización pero consideran prioritarios los procesos personales. Por eso toleran reuniones interminables, procesos de toma de decisiones «menos eficaces» — como se dice desde el primer enfoque-. Aquí, las ONL tienen mucho más de búsqueda de sentido y de grupos de pertenencia que de entidades que pretenden conquistar mejores cotas de mercado o de maximización de sus recursos. Son conscientes de que las cosas que hacen las haría mucho antes y con otro estilo una consultora de las que proliferan en el mercado, pero saben que aportan un plus que no tienen esas otras entidades.

Ambas tendencias no se dan en estado puro. Hemos observado una complejidad creciente, que tiende a incrementarse en la medida en que las ONL optan por crecer hacia ámbitos socioeconómicos, a su vez, de mayor complejidad. Y lo vemos en las asociaciones o fundaciones que pasan de una educación de adultos y jóvenes a la gestión de empresas de inserción, o en las asociaciones deportivas que consiguen éxitos y quieren ir a más, o en entidades que superan sus límites tradicionales porque pasan a disponer de más recursos procedentes de convocatorias mejor dotadas de fondos. Pero también es cierto que cuanto más se aproximan a una actividad o a las fronteras del mercado y más se incrementan los fondos públicos, más preocupación aparece por la primera tendencia.

\section{V.3.2. La cuestión del número y tamaño de las ONL}

Cuanto mayor sea el número de ONL, más posibilidades hay de que el capital social puesto a disposición de la sociedad sea más rico, denso y de calidad. Pero aparece el dilema entre quienes consideran que cuanto más, mejor, más posibilidades..., frente a quienes matizan y dicen que muchas organizaciones generan dispersión, lo que supone falta de eficiencia cuando no son entidades gestoras. Es decir, en un país como el nuestro no es necesario que se multipliquen organizaciones trabajando en el mismo sector, para los mismos destinatarios y con los mismos objetivos. No parece beneficioso ni rentable que en Aragón haya cuatro asociaciones de familiares de enfermos mentales o cinco asociaciones que se ocupen del síndrome de Down. Pero sí que entra dentro de una lógica extendida que haya una en Huesca, otra en Zaragoza y otra en Teruel, que estén federadas y que se dediquen a una función puramente de denuncia y, además, sean más cercanas. 
Es lo mismo que con las asociaciones de vecinos; pues, hombre, es lógico que haya una por barrio, pero no tres por barrio. Pero luego, si ésas, a la vez, están en una federación de asociaciones de vecinos, y ésta, que no podía tener una pequeña estructura de gestión, lo comparte... pues bien. Pero... que todas las asociaciones de vecinos tengan una estructura de gestión... No creo que sea operativo.

Es un asunto claramente opinable, que no se puede resolver diciendo definitivamente qué es mejor, aunque la sabiduría popular afirma que "la unión hace la fuerza" y no carece de lógica el principio, poco extendido en Aragón, de que es mejor sumar, no restar. Con todo, quienes argumentan a favor de un mayor número ven en ello mayor riqueza de opiniones, más capacidad de articular posturas, y, «si eso significa mas personas preocupadas por asuntos públicos, mejor». Quizá el problema de fondo es percibir el mayor número de organizaciones como un elemento de incremento de los competidores en un mundo limitado, con unos recursos que no aumentan y se dispersan. Si cada entidad compite con su homóloga por las mismas personas, por los mismos fondos, para hacer las mismas actividades, entonces la estrategia de la multiplicación no ayuda a tener estructuras fuertes ni a enriquecer el capital social de nuestra comunidad. Sin embargo, también existe el discurso que nos recuerda lo contrario:

Las multinacionales, el gran capital hace eso de las fusiones... concentrar esfuerzos para competir mejor. Lo nuestro es distinto: para cambiar las cosas hay que seguir lo que hacen las hormigas; cuánta más gente moviéndose, mejores resultados.

Ambas opciones están vinculadas a las estrategias generales de apoyo a las dinámicas sociales de participación ciudadana y a la capacidad de auto-organización de la sociedad.

\section{V.3.3. Redes sociales}

El anterior elemento se une con este factor diferenciador del sector no lucrativo, la creación de redes como señal de cooperación y no de exclusión. La eficiencia social de una entidad del sector no lucrativo está ligada a las redes de vinculaciones sociales que define. A mayor implicación con la sociedad donde se inserta, más capital social, más calidad cívica y, por tanto, mayor riqueza ciudadana disponible para el interés general del conjunto y para los intereses individuales de los ciudadanos y de las ciudadanas. 
En el caso aragonés casi todos los sectores de actividad tienen sus propias redes de coordinación y federación. Algunas son de reconocido prestigio — por ejemplo, la recién premiada Federación Aragonesa de Solidaridad, que aglutina a las llamadas ONG de desarrollo- y cumplen papeles tanto de colaboración inter pares, como de lobby o presión política, con unas líneas ideológicas muy marcadas, como puede ser el caso de la FABZ, Federación de Asociaciones de Barrio de Zaragoza.

El ámbito donde las redes se producen de modo consustancial a las entidades es en el mundo deportivo. Cada especialidad genera su red de clubes y su federación, demarcando los escalones de la estructura de modo muy claro. Pero también encontramos en una situación similar a las entidades vinculadas a la Iglesia o relacionadas con los movimientos cristianos. De hecho, en el trabajo de campo se nos han presentado como el conjunto de organizaciones y de redes sociales más activo y con más raigambre e incluso presencia en todo Aragón. No es nada nuevo, ni tampoco muy homogéneo, porque la diversidad es bastante abundante: desde trabajo con niños y jóvenes a implicación en el medio rural, pasando por agrupaciones de carácter espiritual y otras de intervención social.

La capacidad de generar procesos federativos y de coordinación entre las entidades también está relacionada con, al menos, las siguientes variables: el incremento del volumen de actividades, la necesidad de ganar representatividad — tanto ante la opinión pública como ante la Administración-, la necesidad de soluciones a problemas comunes, la respuesta a carencias de gestión, la experiencia como grado de madurez de las entidades del sector.

En la mayor parte de las ONL aragonesas se solapan las presencias en distintas redes, plataformas y mesas con entidades diversas. Pero se distinguen dos tipos distintos. Unas son las que surgen en función de las demandas fruto de la actualidad. Por ejemplo, la recientemente creada Plataforma en Defensa del Ebro o la Plataforma para la Abolición de la Deuda Externa. Pero hay muchas más, que aparecen, se mantienen y desaparecen en función directamente proporcional a la característica de la convocatoria. Otras son las coordinadoras o federaciones constituidas con afán de permanecer y perdurar adaptándose a los cambios.

En ambos casos, las historias particulares reflejan procesos muy distintos, pero en todos ellos encontramos como elemento común la cons- 
ciencia de las personas que participan en ellas de una apuesta por sumar esfuerzos y dar respuestas desde los procesos de auto-organización colectiva. Algunos decían a propósito de esta cuestión: «aquí siempre somos los mismos». En el caso de Teruel y Huesca se reconocen y se saben reconocidos por sus convecinos. En las otras ciudades aragonesas y en los pueblos del país el hecho todavía se acentúa más. En el caso de Zaragoza, si bien se reconocen entre quienes «se mueven en estos rollos», pasan algo más desapercibidos para el conjunto de la ciudadanía.

Hemos constatado que las redes que se crean entre las distintas organizaciones pasan, fundamentalmente, por las relaciones personales y por la capacidad de los individuos que se implican en las entidades de dar cauce a procesos de cooperación. El componente más institucional de las redes sociales viene tras largos tiempos de inercia y de consolidación de cierto humus de interrelación. El nudo desde el que se tejen, esto es, se convocan, constituyen y mantienen estas redes sociales, es el del reconocimiento mutuo a patir de un poso de afiliación afectiva. En más de una ocasión esa premisa es más importante que los vínculos ideológicos. No son cuestiones de lazos de sangre, pero parecerían un correlato algo más elaborado.

\section{V.3.4. Participación y profesionalización: personas y organizaciones}

Si algo nos queda claro en el análisis del sector no lucrativo es la importancia primordial de las personas que constituyen las entidades. Pero también es cierto que debemos diferenciar planos en las ONL. Además de la masa social, tenemos dos elementos destacados: por un lado, órganos de gobierno; por otro, órganos de gestión. Cada uno tiene su lógica y sus ritmos. Son más difíciles de percibir en las organizaciones de tamaño pequeño, pero incluso en ellas sirve para definir mejor los pasos que deben darse. Las entidades tienen que responder a la necesidad de alcanzar un nivel mínimo organizativo para sobrevivir. Es decir, una capacidad de gestión de recursos y un abanico de posibilidades que dé pie a consolidar y, si es oportuno, profesionalizar la entidad: que aquellas tareas cuyo servicio, gestión o administración lo exija, sean desarrolladas con garantías. O sea, "que permitiera una profesionalización, respetando el incuestionable papel que hacen los promotores, los que han tenido la idea, que suelen ser los que tienen las necesi- 
dad, los que viven el problema». Por ejemplo, si en un barrio detectan una necesidad de asistencia a sus vecinos más ancianos, lo que hay que conseguir es la mejor solución. Si las familias no pueden hacerse cargo y se consiguen fondos para una residencia para la tercera edad, «a la hora de abrir la residencia, lo mejor es que esté el mejor gerontólogo al frente, no el presidente de la asociación de vecinos; pero eso en muchos casos no pasa así».

Cuando se intenta concretar qué es eso de la "profesionalización», encontramos dos elementos complementarios, muchas veces coincidentes. El primero es que una persona profesional es aquella "que se dedica a eso». Domina la cuestión, la profesión y los conocimientos que lleva implícitos. Por lo mismo, segundo elemento suele ser necesario que sea remunerado — «el día tiene veinticuatro horas, de algo tienes que vivir, ¿¿no?»—, pero existen casos «donde algo o alguien te libera... digamos; se han dado y se da el caso de no remunerados, pero porque había una entidad religiosa u otra que te apoya... es remunerado por alguna parte de otra manera». La profesionalización significa que se tiene suficiente formación y/o experiencia para hacer bien lo que se tiene que hacer.

Una asociación que cuente entre sus asociados con unos profesionales cualificados en la materia que les ocupa no necesitará contratar a nadie. Pero en la medida en que crecen las actividades, la gestión de iniciativas y algo tan simple como la contabilidad interna o abrir y cerrar el local ya precisan de algo más que socios voluntariosos. Aquellas ONL que entran en dinámicas de gestión de proyectos o iniciativas que superan los límites del tiempo libre disponible por parte de sus socios dan el salto a la contratación de personas que desarrollen con eficacia esas tareas.

Cada vez más los proyectos se están profesionalizando, en el sentido de que cada vez la intervención es, entendedla, profesional, porque hay una especialización, también hay una remuneración y hay una intervención, diría yo, mucho más continuada, que no se puede mantener en ratos libres...; exige una jornada laboral completa, como mínimo.

Por eso, en algunas ONL sus tareas irán asociadas al servicio no remunerado y altruista de sus socios. En otras, cuando alcanzan cierto tamaño, las cosas sólo se podrán hacer bien pagando salarios dignos. La tendencia es «buscar que convivan los profesionales necesarios para dar un buen servicio con los voluntarios, que lo que harán será ese servicio de mínimos». Ello no impide que sigan existiendo entidades con experiencia e historias 
ejemplares donde todo se hace «muy profesionalmente, pero sin cobrar un duro... o un euro, ¿no?».

Pero esto dependerá de cuál de los tres tipos de ONL estemos hablando. Aquellas organizaciones más reivindicativas o las centradas en sí no están en el mismo plano en esta cuestión que aquellas que están gestionando recursos públicos. Sin embargo, incluso en una asociación deportiva de un barrio la "profesionalización" siempre será mejor que su contrario: "creo que es mejor que haya un buen monitor deportivo con titulación en que conozca las partes del cuerpo, que no un "voluntarioso" que a los dos días a lo mejor un crío tiene un esguince, en fin, entiendes...; en ese sentido, creo que hay que profesionalizar las ONG». Se trata de hacer bien lo que se hace: unas veces será necesario remunerar a quien actúa, en otras la calidad de la acción no lo necesitará, porque esa entidad cumple con lo dicho.

\section{V.3.5. Participación y profesionalización: las personas}

La discusión sobre el número de organizaciones cambia si revisamos las historias particulares en el sector. Muchas de las entidades surgen porque unas personas detectan en un momento dado una determinada carencia o porque quieren hacer algo nuevo. De hecho, dicen "si esto no existiera, algo parecido alguien lo tendría que haber puesto en marcha, la Administración o alguien». Y ese "algo" puede ser desde un club deportivo, una federación de asociaciones, una entidad de auto-ayuda, una agrupación cultural, una cooperativa o una asociación de defensa de lo que sea..., hasta cualquier otro asunto.

Pero también vemos que esas historias particulares de escisiones, cismas y rupturas que dividen a las ONL no son para conseguir efectos multiplicadores. Al contrario, provocan desgaste, pérdidas de todo tipo. En tal caso, esta «diversidad» es falsa y no positiva.

La perspectiva que nos da el paso del tiempo es la que permite mostrar cómo van cuajando resultados y obras. Ése es el punto al que mirar. Con dicho enfoque, lo que vemos es que las personas, las familias, las comunidades buscan dar cauce a sus demandas, a sus proyectos, a su imaginación... y esto genera actividades con ritmos cuasi-biológicos: se gestan, nacen, crecen, maduran, permanecen y, también, mueren. Algunas permanecen más tiempo y llaman la atención por su perdurabilidad, otras 
son fugaces. De fondo, lo que parece ser más relevante es que la sociedad civil, en este caso la aragonesa, ha ido modelando sus formas de organización y respuesta a la vida cotidiana.

Tales respuestas ciudadanas se adaptan a lo que encuentran. Por eso, han cambiando bastante en las tres últimas décadas. El fenómeno es «evidente al bajar a la calle» y lógico dados los cambios sociales, políticos y económicos sucedidos. Así, por ejemplo, muchas asociaciones de vecinos —que comenzaron atendiendo demandas propias de un «sub-desarrollo comunitario" y/o articulando protestas políticas, en una sociedad autoritaria- se han tenido que adaptar al nuevo contexto de una España inmersa en la Unión Europea, con un incipiente Estado de bienestar, en una sociedad de consumo generalizado y en un mercado laboral agrietado por las consecuencias de la llamada globalización. Esto ha repercutido internamente: «se trabaja de una forma diferente, se ha evolucionado en lo que es la organización interna». Aun así, hoy encontramos en Aragón entidades que siguen como siempre ("por no modernizarse, no quieren ni ordenador») y otras que han pasado de ser una mera asociación con sus propios socios a una «asociación como ente de relaciones laborales, lo cual es una cuestión novedosa, importante». En ello ha intervenido la adaptación a nuevas formas de acción social y la versatilidad de las propias entidades como generadores de propuestas. Uno de los ámbitos destacados es el de las ONL sociales.

Quizá uno de los ámbitos más activos y donde más se perciben estas transformaciones es en el de las llamadas entidades de iniciativa social nacidas en barrios de Zaragoza y otras equivalentes en el resto de ciudades de Aragón. Son grupos de personas que en muchos casos tienen vínculos con movimientos cristianos y/o con movimientos obreros, pero «casi nunca con una adscripción política, religiosa, cerrada», dicen ellos. Estas entidades surgen porque una o varias personas se deciden a intervenir en un territorio cercano y concreto. Así, en los barrios, en las comunidades se detectan problemas y «se van dando respuesta a esos problemas que por diferentes motivos las Administraciones públicas no cubren». Sobre este aspecto profundizaremos más adelante, al hablar de las relaciones entre las ONL y la Administración.

Inicialmente, esas primeras actuaciones fueron de carácter formativo: «hace veinte años y antes, en la sociedad de los sesenta y de los setenta, 
cuando se empieza a intervenir, entonces en aquellos momentos la cualificación o la formación pura y dura era la clave de la inserción». En ese contexto las pautas de actuación eran muy claras, mucho más que ahora: «si tú tenías una mejor cualificación, en tu empresa conseguías un mejor puesto de trabajo, y, en un momento determinado, tener un título como era un graduado escolar - que pasaba exclusivamente por una formación teórica - te capacitaba o te daba más posibilidades de acceso a un mercado de trabajo». Estas condiciones sociales permitían un tipo de organización no muy compleja, que podía sostenerse con los propios socios y personas afines.

Pero ahora las cosas han alcanzado otra dimensión. Las condiciones sociales son muy distintas, e incluso las posibilidades de desarrollar actividades han superado todos los límites que en aquellos comienzos existían. Así, aquellas entidades que empezaron dando respuesta en clave de formación, hoy encuentran que esa formación ya no es suficiente para buscar cauces para la inserción de las personas con las que trabajan. Por ello, las estructuras asociativas más o menos consolidadas se han tenido que transformar — especialmente a lo largo de la década de los noventa-, hasta llegar a lo actual: «lo que importa es la intermediación para la inserción laboral».

Y se da una paradoja. Mientras proliferan los cursos de formación impartidos por todo tipo de organizaciones — sindicatos, organizaciones de empresarios, academias...-, con millones de euros destinados desde la Unión Europea, las entidades que se mueven en las franjas de exclusión social apuestan por una inserción laboral que sea «formativa desde la práctica productiva». Esto es, pasan de ser entidades que están impartiendo cursos de formación a ser entidades cuya clave es el mundo del trabajo: «lo que estás buscando es un contrato para las personas que están contigo».

La formación teórica de tiempos pasados — y actuales — no es lo único ni lo prioritario. Si antes se suponía que alguien con una cualificación mínima encontraba trabajo o incluso sin ella también, ahora sabemos que el empleo es un bien escaso en que cuenta más la propia experiencia laboral ${ }^{60}$ que las titulaciones básicas que uno pueda tener. Para jóvenes en condicio-

60 A este respecto ver Gómez Bahillo y Ch. Marcuello (1997). 
nes de vulnerabilidad social, que los hay, es fundamental entrar en el mercado laboral y desde esos primeros pasos madurar como personas y como ciudadanos. Así pues, estas entidades, cuyo paso de la formación al empleo supone un salto cualitativo y cuantitativo muy importante, tienen con los participantes «una relación en la que estás planteando un tema laboral, [...] son personas que tienen difícil acceso al mundo del trabajo, es decir, que hay algunas personas que con una formación teórica y práctica laboral sí que tienen acceso al mundo del trabajo, pero hay otras personas, que a pesar de tener esa formación teórica y práctica inicial, no, no entran en el mercado del trabajo». Por eso se han visto obligados a (re)formular sus modos de proceder, de organizarse y de gestionar la vida cotidiana de la entidad.

El proceso de adaptación también ha estado condicionado por las nuevas formas de relación con las diversas Administraciones públicas, y de un tiempo a esta parte, por la entrada en la Unión Europea: «los proyectos europeos han llevado a trabajar de otra manera o a plantearse cosas de otra manera».

Muchas ONL se encuentran con unos niveles de gestión impensables hace dos décadas. Sus propias dinámicas las han llevado a entrar en colaboración con las municipalidades, el Gobierno autónomo, el central, la Unión Europea... De ese modo, en su cartera de proyectos conviven diversas fuentes de financiación, además de la búsqueda de autonomía e independencia.

Esta evolución en el tiempo y en la forma ha derivado en un cambio obligado en la gestión de las ONL. No es sólo saber cuántos socios mantienen al día su cuota y con cuánto se cuenta para el presupuesto anual. Las ONL que han experimentado esta evolución y han optado por adaptarse están ante un panorama totalmente distinto. Primero, su volumen de gestión contable las convierte en organizaciones complejas que requieren de unas destrezas profesionalizadas y rigurosas. La contabilidad ya no se puede llevar de manera voluntariosa y en ratos libres.

Si nos fijamos en las entidades de iniciativa social que han entrado en la dinámica de la inserción laboral señalada, deben afrontar tanto los trámites y gestiones de sus propios trabajadores como los de los participantes/destinatarios que también pasan a ser trabajadores. Así, estas ONL tienen mensualmente un montante y un volumen de gestión laboral y contable muy grande y, por otra parte, peculiar. Si no se tiene bien estructurado el tema en algunos momentos «llega a agobiar y a congestionar casi, casi... casi todos 
los meses; quiero decir, que un volumen muy importante del tiempo, que las entidades... una asociación de vecinos, a veces no tiene».

Con lo cual, la trayectoria y la evolución de estas ONL nos muestra un origen dedicado a la reivindicación, que en este momento se ha convertido en «sacar adelante los proyectos, no tanto el proyecto, porque eso sí que esta muy derivado en manos de los técnicos, de los trabajadores y de las personas cualificadas de la entidad, sino lo que es el tema de la viabilidad económica del conjunto». De esta forma, conviven la gestión técnica de cada programa o proyecto - que depende de los directores de los programas y de los equipos propios- con la gestión política-ideológica de la organización — que depende, bien de la junta de la asociación, que se reúne una vez a la semana o una vez cada quince días, bien de la asamblea, bien del patronato..., según cada caso- - Y en la práctica todo se produce por la misma razón que en tiempos pasados: «las entidades siguen dando respuesta a todo aquello que no se da respuesta desde las Administraciones públicas».

A la vez que se producen estos cambios internos como respuesta a la realidad, se mantiene el poso de compromiso ideológico primigenio: «no creo que haya una ruptura entre lo técnico y lo ideológico; no, yo lo que creo es que lo técnico ha sufrido un desarrollo enorme». Las ONL de iniciativa social y las que desde otros ámbitos han entrado en una vía de especialización y desarrollo se encuentran en estos momentos con unas dimensiones en su trabajo cotidiano que exceden con mucho las expectativas de sus fundadores. Es un sector que cada vez se diversifica más, porque la propia realidad social se nos presenta más compleja y dispar: "¿quién podía imaginar que en unas décadas tendríamos la inmigración que tenemos? $\mathrm{Ni}$ la Administración sabe qué hacer...; nosotros de momento hacemos lo que podemos». Y ése parece ser el destino de las entidades de este tipo, responder a las demandas sociales a medida que se producen, en el ámbito en el que están, con lo que tienen a mano y aprendiendo según se presentan los acontecimientos.

Esto se valora de distintas maneras. Por un lado, están quienes consideran que no se debe pactar con el Estado ni solucionar las contradicciones de un sistema paliando los problemas superficiales. Por otro, quienes piensan que lo importante son las soluciones. Así, el problema o la virtud de las entidades es que están en el territorio, en la realidad: «entonces estás 
dando respuestas a cosas que están pasando; por eso mismo te estás adelantando». Dicho de otro modo, las soluciones se ensayan y se encuentran antes de que se institucionalicen.

Uno de los ejemplos es el caso de las llamadas empresas de inserción. Responden a la necesidad de integrar a población vulnerable. Dejan en un segundo plano los esquemas de formación tradicionales y optan por la inserción productiva como estrategia formativa:

Nosotros hablamos de [...] que a estos señores que están recibiendo el curso de formación haya por medio un contrato, un contrato laboral que implique lo siguiente: que ese contrato laboral, o la relación que tú vayas a establecer con esa persona durante el tiempo que dure, que establezca, [...] una vertiente formativa que va a completar y a complementar las carencias que tengan los chavales [...] y que luego además haya una relación contractual.

Es una estrategia formativa que se apoya en esa relación laboral-contractual para darle contenidos de vida práctica y adulta. Si las personas jóvenes que asisten tienen un sueldo, mediado por un contrato, se permite un nivel de exigencia mayor:

No vamos a hacer un curso sino que tú vas a estar trabajando con nosotros y vas a tener un contrato como tengo yo.

Así se está planteando una inserción laboral formativa, que para muchos es la primera experiencia laboral. Se hace todo lo posible para que no sea una experiencia laboral negativa:

Se hace un contrato a media jornada por las horas que estás aquí, pero te va a permitir derecho a todo tema de la Seguridad Social, vas a tener tu primera cartilla de la Seguridad Social propia, no vas a depender de la de tu familia, y vas a tener tu cuenta propia, porque yo te voy a tener que ingresar tu dinero, y además la relación que vamos a tener va a ser totalmente diferente, porque además vamos a intentar incluso producir.

La ONL que se sumerge en esta dinámica da un paso hacia un terreno mixto donde, según quién analice, se verá una empresa que ofrece puestos de trabajo y que tiene su espacio en el mercado productivo o una entidad que, sin pretender repartir dividendos, tiene que mantener un nivel de rentabilidad económica — «al menos, no tener números rojos»- Si hace una silla, la silla tiene que estar bien hecha. 
Si reforman una cocina, el resultado tiene que satisfacer al señor que paga. Esto hace que la gestión y los objetivos de la ONL tengan que ser estudiados con variables múltiples para poder describir mejor cada campo. Por tanto, los problemas y las actuaciones se perciben de forma distinta al mirar a la trayectoria recorrida. La historia del sector viene definida por sus obras. Y en ellas se mantienen los vicios y virtudes de las personas que las constituyen. Los grupos que han sido capaces de trabajar coordinados y cooperando crean redes y estructuras de coordinación. Las entidades que responden a intereses particulares que en ocasiones, "sirven de tapadera para conseguir subvenciones», se implican en dinámicas muy distintas.

La situación actual es que — dada la evolución y la complejidad que han adquirido algunas de las labores que desarrollan muchas de las ONL aragonesas - se está entrando en un proceso de búsqueda de estrategias comunes para responder a las necesidades internas de gestión y externas de acción. En algunos casos, movidos por lógicas de rentabilidad económica y, en otros, por convicciones de tipo ideológico-estratégico: «además de la rentabilidad económica — hasta ahora hemos estado trabajando en reinos de taifas; eso está clarísimo-, está la necesidad de tener peso para negociar con otros», agentes sociales, administraciones...

\section{V.3.6. Evaluación, transparencia y cauces de comunicación social}

Otro elemento que, a su vez, constituye un reto es la capacidad para intercambiar información y saber-hacer entre las ONL. Se trata de aprender unas de otras. Es decir, si «la Coca-Cola da clase de cómo llevar su administración, porque no considera que eso sea estratégico y no le importa, o incluso ha dado clases de sus técnicas de marketing y lo enseña", las organizaciones que han desarrollado unas capacidades y habilidades tienen la obligación moral de transmitirlas a las otras. De momento, esto es lo contrario de lo que sucede: «no nos enseñamos nada, incluso nos mentimos de unas a otras porque tenemos celetes, en la mayoría de las ONG». Es más, en Aragón, algunas de las ONL han surgido como escisiones de otras. En algunos casos, han sido escisiones, si no violentas, bastante tramáticas. Los recelos y los prejuicios han arraigado en determinados sectores — que es mejor no nombrar- como producto de esos desencuentros anteriores, casi siempre personales. 
Una propuesta formulada por separado desde distintos actores y sectores de las ONL, de cara al avance del sector no lucrativo en Aragón, es que en una mesa se sentasen todos los gestores de entidades y empezasen a hablar de la confección de un libro de buenas prácticas en la gestión de ONL. Ésta es una demanda más común entre las entidades que actúan en temas sociales o con repercusión social, aun cuando su adscripción inicial sean temas de ocio, cultura o deporte.

Los discursos de los gestores con experiencia en el sector insisten en que las organizaciones deben acostumbrarse a trabajar hacia fuera, a ser mucho más transparentes en su gestión. Pero también recalcan que las personas no se tienen que instalar en los cargos. En síntesis, hace falta una mayor movilidad en sus órganos políticos y profesionalización en sus órganos de gestión, junto con un respeto al papel que desempeña cada uno. Por un lado, los órganos políticos definen las pautas y han de controlar que se cumplen, sabiendo que el presidente no ha de convertirse «en un censor de las actividades diarias del gerente, maniatándolo y no dejándole trabajar». Se trata, pues, de respetar al gerente y a sus técnicos. Por otro lado, hay que evitar que éste «sea un gerente todopoderoso, que está en posesión de la verdad y entonces no deje trabajar a sus técnicos». Ese equilibrio dinámico entre las piezas que componen cada entidad permite que después los resultados sean más adecuados. Siempre debe recordarse que en la mayoría de las ONL se está trabajando con personas; por consiguiente: «jay de aquellas ONG que conviertan al sujeto en objeto! Nosotros trabajamos con sujetos, esos sujetos son individuales [sic] y cada uno merece un trato individualizado».

Además de lo dicho, también encontramos en el sector de ONL aragonesas una creciente demanda de planificación y transparencia hacia dentro del sector. Esto es, sí se reclama que la Administración debe planificar y luego asignar los recursos públicos de modo que se apliquen bien, no se solapen y no se inviertan indebidamente... Las ONL tienen el reto de coordinarse, establecer redes de intercambio y cooperación. Es tiempo también de «decir quién hace bien lo que hace y quiénes están dando palos el agua».

Se abre el camino para la revisión de los sistemas de evaluación. Existen, son diversos y se pueden aplicar. Una tendencia detectada es la que insiste en mirar en el espejo del sector lucrativo — «sin caer en la fascinación de la empresa»—. El mundo de las empresas, «el sistema de mercado hace algunas cosas muy bien, pues cópiese lo que sea necesario». Organi- 
zaciones empresariales de prestigio tienen definidos diversos tipos de controles internos, pero lo que al final es la referencia principal es «la cuenta de explotación, si vende o no vende». Así pues, tanto en ese caso como en el que nos ocupa, «la clave es lo que dice el cliente».

En el trabajo de campo hemos detectado una corriente en las ONL aragonesas que asume este enfoque de aplicación de criterios de rentabilidad económica. Es una estrategia polémica en un sector donde han primado - y siguen haciéndolo— los principios y las ideas altruistas. Por eso, aunque no es una novedad, suenan de manera disonante afirmaciones que resaltan estas claves: «sin perder la identidad de asociación, pero empezar a pensar en clave empresa». Esto significa "un vuelco muy grande». Las entidades que entran en tal dinámica formulan una parte de sus acciones como una porción más de los intercambios del mercado. Por eso mismo, hay que saber cuáles son sus claves y sus inercias:

Como tú no des respuesta, cuando estás en el mercado... si no estás a nivel del mercado, el mercado te echa... y eso es así seas quien seas; quiero decir que eso importa también: las personas con las que estamos trabajando no son excusa para que el producto salga o no salga; eso no es, éste es el salto que damos.

Aquellas ONL que estén prestando servicios o cuyos objetivos tengan unos determinados destinatarios tienen que identificar con precisión qué dicen «sus clientes».

A la hora de evaluar, un pilar fundamental es "preguntar a los usuarios, hay que empezar a investigar de manera sistemática qué están opinando». Y entonces detectamos que en este mismo discurso terminan llevando hasta el final su argumento. Por eso concluyen diciendo:

Si de ese análisis de calidad de los servicios se saca como conclusión que se tiene que limpiar el mercado, pues eso, se limpia.

Así, esta clase de actores considera que muchas de las llamadas ONG se quedarían al descubierto. Por eso recalcan que «habrá que hacerlo, porque es que, si no, lo que estamos es manteniendo un sistema en el que no nos está importando el usuario sino nuestras correlaciones de fuerzas y la posibilidad de mantenernos ahí artificiosamente, sin aportar ningún valor añadido a la sociedad; pero, como tenemos amigos en la Administración o no se qué o no se cuántos, nos sigue financiando históricamente y seguimos manteniendo algo que nadie sabe lo que hace». Con ello se nos hacen 
presentes todas las claves de esta perspectiva. Por un lado, permanecer es cuestión de eficiencia y de calidad de los servicios. Lo contrario, si se vive de los fondos públicos, es pernicioso y, la mayoría de las veces, consecuencia de las relaciones e inercias establecidas. El verdadero objetivo y patrón de medida es el usuario o destinatario de los servicios; dicho en general, la propia sociedad.

Para este enfoque el planteamiento es aceptar y coincidir en los indicadores "porque seguro que los hay; el problema es cómo se consensúan". ¿Serán todos los que se puedan describir y, por lo tanto, después permitan hacer un seguimiento y una evaluación? Si es así, en cada caso habrá que buscar los que incidan en la mejora de la calidad de vida de la persona a la que atendemos o de la actividad que se plantea.

Y el proceso de evaluación tiene que tener también una proyección en las relaciones con las diversas Administraciones públicas. Como se ha insistido antes, la Administración es la responsable de evaluar, planificar, priorizar, después asignar o distribuir los recursos...; "por eso, después evalúa a los que están gestionando los recursos».

Incluso si se pasa al ámbito de ONL del sector de ocio o deportivo, podemos encontrar elementos más fáciles de evaluar. Por ejemplo, supongamos que se trata de analizar la eficiencia de un club deportivo. Allí entramos en un terreno donde están atendiendo una demanda más precisa que en el de las prestaciones sociales y, a la vez, sus usuarios suelen tomarse con más calma los resultados, salvo casos de flagrante incuria o dejación. Y se mantiene el criterio: «la calidad te la da el usuario siempre. Siempre. Sea lo que sea...». Sin embargo, encontramos una objeción a este tipo de argumentos. Algunos consideran que los usuarios no son la única clave, ni tampoco se puede aceptar siempre la máxima comercial de que «el cliente siempre tiene la razón». Podría darse el caso de organizaciones cuyos rumbos y horizontes introducen elementos «peligrosos» o inaceptables. Por ejemplo, ¿qué se puede decir de los usuarios de la muy norteamericana Asociación Nacional del Rifle? Es un debate sobre el que sí que conviene reflexionar, pero entendemos que está ligado también a los consensos básicos del funcionamiento de la democracia. ¿Hasta dónde se puede llegar en el ejercicio de la libertad de asociación? Las respuestas no son ni tan obvias ni tan simples como parece. 
Por otra parte, dicho criterio se propone como el eje desde el que vertebrar las evaluaciones que haga la Administración pública. Desde este discurso se recalca que "la máxima de la Administración es que los administrados vivan mejor, y que la sociedad avance en ese sentido, que trabajemos menos horas al año a ser posible, que trabajemos en unas condiciones de menores riesgos laborales, que trabajemos poco y tengamos más ingresos económicos; en definitiva, todas cosas que nos hagan que estemos en una mejor situación».

La Administración, cuando da dinero a una entidad, debe exigir cuentas claras y auditadas. Pero algo más: «debería tener algún equipo de técnicos que fuesen evaluando los servicios, y posiblemente optimizarían mucho los servicios si hubiera esta evaluación». Si se insiste en que los recursos son cada vez más escasos, es necesario establecer prioridades y evaluar su gestión.

Evaluaciones que también deberían realizarse a las propias Administraciones públicas, por cierto.

Por el mero hecho de existir, es preferible que se establezcan cauces de participación, asociación y organización social a que no se haga nada. Se considera mejor participar en una «agrupación de comedores egoístas que quedarse solo en casa, sin hablar con nadie, ni hacer nada». Ahora, si pasamos a valorar la eficiencia social de este tipo de entidades - por ejemplo, una sociedad de cazadores sólo de hombres que se juntan a pegar tiros, comer y además pagan altos precios por un coto-, la cuestión es distinta. Se puede decir que no aportan nada al común de la sociedad, pero si está limitada, si hay unos límites en su actuación de respeto absoluto a los demás... «pues que gasten sus dineros como quieran». Ahora bien, «si no aporta nada a la sociedad y encima nos cuesta dinero a todos, es muy cuestionable». Porque encontramos un consenso a la hora de valorar esto. El punto crucial es la gestión de recursos públicos y los costes sociales/medioambientales de las actividades que se desarrollan. Por eso, aquello que no aporta nada pero tampoco cuesta nada no entra en la discusión:

Si hay cuatro; vamos a ponerlo más fácil, si hay cuatro varones que hacen un club gastronómico y todos los sábados se ponen morados de comer, en todo caso, si sus cuatro señoras lo toleran, a mí me da igual.

Podríamos decir que cuando una actividad es privada — sucede de puertas adentro—, sin producir efectos públicos — de puertas afuera—, 
no hay nada que decir. Sólo cuando el límite de lo privado se desborda con consecuencias para la comunidad se rompe la postura tolerante.

Por eso mismo, a todos como ciudadanos nos interesa saber quién es quién y qué hace. Una tarea a desarrollar, sea desde la Administración o desde una entidad constituida desde ámbitos diversos de ONL, es facilitar esa identificación. No se trata de caer en un juego de apariencias sino de pedir transparencia y responsabilidad. Si es cierto que «hay mucho cuento, mucho cuento y mucha gente que vive de esto... y una idealización de los marchamos de calidades», se trata de superar las nubes de humo y entrar en la sustancia. Porque en muchas organizaciones sí que se valora como elemento de referencia la evaluación de las actividades y de los resultados de los recursos que se manejan. Estamos en un momento donde cada vez se valora más la evaluación y el rendimiento de las cuentas públicas. El discurso sobre la eficiencia económica y social está haciéndose un sitio más importante en todos los ámbitos de la vida. Si en los mercados es la propia dinámica que establecen los consumidores-clientes la que termina validando a las empresas, en el caso de las Administraciones públicas y del Tercer sector tendremos que buscar cómo se pone en práctica. Los beneficios serán para todos. Porque el trasfondo no es censurar, eliminar o controlar a modo feudal...; al revés, es un ejercicio de control, en el sentido de transparencia y de responsabilidad común. Las evaluaciones no están para suspender, sino para mejorar en aquellos aspectos que no funcionan y para aprender de aquellos que están haciendo las cosas con los mejores resultados, no sólo en términos contables y financieros —que también—, sino especialmente en los aspectos sociales y comunitarios.

\section{V.3.7. Comunicación, divulgación y visibilidad}

A mayor implicación con la sociedad donde se inserta, más capital social, más calidad. Pero esto no se tiene que confundir con la presencia mediática o la visibilidad publicitaria. Es más, se trata de saber diferenciar. Si una determinada ONL ocupa muchos titulares en la prensa y esto se hace para desarrollar una determinada estrategia de captación de recursos, pues está dentro de lo habitual. Sin embargo, detectamos un discurso que introduce la sospecha en aquellas ONL, sobre todo en sus representantes, cuya aparente vocación es estar en el punto de mira de todas las cámaras y micrófonos.

Nosotros procuramos hacer y no decir, salir menos en la prensa, tener menos afán de notoriedad. 
También es cierto que hay ámbitos donde es más complicado evitarlo. Por ejemplo, «en el mundo del deporte es imposible evitar eso. En el mundo del deporte lo que puedes hacer es repartirlo». La propuesta de fondo es dar cauce a que no se produzcan personalismos ni acumulación de poder en unos pocos. Por eso, «si estamos hablando de fútbol, que vaya el entrenador de fútbol; si estamos hablando de baloncesto, que vaya el entrenador de baloncesto». No tiene que ser el presidente el que ocupe todos los titulares y lo explique todo. Cuando se hace, es que «detrás hay claros intereses personales puestos en juego y para los cuales la entidad está al servicio». En ese sentido, el prestigio de la entidad tiende a confundirse con una persona. Luego, por tanto, algo falla. No se construye un tejido social fuerte, sino un liderazgo carismático poco interesante de cara a la estructuración y organización de la sociedad. Algo similar a lo que sucede cuando hablamos de organizaciones cuyo interés son ellos mismos, sin pensar para nada en ninguna otra cuestión que supere sus horizontes particulares.

\section{V.4. Administraciones públicas y ONL}

Con lo dicho hasta aquí, entendemos que se bosqueja como núcleo de análisis destacado las relaciones que el sector no lucrativo establece con las distintas capas del Estado. Por eso, en este apartado queremos atender a la relación que se da entre las Administraciones públicas y las ONL en el caso aragonés.

\section{V.4.1. El reparto de papeles: realidades, teorías y percepciones}

Así pues —a pesar de las críticas y de la queja permanente de algunos actores sociales, mayoritariamente auto-posicionados como "progresistas»—, constatamos en los discursos de las personas implicadas en el sector de las ONL aragonesas una posición asertiva respecto de sí. Dicen:

Con todas sus miserias y sus carencias, la sociedad civil organizada casi siempre va por delante de la sociedad, del Estado, de la Administración...; va abriendo camino, y luego a lo mejor consigue que la Administración se suba al carro o por lo menos indirecta o directamente, a veces porque cubre los servicios y otras veces porque te financia para que los hagas.

Y entonces topamos con una controversia de raíces ideológicas conocidas. Unos — ¿derechas? - dicen que las organizaciones sociales deben 
estar en un primer plano respecto de la Administración pública. Otros — ¿izquierdas? - al contrario, dicen que es el Estado, la Administración pública, la que debe liderar los procesos.

Ambas posturas se encuentran presentes en el sector de las ONL aragonesas, que, por otra parte, son fácilmente identificables. La trayectoria de cada ONL nos define dónde está. Pero también aparece una posición alternativa. Podríamos denominarla sui generis tercera vía — si se permite la expresión-, aunque en realidad no lo pretenda. Parten de un punto distinto. Rechazan el debate por la primacía de uno u otro extremo: «no quiero entrar en debates con este tema porque me parece que es perder el tiempo». En esta posición lo que cuenta es la búsqueda de soluciones, la acción ante los problemas: «si te quedas en la cuestión ideológica, mientras tanto el problema subsiste».

Sucede que este pragmatismo también es optar por una posición. Pero introduce un giro cualitativo a la hora de justificarse: el criterio es la creación de calidad de vida en la sociedad. Las tareas son muchas. Si el papel del Estado en la sociedad española ha sido paternalista y autoritario durante muchos años, llega el momento de superar esas inercias.

Para estas ONL, tanto la sociedad civil — de la que forman partecomo el Estado - «que somos todos» - tienen la obligación de «mejorar el nivel de vida o de la calidad de vida de sus ciudadanos». En el cómo se ha de hacer, uno - el Estado - tiene asignado el rol de árbitro y coordinador para alcanzar ese objetivo y otros — sociedad civil— la imaginación, agilidad o lo que quieran poner sobre el tapete para avanzar:

La calidad de vida es la sanidad, la enseñanza, la cultura, el tiempo que tenemos disponible para el ocio, incluso la crispación social que pueda haber como consecuencia de un montón de factores. A partir de ahí, la Administración pública debe ser garante de que el avance social se produzca, y, por lo tanto, creo que no debe nunca renunciar a ser un poco entidad que planifique, porque tiene una visión que no podemos tener individualmente cada ONG, que podemos tener una visión parcial...

Pero tampoco puede pretender hacerlo todo: «bastante será que de verdad se planifique, coordine, garantice...». Es más, se da un paso en esta posición alternativa:

Se deben aprovechar todas las fórmulas de gestión que hay, y entonces, si la Administración pone en funcionamiento un recurso y lo hace bien, pues 
bienvenido; y si la Administración concierta con una entidad privada y lo hace bien, bienvenido. Lo que hay que hacer es garantizar que unos u otros lo hacen bien.

Así pues, la gestión de las ONL, al menos de aquellas cuyas prácticas tienen mayor vinculación con la prestación de servicios sociales o la atención a demandas que la sociedad genera, está inextricablemente unida a la posición que adopte la Administración del Estado en todos sus ámbitos. El diálogo y la coordinación cooperativa son el reto del sector en Aragón:

En este momento la Administración debe hacer algo que creo que hace a medias, esto es: planificar, detectar necesidades, establecer prioridades y, en definitiva, planificación/evaluación; a ver si de verdad lo hace.

Desde este punto de vista, se trata de descubrir y otorgar el papel de cada uno de los sectores: la Administración pública y el Tercer Sector van a estar en algunas actividades muy estrechamente relacionadas. Así, desde las reflexiones teóricas se lanzan diferentes propuestas. En primer lugar, se observa que la provisión conjunta de servicios como educación, servicios sociales, sanidad, cultura..., esto es, Administración y ONL trabajando simultáneamente en los mismos sectores, permite obtener mejores resultados que si solamente concurre uno de los dos actores. Esto significa que las opciones no son sólo ONL, o sólo Administración; es una labor de ambos agentes alcanzar mejores situaciones de bienestar para la sociedad. ${ }^{61}$

En segundo lugar, esta misma conclusión se refuerza cuando nos encontramos con sociedades donde hay una mayor diversidad en la población, ${ }^{62}$ donde las necesidades de las personas son más heterogéneas y la Administración tiene dificultades para adaptarse a las especificidades de la población. En este sentido, de nuevo, las ONL ocupan el lugar al que no puede llegar la Administración: la sociedad civil organizada casi siempre va por delante de la sociedad, del Estado, de la Administración, va abriendo camino. Esto es, las ONL son más flexibles que el sector estatal a la hora de identificar y responder ante demandas no satisfechas. Esta heterogeneidad puede estar marcada por las diferencias culturales, económicas, ideológicas, la dispersión geográfica. En nuestro caso, Aragón, la dispersión geográfica es

61 Weisbrod (1988).

62 James (1987). 
una de las principales causas de la aparición de necesidades heterogéneas en la población, y cada vez es más necesario que las ONL vayan «abriendo camino, y luego a lo mejor consigue que la Administración se suba al carro».

En tercer lugar, los períodos políticos afectan indudablemente al papel de la Administración y al que deben desempeñar las ONL. Weisbrod (1975) sugiere que la Administración tiende a determinar la cantidad y calidad de los bienes públicos a partir de las preferencias del llamado elector medio, por lo que, consecuentemente, quedará insatisfecha la demanda que no se ajuste a esas preferencias. Es decir, formula que es el elector medio - y no el ciudadano ni el consumidor- quien tiene el rol protagonista. Por eso, las diferencias entre las necesidades medias de la población pueden estar más alejadas todavía de la provisión de bienes públicos. De esta forma se otorga un papel muy influyente a las presiones del electorado sobre la provisión de bienes públicos. Otra vez, las ONL van a ocupar el lugar al que la Administración decide no llegar, puesto que las necesidades existen aunque no se resuelvan: hay multitud de ejemplos en la sociedad civil aragonesa.

En cuarto lugar, es un hecho especialmente palpable en los últimos tiempos - tanto en el caso aragonés como en otros lugares- que, por un lado, existe un claro apoyo de los gobiernos a las ONL y, por otro, hay una delegación de responsabilidades en la provisión de servicios públicos a estas entidades. James (1987) insiste en que, además de esta estrecha relación que acabamos de comentar, existe otra forma de encuentro entre la Administración y las ONL: que la Administración se implica indirectamente porque te financia para que lo hagas. La Administración tienen recursos sugerentes para delegar la producción de servicios a entidades privadas, entre ellas las ONL.

Estos recursos son de muy diversa índole, como, por ejemplo: infraestructuras, subvenciones, convenios y tratamiento fiscal especial, tanto a las entidades como a los que contribuyen mediante donaciones.

Finalmente, la última reflexión nos lleva a insistir en que "en este momento la Administración debe hacer algo que creo que hace a medias, esto es: planificar, detectar necesidades, establecer prioridades y, en definitiva, planificación/evaluación; a ver si de verdad lo hace». Con un matiz importante, esta planificación debe realizarse a través de un diálogo fluido entre las ONL y la Administración, pues cada parte tiene características específicas que pueden mejorar notablemente el bienestar general de la sociedad. 


\section{V.4.2. Relaciones, estrategias y burocracias: ONL-Administraciones}

Las relaciones con la Administración son un asunto crucial y relevante para el conjunto de las ONL, pero, en especial, para las que tienen una parte importante de proyectos dependiendo de esta fuente de financiación. La característica general es de asimetría y dependencia. Unas pocas ONL, fundamentalmente fundaciones, tienen la posibilidad de prescindir de ello, quedarse al margen e incluso plantar cara al Estado, a la tramoya de sus técnicos y a las familias políticas que en cada momento tienen encomendada su gestión. También hay asociaciones — las menos- que ni piden, ni quieren, ni se plantean entrar en relación con la Administración, y, por tanto, respecto de este tema ni les importa ni les atañe: «a nosotros con que no nos fastidien ya nos vale». Salvo en estos casos, la Administración juega con ventaja y establece unas relaciones que siguen rezumando un perfume paternalista, imperativo $y$, muchas veces, controlador en sentido negativo... - al viejo estilo autoritario franquista-. Suele manifestarse cuando se quiere dejar claro quién tiene los fondos. Para algunos actores de las ONL se debería evitar siempre que se produzca — "pasa cada vez menos, porque los técnicos saben lo que hacen»-, pero sigue detectándose "un cierto clientelismo que es difícil de erradicar».

Así las cosas, un discurso que aparece es la necesidad de romper esa asimetría -que, por otro lado, es consustancial, dados los roles sociales que se atribuyen a cada una de las partes- - . Para ello, es necesario definir con más claridad qué objetivos se ponen en juego cuando se establecen las relaciones entre las partes. En especial, destaca la cuestión de la financiación: es el nudo del asunto y, también, de la posibilidad de autonomía e independencia. Con la financiación se han de sentar las bases para el ejercicio responsable de las acciones por parte de las ONL y de los mecanismos de garantías por parte de las Administraciones.

Los responsables de proyectos cofinanciados por las Administraciones destacan la importancia de programas concebidos con una cierta visión a largo plazo, que no tengan que sufrir los altibajos burocráticos en una financiación voluble y volátil. Sin embargo, «lo que más abunda, vamos lo que hay, son las convocatorias anuales», y, con ello, planes de financiación con una perspectiva escasa y poco efectiva: «ha de pensarse en financiación de continuidad, que cuando se da el dinero, o sea, todo eso, se piense en que, si no es así, la gestión se dificulta bastante y se complica». 
Por esto mismo un reto es conseguir fuentes diversas de recursos. Aunque si estas fuentes vienen de los distintos niveles del Estado - municipios, diputaciones, Gobierno autónomo, central, europeo-, entonces tampoco es una solución.

En este momento, la diversificación de fuentes de financiación supone complicar la gestión y la vida... porque tienes que hacer múltiples memorias, múltiples proyectos, múltiples justificaciones, o sea... que está bien que se rindan cuentas del dinero público, pero habría que buscar fórmulas más fáciles.

Desde las ONL se pide a las Administraciones públicas que se simplifiquen los trámites y no se reiteren innecesariamente los procedimientos de control:

Los mismos informes se entregan a departamentos distintos porque se tienen que justificar partidas de cada uno de ellos...; podían facilitar las cosas.

Ésta es una tarea pendiente que está en manos de la Administración, respecto de la cual hay un consenso generalizado en el sector de las ONL. La propuesta es buscar cauces de relación más sencillos, coordinados y homologados entre sí. Una mayor coordinación entre las Administraciones "para que se pudieran hacer las cosas con pautas comunes, y no que cada subproyecto tenerlo que gestionar de manera diferente, a veces incluso con parámetros diferentes de evaluación, de justificación; se complica mucho lo que es gestión». Además, se reclama una mayor agilidad por parte de las instituciones en la entrega de los fondos. Con su sistema de pagos y entrega de «dineros obligan a las personas de las ONL a vivir en un constante cambalache financiero..., lo que es liquidez..., lo que es el dinero, los créditos en que se tiene uno muchas veces que empeñar personalmente, es otra dificultad que se tiene».

El sistema debe funcionar con un ritmo más ágil y adecuado a las economías de las entidades. En su mayoría, las ONL aragonesas no son poderosas instituciones financieras que puedan soportar la morosidad y deudas de la Administración durante largos períodos de tiempo. Más bien, al contrario. Pero, por la experiencia constatada, encontramos casos en que un pago que debería haberse librado antes de terminar el ejercicio correspondiente, no se ha ejecutado porque un trámite meramente accesorio ha paralizado el libramiento de fondos.

Desde el sector esto se valora de tres formas distintas. Una, despreciando y vilipendiando a los responsables. Otra, comprendiendo a las per- 
sonas, pero rechazando el sistema burocrático. Y una tercera, percibiendo una confrontación de fondo:

Muchas veces hay cierta rivalidad donde no se valora mucho este tipo de trabajo, no hay esa conciencia positiva; al contrario...; o sea, el dinero es mío y te lo doy... Cuando no es eso: el dinero es de todos, tú lo gestionas como Administración y tienes que dar para que se gestione más adecuadamente, no de una manera clientelista - te doy para que tú me des otros favores-, sino porque creo que lo vas a hacer mejor y que tenemos que articular unos mecanismos de seguimiento y coordinación.

Las inercias clientelistas, que son viejas en el país, todavía se perciben por parte de algunas ONL. Y se ven en ambos lados, tanto en las propias entidades que saben cuándo les toca y con quién se llevan mejor, como en quienes llegan a gestionar la Administración. Es un reto serio, que se resolverá en la medida en que se apliquen mecanismos de evaluación y de seguimiento transparentes y rigurosos. Ese dinero público, por ser de todos, no es patrimonio de nadie. Por tanto, se tienen que crear modelos de comportamiento con las que no se repitan los vicios del pasado:

Creo que eso es difícil: esa cultura no existe mucho, no sólo por parte de la organización que va a pedir, sino tampoco por parte de la Administración. Es difícil, hay momentos en que sí que se puede dar el que se vea que es una parte, no que te doy un dinero, sino que es un complemento en el que hay que, primero, seguir llevando un seguimiento de eso y que no es para tener contentos a unos, o por una presión sino porque es una fórmula interesante, o porque también se tienen que apoyar las organizaciones sociales, que nos beneficia a toda la sociedad.

Pero las valoraciones desde el sector nos muestran que hay mucho camino por recorrer.

Las coyunturas políticas que tenemos tienden a la busca del clientelismo y creo que, por lo menos desde donde he estado trabajando, siempre se ha pedido a la Administración que haga un seguimiento real: pues bueno, vamos a sentarnos y ayúdame también, o sea, que haya una retroalimentación también y una evaluación por parte de ellos, de fondo, porque a veces es muy de papeles o muy burocrática y nada más.

Por eso también se reclama una buena articulación y una buena delimitación de funciones de las distintas Administraciones territoriales, «porque más de una vez no se da, la DGA está duplicando, y el Ayuntamiento de Zaragoza, como es una gran ciudad y tal, están duplicando 
actuaciones... de dependencias administrativas diferentes, cuando tendría que haber una delimitación de qué es competencia de la autonomía, que sería planificación, seguimiento, no se qué... y planes globales, y lo que es actuación, y lo que sería lo municipal». Esta coordinación nos interesa a toda la sociedad, pero mucho más a las propias administraciones.

En definitiva, si se hacen diseños para poner en marcha programas comunes, la tarea consistirá en cumplir con lo que se proclama. Así, las posibles vía de coordinación tienen que tomar como punto de partida un escalón anterior. La Administración, — vista desde las ONL como sociedad civil— debe funcionar según tiene previsto, «o sea, sí, es que el plan de integración de minorías, por ejemplo, que es perfecto - pero que nadie ha puesto en marcha-, el plan de igualdad de la mujer, que es perfecto... y otro tanto. El funcionamiento es, es, es tan lento, tan lento, tan lento que el plan está bien, pero no sirve de nada porque no se pone en práctica». Por eso las personas que trabajan en materias relativas a la cuestión tienen claro que las asociaciones «no vamos por delante en eso de elaborar teorías..., y a nivel europeo ya no te cuento: la capacidad que tiene la Unión de generar reflexiones en torno está a años luz de lo que está la realidad; ahora, entre medio qué pasa, pues no lo sé... Yo creo que lo que habría que hacer es evaluar. No creo que deba desaparecer la cobertura pública, porque es una garantía de igualdad; antes [...] una garantía se supone que era también de calidad (ahora no sé si es una garantía de calidad). Lo lógico sería evaluar a la Administración y aplicarse en consecuencia aquello que se propone».

Por tanto, aparece una demanda de definición de un marco general de actuaciones, con unos consensos en materias diversas que permitan planificar políticas tanto desde la Administración como desde el sector de las ONL, acompañadas de mecanismos de seguimiento. Por eso la planificación es una necesidad en todos los ámbitos. Hasta ahora en Aragón no existe una visión general en la que, además, se resuelvan las duplicidades y deficiencias señaladas anteriormente. Para las personas con más experiencia en las entidades del sector, es un asunto que ha de transcender a los partidos políticos y a los intereses particulares: «es decir, no porque a cada uno se nos ocurran cosas que también están bien, éstas tienen validez ya, de por sí, sino que entre todos, no sólo desde la Administración, —eso sería lo ideal—, articulando vías de participación, habría que ver cuáles son las necesidades y cuáles son las respuestas a esas necesidades, y entonces encajar en esas res- 
puestas a esas necesidades las distintas iniciativas». Entonces, definido el marco, estableciendo cauces de participación, de seguimiento, de evaluación y de revisión se dará pie a establecer criterios de actuación donde tanto las administraciones como la sociedad civil organizada tiene la posibilidad de mejorar la vida cotidiana de todos. Y desde esas coordenadas se decide después: «igual se pueden necesitar los Centros Sociolaborales o no, si se necesitan entonces hay que subvencionarlos, apoyarlos y tal... si no se necesitan no, y si ese es uno de los criterios... muy bien, está muy bien si quieren eso, pero como no entra dentro de los programas de lo prioritario, pues la Administración no participa». Pero esto tiene que ser independiente de los aires políticos y de quienes ocupen los puestos de decisión. Los mismos que lo reclaman vislumbran posibles elementos de duda:

\footnotetext{
O sea, que yo también veo que es un peligro, pero que ahí teóricamente está también el papel de la planificación participativa. Es decir, que a todos definimos qué necesidades hay y qué respuestas tiene que haber a esas necesidades, y ese dinero público cómo se reparte para llegar a todas esas necesidades y qué es lo prioritario.
}

Por encima de las propuestas y de las corrientes ideológicas que las propugnan, lo que sí que queda claro es que se necesita un marco de referencias comunes, estable, consensuado, abierto y donde se den garantías de lo que se hace. Esto exige plantear mecanismos de control transparentes y pautas para el seguimiento de las actuaciones que vayan más allá de las meras auditorías contables actuales. Las dificultades vienen al buscar el cómo se pone en práctica — asunto que excede el propósito de este libro-. Serán los propios actores implicados quienes lo construyan.

\section{V.5. Como contrapunto}

Lo dicho hasta aquí se puede aplicar al conjunto de las ONL aragonesas, pero queda otro aspecto por considerar: la diferencia entre el mundo urbano y el rural. O, lo que es casi lo mismo, Zaragoza y el resto. Nuestra comunidad, Aragón, está condicionada por la macrocefalia zaragozana, que, para bien y para mal, marca la mayoría de los procesos sociales de esta sociedad. Ya sólo desde el punto de vista demográfica representa más de la mitad de la población. Por tanto, su peso determina la marcha del conjunto, cuestión que no vamos a tratar en este momento. 


\section{CAPÍTULO VI CONCLUSIONES}

El sector no lucrativo en Aragón —como sucede en otras sociedades de nuestro entorno- se muestra en crecimiento y gana relevancia en lo que afecta a su dimensión económica, social y política. A la vez, refleja las características particulares del país y las inercias generalizadas por el proceso de mundialización-homogeneización internacional. Respecto de lo primero, hemos visto que los procesos de asociación y creación de redes vienen determinados por las circunstancias sociodemográficas y territoriales de una comunidad cuyo capital humano y social, a pesar de algunas estadísticas, está vivo y es rico. Respecto de lo segundo, se reproducen las tendencias internacionales de incremento del sector, mayor peso en las economías y nuevos roles socioeconómicos detectados por Salamon et al. (1999a) en su informe sobre la Global Civil Society.

A lo largo del libro hemos intentado describir y analizar cómo están las cosas en este ámbito de la sociedad aragonesa. Algunas de esas facetas las queremos destacar de un modo sintético en las conclusiones generales.

En el primer capítulo nos hemos ocupado de precisar, ponderar y acotar nuestro objeto de estudio dando una definición de sector no lucrativo. Como ya hemos dicho, partimos de una posición abierta que intenta aunar la realidad empírica con las teorías existentes, para formular una propuesta propia. Esta propuesta se concreta en que el sector no lucrativo está formado por aquellas organizaciones legalmente reconocidas - dejamos fuera los grupos informales sin legalizar, independientemente de su labor o repercusión-, de carácter privado, con autogobierno, donde los derechos de decisión y control residen en los miembros de la entidad, que 
podrán contar con trabajadores o voluntarios, donde la clave principal radica en la limitación a la apropiación de los posibles excedentes de la actividad y cuyos fines abarcan desde «asistencia social, cívicos, educativos, culturales, científicos, deportivos, sanitarios, de cooperación para el desarrollo, de defensa del medio ambiente, de fomento de la economía social o de la investigación", como se dice en la Ley 30/1994 de Fundaciones, en el artículo 42 del título II.

El conjunto de las ONL produce beneficios sociales externos a cada organización. Sin embargo, distinguimos entre aquellas organizaciones que, bajo la denominación general de no lucrativas, se catalogan como de interés general y aquellas cuyos rasgos son propios de entidades de interés particular. En sentido estricto, en asociaciones y fundaciones confluye el interés altruista de los que las crean con la figura jurídica que las desarrolla. En un sentido más amplio, denominamos ONL de interés particular a las cooperativas, mutuas y cajas de ahorros, entidades en que las personas que las crean tienen un interés particular, que se articula a través de ellas, y de mejora del bienestar de los miembros de la organización.

Volvemos a insistir en que el sector no lucrativo contiene organizaciones que con sus modos de hacer se aproximan más a la empresa lucrativa, mientras que existen otras entidades que actúan bajo el prisma del altruismo. Entre ambos extremos hay otro gran número de posiciones que constituyen un amplio abanico.

Las luces y las sombras de este sector se muestran a través de las acciones de cada una de las ONL. Algunas están claramente comprometidas con su realidad, con la intención de cambiarla o paliarla. Un ejemplo son las cooperativas agrarias, una de las vías de desarrollo que queda en nuestros pueblos, frente a otras más «comerciales» en sus usos y maneras. Otras ONL simplemente no se lo plantean. Pero cada una tiene un papel en la sociedad y la economía de este país, y todas despliegan su particular manera de entender cuál es el camino más adecuado para llegar a sus metas. Sin olvidar que todas ellas deben actuar desde la perspectiva del interés general. $^{63}$

63 Estos términos, que tienen mucha densidad tras de sí, están en la misma línea que los cuasisinónimos bien común o salud social (Pérez Adán, 1999). 
El capítulo II lo hemos dedicado a la revisión y al análisis del entramado legal actual para acabar de concretar las características propias de las ONL. Estamos ante un marco jurídico donde es complicado valorar la situación global de las ONL. Del estudio de las distintas figuras jurídicas, el caso de la asociación es el más paradójico, puesto que hasta marzo de 2002 seguía vigente una ley preconstitucional, la Ley de Asociaciones de 1964. No obstante, a día de hoy, cuando redactamos estas conclusiones se ha aprobado la nueva Ley de Derecho de Asociación 1/2002, y hay un nuevo proyecto de ley de Mecenazgo y de Fundaciones. El propio proceso de elaboración de ambas leyes debería ser un ejemplo de diálogo social, de escucha a las organizaciones y a sus personas para poder formular mejor las claves de una leyes fundamentales para el fermento de nuestra democracia.

Como valoración, consideramos que la labor efectuada en aspectos legislativos por la Comunidad Autónoma de Aragón es adecuada, y, de hecho, actualmente, salvo las fundaciones, el resto de entes están dotados de una legislación aragonesa acorde con las competencias transferidas. En consecuencia, las Cortes de Aragón sólo tienen pendiente el desarrollo de una ley propia para las fundaciones de nuestra comunidad.

Por otro lado, y a la vista de estas circunstancias de nuestro estudio de campo, estimamos conveniente que, en términos procedimentales, el Servicio de Régimen Jurídico y Registros atienda una serie de requerimientos, como: 1) unificar de forma efectiva los registros de asociaciones, bien centralizando funciones procedimentales en el Registro General, bien, en su caso, estableciendo medios de comunicación y protocolos de trabajo adecuados; 2) dotar a los registros, en general, de una herramienta de trabajo que, en primer lugar, sistematice y facilite el ejercicio de las tareas administrativas, y, en segundo lugar, agilice la toma de decisiones para que las instancias superiores estudien, analicen y decidan determinadas actuaciones, como la dotación de subvenciones genéricas o afectadas y, en definitiva, la conducción de una política social congruente con la realidad circundante. Esto permitiría tener una adecuada base de datos de los diferentes registros, según la legislación estatal y autonómica, y crear un sistema de procesamiento de datos.

En nuestra opinión, la Administración pública, tanto a través del marco regulador como de sus diferentes políticas, debe facilitar la vida diaria de las ONL, y no ha de encorsetar el dinamismo ciudadano ni crear estructuras burocráticas rígidas. $\mathrm{Al}$ contrario, como hemos detectado en 
las personas integradas en las diversas organizaciones, debe tener como objetivo garantizar la vitalidad cívica, la conciencia ciudadana, la libertad, la pluralidad e, incluso - por qué no decirlo así-, la imaginación social, pero también debe establecer mecanismos que potencien la transparencia de las entidades y la exigencia de responsabilidades cuando sea preciso. Son algunos de los aspectos que han ido surgiendo a lo largo del libro.

Además - considerando las diversas conversaciones mantenidas durante estos tres años de nuestra investigación-, creemos que hemos de aportar algunas recomendaciones en cuanto a la relación de la Administración con las ONL, o viceversa. Primera, debe primar la participación ciudadana en todos los ámbitos de la vida social. Sólo así podremos decir que vivimos realmente en una democracia. No como ahora, donde claramente existe un déficit de participación y de democracia. Segundo, como corolario de lo anterior, debe apostar por la creación de capital social fomentando las organizaciones ciudadanas vertebradas a partir de objetivos comunes, que en pasos posteriores generan redes que, a su vez, multiplican la suma de voluntades. Tercero, ha de definir procedimientos de gestión que garanticen la transparencia de las entidades - algo que debería ocurrir para el resto de la organizaciones de la sociedad-y el cumplimiento de responsabilidades en las tareas de repercusión general.

En los capítulos III y IV hemos pretendido atrapar la realidad de la sociedad civil aragonesa. En ambos capítulos presentamos datos - a día de hoy en Aragón - que muy pronto habrán de ser revisados, pues estamos ante un sector socialmente muy dinámico y vital. A pesar de esa volatilidad, nos permiten construir una imagen de referencia en la que hay que seguir profundizando.

Los aspectos más relevantes de las figuras analizadas ofrecen dos resultados - uno, desde un punto cualitativo y otro, de carácter cuantitativoque comentamos a continuación. En el capítulo III hemos analizado las organizaciones no lucrativas de interés particular. En primer lugar, las cooperativas contienen en sí mismas una larga tradición que plantea las relaciones sociales de un modo distinto a la mera búsqueda de beneficios monetarios. Incluso el sector cooperativo es una vía de acción y de participación ciudadana en la cual convergen las dimensiones económica, social, y política, que tiene mucho que decir tras las reformas introducidas en la nueva ley aragonesa. 
Como ya hemos señalado, los discursos sobre este sector indican que cualquier cooperativa es una entidad multifacética, en tanto que forma de organización, sociedad, medio de participación ciudadana, mecanismo de creación de redes sociales y herramienta de arraigo de población.

El modelo cooperativo -insistimos- que cumple al menos dos papeles, uno como referente organizativo y otro como actor socioeconómico. En ambos tiene una importante función en la vertebración de la economía y la sociedad de nuestra comunidad. Esto se ha traducido en el papel fundamental que ha desempeñado y sigue desempeñando como factor de progreso-arraigo de las zonas rurales.

En dichos contextos - mayoritarios en Aragón-, este modelo es creador de riqueza y empleo, determina el mantenimiento de los modos de vida particulares y de los referentes culturales locales, al tiempo que articula un tipo de asociación de voluntades de especial relevancia social, el cual se caracteriza por la solidaridad y la participación de los socios en la toma de decisiones.

En cuanto a las cajas de ahorros, desde su fundación, no buscan repartir dividendos entre sus accionistas, puesto que los objetivos sociales han sido siempre su principal signo de distinción. Pero el hecho, además de haber pasado por grandes transformaciones tanto en sus principios de acción como de legitimación, ha tenido que adaptarse a las circunstancias propias de cada época. La nueva legislación se ha hecho cargo del asunto y ha puesto la obra social al servicio de la sociedad, preparando una mayor intervención política en lo que hasta ahora eran acciones más o menos independientes.

En la nueva ley de cajas aragonesa - Ley 4/2000, de 28 de noviembre, de reforma de la Ley 1/1991, de 4 de enero, de las Cajas de Ahorros en Aragón - se reconoce el desarrollo social y económico de Aragón y se refuerza para todas las cajas presentes en la comunidad una estrategia de vinculación de las entidades con la sociedad de la que obtienen sus recursos y de la que gestionan sus ahorros.

El capítulo IV se ha dedicado al conjunto de las organizaciones no lucrativas de interés general: asociaciones y fundaciones. Las asociaciones son una de las expresiones del capital social de una sociedad. A través de ellas se muestra la capacidad que tiene el conjunto de la ciudadanía de organi- 
zarse y dar cauce a sus propuestas ante la vida en sociedad. Por eso, en sus acciones, resultados y concreciones sociales definen — si se permite otra vez la expresión - un reservorio de riqueza de la sociedad en cuestión. A mayor capacidad organizativa y a mayor capacidad de respuesta colectiva, mayor capital social disponible... más personas implicadas. Esto ocurre también a través de las fundaciones, aunque con un modo de participación distinto y en menor medida, ya que las cifras nos indican que en Aragón se han constiuido unas once mil asociaciones, frente a 183 fundaciones.

Hemos dicho que las asociaciones del mundo rural aragonés tienden a ser distintas según los «contextos orográficos culturales». Los tópicos que distinguen entre la montaña y el llano, la ribera, los somontanos y los valles siguen siendo válidos. En el caso de Teruel, se habla de dos universos distintos: la provincia rica y la provincia pobre, pero algo está cambiando con la Plataforma Teruel Existe.

$\mathrm{Y}$ en el medio rural todavía vivo también se percibe una forma de interactuar distinta de la del urbano. Esos signos de distinción se traducen en tendencias asociativas que dinamizan las entidades con modos de comportamiento opuestos. El reto -insistimos_- es dar vida a las actividades comunes, coordinarse y planificar para no multiplicar esfuerzos inútilmente.

Similar es el caso de la provincia de Huesca, donde la tradición distingue las gentes de la Tierra Llana de los montañeses. Mas allá de tópicos, vemos ejemplos muy interesantes de entidades que han sido capaces de generar dinámicas de movilización social de largo alcance.

Sea en Teruel o en Huesca, la realidad insiste: lo que importa son las personas. Y si rastreamos detrás de cada una de las organizaciones, vemos un grupo, o incluso a veces un par de personas, que son quienes han apostado por un ideal hasta llevarlo a la práctica.

Así, nos hemos encontrado con que en todas las organizaciones las formas de gestión y acción dependen del tipo de relaciones humanas que mantienen y de la biografía de la entidad. Es en las relaciones establecidas con el paso del tiempo - tanto en su gestación como en su fase de consolidación - donde se sedimentan modos de ser y formas de canalizar los recursos que aporta cada persona en interacción con los valores socialmente disponibles. 
Para las asociaciones hemos propuesto una tipología de comportamiento: en primer lugar, las entidades auto-centradas, cuyos socios son a su vez los destinatarios finales de la propia organización. En segundo lugar, las entidades semi-centradas, aquellas que, aun primando las actividades de los socios cotizantes, tienden a establecer cauces que benefician a otros que no pagan la cuota. En tercer lugar, las organizaciones semi-externalizadas, aquellas que, si bien priman con sus objetivos finales al destinatario último o usuario, también atienden de forma secundaria a los propios asociados. Por último, las entidades externalizadas, que centran su enfoque en los destinatarios de su actividad.

Otro elemento es el papel de las personas en las asociaciones y fundaciones. Desde finales de los años ochenta se observa una explosión del voluntario: aquellas personas que se aproximan a una asociación o a cualquier tipo de actividad social con «la voluntad» de no ser remunerados, lo cual ha sido habitual en la mayoría de las asociaciones aragonesas desde que se constituyeron. Pero ahora esta distinción, dentro de las asociaciones y de las ONL en general, tiende a diferenciar al socio del voluntario.

Hemos visto que son socios aquellas personas que pagan una cuota establecida (socios de cuota). Otras pasan por encima del abono de cuotas y dicen que socio es quien promueve la existencia y mantiene la entidad participando en las diversas actividades, y preocupándose por su gestión y acudiendo a las asambleas y otros momentos importantes de la asociación (socios activos).

Respecto de la figura del voluntario, hemos elaborado una tipología: voluntario de plantilla, voluntario sin compromiso, voluntario de ocasión y voluntario por terapia, que explicamos con detalle en el apartado IV.1.5 (ver p. 136).

Más allá de etiquetas y tipologías, cada asociación construye sus pautas particulares entre sus integrantes. En el debate sobre la relación entre socios y voluntarios se distinguen dos corrientes de opinión: una que insiste en el valor de suyo del voluntariado, y otra que recalca su perversidad.

En el sector de fundaciones aragonesas nos encontramos con las mismas inercias que en el de asociaciones. El abanico vuelve a ser variado y diverso, tanto en los objetivos y los planteamientos ideológicos como en su acción en la sociedad. 
En las fundaciones, el peso estructural de la gestión y toma de decisiones descansa en el patronato. En la mayoría de los casos traza las líneas generales de actuación y la "política» de la entidad. Ejerce como órgano de supervisión y control, y deja actuar dentro de los límites trazados al equipo gestor de la fundación. Hay fundaciones que se parecen más a una asociación donde las «bases» participan de la gestión, y otras que se alejan completamente, pues queda claro cuál es el orden vertical de jerarquías. Este aspecto afecta especialmente a la relación con las personas voluntarias que se acercan o colaboran con la entidad. Por otra parte, los «usuarios» de las diversas fundaciones son tan heterogéneos como las mismas organizaciones.

Finalmente, los resultados cuantitativos más destacados se concretan en las tablas que presentamos a continuación, donde hemos tratado de sintetizar una visión general del sector no lucrativo aragonés. Somos conscientes de que dicha visión necesita profundizarse más y de que los datos actuales de los registros con los que hemos trabajado son muy limitados.

En Aragón estimamos que existen 13319 ONL. Su distribución geográfica es el reflejo de la situación aragonesa: el 76,35 \% están en Zaragoza provincia, el $16,8 \%$ en Huesca y el $12,3 \%$ en Teruel. El número de entidades no es, precisamente, un indicador de nada, pero es lo poco que ofrece el registro. Sobre la cifra albergamos serias dudas (las hemos expuesto en los capítulos anteriores), y pensamos que una estimación más realista estaría en torno a unas seis mil entidades.

TABLA VI.1

EL SECTOR NO LUCRATIVO EN ARAGÓN.

NÚMERO Y TIPO DE ORGANIZACIONES NO LUCRATIVAS, 2000

(Los datos de los registros están actualizados hasta noviembre de 2000)

\begin{tabular}{|l|r|r|r|r|r|r|r|}
\hline \multirow{2}{*}{ Entidades } & \multicolumn{1}{|c|}{ Aragón } & \multicolumn{2}{|c|}{ Huesca } & \multicolumn{2}{|c|}{ Teruel } & \multicolumn{2}{c|}{ Zaragoza } \\
\cline { 2 - 8 } & Número & Número & \multicolumn{1}{c|}{$\%$} & \multicolumn{1}{c|}{ Número } & $\%$ & Número & \multicolumn{1}{c|}{$\%$} \\
\hline Asociaciones & $11.969 a$ & 1.937 & 16,18 & 1.307 & 10,92 & 8.725 & 72,90 \\
Fundaciones & 183 & 18 & 9,84 & 16 & 8,74 & 149 & 81,42 \\
Cooperativas & 1.149 & 138 & 12,01 & 196 & 17,06 & 815 & 70,93 \\
Cajas (741 oficinas) & 15 & 145 & 19,57 & 116 & 15,65 & 480 & 64,78 \\
& (cajas) & (oficinas) & & (oficinas) & & (oficinas) & \\
Total & 13.319 & 2.238 & 15,94 & 1.638 & 11,64 & 10.169 & 72,42 \\
\hline
\end{tabular}

a Número de asociaciones constituidas, muy alejado del de asociaciones activas, que calculamos en unas cinco mil.

FUENTE: Registros de asociaciones, fundaciones y cooperativas de Zaragoza, Huesca y Teruel. Para las cajas de ahorros, Anuario de la CECA (1999), donde se presenta el número de oficinas. 
TABLA VI.2

NÚMERO DE ENTIDADES POR TIPO DE ACTIVIDAD DEL SECTOR NO LUCRATIVO EN ARAGÓN, 2000

\begin{tabular}{|l|c|c|c|r|r|}
\hline Actividades & Asociaciones $^{a}$ & Fundaciones & Cooperativas y cajas & Total & $\%$ \\
\hline Cultura y ocio & 4.047 & 21 & - & 4.068 & 30,57 \\
Deportivas & 2.523 & 1 & - & 2.524 & 18,97 \\
Educación e investigación & 1.388 & 33 & 4 & 1.425 & 10,71 \\
Salud & 114 & 2 & - & 116 & 0,87 \\
Servicios sociales & 1.463 & 87 & 2 & 1.552 & 11,66 \\
Medio ambiente & 183 & 6 & - & 189 & 1,42 \\
Desarrollo comunitario & 631 & 12 & 199 & 842 & 6,33 \\
Derechos civiles & 462 & 0 & 25 & 487 & 3,66 \\
Intermediarios filantrópicos & 26 & 4 & 7 & 37 & 0,28 \\
Internacionales & 54 & 1 & - & 55 & 0,41 \\
Religiosas & 141 & 10 & - & 151 & 1,13 \\
Profesionales y negocios & 605 & 0 & 18 & 623 & 4,68 \\
Otras de interés general & 317 & 6 & 899 & 1.222 & 9,18 \\
Total & 11.969 & 183 & 1.154 & 13.306 & 100,00 \\
& $89,9 \%$ & $1,4 \%$ & $8,7 \%$ & $100 \%$ & \\
\hline
\end{tabular}

a Asociaciones constituidas

FUENTE: Elaboración propia a partir de los registros de asociaciones, fundaciones, cooperativas

Aun así —y esperando mejorar-, existen datos para toda España en cuanto a número de entidades que nos permiten comparar. En las tablas VI. 2 y VI. 3 presentamos los datos de Aragón y los del conjunto de España, respectivamente. Queremos recordar dos aspectos. Uno, el número de asociaciones, fundaciones y otras figuras presenta unos porcentajes semejantes: $89,9 \%$ de asociaciones, $1,4 \%$ de fundaciones y $8,7 \%$ de otras. Dos, en cuanto a la distribución en los distintos sectores de actividad también hallamos estructuras análogas; las diferencias más significativas se producen en "Cultura y ocio», con un número inferior en Aragón, al igual que en las entidades de "Desarrollo comunitario», y las de "Derechos civiles", mientras que en las de «Servicios sociales» la cifra de Aragón es superior a la de España.

En la tabla VI.4 se muestran los porcentajes por la procedencia de los ingresos, aunque únicamente disponemos de información de las ONL de interés general. Los datos nos indican que en Aragón el 43,06 \% de los ingresos proceden de las cuotas de los socios o pagos por servicios, mientras que las donaciones representan un $24,92 \%$ y la aportación del sector 
público es de un 32,02 \%. Esto nos permite destacar que el peso del Estado en el conjunto de dichas entidades es inferior al que cree el imaginario social, ya que se suele pensar que las ONL dependen principalmente de la financiación pública, cuando, en realidad, casi el $70 \%$ de sus ingresos es de procedencia privada. Sin embargo, sería interesante conocer cómo se distribuye en los diferentes sectores de actividad.

Asimismo, encontramos que los ingresos de las ONL aragonesas presentan una estructura similar al conjunto de las españolas, con la importante diferencia de que las donaciones privadas suponen un porcentaje superior.

TABLA VI.3

NÚMERO DE ENTIDADES POR TIPO DE ACTIVIDAD

DEL SECTOR NO LUCRATIVO EN ESPAÑA, 1995

\begin{tabular}{|l|c|c|c|r|r|}
\hline Actividades & Asociaciones & Fundaciones & Otras & Total & $\%$ \\
\hline Cultura y ocio & 88.328 & 1.140 & & 89.468 & 35,29 \\
Deportivas & 58.085 & & & 58.085 & 22,91 \\
Educación e investigación & 25.999 & 2.002 & 7.005 & 35.006 & 13,81 \\
Salud & 1.834 & 772 & 144 & 2.750 & 1,08 \\
Servicios sociales & 6.472 & 1.450 & & 7.922 & 3,12 \\
Medio Ambiente & 5.508 & 10 & & 5.518 & 2,18 \\
Desarrollo comunitario-cívico & 20.496 & 100 & 6.828 & 27.424 & 10,82 \\
Cooperación internacional & 500 & 30 & & 530 & 0,21 \\
Religiosas & & & & & 0,00 \\
Derechos civiles & 15.334 & 64 & 381 & 15.779 & 6,22 \\
Profesionales y de negocios & 10.445 & 90 & & 10.535 & 4,16 \\
Intermediarios filantrópicos & & 40 & 50 & 90 & 0,04 \\
Otras de interés general & & & 400 & 400 & 0,16 \\
Total & 233.001 & 5.698 & 14.808 & 253.507 & 100,00 \\
& $91,9 \%$ & $2,2 \%$ & $5,8 \%$ & $100 \%$ & \\
\hline
\end{tabular}

FUENTE: Ruiz Olabuénaga (2000ª)

TABLA VI.4

PROCEDENCIA DE LOS INGRESOS DE LAS ONL DE INTERÉS GENERAL

\begin{tabular}{|l|c|c|c|}
\hline & Cuotas y pagos por servicios & Donaciones & Sector público \\
\hline Aragón & 43,06 & 24,92 & 32,02 \\
España (1995) & 49,0 & 18,8 & 32,1 \\
\hline
\end{tabular}

FUENTE: Elaboración propia y Ruiz Olabuénaga (2000ª) 
La distribución del gasto del sector no lucrativo en Aragón y en España (excluido el de las cooperativas) se expone, en porcentaje, en la tabla VI.5. El sector no lucrativo aragonés destina principalmente sus recursos económicos — falta por incorporar el valor del trabajo no retribuido realizado por socios y voluntarios, lo que, desde luego, incrementaría el valor final del gasto y tal vez su distribución - al sector de "Cultura y ocio», al de "Educación e investigación» y al de "Servicios sociales». En comparación con los valores estimados para España, las diferencias se producen ahora en los sectores de «Salud», "Desarrollo comunitario», "Derechos civiles» y "Otras [actividades] de interés general», donde, como se ha visto en las tablas VI.2 y VI.3, el gasto en Aragón es inferior.

De acuerdo con las estimaciones que hemos realizado para asociaciones, fundaciones y cajas, el gasto de las ONL, sin incorporar el valor del trabajo no remunerado, se aproxima en Aragón al 3,6 \% del PIB. Esta cifra se acerca mucho a la estimada para España por Ruiz Olabuénaga $(2000 a)$, que es del $4 \%$, incluidas las cooperativas.

TABLA VI.5

DISTRIBUCIÓN DEL GASTO DEL SECTOR NO LUCRATIVO EN ARAGÓN Y ESPAÑA SIN INCLUIR LAS COOPERATIVAS, 1999

(Porcentajes)

\begin{tabular}{|l|r|r|}
\hline Actividades & Aragón & España \\
\hline Cultura y ocio & 33,90 & 18,79 \\
Deportivas & 5,12 & $-{ }^{a}$ \\
Educación e investigación & 16,69 & 18,60 \\
Salud & 5,53 & 12,02 \\
Servicios sociales & 18,27 & 17,65 \\
Medio Ambiente & 3,79 & 2,08 \\
Desarrollo comunitario-cívico & 3,26 & 12,55 \\
Cooperación internacional & 0,61 & 1,93 \\
Religiosas & 5,24 & - \\
Derechos civiles & 0,51 & 5,71 \\
Profesionales y de negocios & 3,49 & 1,49 \\
Intermediarios filantrópicos & 0,09 & 0,63 \\
Otras de interés general & 3,51 & 8,55 \\
Total & 100,00 & 100,00 \\
\hline
\end{tabular}

a Está incluido en cultura.

FUENTE: Elaboración propia y Ruiz Olabuénaga (2000a) 
Finalmente, el capítulo $\mathrm{V}$ se ha dedicado a la reflexión sobre la función económica y social del sector no lucrativo, en general, y del aragonés, en particular. El punto de partida de la reflexión ha sido la búsqueda de respuestas desde los actores sociales implicados en el sector, lo que ha llevado a preguntarnos qué es la eficiencia social.

No podemos dar una definición final y cerrada de la noción de eficiencia social, pero sí aproximaciones operativas con las que elaborar un repertorio de indicadores - preguntas - de eficiencia social. Con ellos obtenemos descripciones de la realidad que nos permiten valorar la cuestión.

El repertorio recoge once elementos, de los que hemos dado cuenta anteriormente. Proponemos, por tanto, que la eficiencia social de una ONL es directamente proporcional a su capacidad para hacer una sociedad mejor, a partir de cauces de comunicación paritaria, pluralidad e integración social.

Hemos dicho, como valoración de estos indicadores para el sector no lucrativo en Aragón, que el sector presenta grandes diferencias y desigualdades. Sin embargo, prima una tendencia a la búsqueda del «buen y bien hacer» en cada entidad. Algo que está en la línea de la tan manida «calidad». Las ONL aragonesas ofrecen una red de acción ciudadana creativa y eficiente en términos sociales. En general, se funciona con pocos medios y se consiguen resultados impensables, incluso económicamente imposibles. El alcance es desigual, pero hemos visto que no hay ámbito de lo social que se quede al margen. Surgen las respuestas con más rapidez de lo que la Administración pública es capaz de detectar. También es cierto que el número de personas implicadas en las ONL sigue siendo uno de los déficits más destacados, quizá porque la tradición de participación ciudadana continúa siendo escasa.

Como contrapunto, queremos recordar que Aragón es mucho más que Zaragoza. La vida del sector no lucrativo aragonés revela una vez más la cortedad de miras de quienes nos siguen castigando con ese desafortunado juego de palabras de que Aragón existe gracias a Zaragoza (algunos lo dicen incluso en conerencias públicas). Más bien, al contrario. A pesar de Zaragoza y las perversas inercias de desarrollo que la han hecho crecer como metrópoli, la sociedad aragonesa sigue dando 
muestras de una capacidad organizativa y de una vitalidad social que se encuentra en todos los rincones del mapa de la comunidad. Lo dicho hasta aquí se puede aplicar al conjunto de las ONL aragonesas, pero queda otro aspecto por considerar: la diferencia entre el mundo urbano y el rural. O, lo que es casi lo mismo, Zaragoza y el resto. Nuestro país, Aragón, está condicionado por la macrocefalia zaragozana, que, para bien y para mal, afecta a la mayoría de los procesos sociales de esta sociedad. Como todos sabemos, ya sólo desde el punto de vista demográfico representa más de la mitad de la población.

Pero, por eso mismo, cuando salimos fuera del contexto de Zaragoza y miramos a las otras capitales de provincia, a sus cabeceras de comarca y a los pueblos desperdigados por la geografía del país, encontramos algunos referentes que conviene revisar. Uno de los primeros es el tipo de vínculos que se establecen. Las transformaciones culturales producidas han desterrado muchas de las pautas tradicionales y las han sustituido por modelos todavía en germen o en proceso. Sin embargo, detectamos una tendencia a la autoorganización como camino para superar las dificultades y como vía para la permanencia en entornos nada fáciles. Valgan dos ejemplos: el caso de la Asociación Río Ara — que recientemente ha decidido disolverse- respondería a lo primero y el de Artiboraín a lo segundo. Unos se asociaron para salvar su patrimonio natural, cultural y vital. Otros se constituyeron como alternativa al mundo urbano, a modo de organización de autoayuda... 


\section{BIBLIOGRAFÍA}

Aguiar de LuQue, A. (1984): «Derecho de asociación», en Comentarios a las leyes politicas. Constitución española de 1978, Edersa, Madrid, vol. II.

Alberich T. (1994): «Aspectos cuantitativos del asociacionismo en España», Documentación Social, n. ${ }^{\circ}$ 94, pp. 53-74.

Ayuntamiento de Zaragoza (2000): Guia de oportunidades solidarias Zaragoza, Ayuntamiento de Zaragoza.

- (2001): Las organizaciones de voluntariado en la ciudad de Zaragoza, Ayuntamiento de Zaragoza.

BAREA, J. (2000): «El marco conceptual de las instituciones sin fines de lucro», Economistas, n.o 83, pp. 30-34.

- y J. L. MONZÓN (1996): «La economía social desde una perspectiva española», Ekonomiaz, n. ${ }^{\circ} 33$, pp. 140-153.

Bellah, R., et al. (1992): The Good Society, Vintage Books, Nueva York.

BoHM, P. (1987): Social efficiency: a concise introduction to welfare economics, Macmillan Education, Londres.

BuCKLEY, W. (1967): Sociology and Modern Systems Theory, Prentice-Hall, Englewood Cliffs.

CABRA DE LunA, M. A., y R. LoREnzo (1993): «La constelación de las entidades no lucrativas: el tercer sector», en Rodríguez-Piñero et al.: El sector no lucrativo en España, Fundación ONCE, Escuela Libre Editorial, Madrid.

CALLE, A. (2000): Ciudadania y solidaridad, IEPALA, Madrid.

Carbó, S., y J. Coello (1997): «Las Cajas de Ahorros Españolas 1977-1997», Cuadernos de Información Económica, n. ${ }^{\circ}$ 124/125, pp. 101-118.

- y F. RodríGuez (1998): «Tendencias recientes en la obra social de las Cajas de Ahorros Españolas», Papeles de Economia Española, n. ${ }^{\circ}$ 74-75, pp. 226-233.

CASADO, D. (2000): «Organizaciones voluntarias de objeto social en España», Economistas, n. ${ }^{\circ}$ 83, pp. 46-62. 
Casado, D. (dir.) (1995): Organizaciones voluntarias en España, 2. a ed., Hacer Editorial, Barcelona.

Defourny, J. (1994): "Tres enfoques económicos clásicos de las asociaciones», CIRIEC-España. Revista de Debate Sobre Economía Pública, Social y Cooperativa, n. ${ }^{\circ} 16$, pp. 121-146.

- (1996): «Hacia una economía política de las asociaciones. Una síntesis de las aproximaciones francófonas y anglosajonas», Ekonomiaz, n. ${ }^{\circ} 33$, pp. 122-139.

De Meza, D., y J. R. Gould (1992): «The social efficiency of private decisions to enforce property rights", Journal of Political Economy, n. ${ }^{\text {5 }}$, pp. 561-580.

Douglas, J. (1987): "Political Theories of Nonprofit Organization», en W. W. Powell (ed.): The Nonprofit Sector. A Research Handbook, Yale University Press, New Haven.

DruCKer, P. (1993): La sociedad post-capitalista, Apóstrofe, Barcelona.

FundaCión TOMillo (2000): Empleo y trabajo voluntario en las ONG de acción social, Ministerio de Asuntos Sociales, Madrid.

Funes Rivas, M. J. (1994): «La dimensión social del altruismo», Sociedad y Utopía. Revista de Ciencias Sociales, n. 4, pp. 191-204.

García RoA, J. (1994): Las Cajas de Ahorros Españolas: cambios recientes, fusiones y otras estrategias de dimensionamiento, Cívitas, Madrid.

GeYer, F., y J. VAN DER ZouWEN (1986): Sociocybernetic Paradoxes: Observation, Control and Evolution of Self-steering Systems, Sage, Londres.

- y J. VAN Der Zouwen (1990): Self-referencing in Social Systems, Intersystems Publications, Salinas.

- y J. VAN Der ZouWEN (1992): «Sociocybernetics», en C. V. Negoita (ed.): Handbook of Cybernetics, Marcel Dekker, Nueva York, 1992, pp. 95-124. <http://www.unizar.es/ sociocybernetics/chen/felix.html>.

Gómez BAHILlo, C., y Ch. MARCuello (1997): Jóvenes y mundo laboral. Formación y empleo en Aragón, DGA-FSE, Zaragoza.

GutiérREZ ResA, A. (2000): Rostros de la solidaridad, UNED, Valencia.

- y J. GARCÉs FERRER (1999): Los servicios sociales en las comunidades y ciudades autónomas, Tirant lo Blanch, Valencia.

Hall, P. D. (1987): «A Historical Overview of the Private Nonprofit Sector», en W. W. Powell (ed.): The Nonprofit Sector. A Research Handbook, Yale University Press, New Haven.

Hansmann, H. B. (1980): "The Role of Nonprofit Enterprise», The Yale Law Journal, n.o 89, pp. 835-901.

- (1987): «Economic Theories of Nonprofit Organization», en W. W. Powell (ed.): The Nonprofit Sector. A Research Handbook, Yale University Press, New Haven. 
JoHnson, W. R. (1985): «The social efficiency of fixed wages», The Quarterly Journal of Economics, n. ${ }^{\circ}$ 5, pp. 101-118.

LASSERRE, P. (1993): The social efficiency of privately enforced property rights, Dep. des Sciences Économiques, Université du Quebec à Montréal, CRCSE de I'UQAM, cahier n. ${ }^{\circ} 9305$.

LÓPEZ BlanCO, M. (1987): «Eficiencia económica y reforma agraria en Andalucia», Revista de Estudios Agrosociales, n.o 139, pp. 209-243.

LópeZ-NieTo, F. (1987): Manual de asociaciones. Doctrina, legislación, jurisprudencia, formularios, Tecnos, Madrid.

MARCUello, C. (1998a): «Factores determinantes del tamaño del sector no lucrativo. Estudio de la difusión del sector no lucrativo en las comarcas catalanas», Hacienda Pública Española, n. ${ }^{\circ}$ 141/142, pp. 335- 350.

- (1998b): «Determinantes del comportamiento de las contribuciones de dinero a las organizaciones no lucrativas», Información Comercial Española, n. ${ }^{\circ} 775$, pp. $137-148$.

- (1998c): «Determinants of the Non-Profit Sector Size: an Empirical Analysis in Spain", Annals of Public and Cooperative Economics, n. ${ }^{\circ}$ 69, pp. 175-192.

- (1999): «Análisis de la conducta y eficiencia de las organizaciones no gubernamentales para el desarrollo españolas», Información Comercial Española, n. ${ }^{\circ} 778$, pp. $181-196$.

- (2000): «Las organizaciones no lucrativas», Economistas, n. ${ }^{\circ} 83$, pp. 36-45.

- (2001): «Trabajo no remunerado: la aportación de trabajo voluntario a las organizaciones no lucrativas en un contexto familiar», Revista de Economía y Dirección de la Empresa (en prensa).

- y O. URBINA (1998): «The Non-Government Organizations for Development in Spain: Structure and Efficiency», en ISTR III Conference (International Society for Third-Sector Research), Ginebra.

- y Ch. MarCuello (1997): «Un análisis de las ONGD: balance y prospectiva», Cuadernos Aragoneses de Economía, n.o 7, pp. 225-238.

- y Ch. MARCuello (1998): «La afirmación social e identitaria de las organizaciones no gubernamentales para el Desarrollo (ONGD): la Carta de las ONGD Europeas y el Código de Conducta de la Coordinadora de ONGD española», en ISTR III Conference (International Society for Third-Sector Research), Ginebra.

- y Ch. Marcuello (2000): «Determinants of the Decision of Time donations to Nonprofit Organizations», en ISTR IV Conference (International Society for Third-Sector Research), Dublín.

— y V. Salas (2000): «Money and Time Donations to Spanish Non Government Organizations for Development Aid», Investigaciones Económicas, n. ${ }^{\circ}$ 24, pp. 351-392. 
Marcuello, C., y V. Salas (2001): «Non-for-Profit Organizations, Monopolistic Competition and Private Donations: Evidence from Spain», Public Finance Review, n. ${ }^{2}$ 29, pp. 183-207.

Marcuello, Ch. (1996a): "El movimiento 0,7: un pulso colectivo», Acciones e Investigaciones Sociales, n. ${ }^{\circ}$, pp. 201-218.

- (1996b): «Identidad y acción de las Organizaciones No-Gubernamentales», Revista de Gestión Pública y Privada, n.o 1, pp. 103-122.

- (1996c): «Las Organizaciones No-Gubernamentales de Desarrollo y la construcción positiva de su identidad», Revista Acciones e Investigaciones Sociales, n. ${ }^{\circ}$ 5, pp. 103-119.

Maroto, J. A. (1999): «¿Gobierno de las Cajas, o Cajas de los gobiernos?», Economistas, n. ${ }^{\circ} 80$ pp. 205-211.

McDonough, S. M., S. BARnes y A. López Pina (1984): «Authority and association Spanish democracy in comparative perspective», The Journal of Politics, n. ${ }^{\circ}$ 46, pp. 659-660.

Mertens, S. (1999): «Nonprofit Organizations and Social Economy: Two Ways of Understanding the Third Sector", Annals of Public and Cooperative Economics, n. ${ }^{\circ}$ 70, pp. 501-520.

Moneva, J. M., y Ch. Marcuello (2001): Auditoría Social: historia, contexto y problemas prácticos, mimeo.

MonSERRAT, J. (1991): «Hacia una teoría económica del tercer sector: una primera aproximación", Economistas, n. ${ }^{\circ}$ 51, pp. 48-54.

Nyssen, J. (1994): «Social Efficiency of Bubbles in the Grossman and Helpman Endogenous Growth-Model», Economics Letters, n. ${ }^{\circ}$ 45, pp. 197-202.

$V$ Informe sociológico sobre la situación social en España: Sociedad para todos en el año 2000, Fundación FOESSA, Madrid, 1994.

ROdríguez, G., y J. MONSERRAT (1996): Las entidades voluntarias en España. Institucionalización, estructura económica y desarrollo asociativo, Ministerio de Asuntos Sociales, Madrid.

Rose-AcKerman, S. (1996): "Altruism, Nonprofits, and Economic Theory», Journal of Economic Literature, n. ${ }^{\circ}$ 34, pp. 701-728.

Ruiz Olabuénaga, J. I. (1994): "Ocio y estilo de vida», en $V$ Informe sociológico sobre la situación social en España, cap. 4.

- 2000a): El sector no lucrativo en España, Fundación BBV, Bilbao.

- (2000b): «El sector no lucrativo en España», Economistas, n. ${ }^{\circ}$ 83, pp. 63-79.

Sajardo Moreno, A. (1996a): «Economía Social y Sociedad del Bienestar», en J. Barea y J. L. Monzón (dirs.): Informe sobre la situación de las cooperativas y las sociedades laborales en España, CIRIEC-España, Valencia. 
Sajardo Moreno, A. (1996b): Análisis económico del sector no lucrativo, Tirant lo Blanch Libros, Valencia.

- y H. K. ANHEIER (1992): «In search of the nonprofit sector II: The problem of classification", Working Papers Number 3, The Johns Hopkins University, Institute for Policy Studies, Baltimore.

SAlamon, L. M., y H. K. ANHeIR (1994): The Emerging Sector. An overview, The Johns Hopkins University, Institute for Policy Studies, Baltimore.

- et al. (1999a): Global Civil Society: Dimensions of the Nonprofit Sector, Center for Civil Society Studies, Baltimore.

- et al. (1999b): Nuevo estudio del sector emergente. Resumen, Fundación BBV, Bilbao, y Universidad Johns Hopkins, Baltimore.

SAMUels, W. J., y A. S. MilLER (1987): Corporations and society: power and responsibility, Greenwood Press, Nueva York.

SERRA MARTín, A. (1990): «La gestión en el sector no lucrativo», Revista de Economía, n. ${ }^{\circ}$ 4, pp. 74-78.

SUBIRATS, J. (1992): «Administración pública y mercado», Información Comercial Española, n. ${ }^{\circ}$ 712, pp. 33-42.

- (ed.) (1999): ¿Existe sociedad civil en España?, Estudios de la Fundación Encuentro, Madrid.

Titos Martínez, M. (1998): «La creación de las Cajas de Ahorros. Motivación, protagonistas y evolución numérica», Papeles de Economía Española, n. ${ }^{\circ} 74-$ 75, pp. 309-322.

TUCKMAN, H. P. (1984): «Social efficiency and the provision of collective services», The American Journal of Economics and Sociology, n. ${ }^{\circ}$ 5, pp. 257-268.

VERGES, J. (1990): «Empresa pública: determinación del déficit asociado a una gestión socialmente óptima», Investigaciones Económicas. Suplementos, pp. 97-103.

WeIsBRoD, B. A. (1975): «Toward a theory of the voluntary nonprofit sector in a Three-Sector Economy», en E. S. Phelps (ed.): Altruism, Morality and Economic Theory, Russell Sage Foundation, Nueva York, pp. 171-195.

- (1986): «Toward a theory of the voluntary nonprofit sector in a Three-Sector Economy", en S. Rose-Ackerman (ed.): The Economics of Nonprofit Institutions, Yale Studies on Nonprofit Organizations, Oxford University Press.

- (1988): The Nonprofit Economy, Harvard University Press, Londres.

Williams, A. (1975): «La provision óptima de bienes públicos en un sistema de gobierno local», Hacienda Publica Española, n. ${ }^{\circ} 35$, pp. 405-419.

YounG, D. R. (1992): «Emerging Themes in Nonprofit Leadership and Management» en D. R. Young, et al:: Governing, leading, and managing nonprofit organizations, Jossey-Bass, San Francisco. 


\section{ÍNDICE}

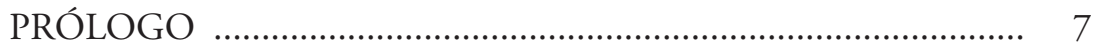

PRESENTACIÓN …………………………………................. 9

CAPÍTULO I. NI SÓLO GOBIERNO, NI SÓLO MERCADO:

EL SECTOR NO LUCRATIVO ARAGONÉS ….................... 13

I.1. De la sombra a la luz propia ............................................... 14

I.2. ¿De qué estamos hablando? Economía Social

vs. Tercer Sector …........................................................... 17

I.3. Una propuesta de definición .......................................... 20

I.4. Los límites de la definición: fronteras difusas ..................... 24

I.5. Una clasificación de las ONL: un camino por recorrer ....... 26

CAPÍTULO II. LOS CIMIENTOS LEGALES DE LAS ONL:

MARCO JURÍDICO ...................................................... 41

II.1. Legislación estatal: el marco común .................................. 42

II.1.1. Asociaciones ......................................................... 45

II.1.1.1. Asociaciones bajo el régimen jurídico general .................................................... 47

II.1.1.2. Asociaciones de regímenes jurídicos especiales ................................................. 48

II.1.2. Fundaciones ….................................................... 50

II.1.3. Cooperativas ........................................................ 55

II.1.4. Mutualidades ........................................................ 58

II.1.5. Cajas de ahorros .................................................. 59

II.2. Legislación aragonesa sobre el sector no lucrativo ............... 60

II.2.1. La regulación jurídica aragonesa en materia de asociaciones ....................................................... 62 
II.2.2. Las fundaciones de iniciativa privada en el panorama jurídico aragonés

II.2.3. Avances en la legislación de cooperativas, mutualidades y cajas de ahorros en Aragón .......... 66

II.3. Anexo legislativo ............................................................. 70

II.3.1. Legislación estatal ................................................. 70

II.3.2. Legislación autonómica de Aragón ......................... 72

II.3.3. Legislación en el resto de comunidades autónomas .... 76

CAPÍTULO III. LA REALIDAD DEL SECTOR NO LUCRATIVO

EN ARAGÓN: LAS ORGANIZACIONES NO LUCRATIVAS

DE INTERÉS PARTICULAR …………................................ 79

III.1. Las cooperativas en Aragón ............................................ 80

III.1.1. Número de cooperativas y distribución geográfica .. 84

III.1.2. Clasificación de las actividades de las cooperativas .. 86

III.1.3. Evolución temporal en la creación de las cooperativas aragonesas ........................................................ 95

III.1.4. Las personas: socios cooperativistas ....................... 93

III.2. Las cajas de ahorros aragonesas ......................................... 98

III.2.1. Número de cajas de ahorros y distribución geográfica ................................................................ 102

III.2.2. Clasificación de las actividades de la obra social de las cajas de ahorros ........................................... 107

III.2.3. Evolución de la obra social de las cajas de ahorros .. 109

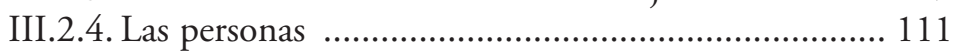

III.2.5. Datos económicos ………………………….......... 113

CAPÍTULO IV. LA REALIDAD DEL SECTOR NO LUCRATIVO

EN ARAGÓN: LAS ORGANIZACIONES NO LUCRATIVAS

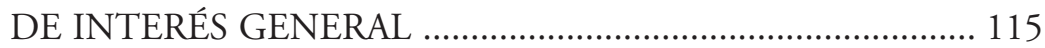

IV.1 Las asociaciones aragonesas ............................................. 118

IV.1.1. Número de asociaciones y distribución geográfica .. 118

IV.1.2. Clasificación de las actividades de las asociaciones .. 122

IV.1.3. Evolución temporal en la creación de las asociaciones. ................................................... 126

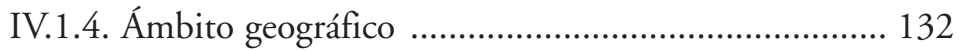

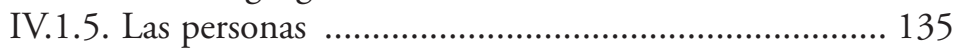

IV.1.5.1. Socios ..................................................... 137

IV.1.5.2. Usuarios ................................................... 141 
IV.1.5.3. Voluntarios y personal contratado ........... 144

IV.1.5.3.1. Voluntarios ............................. 145

IV.1.5.3.2. Personal contratado ................ 147

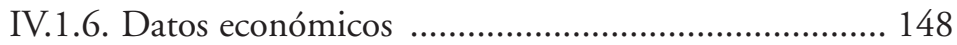

IV.1.6.1. Ingresos ................................................... 148

IV.1.6.2. Infraestructura ...................................... 150

IV.1.6.3. Gastos ...................................................... 151

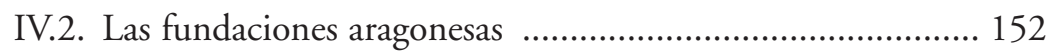

IV.2.1. Número de fundaciones y distribución geográfica .. 152

IV.2.2. Clasificación de las actividades de las fundaciones de Aragón ............................................................... 154

IV.2.3. Evolución temporal en la creación

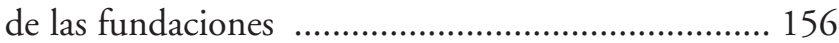

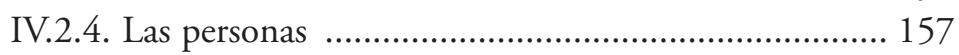

IV.2.4.1. Usuarios ................................................ 158

IV.2.4.2. Voluntarios y personal contratado ........... 159

IV.2.5. Datos económicos: ingresos, infraestructura y gastos .. 160

IV.2.6. Como acotación y contrapunto .............................. 162

CAPÍTULO V. UN ANÁLISIS DE LA FUNCIÓN SOCIAL

Y ECONÓMICA DEL SECTOR NO LUCRATIVO

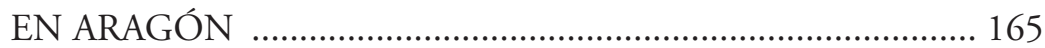

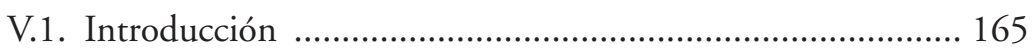

V.2. Una reflexión sobre los conceptos de eficiencia

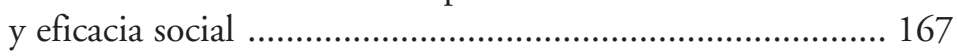

V.2.1. Indicadores de eficiencia social (IES) ..................... 179

V.3. Eficiencia y eficacia del sector no lucrativo en Aragón ....... 180

V.3.1. Modelos de gestión en las ONL ............................. 181

V.3.2. La cuestión del número y tamaño de las ONL ....... 185

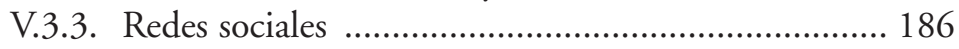

V.3.4. Participación y profesionalización: personas y organizaciones .................................................. 188

V.3.5. Participación y profesionalización: las personas .... 190

V.3.6. Evaluación, transparencia y cauces de comunicación

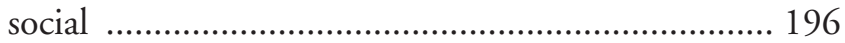

V.3.7. Comunicación, divulgación y visibilidad ................ 201

V.4. Administraciones públicas y ONL ..................................... 202 
V.4.1. El reparto de papeles: realidades, teorías

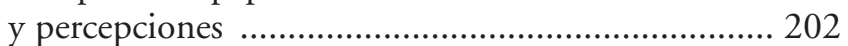

V.4.2. Relaciones, estrategias y burocracias: ONL-Administraciones 206

V.5. Como contrapunto ............................................................ 210

CAPÍTULO VI. CONCLUSIONES _........................................... 211

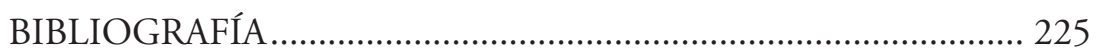


Este libro se terminó de imprimir en los talleres gráficos de Cometa, S.A., de Zaragoza,

el día 24 de octubre de 2002

$$
\approx
$$


a fragilidad aislada de una vara de mimbre se transforma en estructura resistente cuando se entrelaza con otras como ella. El resultado es superior a la simple suma de las partes. Pero sin esas unidades elementales "el todo" se deshilvana, se desmorona. Así, la riqueza y fortaleza de un sistema social —de un país- no se ha de medir sólo por las cifras macroeconómicas. La densidad de las redes sociales y los factores que configuran el sector no lucrativo constituyen un elemento vertebrador para el presente y el porvenir de cualquier sociedad.

Este libro recoge los resultados de una investigación financiada por el CONSI+D, e iniciada en 1999, para evaluar la eficacia económica y social del sector privado no lucrativo aragonés. Se trata, como evidencia la investigación, de un sector en crecimiento en su triple dimensión social, económica y politica. Asimismo, es un sector que refleja los rasgos propios de Aragón, con una Zaragoza absorbente de toda actividad, pero con una gran vitalidad de las zonas más despobladas, en donde el ser "no lucrativo" no se reduce a la mera supervivencia de las costumbres.

Las tablas y comentarios que el lector hallará en el libro no sólo representan un primer paso para conocer y desarrollar en profundidad el sector en nuestra comunidad autónoma -de ello dependerá nuestro bienestar futuro y una sociedad civil aragonesa mejor consolidada-. También proponen un marco teórico para seguir investigando en este ámbito socioeconómico más allá de los límites particulares.

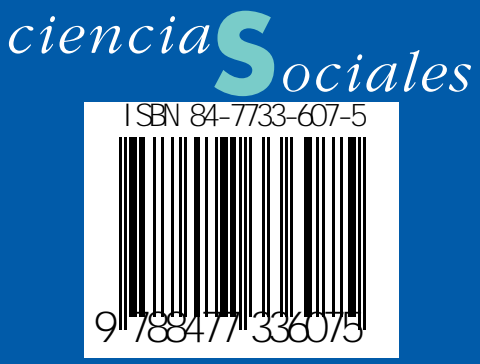

